\author{
Universidade de São Paulo \\ Instituto de Física
}

\title{
Estrutura e Propriedades de Nanopartículas Preparadas via Sol-Gel
}

\section{Javier Bustamante Mamani}

Orientador: Prof. Dr. Giancarlo Esposito de Souza Brito

Co-Orientadora: Profa. Dra. Carmen Silvia de Moya Partiti

Tese de doutorado apresentada ao Instituto de Física para a obtenção do título de Doutor em Ciências.

\section{Banca examinadora:}

Prof. Dr. Giancarlo Esposito de Souza Brito (orientador) - IF-USP

Profa. Dra. Márcia Carvalho de Abreu Fantini - IF-USP

Profa. Dra. Suhaila Maluf Shibli - IF-USP

Profa. Dra. Sandra Helena Pulcinelli - UNESP

Prof. Dr. Luis Vicente de Andrade Scálvi - UNESP

São Paulo

2009 


\section{FICHA CATALOGRÁFICA}

Preparada pelo Serviço de Biblioteca e Informação do Instituto de Física da Universidade de São Paulo

Mamani, Javier Bustamante

Estrutura e Propriedades de Nanopartículas Preparadas via Sol-Gel - São Paulo, 2009.

Tese (Doutorado) - Universidade de São Paulo. Instituto de Física. Departamento de Física Aplicada

Orientador: Prof. Dr. Giancarlo Esposito de Souza Brito e Profa. Dra. Carmen Sílvia de Moya Partiti

Área de Concentração: Física

Unitermos: 1. Nanopartículas; 2. Catalisadores;

3. Hidroxiapatita; 4. Ferrofluidos; 5. Física Experimental. 


\section{AGRADECIMENTOS}

Os meus sinceros agradecimentos

Ao Professor Dr. Giancarlo Esposito de Souza Brito pela orientação, pelo apoio e auxilio oferecido para a pesquisa científica e por proporcionar, confiança e paciência no ambiente de trabalho.

À professora Dra. Carmen Silvia de Moya Partiti pela orientação, condução e participação durante todas as fases desta pesquisa, pela paciência em ensinar e pela amizade.

A mi querida mamá, la señora Francisca Mamani de Bustamante y a mi querido papá, el señor Julian Bustamante, por la ayuda incondicional en todas la etapas de mi vida.

A mis hermanas Nerida y Yesica por el incentivo que siempre me brindan lejos de casa.

A Iara pelo seu carinho, afeto e momentos felizes que passamos juntos.

Ao Dr. Lionel F. Gamarra pela amizade e colaboração. Também pela disponibilidade de utilização do Laboratório.

Aos colegas do grupo de pesquisa que me acompanharam durante a realização deste trabalho.

Agradeço a todos que de alguma forma, direta ou indireta, me auxiliaram na execução deste projeto.

À COPAX industria por proporcionar materiais para a pesquisa com nanopartículas catalíticas.

À CAPES - Coordenação de Aperfeiçoamento de pessoal de Nível Superior - e ao CNPq - Conselho Nacional de Desenvolvimento Científico e Tecnológico pelo apoio financeiro. 


\section{RESUMO}

Este trabalho propõe a síntese de vários materiais nanoestruturados pelo processo sol-gel. Foram preparados sóis a base de óxido de cério, hidroxiapatita e magnetita. Filmes a base de paládio metálico foram obtidos pela técnica de decomposição térmica e redução em atmosfera de nitrogênio. A caracterização estrutural dos materiais preparados foi realizada por DRX; a caracterização morfológica foi feita mediante SAXS, MET e MEV; a caracterização química por EDS; a caracterização térmica por DSC; a caracterização magnética por RPE e a caracterização relaxometrica por IRM. No caso da hidroxiapatita, foram realizadas medidas de FTIR.

Nanopartículas a base de óxido de cério e $\mathrm{Pd}^{\mathrm{o}}$ com propriedades catalíticas foram depositadas na forma de filme sobre substratos de alumínio anodizado e na região da cabeça de pistões automotivos de motor a gasolina. Os catalisadores foram suportados nos poros que os anodizados apresentam. Os pistões foram submetidos a testes catalíticos e apresentaram redução nas emissões de $\mathrm{CO}$, compostos orgânicos voláteis e $\mathrm{NO}_{\mathrm{x}}$. Além disso, verificou-se a diminuição no consumo de combustível e aumento na eficiência do motor automotivo a gasolina.

A síntese de nanopartículas a base de hidroxiapatita produz um material de morfologia nanométrica, apresentando um comportamento ferromagnético atribuído ao ferro como impureza nos precursores da síntese. Também foram obtidas sóis estáveis a base de nanopartículas de hidroxiapatita revestidas por ácido oléico.

A síntese e caracterização do ferrofluido à base de nanopartículas de magnetita superparamagnéticas levaram a fabricação de um agente de contraste negativo, característica principal para aplicações na IRM.

Palavras chave: Hidroxiapatita, ferrofluido, catalise heterogênea, óxido de cério, paládio, filme, sol-gel, nanopartículas. 


\begin{abstract}
This work proposes the synthesis of several nonostructured materials by the sol-gel process. Cerium oxide, hydroxyapatite and magnetite based sols were prepared. Metallic palladium based films were obtained by the thermal decomposition technique followed by reduction under nitrogen atmosphere. Structural characterizations of the prepared materials were accomplished by XRD; morphologic characterization were carried out by SAXS, TEM and SEM, chemical characterization by EDS, thermal characterization using DSC, magnetic characterization by EPR, and the relaxometry characterization by MRI. FTIR's measurements were also accomplished in hydroxyapatite samples.

Cerium oxide and palladium nanoparticles presenting catalytic properties were deposited as a film on anodized aluminum substrates and on automotive piston heads for gasoline motors. The catalyzers were supported by pores present in anodized aluminum surfaces. Catalytic test of the pistons have shown emission reduction of $\mathrm{CO}$, organic volatile compounds, and $\mathrm{NO}_{\mathrm{x}}$. Moreover, decrease in the fuel consumption and increase in automotive motor efficiency were verified.

The synthesis of nanoparticles based on hydroxyapatite gives rise to a material of nanometric morphology. It presents a ferromagnetic behavior due to the iron as impurity in the synthesis precursors. Stable sols of hydroxyapatite nanoparticles covered by oleic acid were also obtained.

Synthesis and characterization of ferrofluid based on superparamagnetic nanoparticles of magnetite lead to the production of an agent for negative contrast. It is the main characteristic for applications in MRI.
\end{abstract}

Key-words: Hydroxyapatite, ferrofluid, heterogeneous catalysts, cerium oxide, palladium, film, sol-gel, nanoparticles. 


\section{LISTA DE ABREVIATURAS}

COV: Compostos Orgânicos Voláteis

DRX: Difração de Raios X

DSC: Calorimetria Exploratória Diferencial

EDS: $\quad$ Espectroscopia de Energia Dispersiva

FTIR: Espectroscopia no Infravermelho por Transformada de Fourier

GE: $\quad$ Multi-Echo Gradient Echo

HAp: Hidroxiapatita

IRM: Imagem por Ressonância Magnética

MET: Microscopia Eletrônica de Transmissão

MEV: Microscopia Eletrônica de Varredura

RFM: Ressonância Ferromagnética

RMN: Ressonância Magnética Nuclear

RPE: Ressonância Paramagnética Eletrônica

SAXS: Espalhamento de raios $\mathrm{X}$ a baixo ângulo

SE: $\quad$ Multiple Spin Echo

SE_MC: Multi-Contrast turbo-spin echo

SPION: Nanopartícula de óxido de ferro superparamagnética

TE: $\quad$ Tempo de echo.

TR: $\quad$ Tempo de repetição

TWC: Catalisador de três vias 


\section{LISTA DE FIGURAS}

Figura 2.1: Diagrama mostrando a interferência construtiva de raios $X$ monocromático.

Figura 2.2: Desenho esquemático mostrando (a) o modo uniforme e (b) de onda de spin em sistema ferromagnético. [9].

Figura 2.3: Decaimento da magnetização transversal $\left(\mathrm{M}_{\mathrm{T}}\right)$ relacionado com $T_{2}, \quad 25$ assim como a volta da magnetização longitudinal $\left(\mathrm{M}_{\mathrm{L}}\right)$ ao equilíbrio térmico $\mathrm{M}_{0}$ devido à relaxação $T_{1}$, aplicando um pulso de excitação de $90^{\circ}$.

Figura 2.4: Curva de intensidade do feixe espalhado em função do vetor de espalhamento (q) [24] para sistemas de partículas densas (a) e agregados (b) [25].

Figura 3.1: Produtos que podem ser formados por meio da síntese pelo método sol-gel [4].

Figura 3.2: Mecanismos de formação de partículas uniformes em solução: curva I: Nucleação única e crescimento uniforme por difusão (modelo clássico de LaMer e Dinegar (1950)) [9]; curva II : Nucleação, crescimento e agregação de pequenas subunidades; curva III eventos de nucleação múltipla e crescimento maturativo de Ostwald (1991) [10].

Figura 4.1: Estrutura tipo fluorita de $\mathrm{CeO}_{2}$. As esferas grandes representam os átomos de $\mathrm{Ce}$, as esferas pequenas os átomos de $\mathrm{O}$.

Figura 4.2: Difratogramas de DRX da solução de nitrato de cério submetida a diferentes temperaturas de calcinação sob atmosfera de ar: (a) temperatura ambiente, (b) $200^{\circ} \mathrm{C}$ e (c) $450^{\circ} \mathrm{C}$.

Figura 4.3: Curvas de $\mathrm{SAXS}$ correspondentes a sóis de $\mathrm{CeO}_{2}$ nas temperaturas indicadas.

Figura 4.4: Gráfico de Guinier da intensidade SAXS apresentada na figura anterior. As temperaturas de tratamento térmico estão apresentadas na figura.

Figura 4.5: $\quad$ Gráficos de SAXS mostrando ajustes aos dados experimentais e as funções de distribuição de distância $\mathrm{P}(\mathrm{R})$, obtidos utilizando o programa GNOM, das amostras de oxido de cério. Os tempos de tratamento térmico estão apresentados na figura. 
Figura 4.6: $\quad$ Espectros de RPE das nanopartículas de óxido de cério $\left(\mathrm{CeO}_{2}\right)$ obtidos a temperatura de $4 \mathrm{~K}$. (a) sinal da cavidade mais o porta amostra, (b) sinal do $\mathrm{CeO}_{2}$ no porta amostra mais a cavidade e (c) sinal do $\mathrm{CeO}_{2}$ obtido da subtração do porta amostra e da cavidade.

Figura 4.7: $\quad$ Espectros de RPE da amostra de $\mathrm{CeO}_{2}$ na faixa de temperatura de 78 90 até $273 \mathrm{~K}$.

Figura 4.8: $\quad$ Espectros de RPE da amostra de $\mathrm{CeO}_{2}$ na faixa de temperatura de $4 \quad 79$ até $80 \mathrm{~K}$.

Figura 4.9: Difratogramas de raios $X$ da amostra na forma de filme após tratamento térmico à temperatura de $400^{\circ} \mathrm{C}$. (a) filme a base de $\mathrm{PdO}$ em atmosfera de ar e (b) filme a base de $\mathrm{Pd}^{\circ}$ em atmosfera de $\mathrm{N}_{2}$.

Figura 4.10: Difratograma de raios $\mathrm{X}$ do filme de nanopartículas de $\mathrm{CeO}_{2}$ suportado no anodizado de aluminio.

Figura 4.11: Difratogramas de raios $X$ do filme de paládio depositado sobre $o$ anodizado de aluminio.

Figura 4.12: $\quad$ MEV do anodizado de alumínio.

Figura 4.13: $\quad$ MEV do depósito de paládio no anodizado de alumínio.

Figura 4.14: $\quad$ MEV do anodizado de alumínio.

Figura 4.15: $\quad$ MEV do filme de céria depositado sob anodizado de alumínio.

Figura 4.16: Concentração de COV (compostos orgânicos voláteis) para diversas rotações do motor.

Figura 4.17: Concentração de $\mathrm{NO}_{\mathrm{x}}$ em função da rotação do motor.

Figura 4.18: Concentração de $\mathrm{CO}_{2}$ em função da rotação.

Figura 4.19: Consumo do motor em função da rotação.

Figura 5.1: Cela unitária da HAp. Os íons de $\mathrm{OH}^{-}$localizados nos cantos da célula unitária estão rodeados por dois grupos de $\mathrm{Ca}^{2+}$ arranjados em um triângulo nas posições $\mathrm{z}=1 / 4$ e $\mathrm{z}=3 / 4$; por dois grupos de tetraedro de $\mathrm{PO}_{4}$ também arranjados em posições triangulares, e por um arranjo hexagonal de átomos de $\mathrm{Ca}^{+}$mais afastado $[12,13]$.

Figura 5.2: A figura mostra a forma de uma cela unitária hexagonal, onde os 103 vetores $a, b$ e c são os vetores primitivos. 
Figura 5.3: Dados de DRX da HAp sintetizada. Os índices (hkl) representam

HAp padrão de acordo a JCPDS \# 721243. A intensidade (eixo-y) é em unidades arbitrárias.

Figura 5.4: Resultados de DRX da HAp comercial. Os índices (hkl) intensidade (eixo-y) é em unidades arbitrárias.

Figura 5.5: Curva de DSC para o precipitado de HAp.

Figura 5.6: Espectro FTIR da amostra de HAp sem revestimento exibindo bandas características de grupos fosfato e hidroxila.

Figura 5.7: Perfil de DRX da HAp mostrando o grau de cristalinidade da amostra sintetizada e submetidas a tratamento em diferentes temperaturas $\left(110,200,400,600,800\right.$ e $\left.1000^{\circ} \mathrm{C}\right)$.

Figura 5.8: Evolução dos perfis de DRX no plano cristalográfico (002) da HAp e (1 0 10) do $\mathrm{Ca}_{3}\left(\mathrm{PO}_{4}\right)_{2}$ com a temperatura de sinterização durante 30 minutos.

Figura 5.9: Evolução dos perfis de difração de raios $X$ no plano cristalográfico (311) e (1 0 16) com a temperatura de sinterização durante 30 minutos.

Figura 5.10: Evolução do tamanho médio de cristalito com a temperatura nos planos (002) e (311) para HAp e (l $\left.\begin{array}{lll}1 & 10\end{array}\right)$ e $\left(\begin{array}{lll}1 & 0 & 16\end{array}\right)$ para $\mathrm{Ca}_{3}\left(\mathrm{PO}_{4}\right)_{2}$. para um tempo de sinterização de $30 \mathrm{mim}$.

Figura 5.11: Espectros de RPE de micropartículas de HAp comercial (HAc) obtidos com mudança de temperatura na faixa de 70-290 K.

Figura 5.12: Espectros de RPE de nanopartículas de HAp sintetizada (HAp) obtidos com mudança de temperatura na faixa de 90-247 K.

Figura 5.13: Fator giromagnético g em função da temperatura da amostra HAp e 119 HAc.

Figura 5.14: Campo de ressonância em função da temperatura para HAp e HAc. 119

Figura 5.15: Largura de linha pico pico $\left(\Delta \mathrm{H}_{\mathrm{PP}}\right)$ em função da temperatura para 120 HAp e HAc.

Figura 5.16: Numero de spin $\left(\mathrm{N}_{\mathrm{S}}\right)$ em função da temperatura para HAp e HAc.

Figura 5.17: Tempo de relaxação spin-spin em função da temperatura para HAp e HAc.

Figura 5.18: Dados de DRX das amostras a base de HAp revestidas com ácido oléico. 
Figura 5.19: Curvas de SAXS correspondentes aos sóis a base de HAp revestidas com ácido oléico. A figura apresenta $\log (\mathrm{q})$ vs. $\log q$.

Figura 5.20: Estrutura da molécula de ácido oléico.

Figura 5.21: Espectro de FTIR de soluções contendo nanopartículas de HAp revestidas com ácido oléico.

Figura 6.1: Esquema da dupla camada elétrica perto de um colóide.

Figura 6.2: $\quad$ Representação esquemática de um ferrofluido; as partículas foram revestidas com surfactante.

Figura 6.3: $\quad$ Parâmetros usados nas equações.

Figura 6.4: Estrutura da magnetita $\left(\mathrm{Fe}_{3} \mathrm{O}_{4}\right)$ spinelio invertida. As esferas grandes representam os átomos de oxigênio, as esferas claras pequenas os sítios $\mathrm{A}$ e as esferas escuras pequenas denotam os sítios B [24].

Figura 6.5: $\quad$ Estrutura cristalina do $\mathrm{Fe}_{3} \mathrm{O}_{4}[25]$.

Figura 6.6: Esquema de uma parede de $180^{\circ}$ (A) e da ordenação dos momentos em uma parede de domínios adjacentes (B) [29].

Figura 6.7: Esquema de dois materiais ferromagnéticos exibindo estrutura de multidomínios (A) e de monodomínios (B).

Figura 6.8: Representação esquemática da barreira de energia para magnetização reversa.

Figura 6.9: Difratograma de raios $X$ da amostra sintetizada à base de SPIONs.

$\mathrm{O}$ difratograma evidencia a presença de uma fase de óxido de ferro-Magnetita.

Figura 6.10: Imagem obtida mediante MET do ferrofluido em pó após sonificação e centrifugação e, o correspondente histograma de distribuição de tamanho de partículas. O diâmetro médio das partículas e o desvio padrão são $\left\langle D_{P}\right\rangle=8,65 \mathrm{~nm}$ e $\sigma_{P}=0,12 \mathrm{~nm}$, respectivamente.

Figura 6.11: Curva de DSC para a oxidação da magnetita em $20 \% \mathrm{O}_{2}$ e $80 \% \mathrm{~N}_{2} . \quad 158$

Figura 6.12: $\quad$ Espectro de RFM da suspensão coloidal à base de SPIONs obtido a 159 temperatura ambiente, $\mathrm{T}=300 \mathrm{~K}$.

Figura 6.13: Espectros de RFM do ferrofluido, para temperaturas variando entre 160 4 e $261 \mathrm{~K}$. 
Figura 6.14: Variações térmicas do fator $\mathrm{g}$.

Figura 6.15: Variações térmicas de $\Delta \mathrm{H}_{\mathrm{PP}}$ do sinal do espectro de absorção.

Figura 6.16: Variações térmicas dos campos de ressonância da amostra à base de nanopartículas de óxido de ferro.

Figura 6.17: Relação entre $\delta H_{\text {ressonanncia }}$ e $\Delta H_{P P}$, mostrando uma dependência de ordem $n \cong 2,8 \pm 0,1$ e $n \cong 7,0 \pm 0,1$.

Figura 6.18: Tempo de relaxação spin-spin, $T_{2}$, em função da temperatura.

Figura 6.19: Numero de spins $\left(\mathrm{N}_{\mathrm{S}}\right)$ em função da temperatura.

Figura 6.20: Curvas de $\mathrm{SAXS}$ correspondentes a xerogéis de $\mathrm{Fe}_{2} \mathrm{O}_{3}$.

Figura 6.21: Gráfico de Guinier da intensidade SAXS apresentada na figura anterior.

Figura 6.22: " "Phanthom" utilizado na caracterização relaxometrica para a obtenção de imagens no tomografo de RMN.

Figura 6.23: Tempos de relaxação $T_{1}$ em função da concentração de SPIONs uniformemente distribuído em solução surfactada com concentrações de ferro na faixa de $1 \mu \mathrm{M}$ a $3125 \mu \mathrm{M}$. As imagens foram feitas a temperatura ambiente utilizando um tomógrafo de RMN de corpo inteiro de $3 \mathrm{~T}$.

Figura 6.24: Tempo de relaxação $T_{2}$ em função da concentração de SPIONs uniformemente distribuído em solução surfactada com concentrações de ferro na faixa de $1 \mu \mathrm{M}$ a $3125 \mu \mathrm{M}$. As imagens foram feitas a temperatura ambiente utilizando um tomógrafo de RMN de corpo inteiro de $3 \mathrm{~T}$.

Figura 6.25: Tempos de relaxação $T_{2} *$ em função da concentração de Ferro em concentrações na faixa de $1 \mu \mathrm{M}$ a $3125 \mu \mathrm{M}$ como é indicado no phantom. As IRMs foram adquiridas a temperatura ambiente usando um tomógrafo de RM de 3T.

Figura 6.26: Correlação entre a taxa de relaxação $R_{2}=1 / T_{2}$ e a concentração dos SPIONs.

Figura 6.27: Imagens ponderadas em $\mathrm{T}_{2}$ obtidas utilizando a sequiência de $\mathrm{TE}=26,2 \mathrm{~ms}$ e (B) $\mathrm{TE}=3013 \mathrm{~ms}$. 
Figura 6.28: Correlação entre a taxa de relaxação $R_{2} *=1 / T_{2} *$ e a concentração dos SPIONs.

Figura 6.29: Imagens ponderadas em $\mathrm{T}_{2} *$ obtidas mediante a sequiência GE do phantom com um TR constante de $100 \mathrm{~ms}$ com um (A) TE=3,61 ms e (B) $\mathrm{TE}=11,49 \mathrm{~ms}$.

Figura 6.30: Correlação entre a taxa de relaxação $R_{1}=1 / T_{1}$ e a concentração dos SPIONs.

Figura 6.31: Imagem ponderada em $T_{1}$ obtida mediante a seqüência de multiple 175 SE do phantom com um TR de $250 \mathrm{~ms}$ e um TE de $11 \mathrm{~ms}$. 


\section{LISTA DE TABELAS}

Tabela 4.1: Concentração de paládio na amostra determinada por EDS (\% at. Pd).

Tabela 4.2: Concentração de cério na amostra determinada por EDS (\% at. $\mathrm{Ce})$.

Tabela 5.1: Parâmetros resultado da análise dos perfis de DRX dos planos (002) e (311) para HAp e (lllll) e 0 (1 0 10 16) para $\mathrm{Ca}_{3}\left(\mathrm{PO}_{4}\right)_{2}$.

Tabela 5.2: $\quad$ Caracterização fractal das soluções de HAp estudadas.

Tabela 6.1: Concentrações, em $\mu \mathrm{M}$, de SPIONs utilizadas no phantom na avaliação do agente de contraste para medidas dos tempos de relaxação nuclear. 


\section{SUMÁRIO}

AGRADECIMENTOS I

RESUMO II

ABSTRACT

LISTA DE ABREVIATURAS IV IV IV

LISTA DE FIGURAS $\quad$ V

LISTA DE TABELAS $\quad$ XI

SUMÁRIO XII

\section{Capítulo 1 - Introdução}

Introdução Geral - Nanociência e nanotecnologia 1

$\begin{array}{ll}\text { Nanomateriais } & 2 \\ & \end{array}$

Aplicações das nanopartículas $\quad 3$

Aplicações catalíticas $\quad 3$

Aplicações biomédicas $\quad 5$

Objetivos $\quad 8$

$\begin{array}{lr}\text { Organização da tese } & 8\end{array}$

$\begin{array}{lr}\text { Referências Bibliográficas } & 10\end{array}$

\section{Capítulo 2 - Técnicas Experimentais}

2.1. Difração de Raios X (DRX) 12

2.2. Microscopia Eletrônica de Transmissão (MET) 14

2.3. Microscopia Eletrônica de Varredura (MEV) e Espectroscopia de Energia 15

2.4. Ressonância Ferromagnética (RFM) 16

2.5. Ressonância Magnética Nuclear (RMN) 23

2.6. Espalhamento de Raios-X a baixos ângulos (SAXS) 27

2.6.1. Sistemas diluídos 28

2.6.2. SAXS de partículas e sistemas desordenados 30

2.7 Equipamentos utilizados na caracterização das nanopartículas 33

2.8 Referências Bibliográficas 36

\section{Capítulo 3 - Síntese de Nanopartículas}

3.1. O processo sol-gel 38

3.2. Processo de coprecipitação $\quad 42$

3.3. Métodos de síntese de nanopartículas para aplicações em diversas áreas da $\quad 44$

3.3.1. Compostos magnéticos $\quad 45$

3.3.2. Compostos a base de fosfato de cálcio 45

3.3.2.1. Métodos de síntese de nanopartículas de hidroxiapatita 45

3.3.3. Compostos a base de cério e paládio 46

3.4. Métodos de seleção de tamanho 47

3.5. Métodos utilizando técnicas de aerosol/deposição em vapor 48

3.6. Referências Bibliográficas 49 


\section{Capítulo 4 - Nanopartículas a base de Oxido de Cério e Paládio}

4.1.

4.1.1.

4.1.2.

4.1.3.

4.1.4.

4.1.5.

4.1.6.

4.1.7.

4.2 .

4.2.1.

4.3.

4.4 .

4.5 .

4.5.1.

4.5.1.1.

4.5.1.2.

4.5.2.

4.6.

4.6.1.

4.6.1.1.

4.6.1.2.

4.7.

4.7.1.

4.8 .
Introdução a nanocatálise

Absorção de nanopartículas sob suportes

Reações químicas catalisadas utilizando nanocristais metálicos de transição

Estrutura dos metais na catálise heterogênea

Suportes

Oxidação catalítica

$\mathrm{CeO}_{2} / \mathrm{Al}_{2} \mathrm{O}_{3}$

Desativação dos catalisadores

Paládio como catalisador

Paládio como fase ativa

$\mathrm{O}$ óxido de Cério $\left(\mathrm{CeO}_{2}\right)$

Pesquisa de inovação com nanopartículas de paládio metálico e óxido de cério depositadas em anodizados de alumínio

Preparação das amostras e caracterização

Síntese de nanopartículas de óxido de cério

Estudo da morfologia da amostra sintetizada submetida a tratamento térmico mediante a técnica SAXS

Caracterização magnética da amostra mediante a técnica de RFM

Síntese de nanopartículas de paládio metálico

Caracterização dos filmes à base de nanopartículas depositados sobre anodizado de alumínio

Resultados e discussões

Difração de raios X (XRD)

Microscopia eletrônica de varredura (MEV) e espectroscopia de energia dispersiva (EDS)

Filmes de nanopartículas de Céria e Paládio depositados na cabeça do pistão automotivo

Avaliação do desempenho catalítico - Testes catalíticos

Referências Bibliográficas

\section{Capítulo 5 - Nanopartículas a base de Hidroxiapatita}

5.1 .

5.1.1.

5.1.2.

5.1.3.

5.1.4.

5.2

5.2.1.

5.2.2.

5.3 .

5.3.1.

5.3.2.

5.3.3.

5.3.4.

5.3.5.

5.3.6.

5.3.6.1.
Introdução

99

99

$\begin{array}{ll}\text { Hidroxiapatita (HAp) } & 100 \\ \text { Estrutura cristalina da HAp } & 101\end{array}$

$\begin{array}{ll}\text { Estado de aglomeração das partículas } & 103\end{array}$

$\begin{array}{ll}\text { Preparação da amostra e caracterização } & 104\end{array}$

$\begin{array}{ll}\text { Síntese de nanopartículas de HAp } & 104\end{array}$

Sóis a base de nanopartículas de HAp revestidas 105

Resultados e discussões 106

Caracterização estrutural de nanopartículas de HAp 106

Calorimetria exploratória diferencial (DSC) 108

FTIR da HAp sintetizada sem revestimento $\quad 109$

Sinterização

110

115

122

122 
5.3.6.2. $\quad$ SAXS de soluções de HAp

5.3.6.3. Espectroscopia de absorção na região do infravermelho (FTIR) de

5.4. Referências Bibliográficas

\section{Capítulo 6 - Nanopartículas a base de Magnetita}

6.1. Introdução 134

$\begin{array}{lll}\text { 6.1.1. Colóides } & 134\end{array}$

6.1.2. Fluídos magnéticos 135

$\begin{array}{lll}\text { 6.1.3. } & \text { Estabilidade coloidal } & 138\end{array}$

6.1.4. Características físico-químicas dos agentes de contraste de óxido de 143

$\begin{array}{lll}\text { 6.1.5. A magnetita } & 144\end{array}$

$\begin{array}{lll}\text { 6.1.6. } & 146\end{array}$

$\begin{array}{lll}\text { 6.1.7. } & 148\end{array}$

6.1.8. $\quad$ Relaxação Superparamagnética 149

6.1.8.1. Comportamento dos tempos de relaxação nuclear dos prótons de 151

6.2. Síntese de nanopartículas de magnetita 153

$\begin{array}{lll}\text { 6.3. } & 155\end{array}$

6.3.1. Difração de raios X (DRX) 155

6.3.2. Microscopia eletrônica de transmissão (MET) 156

$\begin{array}{lll}\text { 6.3.3. } & \text { Calorimetria exploratória diferencial (DSC) } & 158\end{array}$

6.3.4. Ressonância Ferromagnética (RFM) 158

6.3.5. Espalhamento de Raios-X a baixo ângulo (SAXS) 166

6.3.6. Caraterização Relaxométrica mediante IRM 168

$\begin{array}{lll}\text { 6.4. } & 177\end{array}$

\section{Capítulo 7 - Conclusões e Perspectivas}

Nanopartículas a base de Céria $\quad 180$

Nanopartículas a base de Paládio $\quad 181$

Testes catalíticos no motor automotivo 181

Nanopartículas a base de Hidroxiapatita $\quad 182$

Nanopartículas a base de Magnetita 183

Perspectivas para Trabalhos Futuros 184 


\section{CAPÍTULO 1 - Introdução}

\section{Introdução Geral - Nanociência e nanotecnologia}

A nanociência é o estudo da natureza em escala nanométrica e a nanotecnologia é a aplicação desse conhecimento para a criação de produtos e serviços. Estes conceitos estão relacionados com diversas áreas do conhecimento tais como: engenharia, física, química, biologia, eletrônica, computação e medicina. "Nano" é um prefixo que vem do grego "nannós" que significa "excessiva pequenez".

A nanotecnologia permite que cientistas, engenheiros, físicos, químicos, biólogos e médicos, entre outros, trabalhem em níveis celulares e moleculares a fim de produzir maiores avanços nas ciências da vida e da saúde. Aplicações reais em larga escala de materiais nanoestruturados em ciências da vida não são muito comuns na atualidade, entretanto a excelência de suas propriedades quando comparados aos com seus equivalentes maciços, prevêm um futuro muito promissor para este campo [1,2].

A combinação de dois fatores alteram as propriedades de um material quando este atinge a escala nanométrica. Por um lado, materiais nesta escala manifestam efeitos quânticos; a limitação sobre o movimento dos elétrons (confinamento quântico), tem efeito direto sobre diferentes propriedades físicas das amostras nanoscópicas, como, por exemplo, sua cor e sua condutividade elétrica. Por outro lado, os efeitos de superfície são observados com a diminuição do tamanho da amostra devido ao aumento da razão entre sua área e seu volume. Os átomos na superfície participam de todas as interações físicas e químicas do material com o meio no qual ele está inserido.

O estudo para compreender as alterações drásticas que as propriedades dos materiais e elementos químicos apresentam em escala nanométrica é essencial para o aproveitamento dessas novas propriedades, possibilitando a cientistas reorganizar ou desenvolver moléculas e células inteligentes, construir novas estruturas e materiais, 
dispositivos tecnológicos com finalidades específicas, miniaturização dos dispositivos para economia de espaço e de energia.

\section{Nanomateriais}

Conforme acabamos de dizer, a transição de micropartículas para nanopartículas pode levar a uma série de mudanças nas propriedades físicas. Dois dos principais fatores que estão presentes são o aumento da razão entre a superfície e o volume, e o tamanho da partícula que se deslocam para o reino onde predominam efeitos quânticos.

Nanomateriais são formados por nanoagregados de partículas ultrafinas de dimensões nanométricas localizadas na região de transição entre moléculas e estruturas microscópicas. Vistas como moléculas, elas são tão grandes que proporcionam acesso a propriedades com comportamento quântico que não são acessíveis de outra forma; vistas como materiais, são tão pequenas que exibem características que não são observadas em estruturas maiores (até $100 \mathrm{~nm}$ ). Em seu regime de tamanho, muitos avanços recentes foram feitos na Biologia, Física e Química [3]. Por exemplo, quando as dimensões da partícula de materiais semicondutores se tornam comparáveis ao raio de Bohr, um acréscimo no gap da banda de energia é observado [4,5]. Em metais nobres, o decréscimo do tamanho abaixo do caminho livre médio do elétron implica em um intenso aumento da absorção na região visível próxima ao ultravioleta [6].

O aumento na razão entre a área de superfície e o volume em nanomateriais, afeta tanto as propriedades das partículas isoladas quanto sua interação com outros sistemas. A elevada área superficial é um fator crítico no desempenho de catalisadores e eletrodos, permitindo a melhoria no desempenho de tecnologias tais como as células de combustível e baterias. A área de superfície elevada de nanopartículas também resulta numa série de interações entre os materiais intermisturados em nanocompósitos, levando a propriedades especiais, tais como aumento da força e / ou aumento da resistência química/térmica. 
Acrescenta-se o fato de que as nanopartículas têm dimensões inferiores ao comprimento de onda crítico de luz, tornando-as transparentes, uma propriedade que as torna muito útil para aplicações em embalagens, cosméticos e revestimentos.

Nanopartículas são atualmente fabricadas a partir de uma vasta diversidade de materiais, particularmente importantes são as cerâmicas, que são melhor divididas em cerâmicas de óxido metálico, tais como o titânio, zinco, alumínio e ferro.

Nanopartículas metálicas também exibem uma ampla gama de comportamentos mecânicos fascinantes tais como ocorrem no superplástico [7]. Materiais cerâmicos, compostos de pós com dimensões nanométricas, podem ser produzidas com diferentes taxas de sinterização ou a temperaturas mais baixas, quando comparados aos métodos para produsão de materiais em volume [8,9]. Também a matriz cerâmica composta com nanopartículas dispersas tem propriedades mecânicas não usuais [7-9].

\section{Aplicações das nanopartículas}

\section{Aplicações catalíticas}

As substâncias que permitem que as transformações de matérias primas, num determinado processo químico, sejam rápidas, são denominadas catalisadores. Os catalisadores modificam a rota química ou o caminho da reação química sem serem consumidos no processo. A introdução do catalisador no sistema proporciona um novo percurso reacional energeticamente mais favorável, o que se traduz geralmente por uma diminuição da energia de ativação, com o conseqüente aumento de velocidade da reação. Generalizando, o catalisador aumenta a velocidade de uma reação sem ser consumido no processo.

As principais propriedades dos catalisadores (atividade, seletividade, estabilidade, resistência mecânica e condutividade térmica) estão intimamente relacionadas à sua composição e tecnologia de preparação [10,11]. Essas propriedades dependem, 
principalmente, da seleção entre os diversos materiais e os métodos de preparação. Dentro dos métodos de preparação frequentemente usados para obter esses catalisadores estão os métodos de impregnação e sol gel [11]. Muitos catalisadores usados em processos industriais são sólidos inorgânicos robustos, usualmente óxidos de metais ou estruturas suportadas, preparados por impregnação [10]. Este processo não permite, em geral, o controle essencial dos sítios metálicos, obtendo-se assim catalisadores com superfície não uniforme. Este fato dificulta a caracterização e na maioria dos casos a análise da relação entre estrutura e desempenho é mal definida. Como resultado, os mecanismos catalíticos são entendidos somente a nível macroscópico. Portanto, o progresso da eficiência da catálise a nível molecular é um desafio [12].

Nanopartículas catalíticas são catalisadores na dimensão nanométrica, muito eficientes, por que o processo de catálise é fortemente dependente dos átomos que estão na superfície do material.

Atualmente, com as novas regulamentações para diminuir a emissão de gases poluentes como monóxido de carbono ( $\mathrm{CO}$ ), hidrocarbonetos $(\mathrm{HC})$ e óxidos de nitrogênio do tipo $\mathrm{NO}_{\mathrm{X}}$, há um grande interesse para o desenvolvimento de catalisadores mais eficientes [13]. A maioria dos catalisadores tem a capacidade de diminuir as emissões dos gases poluentes, isto é, a capacidade de transformar o $\mathrm{HC}$ e $\mathrm{CO}$ residuais, em dióxido de carbono $\left(\mathrm{CO}_{2}\right)$ e vapor da água $\left(\mathrm{H}_{2} \mathrm{O}\right)$ e de reduzir o $\mathrm{NO}_{\mathrm{X}}$ a seus componentes básicos: nitrogênio $\left(\mathrm{N}_{2}\right)$ e oxigênio $\left(\mathrm{O}_{2}\right)$.

Processos catalíticos: Os esforços realizados em pesquisas na área de catálise, buscam em sua maioria, a simplificação dos processos ou mudança de sistemas, no qual a seletividade ou o rendimento é baixo ou o gasto de energia é muito elevado. Portanto, o desenvolvimento de processos que possibilitem as operações, em temperaturas e pressões menores é atraente e compensador [14]. Sabe-se que o desenvolvimento de um catalisador que apresente bons resultados num dado processo industrial requer um investimento elevado, sendo que, na maioria das vezes o estágio exploratório é conduzido em instituições de ensino e pesquisa, as quais preparam e testam os 
catalisadores em micro escala, depois de definida a reação química. A projeção de catalisadores com aglomerados metálicos, suportados em superfícies ativas, leva ao surgimento de diferentes tipos de reações químicas nos processos catalíticos, decorrentes das interações entre os sítios ativos metálicos e os suportes do catalisador.

Suportes a base óxido de zircônio, titânio, alumínio, sílica e nióbio entre outros, são freqüentemente usados como suportes de metais com fins catalíticos. Os mesmos possuem características importantes que devem ser levadas em consideração, nos diversos processos catalíticos, tais como: atividade, seletividade, estabilidade, resistência mecânica e condutividade térmica [10,15-19]. Neste trabalho são apresentadas a síntese e caracterização de nanopartículas à base de Ce e Pd metálico suportadas em uma matriz cerâmica de alumina porosa para aplicações automotivas em catálise heterogênea depositadas pelo método de impregnação, assim como o estudo das propriedades catalíticas destes materiais no processo de exaustão e na eficiência do motor automotivo.

\section{Aplicações biomédicas}

Atualmente, a nanotecnologia biomédica, na qual os bioengenheiros constroem partículas combinando materiais orgânicos e inorgânicos, está assumindo a fronteira deste campo científico que progride em velocidade assustadora. A nanotecnologia biomédica produzirá avanços importantes em diagnóstico, terapêutica, biologia molecular e bioengenharia. Se por um lado a viabilidade de construção de grande parte dos nanodispositivos imaginados ainda está longe, hoje é bastante plausível o uso de nanossistemas para a veiculação de drogas e tratamento de inúmeras doenças, como os que se baseiam em lipossomos e nanopartículas. Estes sistemas tornam-se especialmente interessantes se forem construídos a partir de nanopartículas magnéticas e nanopartículas de hidroxiapatita.

Nanopartículas magnéticas apresentam superparamagnetismo, alta irreversibilidade de campo, alto campo de saturação, contribuições de anisotropia extra ou loops deslocados após congelamento do campo. Estes fenômenos surgem do tamanho 
finito e efeitos de superfícies que dominam o comportamento magnético das nanopartículas individuais [20]. Frenkel e Dorfman [21] foram os primeiros a prever que uma partícula de material ferromagnético, abaixo de uma dimensão crítica $(<15 \mathrm{~nm}$ para os materiais comuns), constituem um monodominio magnético, isto é, uma partícula que está em um estado de magnetização uniforme em qualquer campo. O comportamento da magnetização destas partículas até uma certa temperatura, isto é, a temperatura de bloqueio, é idêntica àquela de átomos paramagnéticos (superparamagnetismo) exceto que o momento é extremamente grande e assim, suscetibilidades grandes estão envolvidas [22].

Para aplicações biomédicas, onde são usadas partículas que apresentam comportamento superparamagnético a temperatura ambiente, é desejável que nenhuma remanência permaneça durante uma rápida mudança do estado magnético [23]. Além disso, aplicações na Biologia e no diagnóstico e terapia médica requerem que as partículas magnéticas sejam estáveis em água com $\mathrm{pH}$ neutro e salinidade fisiológica. A estabilidade coloidal deste fluído dependerá primeiro, das dimensões das partículas, que deverão ser suficientemente pequenas para que o movimento Browniano predomine sobre a força gravitacional. Segundo, a presença de cargas na superfície resulta no aumento de repulsões coulombianas evitando a formação de aglomerados [24]. Restrições adicionais para aplicações biomédicas dependem fortemente de estas partículas serem usadas para aplicações in vivo ou in vitro.

Hidroxiapatita é amplamente estudada e aplicada em uma variedade de campos devido à sua semelhança com o principal constituinte inorgânico dos ossos e dentes. Hidroxiapatita sintética tem excelente biocompatibilidade e bioatividade [25], é amplamente utilizada em muitas aplicações biomédicas [26-29], tais como implantes e revestimentos para próteses [30-33]. Hidroxiapatita também encontra aplicações em outros campos da atividade industrial ou tecnológica, interesse como catalisador em cromatografia ou em sensores de gases, purificação da água, fertilizante e carregadores de medicamentos [34-37]. Para aplicações ortopédicas e dentárias bem sucedidas de cerâmicas baseadas na hidroxiapatita, sinterização e tenacidade são desejáveis [38]. 
Infelizmente, devido à baixa taxa de sinterização, as cerâmicas de hidroxiapatita apresentam baixa resistência e tenacidade, especialmente em ambiente úmido sob condição fisiológica, o que o torna impróprio até mesmo para aplicações de baixa concentração. Por outro lado, materiais nanoestruturados podem ser sinterizados devido a elevada energia superficial e, consequentemente, melhorar as propriedades mecânicas. Mas a sinterização não depende só da dimensão das partículas, mas também da distribuição, morfologia e mobilidade atômica nas mesmas [39]. Partículas grosseiras e aglomerados exibem baixa densificação no caso da hidroxiapatita [39].

Recentemente muitas tentativas foram feitas para desenvolver processos e técnicas para produzir colóides monodispersos constituídos por nanopartículas uniformes, tanto em tamanho, como em forma [40]. Nestes sistemas, as propriedades físico-químicas uniformes refletem diretamente as propriedades de cada partícula constituinte. Colóides monodispersos são explorados em pesquisa fundamental e como modelo de avaliação quantitativa das propriedades que dependem do tamanho e da forma das partículas. Estes pós encontram aplicações em fotografia, tintas de impressão em alta velocidade, cerâmica, catálise e especialmente em medicina.

Após a síntese e caracterização de uma suspensão coloidal, a realização de testes biológicos preliminares antes de implementar qualquer aplicação biomédica específica é necessária para a sua otimização. Os testes de toxicidade são baseados em alterações morfológicas, alterações citométricas e análise citogenética, cinética de eliminação e biodistribuição da suspensão coloidal no organismo, sendo estudadas mediante técnicas como RPE, microscopia de luz, imagem por ressonância magnética, entre outros.

Neste trabalho são apresentadas a síntese e a caracterização de nanopartículas à base de óxido de ferro e nanopartículas de hidroxiapatita para aplicações biomédicas como agente de contraste em imagem por ressonância magnética nuclear e em aplicações na área de ortopedia e ortodontia, respectivamente. 


\section{Objetivos}

O presente trabalho visa o desenvolvimento de pesquisas relacionadas com a obtenção e a caracterização de nanopartículas, como, $\mathrm{CeO}_{2}$ e $\mathrm{Pd}$ metálico para aplicações catalíticas, assim como nanopartículas de $\mathrm{Fe}_{3} \mathrm{O}_{4}$ e hidroxiapatita para aplicações biomédicas, preparados via sol-gel.

O presente trabalho tem como objetivos principais: (i) sintetizar e caracterizar suspensões coloidais biocompatíveis estáveis (nanopartículas superparamagnéticas à base de óxido de ferro e nanopartículas de hidroxiapatita) obtidas mediante o processo sol-gel, estabelecendo as condições básicas e necessárias para o processamento reprodutível das suspensões estáveis; (ii) sintetizar e caracterizar nanopartículas de céria e paládio em suporte de alumina obtida pelo processo de redução e oxidação propondo uma metodologia para a formação de nanopartículas na cabeça de pistões anodizados, necessários para avaliação da atividade catalítica no motor de exaustão; (iii) estudar as características morfológicas, térmicas, estruturais e magnéticas das suspensões coloidais e das nanopartículas com propriedades catalíticas.

\section{Organização da tese}

No capítulo II apresentamos os fundamentos teóricos das técnicas experimentais empregadas neste estudo para a caracterização morfológica, estrutural, magnética e relaxométrica das amostras de nanopartículas.

No capítulo III apresentamos a metodologia para a síntese de suspensões coloidais biocompatíveis, assim como, a metodologia para a obtenção de nanopartículas para aplicações em catálise heterogênea.

No capítulo IV são discutidos os fundamentos teóricos, em catálise heterogênea, de nanopartículas de céria e paládio, necessárias para a descrição das propriedades catalíticas destas nanopartículas em filmes para aplicações automotivas de exaustão, este 
capítulo inclui a síntese e o processo de deposição dos filmes no anodizado de alumina, contendo os resultados e a discussão dos resultados referentes à caracterização e ao estudo da avaliação catalítica no motor automotivo.

No capítulo V são apresentados a base teórica das nanopartículas de hidroxiapatita, em seguida é descrito o processo de síntese para a obtenção das nanopartículas de hidroxiapatita para aplicações em ortopedia e ortodontia. Finalmente, apresentamos e discutimos os resultados referentes à caracterização das nanopartículas de hidroxiapatita.

No capítulo VI apresentamos a base teórica das suspensões coloidais biocompatíveis e posteriormente é descrita a síntese para a obtenção de nanopartículas magnéticas para aplicações biomédicas. Em seguida, apresentamos e discutimos os resultados referentes à caracterização do ferrofluido, para finalmente apresentarmos a caracterização dos tempos de relaxação realizada por imagem de ressonância magnética nuclear do agente de contraste à base de nanopartículas de oxido de ferro superparamagnético.

No capítulo VII, por fim, apresentam-se as conclusões destes estudos e propõe-se a realização de trabalhos futuros, com vistas ao esclarecimento de questões relativas ao assunto em questão. 


\section{Referências Bibliográficas}

[1] Niemeyer, C.M. Angewandte Chemie International Edition, v.40, p.4128, 2001.

[2] Hood, J. D.; Bednarski, M.; Frausto, R.; Guccione, S.; Reisfeld, R.; Xiang, R.; Cheresh, D.A. Science, v.296, p.2404, 2002.

[3] Whitesides, G.; Alivisatos, A.P. Nanotechnology Research Directions ed. A.P. Alivisatos et. al. (IWGN Workshop Report), 1999.

[4] El-Sayed, M.A. Accounts of Chemical Research, v.34, p.257, 2001.

[5] Heath, J.R. Science, v.270, p.1315, 1995.

[6] Bohren, C.F.; Huffman, D.R. New York, Wiley, 1983.

[7] Kung, H.; Foeke, T. MRS Bulletin, v.24, n.2, p.14, 1999.

[8] Hahn, H.; Logas, J; Averback, R.S. Journal of Materials Research, v.5, p.609, 1990.

[9] Zhou, Y.C.; Rahaman, M.N. Journal of Materials Research, v.8, p.1680, 1993.

[10] Figueiredo, L.L.; Ribeiro, F. Catalise Heterogênea, Lisboa: Edição de Fundação Calouste Gulbenkion, 1989.

[11] Gates, B.C.; Katzer, J.R.; Schuit, G.C.A. Chemistry of Catalytic Processes, GrawHill Book Company, New York, p.276, 1979.

[12] Ichikumi, N.; Shirai, M.; Iwasawa, Y. Catalysis Today, v.28, p.49, 1996.

[13] Shelef, M.; McCabe, R.W. Catalysis Today, v.62, p.35, 2000.

[14] Chem. Eng. Mag, Ed.: Nicholas P. Chapey; The Mc Graw-Hill Companies, Inc., p.106,10,70, 1999.

[15] Brayner, R.; Ciuparu, D.; Da Cruz, G.M.; Fiévet-Vincent, F.; Bozon-Verduraz, F. Catalysis today v.57, p.261, 2000.

[16] Semikolenov, V.A.; Llyna, I.I.; Simakova, I.L. Appl. Catalysis A: General, v.211, p.91, 2001.

[17] Trovarelli, A. Catalysis Rev., v.38, p.439, 1996.

[18] Freni, S.; Calogero, G.; Cavallaro, S. J. Power Sources, v.87, p.28, 2000.

[19] Carreño, N.L.V.; Valentini, A.; Maciel, A.P.; Weber, I.T.; Leite, E.R.; Probst, L.F.D.; Longo, E. Cerâmica, v.48 Jul/Ago/Set, 2002.

[20] Batlle, X.; Labarta, A. Journal of Physics D: Applied Physics, v.35, p.R15, 2002.

[21] Frenkel, J.; Dorman, J. Nature, v.126, p.274, 1930.

[22] Bean, C.P.; Livingston, J.D. Journal of Applied Physics, v.30, p.120, 1959.

[23] Bangs, L.B. Pure and Applied Chemistry, v.68, p.1873, 1996.

[24] Langer, R. Science, v.249, p.1527, 1990.

[25] Banerjee, A.; Bandyopadhyay, A.; Bose, S. Materials Science and Engineering C, v.27 p.729, 2007.

[26] Wan, Y.Z.; Hong, L.; Jia, S.R.; Huang, Y.; Zhu, Y.; Wang, Y.L.; Jiang, H.J. Composites Science and Technology, v.66, p.1825, 2006.

[27] Zhu X.; Eibl, O.; Berthold, Ch.; Scheideler, L.; Geis-Gerstorfer, J. Nanotechnology, v.17, p.2711, 2006.

[28] Yin, M.Z.; Han, Y.Ch.; Bauer, I.W. Chen P. Biomed. Mater., v.1, p.38, 2006.

[29] Liu, A.S.; Tang, Sh.L.; Ai, Z.L. World J. Gastroenterol, v.9(9), p.1968, 2003.

[30] Hench, L.L. J. Am. Ceram. Soc., v.74, p.1487, 1991. 
[31] Suchanek, W.; Yoshimura, M. J. Mater. Res., v.13, p.94, 1998.

[32] Suchanek, W.; Suda, H.; Yashima, M.; Kakihana, M.; Yoshimura, M. J. Mater. Res., v.10, p.521, 1995.

[33] Shuk, P.; Suchanek, W.L.; Hao, T.; Gulliver, E.; Riman, R.E.; Senna, M.; Tenhuisen, K.S.; Janas, V. F. J. Mater. Res., v.16, p.1231, 2001.

[34] Hench, L. L. J. Am. Ceram. Soc., v.74, p.1487, 1991.

[35] Suchanek, W.; Yoshimura, M. J. Mater. Res., v.13, p.94, 1998.

[36] Suchanek, W.; Suda, H.; Yashima, M.; Kakihana, M.; Yoshimura, M. J. Mater. Res., v.10, p.521, 1995.

[37] Shuk, P.; Suchanek, W.L.; Hao, T.; Gulliver, E.; Riman, R.E.; Senna, M.; Tenhuisen, K.S.; Janas, V.F. J. Mater. Res.,v.16, p.1231, 2001.

[38] Sung, Y.; Shin, Y.; Ryu, J.J. Nanotechnology, v.18, p.065602, 2007.

[39] Nayar, S.; Sinhá, M.K.; Basu, D.; Sinhá, A. J. Mater. Sci.: Mater. Med., v.17, p.1063, 2006.

[40] Zhao, Y.; Zhang, Y.; Ning, F.; Guo, D.; Xu, Z. Journal of Biomedical Materials Research Part B: Applied Biomaterials DOI 10.1002/jbmb. 


\section{CAPÍTULO 2 - Técnicas experimentais}

Este capítulo apresenta uma breve revisão das técnicas empregadas para obter informações sobre a estrutura cristalina, morfologia, propriedades magnéticas e tempos de relaxação de nanosistemas.

\subsection{Difração de Raios X (DRX)}

O fenômeno da Difração de Raios X (DRX) é explicado supondo que as ondas de raios X são espalhadas por átomos individuais, esfericamente, na rede cristalina (Figura 1). Para as ondas interferirem construtivamente, a condição de Bragg tem que ser satisfeita, ou seja, deve ocorrer interferência construtiva igual a:

$$
n \lambda=2 d \operatorname{sen} \theta
$$

onde $n$ é a ordem de reflexão (número inteiro), $\lambda$ é o comprimento de onda da radiação incidente, $\theta$ é o ângulo de Bragg, e $d$ é a distância entre dois planos atômicos. $\mathrm{O}$ lado direito da equação é essencialmente a diferença entre os caminhos percorridos pelas ondas espalhadas nas posições $\mathrm{O}$ e $\mathrm{O}^{\prime}$, ver figura 2.1 [1].

Esta lei estabelece que para um dado comprimento de onda da radiação $\mathrm{X}$ incidente, o raio espalhado emergirá apenas em ângulos para os quais esta condição é satisfeita. Então, cada pico de difração é produzido por um certo conjunto de planos que satisfaça esta condição, permitindo a identificação do composto cristalino formado [2]. 


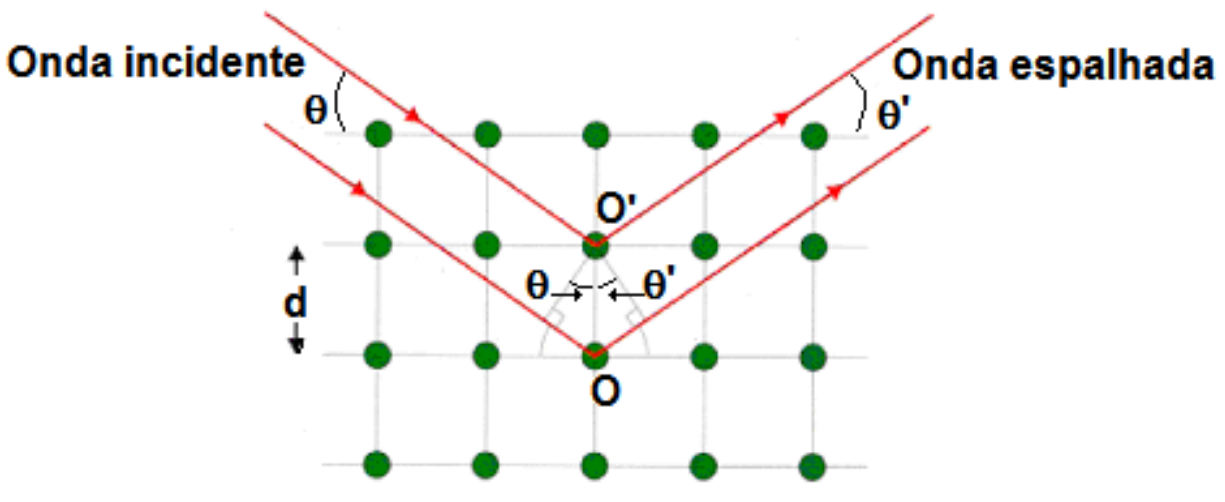

Figura 2.1: Diagrama mostrando a interferência construtiva de raios $X$ monocromático.

O fenômeno da DRX é amplamente utilizada no estudo de estruturas cristalográficas em escala macroscópica. É possível determinar a estrutura correspondente a um determinado material, os domínios cristalinos e as fases presentes. Entretanto, na caracterização de nanoestruturas, a interpretação dos difratogramas é mais complexa. O número finito de planos cristalinos resulta no alargamento dos picos de difração, além da superposição dos mesmos. Quanto menor for o número de planos atômicos no espaço real, maior será o truncamento no espaço recíproco e, consequentemente, mais largo será o pico correspondente à direção dos planos de átomos que estão espalhando. Por causa do número restrito de planos, a deslocalização e superposição dos picos faz com que suas posições e formas variem com o tamanho das nanopartículas, o que dificulta a interpretação dos difratogramas. Por exemplo, uma nanopartícula com cerca de $5 \mathrm{~nm}$ de diâmetro apresenta aproximadamente 20 planos atômicos em uma direção em estudo. A presença de mais de um tipo de estrutura torna ainda mais complexa a análise.

Outra consequiência do número limitado de planos atômicos é a baixa intensidade difratada. Durante os experimentos, é essencial que o feixe esteja bem alinhado e incidindo na maior região possível da amostra para que se obtenha uma boa relação sinal/ruído. Como a intensidade difratada é proporcional ao quadrado do número 
atômico $Z$ é de se esperar que as amostras de $\mathrm{Au}(Z=79)$ apresentem um sinal mais intenso do que as de $\operatorname{Ag}(Z=47)$, por exemplo.

\subsection{Microscopia Eletrônica de Transmissão (MET)}

Um modo relativamente simples de se obter a morfologia e as dimensões das NPs é a Microscopia Eletrônica de Transmissão (MET). Está técnica utiliza um feixe de elétrons produzidos pelo aquecimento de um filamento de tungstênio e acelerados por uma diferença de potencial de 60 a $300 \mathrm{kV}$, entre catodo e anodo. O comprimento de onda dos elétrons é da ordem de 0,01 nm. Lentes magnéticas direcionam e aumentam consideravelmente o poder de resolução. Essa resolução pode chegar a 500000 vezes, com possibilidade de observar estruturas com dimensões próximas a $0,1 \mathrm{~nm}$. Tipicamente, a preparação da amostra consiste em secar a suspensão coloidal em uma tela de microscópio coberta por uma membrana de carbono. No caso de partículas homogêneas em forma os histogramas são obtidos medindo-se o diâmetro de um número grande de nanopartículas nas imagens obtidas [3]. A polidispersão do diâmetro D das partículas pode ser obtida através de uma função do tipo lognormal, dada por [4]:

$$
P(D)=\frac{1}{4 \pi^{2} D \sigma} \exp \left[-\frac{\left(\ln D-\ln D_{M E T}^{2}\right)}{2 \sigma^{2}}\right]
$$

onde $\sigma$ é o desvio padrão do diâmetro ou dispersão e $\mathrm{D}_{\mathrm{MET}}$ é o diâmetro médio.

As medidas de MET foram realizadas para partículas de ferrofluido à base de magnetita. Para esta medida foi feita a centrifugação e a diluição da amostra concentrada de fluído magnético. 


\subsection{Microscopia eletrônica de varredura (MEV) e espectroscopia de energia dispersiva (EDS)}

A Microscopia Eletrônica de Varredura (MEV) é uma técnica de caracterização que consiste em submeter a amostra a um feixe de elétrons. $\mathrm{O}$ feixe interage com a região de incidência da amostra até uma profundidade que pode variar de alguns microns, dependendo da natureza da amostra, e gera elétrons secundários ou elétrons retroespalhados em relação ao feixe primário. Esta região é conhecida por volume de interação, o qual gera os sinais que são detectados e utilizados para a formação da imagem e para microanálise, nesse trabalho estamos interessados no contraste devido à topologia da superfície dos catalisadores, a fim de caracterizar as espécies metálicas em relação à sua dispersão, tamanho dos componentes da amostra (suporte e espécies metálicas), morfologia do suporte, porosidade, composição e problemas de sinterização.

A espectroscopia de energia dispersiva (EDS) é uma técnica não destrutiva e útil para identificar e quantificar os elementos químicos numa amostra determinada. Quando um feixe atinge as amostras, seus átomos são excitados e, ao voltarem para o estado fundamental, emitem fótons com energias características do átomo. Os fótons são assim identificados em termos de sua energia e contados pelo detector de raios X. Desta forma o sistema de aquisição coleta e gera o espectro relativo ao número de contagens em função da energia, em keV, identificando os elementos químicos presentes no filme de nanopartículas depositados sobre suporte de alumínio anodizado. Os átomos a partir do número atômico do boro são identificáveis, uma vez que o detector possui filtro tipo NORVAR ao invés de berílio. Além dos espectros, o sistema realiza análise de pontos, linhas e regiões definidas sobre a imagem gerada pela amostra e obtém também o mapa dos elementos sobre a imagem final. 


\subsection{Ressonância Ferromagnética (RFM)}

A absorção de microondas por materiais ferro(i)magnéticos na presença de um campo é chamada Ressonância Ferro(i)magnética (RFM) que, em princípio, é similar à Ressonância Paramagnética Eletrônica (RPE) exceto pelo fato que os spins eletrônicos interagem na rede ferromagnética (ou ferrimagnética) constituída de nanopartículas de monodominios magnéticos. A intensidade do sinal de RFM é maior que a de RPE no mesmo campo, devido às relações entre as magnetizações das duas espécies de materiais. É importante destacar a dependência da RFM com a forma do material e sua orientação devido à contribuição dos campos de desmagnetização e de anisotropia. Assim, o momento magnético total de cada nanopartícula precessiona em torno da direção do campo estático total, que é a soma do campo estático externo e das contribuições internas, tais como o campo anisotrópico da nanopartícula [5]. Esta técnica é bastante adequada para o estudo [6] e a detecção de nanopartículas ferromagnéticas [5,7]. As partículas são dispersas em um fluido (fluído magnético); grãos de material magnético nano-estruturados representados por estruturas cristalinas de óxido de ferro descritas pela fórmula geral $\mathrm{Fe}^{3+}{ }_{2} \mathrm{O}_{3} \mathrm{M}^{2+} \mathrm{O}$, onde $\mathrm{M}^{2+}$ é um íon de um metal divalente tal como o ferro, manganês, níquel, cobalto ou magnésio. Para a síntese dos agentes de

contraste, pequenos cristais de magnetita $\mathrm{Fe}^{3+}{ }_{2} \mathrm{O}_{3} \mathrm{Fe}^{2+} \mathrm{O}$ são predominantemente usados [8].

Uma experiência de RPE de partículas ferromagnéticas é denominada na literatura como RFM ou, mais precisamente, ressonância superparamagnética. Em amostras ferromagnéticas com estruturas de monodomínio, as partículas carregam momento magnético gigante e sob efeito da agitação térmica o sistema pode ser descrito como superparamagnético. Sistemas ferromagnéticos que estão no regime superparamagnético podem ser caracterizados como um sistema paramagnético com super spin eletrônico efetivo $\mathrm{S}=1 / 2$, ou seja, um sistema de dois níveis. 
A descrição fenomenológica da RFM pode ser feita com base na dinâmica do vetor magnetização $\mathbf{M}$ em um campo magnético externo $\mathbf{H}$, cujo movimento de precessão é descrito por [9]:

$$
\frac{d}{d t} \vec{M}=\gamma\left(\vec{M} \times \vec{H}_{e f}\right)
$$

onde $\gamma$ é a razão giromagnética e $\mathbf{H}_{\mathrm{ef}}$ é um vetor que inclui os campos estático (efetivo) e de microondas, bem como campos efetivos associados a torques internos sobre o sistema de spins (v. abaixo).

Em sistemas ferromagnéticos, os spins vizinhos estão acoplados por meio da interação de intercâmbio (exchange). Assim, as excitações do sistema de spins correspondem a precessões coletivas em torno da posição de equilíbrio. A excitação de menor energia é o modo uniforme, no qual os spins precessionam em torno de $\boldsymbol{H}$ mantendo-se paralelos uns aos outros, ou seja com a mesma fase, como ilustrado na Figura 2.2(a). Neste caso a interação entre os spins não contribui para a frequência de precessão, que é dada pela mesma expressão da Equação (2-3). Devido à interação entre os spins, o sistema tem também modos coletivos nos quais a fase da precessão varia no espaço, chamados ondas de spin. A Figura. 2.2(b) ilustra uma onda de spin, na qual a diferença de fase do primeiro ao último spin é $2 \pi$, correspondendo a um comprimento de onda. O modo uniforme é, na realidade, uma onda de spin com comprimento de onda infinito. A medida que o comprimento de onda diminui, aumenta o ângulo entre spins vizinhos e, por conseguinte, aumenta a contribuição da energia de intercâmbio para a energia da excitação. 


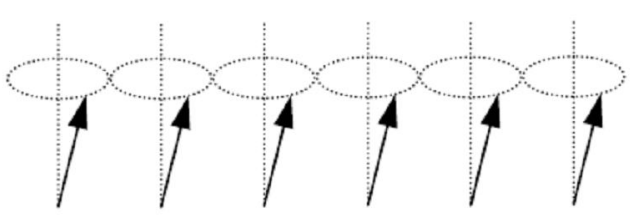

(a)

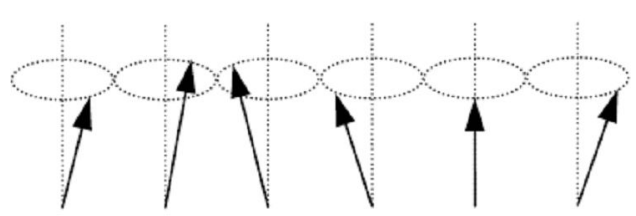

(b)

Figura 2.2: Desenho esquemático mostrando (a) o modo uniforme e (b) de onda de spin em sistema ferromagnético [9].

Como em RPE, a idéia básica de um experimento de ressonância ferromagnética consiste em aplicar um campo de microondas numa amostra situada num campo magnético estático $\boldsymbol{H}_{\mathbf{0}}$, e observar as linhas de absorção ressonante. O campo magnético da radiação de micro-ondas é aplicado perpendicularmente ao campo estático, de modo que ele tende a perturbar os spins e desviá-los da posição de equilíbrio. Quando a freqüência da radiação está próxima da freqüência do modo uniforme, o campo de microondas produz o movimento de precessão dos spins e a amostra absorve energia da radiação.

O campo magnético efetivo sentido pela nanopartícula magnética (monodomínio magnético com momentos magnéticos gigantes) é dado pela derivada primeira da densidade de energia livre da partícula com relação à projeção do vetor magnetização na direção correspondente ao estado de equilíbrio, ou seja,

$$
H_{e f}=-\left.\frac{\partial \varepsilon}{\partial M}\right|_{e q}
$$

A densidade de energia tem contribuições de origens diferentes. A primeira delas é a interação Zeeman tradicional em ressonâncias magnéticas. Outra contribuição está relacionada a uma das características marcantes de materiais magnéticos que é o efeito de desmagnetização. Ele resulta dos campos criados pelos dipolos magnéticos não compensados nas superfícies da amostra. Por fim, existe ainda uma contribuição relacionada com as interações entre o campo elétrico cristalino e os momentos 
magnéticos atômicos que tendem a dirigir a magnetização local para certas direções de grande simetria do cristal. Estas interações podem ser representadas por uma energia magnetocristalina, também chamada de energia de anisotropia. A origem microscópica da anisotropia reside no fato de que os spins dos elétrons interagem com os momentos orbitais, através da interação $\boldsymbol{L} . \boldsymbol{S}$, e as cargas eletrônicas dos orbitais sofrem a ação do campo elétrico cristalino. Sendo assim, o campo efetivo sentido pelos spins contem contribuições tanto dos campos externos aplicados à amostra, quanto dos campos efetivos que representam torques internos sobre os spins.

Portanto, na equação (2-49), a densidade de energia é dada por.

$$
\varepsilon=-\vec{M} \cdot \vec{H}_{0}+\varepsilon_{a}\left(K_{u}\right)+\frac{1}{2} \mu_{0} \vec{M} \cdot \vec{\eta} \cdot \vec{M}
$$

O primeiro termo de (2-50) é a energia Zeeman com relação ao campo estático aplicado $\mathbf{H}_{0}$, o segundo é a energia magnética anisotrópica considerando que a partícula possui simetria uniaxial e o último termo é a energia devido ao efeito de desmagnetização, onde $\eta$ é o tensor de desmagnetização da amostra, considerando que a partícula tem forma elipsoidal. Estes dois últimos são dependentes da orientação e provocam, portanto, a dependência angular do espectro de RFM.

A resposta do sistema de spins à aplicação do campo de microondas é representada através de uma susceptibilidade complexa, cuja componente imaginária ( $\chi$ ') é a responsável pela potência média absorvida pela amostra, originando o espectro de RFM. O desenvolvimento teórico que evidencia este fato é análogo àquele utilizado no caso da RPE e encontra-se descrito em uma série de textos clássicos.

Alguns trabalhos sobre ressonância magnética em fluidos magnéticos, indicam uma relação linear para $\mathrm{Hr} \times \mathrm{T}$, isto é uma relação linear entre a anisotropia e a temperatura. As medidas do campo de ressonância em função da temperatura são analisados pela seguinte expressão [10,11]: 


$$
H_{R}=\left(\frac{\omega}{\gamma}-H_{D}-H_{A}\right),
$$

onde $\omega$ é a frequência angular de ressonância, $\gamma$ é a razão giromagnética, $H_{D}$ é o campo de desmagnetização e $\mathrm{H}_{\mathrm{A}}$ é o campo de anisotropia. Estes dois termos, em geral, são dependentes da temperatura, contudo, no intervalo de temperaturas aqui estudado, a dependência de $\mathrm{K}_{\text {eff }}$ com a temperatura é mais significativa. Uma descrição simples deste campo (nanopartículas esféricas) é dada por:

$$
H_{A}=\frac{2 K_{e f f}}{M_{S}}
$$

onde $\mathrm{K}_{\mathrm{eff}}$ é a anisotropia magnetocristalina efetiva da nanopartícula e é escrita como a soma da sua componente $K_{B}$ (anisotropia do material massivo) mais $K_{S}$ (anisotropia de superfície) e $M_{S}$ é a magnetização de saturação. A componente superficial é dada por $K_{S}=(6 / D) k_{S}$, onde $D$ é o diâmetro da nanopartícula e $k_{S}$ é a anisotropia de superfície.

O comportamento do campo de ressonância de fluidos magnéticos em função da temperatura exibe duas regiões distintas; uma região abaixo da temperatura de descongelamento e outra região acima desta temperatura [12]. As medidas do campo de ressonância em função da temperatura realizadas no ferrofluído mostram uma descontinuidade com o aumento da temperatura. A anisotropia efetiva pode ser representada por uma relação empírica dada por $K_{\text {eff }}=K_{0}+k_{\text {eff }} T$, onde $\mathrm{K}_{0}$ é uma constante e o coeficiente $k_{\text {eff }}$ está relacionado com a variação de temperatura. Portanto, para os dados obtidos neste trabalho, na faixa de temperatura de 4 a $300 \mathrm{~K}$, o campo de ressonância é dado pela relação empírica [12]:

$$
H_{R}=\left(\frac{\omega_{R}}{\gamma}-\frac{2 K_{0}}{M_{S}}-\frac{4 \pi}{3} M_{S}\right)-\frac{2 k_{e f f}}{M_{S}} T .
$$


Temos que, $\mathrm{H}_{\mathrm{R}}=\mathrm{B}+\mathrm{AT}$, onde $\mathrm{A}=-2 \mathrm{k}_{\mathrm{eff}} / \mathrm{M}_{\mathrm{S}}$ e $\mathrm{B}=\left(\omega / \gamma-2 \mathrm{~K}_{0} / \mathrm{M}_{\mathrm{S}}-\mathrm{H}_{\mathrm{D}}\right)$. O parâmetro $\mathrm{A}$ está associado ao diâmetro da nanopartícula, à constante de anisotropia de superfície $\left(\mathrm{k}_{\mathrm{S}}\right)$ e à magnetização de saturação $\left(\mathrm{M}_{\mathrm{S}}\right)$. Já o parâmetro $\mathrm{B}$ está associado à razão entre a frequência de ressonância $(\omega)$ e a razão giromagnética $(\gamma)$, o campo de desmagnetização $\left(\mathrm{H}_{\mathrm{D}}\right)$ e o campo de anisotropia $\left(\mathrm{H}_{\mathrm{A}}\right)$.

A dependência da largura de linha com a temperatura, pode ser descrita através dos termos que contribuem para a barreira de energia de anisotropia $\Delta \mathrm{E}$ [13], dada por [14]:

$$
\Delta H_{p p}=\frac{A}{r^{3}} \tanh \left(\frac{\Delta E}{2 k T}\right)
$$

Onde $A=5 g \beta S n$ e $\Delta E=\left(B+C / r^{3}+D / r+E / r^{6}\right)$. No termo de energia $\Delta E$ temos $B=(K V+\gamma \mu H) / 2 k T, C=\left(\delta \mu^{2} / 2 k T\right), \quad D=\left(\theta \sigma^{2} / 2 k T\right)$ e $E=(\varepsilon / 2 k T)$. O termo B é formado pela energia de anisotropia magnetocristalina $(K V)$ e a energia magnética $(\gamma \mu H)$. O termo $C$ refere-se à interação dipolar magnética, o termo D à interação coulombiana e o termo $E$ à interação dipolar elétrica. $\sigma$ representa a densidade superficial de carga. $\gamma, \delta, \theta$ e $\varepsilon$ são as constantes de acoplamento.

A largura de linha de ressonância depende da temperatura e da distância média entre partículas adjacentes. No caso de suspensões coloidais à base de nanopartículas de óxido de ferro superparamagnéticas (SPIONs), os termos D (interação Coulombiana) e E (interação dipolar elétrica) podem ser omitidos. Portanto a largura de linha para ferrofluidos resulta [14]:

$$
\Delta H_{p p}=\frac{5 g \mu \beta S n}{r^{3}} \tanh \frac{G}{T}
$$


onde $G=\frac{\left(K V+\gamma \mu H+\frac{\delta \mu^{2}}{r^{3}}\right)}{2 \times 10^{3} k}$. A separação entre as partículas (r) varia com a concentração de partículas. O parâmetro $G$ está relacionado com a barreira de energia $\Delta E$, onde estão incluídos os termos da energia magnetocristalina, interação Zeeman e interações dipolares magnéticas. O termo associado ao movimento Browniano foi desprezado por se tratar de medidas a baixas temperaturas.

O alargamento da linha de ressonância magnética depende da temperatura e da barreira de energia através da qual o momento magnético da partícula sofre relaxação. $\mathrm{O}$ mecanismo de relaxação associada as nanopartículas é do tipo Néel, que é termicamente assistida e relacionada com a energia de anisotropia magnetocristalina ( $\Delta E=K_{\text {eff }} V$ ). Entretanto, para amostras relativamente concentradas, há ainda a interação dipolo-dipolo entre partículas adjacentes $\left(\mu^{2} / r^{3}\right)$ e, na presença de um campo magnético externo, há a interação entre o momento magnético da partícula e o campo externo $\left(\mu H_{e x t}\right)$. Ainda, para medidas a baixas temperaturas ou a temperaturas onde o fluido magnético está congelado, a contribuição para a barreira de energia não está relacionada com o termo Browniano. Portanto, a barreira de energia pode ser escrita como $\Delta E=K_{e f f} V+\mu H_{e x t}+\delta \mu / R^{3}$, onde $\delta$ é um coeficiente de acoplamento [12].

Cabe observar, para o nosso estudo, que a expressão da Equação 2-10 é escrita sob a premissa de que o processo de relaxação dos momentos magnéticos é do tipo Néel, ou seja, considera-se a amostra no estado sólido, onde a partícula fica imóvel na matriz. Para se estudar o caso líquido, seria necessário levar em conta a relaxação tipo browniana, onde o movimento termicamente induzido vai contra a viscosidade do meio.

O processo de relaxação de spins é caracterizado mediante uma constante do tempo, a qual é uma função do campo magnético estático e depende da taxa na qual a energia de microondas pode ser absorvida e dissipada. O processo de relaxação spin-spin é a 
diferença de energia $(\Delta \mathrm{E})$ transferida para elétrons vizinhos. O tempo de relaxação $\left(\mathrm{T}_{2}\right)$ pode ser determinado da largura de linha pico a pico de acordo com a seguinte relação:

$$
\frac{1}{T_{2}}=\frac{\sqrt{3} g \beta \Delta H_{P P}}{\hbar},
$$

$\left(\mathrm{em} \mathrm{s}^{-1}\right)$, onde $\beta$ é o magneton de Borh, e $\hbar$ é a constante de Planck.

O número de spins eletrônicos não emparelhados na amostra é proporcional a área sob a linha de absorção de FMR, sendo esta determinada pelo produto $\Delta H_{P P}^{2} \cdot h$ onde $h$ é a altura pico a pico [15].

$$
N_{\text {spins }} \cong \Delta H_{P P}^{2} h
$$

\subsection{Ressonância magnética nuclear (RMN)}

No presente item daremos maior ênfase ao comportamento de agentes de contraste à base de SPIONs, uma vez que o interesse deste trabalho é sintetizar o ferrofluido para seu posterior uso como agente de contraste por Imagem de Ressonância Magnética (IRM).

Os agentes de contraste à base de SPIONs são extremamente fortes no incremento do processo de relaxação do próton. Estes agentes superparamagnéticos foram extensivamente pesquisados na década passada. Enquanto muitos dos agentes permanecem ainda em testes clínicos ou estágios de estudos experimentais, alguns dos produtos investigados já foram introduzidos no mercado [16-18]. Os agentes de SPIONs incluem uma grande escala de preparações envolvendo propriedades fisicoquímicas que diferem extremamente umas das outras. O tamanho das SPIONs destes agentes de contraste varia extensamente, influenciando as propriedades fisicoquímicas e farmacocinéticas, assim como as respectivas aplicações clínicas. 
Hoje em dia, o uso do efeito de SPIONs está baseado em uma distribuição no sistema mononuclear fagocítico. Os agentes de contraste consistem em SPIONs, revestidas com um polissacarídeo, cujos íons paramagnéticos produzem domínios de magnetização espontânea que alinham seus momentos de dipolo magnético e se tornam magnetizados fortemente por um campo magnético externo. A presença de SPIONs aumenta localmente o campo magnético externamente aplicado, produzindo heterogeneidade no campo magnético que por sua vez, promove defasagem resultando em perda do sinal, alterando assim o tempo de relaxação $\mathrm{T}_{2}$. As SPIONs são eliminadas do sangue por fagocitose realizada pelo sistema mononuclear fagocítico.

Dois parâmetros do fenômeno da ressonância magnética, muito usados para o estudo dos agentes de contraste, resultam do processo de relaxação dos spins após o término do pulso de excitação. Estes parâmetros são: (a) $\mathrm{O}$ tempo $T_{2}$ ou $\mathrm{T}_{2}$ *, denominado tempo de relaxação spin-spin, ou tempo de relaxação transverso, sendo este relacionado com os campos locais vizinhos, associados com as distribuições dos núcleos vizinhos e que descreve o decaimento da magnetização transversal e (b) o tempo $\mathrm{T}_{1}$, denominado tempo de relaxação spin-rede, é o tempo necessário para que o sistema de spin retorne ao equilíbrio térmico com a rede, após terminado o pulso de radio freqüência. Na Figura 2.3 ilustramos os processos de relaxação de $T_{1}$ e $T_{2}$ [19]. 

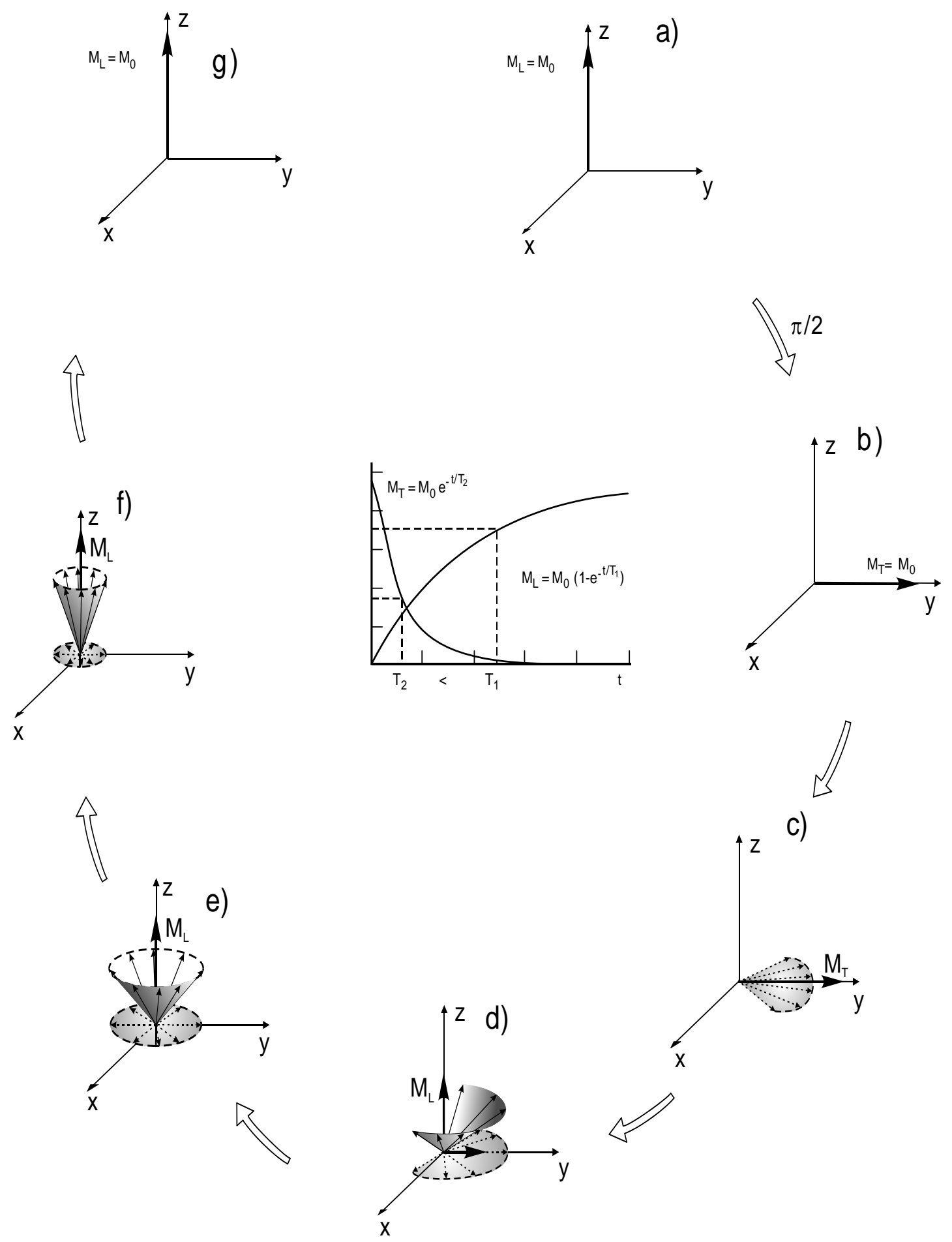

Figura 2.3: Decaimento da magnetização transversal $\left(\mathrm{M}_{\mathrm{T}}\right)$ relacionado com $T_{2}$, assim como a volta da magnetização longitudinal $\left(\mathrm{M}_{\mathrm{L}}\right)$ ao equilíbrio térmico $\mathrm{M}_{0}$ devido à relaxação $T_{1}$, aplicando um pulso de excitação de $90^{\circ}$. 
A técnica de IRM é amplamente empregada em práticas clínicas na medicina devido à sua capacidade para intensificar o contraste entre tecidos saudáveis e patológicos. Imagens de seções do corpo refletem precisamente a variação na densidade de prótons, tempo de relaxação transversal $\left(T_{2}\right)$ ou tempo de relaxação longitudinal $\left(T_{1}\right)$ dos tecidos. Apesar da inerente versatilidade desta modalidade de imagem, pesquisadores e clínicos estão dedicando grande esforço para desenvolver agentes de contrastes biocompatíveis e eficazes que ampliariam a utilidade do diagnóstico e melhoram a precisão de IRM. A principal aplicação dos agentes de contraste consiste em diminuir o tempo de relaxação dos prótons da água. Assim, agentes de contraste positivos reduzem $T_{1}$ resultando em um sinal brilhante, e agentes de contraste negativos reduzem $T_{2}$ resultando em um sinal escuro. Os recíprocos dos tempos de relaxação são chamados de taxas de relaxação, $R_{l}$, $R_{2}$ e $R_{2} *$

Os agentes de contraste superparamagnético à base de SPIONs realçam a relaxação $T_{1}$ e, $T_{2}$ ou $T_{2}{ }^{*}$ que na maioria das situações possui a capacidade significativa de reduzir o tempo de relaxação $T_{2}$ ou $T_{2}{ }^{*}$ a ser utilizado. A relaxatividade $T_{1}$ pode ser melhorada e o efeito $T_{2}$ ou $T_{2}{ }^{*}$ pode ser reduzido usando partículas pequenas e seqüências de imagens ponderadas em $T_{1}$.

Em soluções aquosas de SPIONs, os $T_{1}$ e $T_{2}$ dos prótons de hidrogênio de moléculas de água são influenciados pelas partículas magnéticas circundantes de ferro-ferrita, e os tempos de relaxação resultam mais curtos que da água pura ( $T_{1}$ e $T_{2}$ tem o mesmo valor em torno de quatro segundos na água pura). O tempo de relaxação $T_{l}$ é principalmente relacionado à transferência de energia entre prótons de hidrogênio e seu meio. Por outro lado, o tempo de relaxação spin-spin, $T_{2}$, é relacionado ao processo de defasagem dos vetores de spin dos prótons de hidrogênio.

Espera-se que uma solução aquosa de determinada concentração de um agente de contraste apresente um tempo característico de relaxação longitudinal e transversal que depende da temperatura e da intensidade de campo magnético estático onde a medida foi realizada [20]. O processo de relaxação da água induzida pela presença de agentes de 
contraste são mediados pelo processo de difusão dos prótons através do campo magnético gerado por cada partícula e a troca química de prótons com água volumétrica.

Os $T_{1 m}, T_{2 m}$ e $T_{2 m} *$ de prótons de hidrogênio em uma solução aquosa de SPIONs são relacionados ao $T_{1}, T_{2}$ e $T_{2}$ * em água pura como:

$$
\frac{1}{T_{i m}}=\frac{1}{T_{i}}+r_{i}[C]
$$

onde $i=1$ ou 2, $r_{i}$ 's denota a relaxatividade de $T i$ 's de prótons de hidrogênio, e $C$ representa a concentração de nanopartículas distribuídas homogeneamente em uma solução aquosa. Espera-se que uma relação sistemática entre a concentração de nanopartículas de ferrita e o contraste de IRM seja obtida. Isto conduz ao desenvolvimento de agentes de contraste de IRM cujos tempos de relaxação são controláveis ajustando a concentração de partículas magnéticas.

\subsection{Espalhamento de raios $\mathrm{X}$ a baixos ângulos (SAXS)}

$\mathrm{O}$ regime coberto pela técnica de espalhamento de raios $\mathrm{X}$ a baixo ângulo (SAXS) tipicamente abrange 0,5 a $100 \mathrm{~nm}$ e, de acordo com a equação de Bragg, isto só é possível em poucos graus em $2 \theta$ para $\lambda \approx 0,1 \mathrm{~nm}$. Este regime torna possível a aplicação da técnica para examinar muitos tipos de nanoestruturas. Em geral, para aplicações de nanoestruturas, costuma-se ter uma camada de revestimento polimérico sob cada partícula. Informações do tamanho, forma, correlações interpartícula e flutuações de densidade de nanoestruturas são de vital importância e podem ser obtidas usando esta técnica.

As análises dos dados de SAXS podem ser divididas em três grupos: sistemas diluídos, sistemas altamente correlacionados e fractais. Nos sistemas diluídos, quando as estruturas não estão interagindo, informações sobre forma, tamanho e massa das moléculas podem ser obtidas. Para sistemas altamente correlacionados, a formulação 
básica segue a lei de Bragg. A descrição fractal é geralmente utilizada para polímeros $[16,21]$.

\subsubsection{Sistemas diluídos}

O espalhamento para sistemas diluídos assume que o espalhamento de cada partícula é independente. A interação dos raios $\mathrm{X}$ com as flutuações eletrônicas circundando as partículas e a intensidade total é a soma de todas as componentes individuais de espalhamento. Portanto, informação a respeito dos tamanhos, formas e massa podem ser obtidas. A função de espalhamento generalizada é essencialmente dada por:

$$
I(q)=\left(\rho_{0} v\right)^{2} F^{2}(q)
$$

onde $\rho_{0}$ é a diferença de densidade sob o volume total v, e $F(q)$ é o fator de estrutura sendo $q=4 \pi \operatorname{sen} \theta / \lambda$. O fator de estrutura é simplesmente representado por

$$
F(q)=\int \rho(r) e^{i q r} d r
$$

onde a integral é sob a densidade eletrônica de cada partícula e a componente exponencial é o fator de forma. Expandindo o fator de forma e omitindo os termos de ordem mais altos, Guinier mostrou que a função de intensidade é:

$$
I(q)=\rho_{0}^{2} v^{2} \exp \left(-\frac{1}{3} q^{2} R_{g}^{2}\right)
$$

ou

$$
I(q)=I(0) \exp \left(-\frac{1}{3} q^{2} R_{g}^{2}\right)
$$


onde $I(0)$ é o espalhamento no ângulo zero. $R_{g}$ é o raio de giro da partícula. Desta forma, a partir do coeficiente angular da porção linear da curva $\ln I(q) x q^{2}$ pode-se calcular o raio de giro das partículas.

A curva de intensidade do feixe espalhado em função do vetor de espalhamento (q) ou do ângulo $(\theta)$ possui duas regiões que contêm informações topologicas das partículas, vide Figura 2.4.

Para $\mathrm{q} R<1$ (região 1) os sistemas diluídos de partículas idênticas e orientadas ao acaso seguem a Lei de Guinier.

A região 2 da curva de espalhamento fornece informações sobre a interface entre a fase dispersa e a matriz. No caso de sistemas bifásicos, apresentando interface lisa e bem definida, esta região da curva de SAXS satisfaz a lei de Porod [22]:

$$
I(q) q^{4}=2 \pi\left(\rho_{1}-\rho_{2}\right) Q
$$
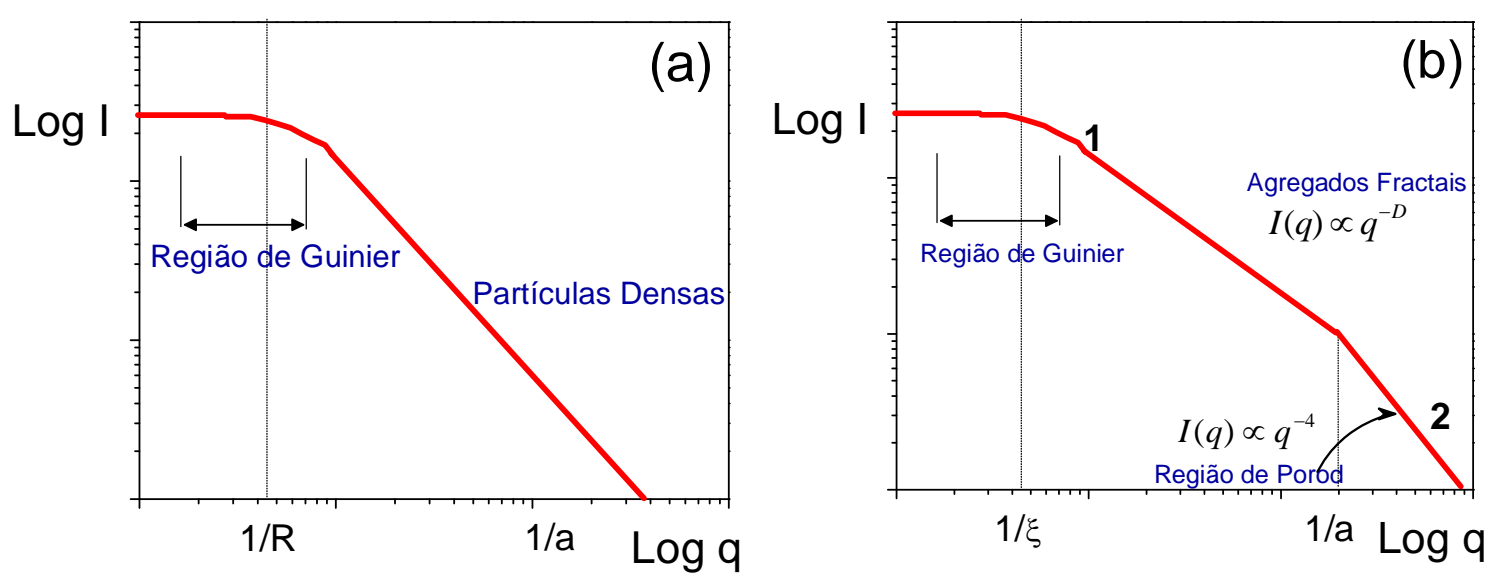

Figura 2.4: Curva de intensidade do feixe espalhado em função do vetor de espalhamento (q) [23] para sistemas de partículas densas (a) e agregados (b) [2,24]. 
Onde Q, o invariante de Porod, representa a superfície da interface entre as partículas e a matriz, $\rho_{1}$ e $\rho_{2}$ a densidade eletrônica da partícula e da matriz, respectivamente. O afastamento da lei de Porod (expoente 4) é um indicativo do grau de rugosidade da superfície das partículas.

Em muitos sistemas as partículas não são densas, ou seja, são agregados que podem exibir estruturas com geometria fractal. Estes sistemas são caracterizados pela autosimilaridade geométrica em qualquer escala de resolução espacial, isto é, mudando-se a escala de tamanho observam-se estruturas similares. Nestes sistemas o valor da dimensão fractal pode ser obtido diretamente a partir da região 1 (Figura 2.4 b) das curvas de espalhamento que obedecem a lei de potência:

$$
I(q) \propto q^{-D}
$$

A dimensão fractal (D) é uma propriedade que caracteriza a textura do sistema e fornece informações adicionais sobre a estrutura e o mecanismo de formação do material [24]. Nos agregados fractais a auto-similaridade é limitada pelo raio da partícula primária $a$ e pela distância de correlação $\xi$ (tamanho de agregados). Na realidade, $\xi$ representa uma distância característica a partir da qual a estrutura não é fractal.

Nesse trabalho a análise da curva de espalhamento foi realizada através das aproximações de Guinier. Devido à caracterista fractal apresentada por todas as amostras a análise para valores grandes de $q$ não foi realizada porque a curva de espalhamento não segue a lei de Porod.

\subsubsection{SAXS de partículas e sistemas desordenados}

Estudos de SAXS foram realizados nas diferentes soluções de HAp, estas soluções são caracterizadas pela suspensão coloidal de nanopartículas. A relação entre os perfis das curvas de SAXS e a nanoestrutura das amostras foi analisada. A geometria fractal provou ser muito útil nesta análise. Dois tipos de fractalidade foram encontrados 
(fractalidade de massa e de superfície) nas amostras objeto deste estudo. Gráficos de Porod apresentaram-se muito sensíveis aos detalhes estruturais dos objetos de espalhamento.

Para o estudo de materiais heterogêneos em nanoescala são muito úteis os métodos baseados em fenômenos de espalhamento. Quando o espalhamento é do tipo partícula isolada, os cálculos das distribuições de tamanho podem ser realizadas de espalhamento onde as seguintes condições são satisfeitas:

1. a partícula espalhadora e o meio circundante são uniformes mas com diferentes densidades eletrônicas;

2. a concentração de partículas é baixa (geralmente abaixo de 5 vol.\%);

3. as partículas espalhadoras são aproximadamente as mesmas, com geometria conhecida;

4. não há ordem na localização mútua de partículas, o que significa que a localização de cada partícula não depende da localização das outras partículas;

5. não há orientação preferencial de partículas de forma não esférica com relação à direção do raio primário.

A interpretação dos efeitos de espalhamento de materiais complexos desordenados simplifica-se notavelmente quando a geometria fractal pode ser aplicada na descrição da sua estrutura. A intensidade de SAXS de objetos fractais tem forma simples de lei de potência [25]:

$$
I(q) \propto q^{-\alpha}
$$

Onde $\alpha$ é constante. 
Os valores do expoente da lei de potências $\alpha$ podem ser determinados da inclinação da parte linear do gráfico $\log \mathrm{I}(\mathrm{q})$ vs. $\log$ q. Destes valores, As dimensões fractais da massa $\left(D_{m}\right)$ e superfície $\left(D_{S}\right)$ podem ser calculadas.

Para fractais de volume (massa),

$$
\alpha=D_{m}, \quad \text { assim } 1<\alpha<3 \text { já que } 1<D_{m}<3,
$$

enquanto que para superfícies fractais,

$$
\alpha=6-D_{S}, \operatorname{assim} 3<\alpha<4 \text { já que } 2<D_{S}<3 \text {. }
$$

Os valores se distinguem quando a estrutura dos espalhadores representa um volume fractal ou uma superfície fractal. As considerações anteriores são válidas quando os espalhadores mostram uma polidispersividade estreita. A polidispersividade do tipo lei de potência afeta consideravelmente o valor do expoente $\alpha$ [26].

A evolução estrutural de xerogéis pode levar ao surgimento de estruturas fractais de superfície [24]. Uma superfície perfeitamente lisa apresenta $D_{S}=2,00$ e $\alpha=4,00$, assim a equação resulta na lei de Porod $I(q) \sim q^{-4}$.

Geralmente, os desvios da lei clássica de Porod podem ser causados por:

1. flutuações de densidade eletrônica de curto alcance na fase sólida,

2. a rugosidade ou diminuição fractal da interfase entre espaço vazio e sólido,

A auto similaridade de um objeto em estudo pode ser satisfeita apenas estatísticamente e a maioria dos objetos pode revelar propriedades fractais sob uma faixa limitada de comprimento:

$$
\alpha<\ell<\xi \text {. }
$$


A razão $\xi / \alpha$ pode ser considerada como a medida do intervalo de fractalidade. É postulado que fractais físicos deviam mostrar propriedades de fractal sobre pelo menos uma ordem de grandeza para a relação $\xi / \alpha$. Os valores dos parâmetros $\alpha$ e $\xi$ correspondem à escala do raio de giração.

\subsection{Equipamentos utilizados na caracterização das nanopartículas}

No presente trabalho foi realizado a caracterização morfológica, térmica, estrutural, magnética e relaxométrica de amostras nanoestruturadas.

A caracterização morfológica foi realizada com a técnica de Microscopia Eletrônica de Transmissão (MET) (Instituto Butantan), Microscopia Eletrônica de Varredura (MEV) (Lab. de filmes finos do IF-USP), e Espalhamento de Raios $\mathbf{X} \mathbf{a}$ Baixo Ângulo (SAXS) (Lab. Cristalografia do IF-USP), a caracterização estrutural mediante a técnica de Difração de Raios X (XRD) (Lab. Cristalografia do IF-USP), a análise térmica mediante Calorimetria Exploratória Diferencial (DSC) (H. I. Albert Einstein), a caracterização magnética mediante a técnica de Ressonância Ferromagnética (RFM) (IFQSC-USP) e a caracterização relaxometrica por Imagem de Ressonância Magnética (IRM) (H. I. Albert Einstein). A análise por RFM foi realizada com variação de temperatura com o objetivo de compreender o fenômeno de ferromagnetismo que apresentam as nanopartículas. A caracterização dos tempos de relaxação de RMN foi realizada com variação da concentração de SPIONs para determinar a influência no contraste da imagem obtido por IRM. A determinação dos elementos químicos presentes nos filmes de paládio e céria depositados sobre alumínio anodizado foram realizadas mediante a Espectroscopia de Energia Dispersiva (EDS) (Lab. de filmes finos do IF-USP). Médidas de Espectroscopia no infravermelho por transformada de Fourier (FT-IR) (IQ-USP) foram feitas em amostra de hidroxiapatita.

A caracterização morfológica foi realizada por MET, MEV e SAXS. Para MET a amostra utilizada foi o ferrofluido em suspensão coloidal sonificado e diluído, esta amostra foi dispersa sobre grades de cobre cobertas com colodium e carbono e então 
elas foram examinadas num microscópio eletrônico de transmissão Leo 906E (Zeiss) MET em $80 \mathrm{kV}$. Amostras de céria e paládio depositadas sobre alumínio anodizado com uma área superficial de $1 \mathrm{~cm}^{2}$ foram obtidas as micrografias com o microscópio eletrônico de varredura 6460LV da Jeol, este equipamento conta com a capacidade de gerar imagens de amostras isolantes sem a necessidade de metalização, através do modo baixo vácuo, com resolução de $3 \mathrm{~nm}$ para alto vácuo e $4 \mathrm{~nm}$ para baixo vácuo. Modo baixo vácuo - pressão ajustável de 10 a 270 Pa.Curvas de SAXS foram obtidas usando uma câmara da Rigaku-Denki de baixo ângulo, acoplada a um gerador de anodo rotatório de $18 \mathrm{~kW}$, utilizando uma geometria de transmissão de feixe linha e comprimento de onda da radiação $\mathrm{Cu} \mathrm{K}_{\alpha}$ (monocromador de grafite, $\lambda=1,5418 \AA$ ).

A caracterização estrutural foi realizada por DRX. A fase cristalina e a estrutura das nanopartículas dos pós foram caracterizadas mediante um sistema de difratometria de raios $\mathrm{X}$ de pó (Rigaku D/max- $\gamma$, Japan) usando radiação $\mathrm{Cu}-\mathrm{K} \alpha(\lambda=1,5418 \stackrel{\circ}{A})$ e monocromador de grafite, foi utilizado para realizar a caracterização estrutural. O difratômetro foi operado em $40 \mathrm{kV}$ e $30 \mathrm{~mA}$. As medidas foram realizadas usando um passo angular de $0,05^{\circ}$, com tempo de exposição de $5 s$, na faixa de $(2 \theta)$ de interesse.

A análise térmica das nanopartículas superparamagnéticas à base de óxido de ferro foi feita por DSC. A curva de DSC foi obtida no intervalo de -170 até $600{ }^{\circ} \mathrm{C}$ com razão de aquecimento de $10{ }^{\circ} \mathrm{C} /$ minuto sob atmosfera dinâmica de $\mathrm{O}_{2}(20 \%)$ e $\mathrm{N}_{2}(80 \%)$ usando cadinho de $\mathrm{Al}$ aberto contendo cerca de $4,7 \mathrm{mg}$ de amostra. A medida de DSC foi realizada com o NETZSCH DSC 200 F3 Maia ${ }^{\circledR}$ Intrument. O DSC foi utilizado para conhecer a temperatura de oxidação do óxido de ferro.

A caracterização magnética foi realizada por RFM e RMN. A composição espectral da absorção de RFM foi obtida com um espectrômetro Bruker homodyne, modelo EMX, operando com uma freqüência de $9,2 \mathrm{GHz}$ na banda $\mathrm{X}$ e modulada em $100 \mathrm{kHz}$, utilizando uma cavidade de um microondas retangular no modo operante da cavidade dominante $\mathrm{TE}_{102}$. Para a obtenção dos espectros de RFM em diferentes 
temperaturas $(4-300 \mathrm{~K})$ foram utilizadas as nanopartículas superparamagnéticas à base de óxido de ferro em suspensão coloidal a 3,5 mM em um volume de $10 \mu \mathrm{L}$.

A caracterização relaxométrica foi realizada usando um tomógrafo de IRM clínico de 3 T (Trio, SIEMENS, Germany). Os tempos de relaxação de agentes de contraste de SPIONs foram medidos para diferentes concentrações. As diferentes concentrações foram preparadas diluindo o ferrofluido com água milli-Q (resistência 18,2 M $\Omega$ ). Para as medidas de $\mathrm{T}_{2}$ foi utilizada a sequiência de multi-contrast turbo-spin echo (SE_MC) em 31 tempos de echo $(\mathrm{TE}=26,2 ; 39,3 ; 52,4 ; \ldots ; 419,2 \mathrm{~ms})$ com um tempo de repetição (TR) constante de $3000 \mathrm{~ms}$. O tempo de relaxação $\mathrm{T}_{2}$ de cada amostra de nanopartículas foi calculado ajustando a curva de decaimento usando um algoritmo monoexponencial linear

$$
\text { signal }_{S E_{-} M C}=S_{0} \exp \left(-T E / T_{2}\right) .
$$

Para as medidas de $T_{2}^{*}$ foi utilizada a seqüência multi-echo Gradient Echo (GE) em $13 \mathrm{TE}=3,61 ; 7,55 ; 11,49 ; 16,0 ; 25,76 ; 29,7 ; 33,64 ; 37,58 ; 41,52 ; 45,46 ; 60$ e $70 \mathrm{~ms}$ com um TR constante de $100 \mathrm{~ms}$. Os valores de $\mathrm{T}_{2}{ }^{*}$ foram obtidos ajustando as intensidades do sinal de IRM versus TEs de acordo com a equação

$$
\text { signal }_{G E}=S_{0} \exp \left(-T E / T_{2}^{*}\right) \text {. }
$$

Para as medidas de $\mathrm{T}_{1}$ foi utilizada a sequiência multiple spin echo $(\mathrm{SE})$ com $\mathrm{TR}=19$; 250; 500; 700; 900; 1200; 1600; 1800; 2000; 2400; 2600; 2800; 3000; 4000; 6000 e $8500 \mathrm{~ms}$. Com um TE constante de $11 \mathrm{~ms}$. A equação da intensidade do sinal para medidas de $\mathrm{T}_{1}$ é

$$
\text { signal }_{S E}=S_{0}\left(1-\exp \left(-T R / T_{1}\right)\right) .
$$

Todas as medidas foram realizadas com uma bobina de cabeça e a imagem foi obtida numa fatia com espessura de $5 \mathrm{~mm}$, campo de vista de 15,9x20,0 cm, matriz de imagem de 256x256 e um sinal adquirido. Não foram realizadas médias do sinal adquirido. A intensidade do sinal foi medida usando uma região circular homogênea de interesse de $20 \mathrm{~mm}^{2}$. As relaxatividades $r_{1}, r_{2}$ e $r_{2}{ }^{*}$, foram determinadas mediante as inclinações dos gráficos $1 / \mathrm{T}_{1}, 1 / \mathrm{T}_{2}$ e $1 / \mathrm{T}_{2} *$ versus concentração molar do agente de contraste. 


\subsection{Referências Bibliográficas}

[1] Cullity, B. D., Elements of X-ray diffraction. $2^{\text {nd }}$ ed. New York: Addison Wesley, p. 110, 1978.

[2] Kawaguti, C. A., Influência da modificação da superfície de nanopartículas de $\mathrm{SnO} 2$ por tensoativos na formação e estabilidade de suspensões coloidais e de filmes suportados, 190 f. tese (Doutorado em Química) - Instituto de Química, Universidade Estadual Paulista, Araraquara, 2006.

[3] Neveu, S.; Bee, A.; Robineau, M.; Talbot, D., J. Coll. Inter. Scien., v.225, n.2, p.293, 2002.

[4] Popplewell, J.; Sakhnini, L., J. Magn. Magn. Mater., v.149, n.1-3, p.72, 1995.

[5] Bakuzis, A.F.; Morais, P.C.; Pelegrini, F., J. Appl. Phys., v.85, p. 7480, 1999.

[6] Pelegrini, F.; Pereira,A.R.; Araújo, M.B.; Tronconi, A.L.; Morais, P.C., J. Magn. Magn. Mater., v.272-276, p. 2381, 2004.

[7] Tronconi, A.L.; Morais, P.C.; Pelegrini, F.; Tourinho, F.A., J. Magn. Magn. Mater., v.122, p. 90, 1993.

[8] Kawamura, Y.; Endo, K.; Watanabe, Y.; Saga, T.; Nakai, T.; Hikita, H.; Kagawa, K.; Konishi, J., Radiology, v.174, p. 357, 1990.

[9] Rezende, S.M., Ressonância Ferromagnética e Ondas de Spin, http://www.cbpf.br/ labmag/srezende.pdf.

[10] Morais, P.C.; Lima, E.C.D.; Rabelo, D.; Reis, A.C.; Pelegrini, F.; IEEE Trans. Magn., v.36, p. 3038, 2000.

[11] Lacava, B.M.; Azevedo, R.B.; Silva, L.P.; Lacava, Z.G.M.; Skeff Neto, K.; Buske, N.; Bakuzis, A.F.; Morais, P.C., Appl. Phys. Lett., v.77, p. 1876, 2000.

[12] Santos, J.G., Tese de doutorado, IF-UnB, 2004.

[13] Van Vleck, J.H., Phys. Rev., v.74, p. 1168, 1948.

[14] Silveira, L.B.; Santos, J.G.; Pelegrini, F.; Gansau, C.; Buske, N.,; Morais, P.C., IEEE Trans. Magn., v.39, p. 2642, 2003.

[15] Raber, J.F., Experimental Methods in Polymer Chemistry-Physical Principal and Applications, New York, Wiley, p 332, 1980.

[16] Bach-Gansmo, T., Acta Radiologica. [supplementum], v.387, p. 1, 1993.

[17] Reimer, P.; Tombach, B., European Radiology, v.8, p. 1198, 1998.

[18] Grubnic, S.; Padhani, A.R.; Revell, P.B.; Husband, J.E., AJR American Journal of Roentgenology, v.173, p.173, 1999.

[19] Gamarra, L.F. Espectroscopia por ressônancia magnética nuclear localizada: prometo e implementação, 93p. Dissertação (mestrado)- Instituto de Física, Universidade de São Paulo, 2001.

[20] Roch, A.; Muller, R.N., Journal of Chemical Physics, v.110, n.11, p. 5403, 1999.

[21] Wilcoxon, J. P.; Schaefer, D. W.; Kaler, E. W. Nonequilibrium structure during phase-separation. Physical Review Letters, v. 60, n. 4, p. 333, 1988.

[22] Porod, G. Small angles X-ray scattering. London: Academic Press, p. 17, 1982.

[23] J.F. Raber, Experimental Methods in Polymer Chemistry-Physical Principal and Applications, Wiley, New York, 1980, p. 332. 
[24] Pajak, L.; Bierska-Piech, B.; Mrowiec-Bialon, J.; Jarzebski, A.B.; Diduszko, R., FIBRES \& TEXTILES in Eastern Europe, v.13, No5 (53), p. 69, 2005.

[25] Porod, G. Small angles X-ray scattering. London: Academic Press, p. 17, 1982.

[26] Schmidt, P.W., J. Appl. Cryst., v.24, p. 414, 1991. 


\section{CAPÍTULO 3 - Síntese de Nanopartículas}

\subsection{O processo sol-gel}

O processo sol-gel tornou-se uma importante rota para síntese química de materiais nanoestruturados. O termo sol é geralmente usado para definir uma dispersão de partículas coloidais, com dimensão entre 1 e 100 nm, estável em um fluído. Outra característica importante, é que as partículas coloidais não se difundem através de membranas semipermeáveis como acontece no caso de soluções verdadeiras [1]. O termo gel define um sistema formado pela estrutura rígida tridimensional de partículas coloidais (gel coloidal) ou de cadeias poliméricas (gel polimérico), que imobiliza o solvente formando um estado intermediário entre um sólido e um líquido. O termo gel, aplicado a precipitados gelatinosos, forma-se quando uma substância muito pouco solúvel é rapidamente precipitada. A formação do gel é devida a precipitação incompleta de um sol. Na formação de um gel, as partículas coloidais do sol se unem formando fibras, que se entrelaçam formando um sólido muito poroso. Neste processo, pode ocorrer a solvatação das partículas. Porém, a maior parte do solvente pode ficar retida nas cavidades da estrutura porosa. Quando o sol é deixado em repouso ocorre a gelificação; se o gel for agitado, retorna-se o sol, esta transformação isotérmica reversível é devida à diminuição da viscosidade pela agitação[2].

As características físicas e químicas do gel dependem basicamente das condições em que ocorre a transição sol-gel. Alterando-se determinados parâmetros tais como solvente, temperatura, $\mathrm{pH}$, envelhecimento, remoção da fase líquida, compostos orgânicos utilizados durante a secagem (amidas, polióis), pode-se promover a gelatinização e projetar a estrutura morfológica do sistema. Considerando-se um mesmo composto, pode-se preparar pós monodispersos ou constituídos por agregados relativamente densos, em meio alcalino, ou ainda sistemas formados por cadeias ramificadas com estrutura fractal, em meio ácido. Fibras, camadas delgadas, aerogéis 
com porosidade superior a $95 \%$ ou corpos monolíticos podem ser preparados pelo controle das condições de secagem e de gelatinização [3].

Na preparação de híbridos o processo sol-gel é o mais empregado. Este método controlável e prático é de particular interesse na preparação de nanopartículas (Figura 3.1)

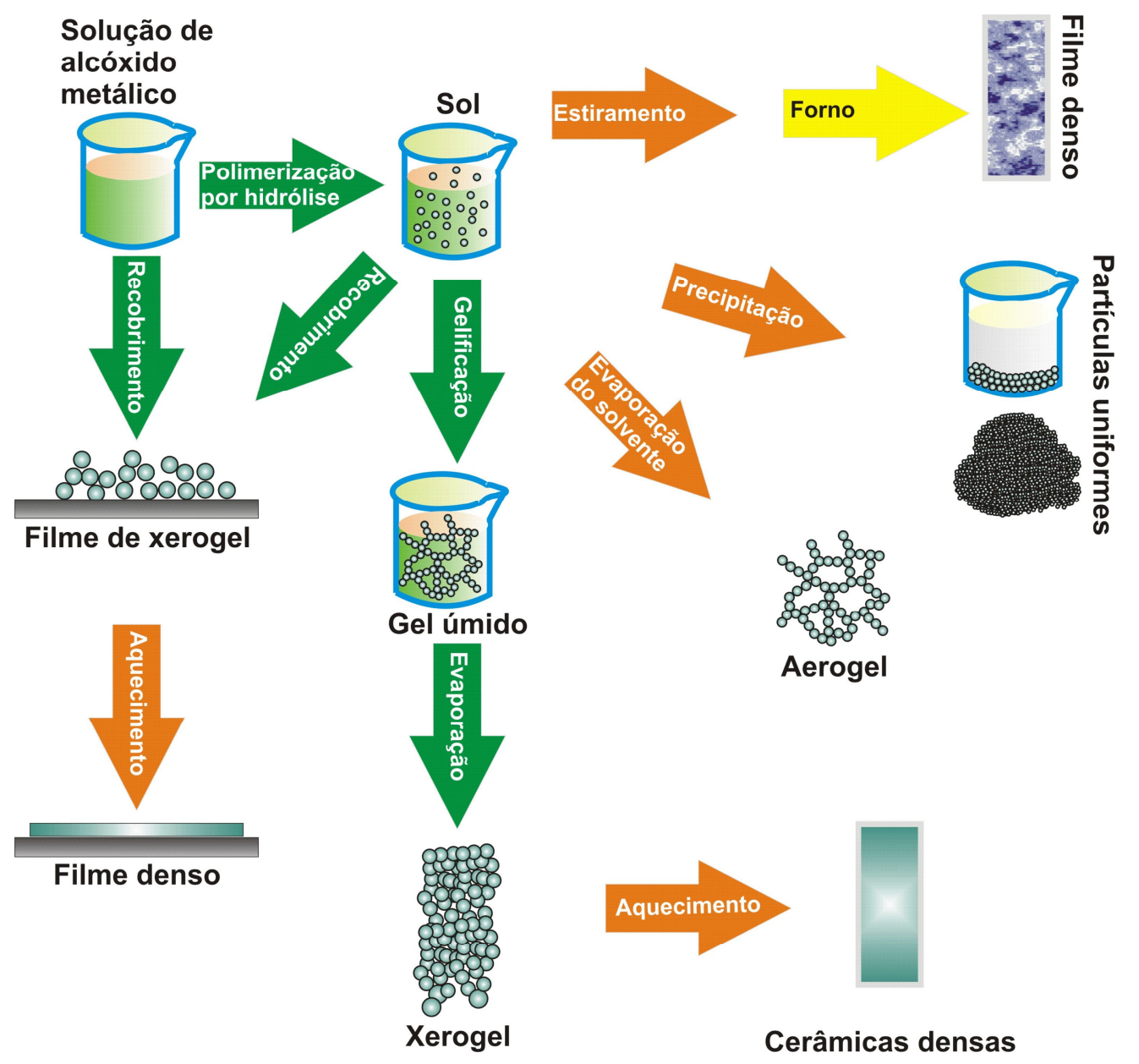

Figura 3.1: Produtos que podem ser formados por meio da síntese pelo método solgel [4]. 
Este processo de síntese usualmente utiliza soluções aquosas de sais inorgânicos (base inorgânica) ou alcóxidos metálicos dissolvidos em solventes orgânicos (base alcóxida).

Com a reação de policondensação, o gel é então envelhecido de modo que uma estrutura mais rígida seja desenvolvida [4]. O gel é então seco por evaporação ou por meio de um processo de secagem supercrítica.

O processo sol-gel permite preparar materiais com estruturas distintas a partir do controle da cinética de transformação. Deste ponto de vista, o processo assemelha-se à transformação líquido-sólido e pode ser razoavelmente bem compreendido, através da teoria termodinâmica dos fenômenos críticos e dos modelos cinéticos de agregação. Isto permite projetar novos materiais com propriedades peculiares. Além disso, como a cinética deste processo é lenta, é possível analisar "in situ” as reações de hidrólise e condensação, bem como obter informações valiosas sobre os mecanismos reacionais [1].

O processo sol-gel possibilita o controle de todas as etapas do processo de síntese, permitindo um melhor controle do processo global e possibilita a obtenção de materiais com as características e propriedades pré-planejadas.

A força gravitacional que as partículas de uma suspensão coloidal experimentam é insignificante, sendo a interação entre partículas dominada principalmente por forças de curto alcance, tais como as forças de Van der Waals e forças elétricas, devido à carga superficial das partículas. Se o sol sofrer uma desestabilização por algum motivo, a conectividade das partículas pode aumentar. Consequentemente, a viscosidade do sol aumenta, devido ao incremento do número de ligações entre as partículas, tornando o sol rígido. Assim sendo, podemos dizer que o sol gelatinizou e por isto recebe o nome de gel.

Alguns materiais preparados pelo método sol-gel são formados por cadeias ramificadas ou por agregados com estrutura fractal [5]. Este tipo de estrutura é associada a objetos que possuem auto-similaridade geométrica, i.e., mudando-se a escala de 
dimensão observa-se sempre a mesma forma. Além disso, um objeto de estrutura fractal ocupa simultaneamente uma dimensão Euclidiana $d_{e}(3)$ e uma dimensão fractal D. No caso de um aglomerado relativamente grande, o máximo valor de $\mathrm{D}$ possível é $\mathrm{d}_{\mathrm{e}}$, e quando considera-se aglomerados completamente conectados, o menor valor de D é um. Em geral, pequenos valores de D são associados a estruturas pouco compactas, enquanto D próximo de 3 é típico de agregados mais densos.

A dimensão fractal é determinada através de relações que são únicas para este tipo de geometria, por exemplo, no caso de um objeto fractal de massa têm-se [5]:

$$
\langle M(L)\rangle \propto L^{D}
$$

onde $\langle\mathrm{M}(\mathrm{L})>$ é a massa média contida na distância $\mathrm{L}$, medida a partir do centro do objeto. Esta relação aplica-se também a objetos com geometria Euclidiana, como hastes, discos e esferas, onde o valor do expoente D é 1, 2 e 3, respectivamente. Os fractais ditos de superfície são uniformemente densos, mas apresentam uma superfície rugosa. Neste caso, a área de superfície, S(L), é representada por uma relação do tipo [3]:

$$
\langle S(L)\rangle \propto L^{D_{S}}
$$

Sendo $D_{S}$ um parâmetro relacionado com a rugosidade e varia entre 2 e $3(d=2$, superfície lisa).

O conceito matemático de fractalidade é rigorosamente válido para dimensão infinita de auto-similaridade. Isto é dificilmente observado na prática, devido às características físicas inerente a cada sistema e ao limite de sensibilidade das técnicas de caracterização empregadas. 


\subsection{Processo de coprecipitação}

Atualmente existem vários métodos de preparação para a obtenção de partículas com tamanho nanométrico. O método de coprecipitação apresenta inúmeras vantagens tais como: homogeneidade química, temperaturas de reação e sinterização baixas, partículas finas com distribuição de tamanho estreita, equipamento para produção de baixo custo, pós com boa reatividade, uniformes com fraca ou nenhuma aglomeração, econômica de tempo, fácil ampliação de escala e custo baixo [6]. No entanto, o processo de síntese por coprecipitação homogênea pode resultar em nanopartículas com um largo espectro de tamanho. O processo é simples e consiste na mistura de sais inorgânicos em ambiente aquoso seguido de precipitação com hidróxido [7]. O precipitado resultante é então digerido, filtrado e seco em estufa ou forno.

Em geral, este método permite a preparação de nanopartículas com um controle rigoroso no tamanho e forma. Partículas uniformes são normalmente preparadas através de reações homogêneas de precipitação, um processo que envolve a separação da nucleação e crescimento dos núcleos [8]. Uma representação esquemática dos diferentes mecanismos propostos na bibliografia, que explica a formação de partículas uniformes é mostrada na Figura 3.2. 


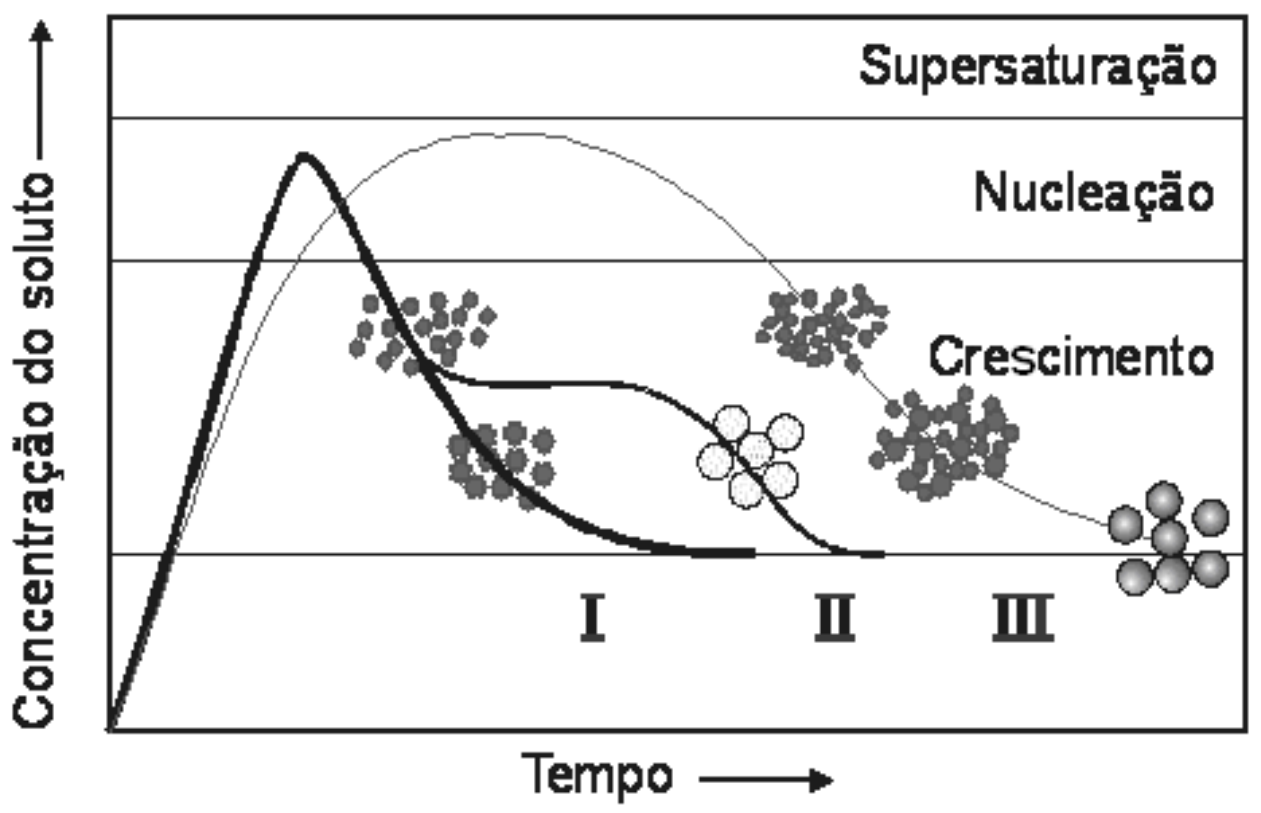

Figura 3.2: Mecanismos de formação de partículas uniformes em solução: curva I: Nucleação única e crescimento uniforme por difusão (modelo clássico de LaMer e Dinegar (1950)) [9]; curva II : Nucleação, crescimento e agregação de pequenas subunidades; curva III eventos de nucleação múltipla e crescimento maturativo de Ostwald (1991) [10].

Em uma precipitação homogênea, uma única e pequena explosão da nucleação ocorre quando a concentração da espécie constituinte alcança a supersaturação crítica. Então, os núcleos assim obtidos podem crescer uniformemente pela difusão de solutos da solução para suas superfícies até o tamanho final ser atingido. Para realizar a monodispersão, estes dois estágios devem ser separados e a nucleação deve ser evitada durante o período de crescimento. Este é o modelo clássico proposto por LaMer e Dinegar (1950) [9] para explicar o mecanismo de formação de colóides sulfúricos e também para um número limitado de casos (curva I da Figura 3.2). No entanto, partículas uniformes têm também sido obtidas após eventos de nucleação múltiplas. A uniformidade do produto final é alcançada, neste caso, através de um processo de crescimento autocontrolado (amadurecimento de Ostwald, curva III da Figura 3.2) [11]. Além disso, partículas uniformes têm também sido obtidas como um resultado da agregação de subunidades muito menores preferidas em lugar de crescimento contínuo por difusão (curva II da Figura 3.2) [11,12]. Uma separação artificial entre nucleação e 
processo de crescimento pode ser alcançada, semeando partículas externas que são introduzidas na solução dos monômeros abaixo da supersaturação crítica [13].

$\mathrm{O}$ processo de coprecipitação homogênea à temperatura ambiente, resulta na formação de sólidos, cristalinos ou amorfos, nos quais as propriedades químicas e magnéticas dependem das condições do processo no qual foram formados. Para garantir uma boa reprodutibilidade e um bom desempenho do produto final, o controle cuidadoso de algumas variáveis é muito importante. As variáveis que devem ser controladas com maior cuidado são: pH final da solução de precipitação, tipo de ânion, ordem de adição dos reagentes, concentrações dos metais, razão molar dos metais, temperaturas de precipitação e calcinação, velocidade de agitação, e outras. Estas variáveis afetam de forma significativa a natureza, a homogeneidade, o tamanho, o comportamento magnético e a energia da superfície das partículas resultantes.

Os métodos mais importantes descritos na bibliografia para obter nanopartículas uniformes são: co-precipitação [14-17], microemulsões [18-22], processo de poliol [2325], descomposição em altas temperaturas de precursores orgânicos [26-28], sonoquímica assistida [29-32], métodos eletroquímicos [33] e o método sol-gel, no qual as sinteses realizadas neste trabalho para obter suspensões coloidais foram baseadas.

\subsection{Métodos de síntese de nanopartículas para aplicações em diversas áreas da ciência}

Uma das tendências recentes na ciência dos materiais é obter produtos clássicos com propriedades controladas para sintetizar nanopartículas para aplicações em diversas áreas da ciência. Existem diversos métodos de síntese que podem ser classificados como aqueles que produzem (1) nanopartículas mediante técnicas de soluções ou de fases aerossóis/vapores e (2) aqueles que produzem compostos consistindo de nanopartículas dispersas em matrizes orgânicas ou inorgânicas. Além disso, existe também outro grupo de métodos que usam princípios de seleção de tamanho para produzir nanopartículas uniformes a partir de partículas polidispersas. 


\subsubsection{Compostos magnéticos}

Para os processos de separação, isto é, aplicações in vitro, são utilizados compostos de nanocristais superparamagnéticos dispersos em matrizes diamagnéticas de dimensões nanométricas que têm tempos longos de sedimentação na ausência de um campo magnético. Uma vantagem de usar matrizes diamagnéticas é que o composto superparamagnético pode ser facilmente conseguido com biocompatibilidade e funcionalidade.

Os métodos mais importantes descritos na bibliografia para obter nanopartículas uniformes, apropriadas para aplicações biomédicas (aplicações in vitro) são: métodos de deposição [34-37]; encapsulamento de nanopartículas magnéticas em matrizes poliméricas [38-41] e encapsulamento de nanopartículas magnéticas em matrizes inorgânicas $[42,43]$.

\subsubsection{Compostos à base de fosfato de cálcio}

Materiais promissores para carregadores de fármacos e aumento da massa óssea são os fosfatos de cálcio $[44,45]$. Particularmente, hidroxiapatita possui uma excelente biocompatibilidade e excelente osteocondutividade. Nanopartículas de hidroxiapatita podem ser produzidas através de uma variedade de métodos tais como: processo de precipitação [46], técnicas hidrotérmicas [47] e processo sol-gel [48,49].

\subsubsection{Métodos de síntese de nanopartículas de hidroxiapatita}

A Hidroxiapatita (HAp) sintetizada por métodos de solução aquosa é geralmente deficiente de cálcio $(\mathrm{Ca} / \mathrm{P}<1,67)$ ou apresenta, na sua constituição, carbonato $(\mathrm{Ca} / \mathrm{P}>1,67)$ [15]. 
A síntese de HAp pelo método de Rathje [16] baseia-se na adição gota a gota de ácido fosfórico $\left(\mathrm{H}_{3} \mathrm{PO}_{4}\right)$, na suspensão em agitação de hidróxido de cálcio obedecendo a seguinte reação:

$$
10 \mathrm{Ca}(\mathrm{OH})_{2}+6 \mathrm{H}_{3}\left(\mathrm{PO}_{4}\right)_{2} \rightarrow \mathrm{Ca}_{10}\left(\mathrm{PO}_{4}\right)_{6}(\mathrm{OH})_{2}+18 \mathrm{H}_{2} \mathrm{O}
$$

Este processo de síntese foi modificado para a utilização do hidróxido de amônio $\left(\mathrm{NH}_{4} \mathrm{OH}\right)$ com o objetivo de manter o $\mathrm{pH}$ da solução mais básica aumentando desta maneira a eficiência da reação evitando a mudança de fase da HAp durante a sinterização do precipitado obtido [17,18,19]

A síntese de HAp pelo método proposto por Hayek e Newsely [20] baseia-se na reação de nitrato de cálcio $\left(\mathrm{Ca}\left(\mathrm{NO}_{3}\right)_{2}\right)$ e fosfato de amônio $\left(\left(\mathrm{NH}_{4}\right)_{2} \mathrm{HPO}_{4}\right)$ utilizando, também, hidróxido de amônio, a suspensão em agitação obedece à seguinte reação:

$$
10 \mathrm{Ca}\left(\mathrm{NO}_{3}\right)_{2}+6\left(\mathrm{NH}_{4}\right)_{2} \mathrm{HPO}_{4}+8 \mathrm{NH}_{4} \mathrm{OH} \rightarrow \mathrm{Ca}_{10}\left(\mathrm{PO}_{4}\right)_{6}(\mathrm{OH})_{2}+20 \mathrm{NH}_{4} \mathrm{NO}_{3}+6 \mathrm{H}_{2} \mathrm{O}
$$

Com a finalidade de evitar transformação de fase na sinterização do precipitado obtido, é necessário um controle nas concentrações dos reagentes e do pH da solução $[21,22]$. O intervalo de temperatura ideal para o processo de precipitação na síntese de HAp é de 95 até $100^{\circ} \mathrm{C}[20]$.

A pureza e a composição dos reagentes, o tamanho de partícula, a temperatura bem com as condições de calcinação e ou sinterização, podem afetar o tipo e a quantidade de outras fases no produto sintetizado.

\subsubsection{Compostos à base de óxido de cério e paládio}

A céria é amplamente utilizada em cerâmicas, catálises, polimento, luminescência e materiais de eletrólito sólido. A vantagem da utilização de terras raras é por suas propriedades óticas, elétricas e magnéticas específicas à distribuição eletrônica dos elementos de terras raras [50]. 
Os principais métodos de preparação de nanopartículas de céria, descritos na literatura, são: precipitação [51], hidrotérmico [52,53], sol-gel [54], método de alcóxido [55], microemulsão [56], sínteses de template [57], reação de gás [58], etc.

As partículas de metais nobres de tamanho nanométrico, como paládio, apresentam propriedades novas, tal como elevada atividade catalítica, propriedades óticas interessantes, dentre outras. O paládio é utilizado em uma grande variedade de importantes aplicações tecnológicas tais como catálise, sensores de gás e em membranas pré seletivas de hidrogênio [59-61].

Várias técnicas são utilizadas para preparar nanopartículas de paládio, tais como decomposição fotolítica [62], decomposição térmica [63], redução sonoquímica [64], redução de hidrogênio [65], decomposição eletroquímica [66], entre outras.

\subsection{Métodos de seleção de tamanho}

As aplicações biomédicas como em IRM, separação celular magnética ou magnetorelaxometria, enxerto ósseo ou revestimento de implantes ósseos utilizam as propriedades das nanopartículas contidas nas suspensões coloidais. Essas aplicações dependem das dimensões das nanopartículas e em muitos casos somente uma pequena quantidade contribui para o efeito desejado. A quantidade relativa de partículas com as propriedades desejadas pode ser incrementada pelo fracionamento das suspensões coloidais [67].

Os métodos comuns normalmente aplicados para o fracionamento incluem centrifugação e a cromatografia de exclusão de tamanho [68]. Estes métodos separam as partículas através das propriedades não-magnéticas por densidade ou tamanho. Existem ainda outros métodos de fracionamento reportados na literatura [69-71]. 


\subsection{Métodos utilizando técnicas de aerosol/deposição em vapor}

Spray-pirólise [72-76], e pirólise de aerossol a laser [77,78] têm demonstrado ser excelentes técnicas para a produção contínua e direta de nanopartículas, bem definidas sob controle exaustivo de condições experimentais, tendo um alto potencial para aplicações in vivo e in vitro. A principal diferença entre spray-pirólise e pirólise a laser é o estado final das partículas ultrafinas. $\mathrm{Na}$ spray-pirólise as partículas ultrafinas são normalmente agregadas em partículas maiores, enquanto que na pirólise a laser as partículas ultrafinas são menos agregadas devido à reação de tempo menor [79]. 


\subsection{Referências Bibliográficas}

[1] Hiratsuka, R. S. "Preparação e caracterização estrutural de sóis e géis a base de oxidróxido de estanho", Dissertação de Mestrado, IQ/UNESP, 1992.

[2] Brito, G.E.S, Evolução da textura durante a sinterização de xrogéis de $\mathrm{SnO} 2$ : Contribuição à análise de tamanho de cristalito e distribuição de tamanho de microporos, Dissertação de Mestrado, IQ/UNESP, 1993.

[3] Brinker, C. J.; Scherer, G. W."Sol-gel Science - The physics and chemistry of solgel processing”, Academic Press Inc., San Diego, 1992.

[4] Brinker, C. J.; Scherer, G.W. Sol-gel science. The physics and chemistry of sol-gel processing. Academic Press, San Diego, California, 1990.

[5] La Rosa, J. L.; Cawley, J.D. J. Am. Ceram. Soc., v.75(7), p.1981, 1992.

[6] Janasi, S.R.; Emura, M.; Landgraf, F.J.G.; Rodríguez, D. J. Magn. Magn. Mater., v.238, p.168, 2002.

[7] Blaskov, V.; Petrov, V.; Rusanov, V.; Martinez, Li. M.; Martinez, B.;Muños, J.S.; Mikhov, M. J. Magn. Magn. Mater., v.162, p.331, 1996.

[8] Sugimoto, T., Fine Particles: Synthesis, Characterization and Mechanism of Growth, New York, Marcel Dekker, 2000.

[9] Lamer, V.K.; Dinegar, R.H. Journal of the American Chemical Society, v.72, p.4847, 1950.

[10] Ostwald (1991)

[11] Den Ouden, C.J.J.; Thompson, R.W. Journal of Colloid and Interface Science, v. 143, p.77, 1991.

[12] Morales, M.P.; Gonzáles-Carreno, T.; Serna, C.J. Journal of Materials Research, v.7, n.9, p.538, 1992.

[13] Sugimoto, T., Fine Particles: Synthesis, Characterization and Mechanism of Growth, New York, Marcel Dekker, 2000.

[14] Sugimoto, T.; Matijevic, Journal of Colloid and Interface Science, v.74, p.227, 1980.

[15] Molday, R.S.; Mackenze, D. Journal of Immunological Methods, v.52, p.353, 1982.

[16] Palmacci, S.; Josephson, L. Synthesis of Polysaccharide Covered Superparamagnetic Oxide Colloids, U.S. Patent 5262176, 1993.

[17] Bergemann, C. German Patent 19624426 A1, 1996.

[18] Pileni, M.P. Journal of Physical Chemistry, v.97, p.6961, 1993.

[19] Lisiecki, I.; Pileni, M.P. Journal of the Americam Chemical Society, v.115, p.3887, 1993.

[20] Zhang, K.; Chef, C.H.; Xu, G.Q.; Wang, J.; Gan, L.M. Langmuir, v.15, p.3056, 1999.

[21] Feltin, N.; Pilen, M.P. Langmiur, v.13, p.3927, 1997.

[22] Carpenter, E.E. Journal of Magnetism and Magnetic Materials, v.225, p.17, 2001.

[23] Viau, G.; Ravel, F.; Ache, O.; Fiévet-Vicent, F.; Fiévet, F. Journal of Applied Physics, v.76, p.6570, 1994. 
[24] Viau, G.; Fiévet-Vicent, F.; Fievet, F. Journal of Materials Chemistry, v.6, p.1047, 1996a.

[25] Viau, G.; Fiévet-Vicent, F.; Fievet, F. Journal of Solid State Ionics, v.84, p.259, 1996b.

[26] Rockenberger, J.; Scher, E.C.; Alivisatos, A.P.A. Journal of the American Chemical Society, v. 121, p.11595, 1999.

[27] Hyeon, T.; Lee, S.S.; Park, J.; Chung, Y.; Na, H.B. Journal of the American Chemical Society, v.123, p.12798, 2001.

[28] Shen, S.; Zeng, H. Journal of the American Chemical Society, v.124, p.8204, 2002.

[29] Cao, X.; Koltypin, Y.; Katabi, G.; Prozorov, R.; Felner, I.; Gedanken, A. Journal of Materials Research, v.12, p.402, 1997.

[30] Shafi, K.V.P.M.; Ulman, A.; Yan, X.; Yang, N-L.; Estournes, C.; White, H.; Rafailovich, M. Langmuir, v.17, p.5093, 2001.

[31] Shafi, K.V.P.M.; Ulman, A.; Yan, X.; Yang, N-L.; Estournes, C.; White, H.; Rafailovich, M. Langmuir, v.17, p.5093, 2001.

[32] Suslick, K.S. Science, v.247, p.1439, 1990.

[33] Pascal, c.; Pascal, J.L.; Favier, F.; Elidrissi-Moubtassim, M.L.; Payen, C. Chemistry of Materials, v.11, p.141, 1999.

[34] Garg, A.; Matijevic, E. Langmuir, v.4, p.38, 1988.

[35] Aiken, B.; Matijevic, E. Journal of Colloid and Interface Science, v.126, p.645, 1988.

[36] Shiho, H.; Manabe, Y.; Kawahashi, N. Journal of Materials Chemistry, v.10, p.333, 2000.

[37] Donath, E.; Sukborukov, G.B.; Caruso, F.; Davies, S.A.; Möhwald, H. Angewandte Chemie International Edition, v.37, p. 2201, 1998.

[38] Ziolo, R.F.; Giannelis, E.P.; Weinstein, B.A.; O’horo, M.P.; Ganguly, B.N.; Mehrotra, V.; Russell, M.W.; Huffman, D.R. Science, v.257, n.5067, p.219, 1992.

[39] Bourgeat-Lami, E.; Lang, J.J. Journal of Colloid and Interface Science, v.197, p.293, 1998.

[40] Zaitsev, V.S.; Filimonov, D.S.; Presnyakov, I.A.; Gambino, R.J.; Chu, B. Journal of Colloid and Interface Science, v.212, p.49, 1999.

[41] Dresco, P.A.; Zaitsev, V.S.; Gambino, R.J.; Chu, B. Langmuir, v.15, p.1945, 1999.

[42] Del Monte, F.; Morale, M.P.; Levy, D.; Fernandez, A.; Ocana, M.; Roig, A.; Mollins, E.; O’grady, K.; Serna, C.J. Langmuir, v.13, p.3627, 1997.

[43] Tartaj, P.; Gonzales-Carreño, T.; Serna, C.J. Advanced Materials, v.13, p.1620, 2001.

[44] Sogo, Y.; Ito, A.; Fukasawa, K.; Sakurai, T.; Materials Science and Technology, v.20, p.1079, 2004.

[45] Shirkhanzadeh, M.; J. Mater. Sci.: Mater. Med., v.16, p.37, 2005.

[46] Saeri, M.R.; Afshar, A.; Ghorbani, M.; Ehsani, N.; Sorrell, C.C.; Materials Letters, v.57, p.4064, 2003.

[47] Liu, H.S.; Chin, T.S.; Lai, L.S.; Chiu, S.Y.; Chuang, K.H.; Chang, C.S.; Lui, M.T.; Ceram. Int., v.23, p.19, 1997.

[48] Bogdanoviciene, I.; Brganskiene, A.; Tõnsuaadu, K.; Glaser, J.; Meyer, H.-J; Kareiva, A.; Materials Research Bulletin, v.41, p.1754, 2006. 
[49] Schmidt, H.K.; Geiter, E.; Mennig, M.; Krug, H.; Becker, C.; Winkler, R.-P; J. Sol-Gel Sci. Technol., v.13, p.397, 1998.

[50] Su, Q., Rare Earth Chemistry, Henan Sci. \& Technol. Publishing Com., Zhengzhou, p. 202, 1993.

[51] Masui, T.; Hirai, H.; Imanaka, N. et al., J. Mater. Sci. Lett., v.21, p.489, 2002.

[52] Dong, X.T.; Yan, J.H.; Wei, Y. Rare Metal Mater. Eng., v.1, p.312, 2002.

[53] Hou, W.H.; Xu, L.; Qiu, J.H. et al., J. Nanjing Univ., v.7, p.487, 1997.

[54] Dong, X.T.; Liu, G.X.; Sun, J. et al., Rare Metal Mater. Eng., v.31, p. 229, 2002.

[55] Shi, S.; Lu, Y.H.; Wang, H.Q. Chemistry, v.12, p.51, 1998.

[56] Zhang, L.D.; Cai, W.P.; Mo, C.M. Prog. Natural Sci., v.9, p.103, 1999.

[57] Guillou, N.; Nistor, L.C.; Fuess, H. et al., Nanostructured Mater., v.8, p.545, 1997.

[58] Valenzuela, R.X.; Bueno, G; Solbes, A. et al., Topics Catal., v.15, p.181, 2001.

[59] Schalow, T; Brandt, B; Laurin, M; Schauermann, S; Libuda, J; Freund, H -J. Journal of catalysis, v.242, p.58, 2006.

[60] Shu, J; Granjean, B P A; Neste, A V; Kaliaguine, S. Can. J. Chem. Eng., v.69, p.1036, 1991.

[61] Hughes, R C; Schubert, W K; Buss, R J. J. Electrochem. Soc., v. 142, p.249, 1995.

[62] Narayan, A; Landstrom, L; Boman, M. Appl. Surf. Sci., v.208, p.137, 2003.

[63] Kim, S -W; Park, J; Jang, Y; Chung, Y; Hwang, S; Hyeon, T; Kim, Y W. Nano Lett., v.3, p.1289, 2003.

[64] Dhas, N A; Gedanken, A J. Mater. Chem., v.8, p.445, 1998.

[65] Schmid, G; Harms, M; Malm, J -O; Bovin, J -O; van Ruitenbeck, J; Zandbergen, H W; Fu, W T. J. Am. Chem. Soc., v.115, p.2046, 1993.

[66] Reetz, M T; Helbig W. J. Am. Chem. Soc., v.116, p.7401, 1994.

[67] Rheinländer, T.; Kotitz, R.; Weitschies, W.; Semmler, W. Journal of Magnetism and Magnetic Materials, v.219, p.219, 2000.

[68] Nunes, A.C.; Yu, Z.C. Journal of Magnetism and Magnetic Materials, v.65, p.265, 1987.

[69] Lefebure, S.; Dubois, E.; Cabuil, V.; Neveu, S.; Massart, R. Journal of Materials Research, v.13, p.2975, 1998.

[70] Williams, S.K.R.; Lee, H.; Turner, M.M. Journal of Magnetism and Magnetic Materials, v. 194, p.248, 1999.

[71] GIDDINGS, 1993)

[72] Messing, G.L.; Zhang, S.; Jayanthi, G.V. Journal of the American Ceramic Society, v.76, p.2707, 1993.

[73] Lu, Y.; Fan, H.; Stump, A.; Ward, T.L.; Rhieker, T.; Brinker, C.J. Nature, v.398, p.223, 1999.

[74] Xia, B.; Lenggoro, I.W.; Okuyama, K. Advanced Materials, v.13, p.1579, 2001.

[75] Pecharroman, C.; Gonzales-Carreño, T.; Iglesias, J.E. Physics and Chemistry of Minerals, v.22, p.21, 1995.

[76] Gonzales-Carreño, T.; Morales, M.P.; Garcia, M.; Serna, C.J. Materials Letters, v.18, p.151, 1993. 
[77] Cannon, W.R.; Danforth, S.C.; Flint, J.H.; Haggerty, J.S.; Marra, R.A. Journal of the American Ceramic Society, v.65, p.324, 1982.

[78] Veintenillas-Verdaguer, S.; Morales, M.P.; Serna, C.J. Materials Letters, v.35, p.227, 1998.

[79] Tartaj, P.; Del Puerto, M.; Morales, S.; Veintenillas-Verdaguer, Gonzales-Carreño, T.; Serna, C. Journal of Physics D: Applied Physics, v.36, p.R182, 2003. 


\section{CAPÍTULO 4 - Nanopartículas a base de Óxido de Cério e Paládio}

Neste capítulo apresentamos, inicialmente, uma breve introdução às pesquisas realizadas na área de catálise heterogênea utilizando catalisadores à base de paládio e oxido de cério, em seguida é descrito o processo de síntese e a caracterização das amostras à base de nanopartículas de dióxido de cério e paládio metálico. Finalmente, são apresentados alguns resultados preliminares da avaliação catalítica no motor automotivo, realizados pela empresa Volkswagen do Brasil.

A utilização de um filme à base de nanopartículas de dióxido de cério e paládio metálico depositados na cabeça de pistões anodizados de alumínio visa aplicações em catálise automotiva. O objetivo é aumentar a eficiência do motor automotivo e de melhorar o sistema de exaustão do automóvel o que resultaria na maior economia de combustível.

Este estudo apresenta um novo método, não descrito na literatura, de deposição de filmes a base de nanopartículas de céria e paládio metálico depositados na cabeça de pistões anodizados de motores automotivos.

\subsection{Introdução a nanocatálise}

Na última década a utilização de nanopartículas para reações catalíticas teve um grande crescimento, tanto em catálise homogênea quanto em catálise heterogênea. Devido ao fato de apresentarem uma grande razão entre a área de superfície e o volume comparadas com materiais maciços, nanopartículas são interessantes para uso como catalizador.

Em catálise heterogênea, nanopartículas suportadas em diferentes substratos são utilizadas como catalisadores. Os principais caminhos para preparar nanocatalisadores heterogêneos a base de metais de transição suportados de nanopartículas são o enxerto 
de nanopartículas e a fabricação de nanoestruturas mediante técnicas de litografia. $\mathrm{O}$ efeito do suporte utilizado com a atividade do catalisador com nanopartículas monometálicas e bimetálicas foi pesquisado e é narrado na literatura [1]. As propriedades catalíticas de nanopartículas de metais de transição aplicadas em suportes óxidos, como a céria, também foram reportadas [2]. A utilização de nanopartículas para catalisar uma variedade de reações de hidrogenação foi amplamente revisada e está bem documentada na literatura [3]. Nesta seção da nossa revisão, focalizaremos no método de produção de nanopartículas, no tipo de suporte utilizado e nas reações que são catalisadas utilizando nanocatalisadores metálicos de transição heterogêneos.

\subsubsection{Adsorção de nanopartículas sobre suportes}

O método mais comum de preparar nanocatalisadores metálicos de transição suportados é via a adsorção de nanopartículas de metais de transição, sobre diferentes tipos de suportes. O processo de absorção implica preparar uma suspensão coloidal de nanopartículas a base de metais de transição, impregnando as nanopartículas coloidais sobre o suporte, e lavando o sólido obtido. Na primeira etapa, as nanopartículas coloidais são sintetizadas mediante um processo químico. Há muitos tipos diferentes de suportes para impregnar as nanopartículas, tais como alumina, sílica, dióxido de titânio, entre outros.

\subsubsection{Reações químicas catalisadas utilizando nanocristais metálicos de transição}

Muitos tipos diferentes de reações químicas são catalisadas utilizando nanocristais a base de metais de transição. A maior área industrial que utiliza nanocristais de metais de transição é a indústria de células combustíveis. Alguns tipos de reações que são catalisadas utilizando nanocatalisadores metálicos heterogêneos incluem: hidrogenação, redução, decomposição, dentre outras. 
Numerosas reações de hidrogenação são catalisadas mediante diferentes tipos de nanopartículas a base de metais de transição. Dentre as reações de hidrogenação específicas utilizando-se nanocatalisadores a base de metais de transição suportados inclui-se a hidrogenação do benzeno e a hidrogenação do propeno.

Há muitos tipos de reações de redução e decomposição catalisadas mediante nanocatalisadores metálicos de transição suportados. Alguns tipos de reações de redução incluem redução de $\mathrm{NOx}$, redução de $\mathrm{SO}_{2}$ etc. Algumas reações de decomposição catalisadas por nanopartículas de metais de transição suportados incluem a decomposição de metano, de ácido fórmico, de amônia, de acetileno, entre outras. Diferentes tipos de nanopartículas de metais de transição suportados são utilizados para catalisar reações de redução e decomposição tais como catalisadores de paládio e platina.

\subsubsection{Estrutura dos metais na catálise heterogênea}

Em catálise heterogênea, uma etapa de vital importância no processo catalítico é a interface entre a superfície metálica (suporte) e as nanopartículas adsorvidas. A quantidade de átomos na superfície do catalisador é relacionada com suas propriedades catalíticas. A interação entre o catalisador e o suporte, bem como a eficiência do catalisador, são afetados pela forma, o tamanho e a morfologia das partículas.

\subsubsection{Suportes}

Os catalisadores metálicos ativos e seletivos que apresentam alta estabilidade térmica, são necessários nos processos realizados a temperaturas elevadas. A combinação de uma área específica grande e uma estabilidade térmica alta leva à deposição de metais ativos sobre o suporte.

Os suportes possuem diversas funções, sendo a mais importante a manutenção da área superficial específica do catalisador. O suporte ideal para um determinado 
catalisador é aquele cuja função é a de melhorar a dispersão das fases ativas, e que não apresente atividade catalítica em reações paralelas indesejáveis. As propriedades do material utilizado como suporte são de grande importância na determinação da eficiência de catálise final. Estas propriedades incluem área superficial do suporte, volume do poro, acidez da superfície e atividade catalítica, condutividade térmica e expansão térmica $[4,5]$.

Nos processos de hidrocraqueamento dos derivados do petróleo, nos processos de catálise de três vias (TWC) e na reforma do petróleo, a $\gamma-\mathrm{Al}_{2} \mathrm{O}_{3}$ é muito utilizada devido a sua alta área superficial e estabilidade mecânica, baixo custo e capacidade de interagir com a fase ativa. A temperaturas relativamente elevadas, entre $600^{\circ} \mathrm{C}$ e $1100^{\circ} \mathrm{C}$, sua habilidade torna-se prejudicada observando-se a sinterização e consequentemente a transformação de fase $\gamma-\mathrm{Al}_{2} \mathrm{O}_{3}$ em $\alpha-\mathrm{Al}_{2} \mathrm{O}_{3}$ responsáveis pela perda de área superficial do suporte e de área metálica da sinterização da fase ativa [6].

A alumina na fase $\gamma$ apresenta uma estrutura cúbica, com empacotamento tetragonal distorcido dos átomos de oxigênio, em relação aos átomos de alumínio. A fase $\alpha$, a alumina conhecida como Corundum, apresenta um empacotamento hexagonal denso dos átomos de oxigênio em relação aos átomos de alumínio. Portanto, para promover o rearranjo dos átomos de oxigênio para a fase cristalina $\alpha$ da alumina é necessário o aumento da temperatura.

A alumina tem sido utilizada como suporte para a preparação de catalisadores heterogêneos a base de metais de transição. Algumas reações catalisadas usando nanopartículas metálicas suportadas em alumina, incluem a redução de NOx, oxidação de $\mathrm{CO}$, síntese de amônia, entre outras. Algumas nanopartículas metálicas que foram suportados em alumina incluem platina, ródio, rutênio etc. Nanopartículas de platina suportadas em alumina são utilizadas para a reação de redução de NOx. Uma evolução morfológica de nanopartículas grosseiras de platina é observada durante a reação de redução de NOx. 


\subsubsection{Oxidação catalítica}

Os catalisadores ambientais são usados para melhorar e proteger nosso ambiente limpando o ar, água e terra. Os catalisadores são usados em tecnologias ambientais para converter os materiais que prejudicam o ambiente em compostos menos tóxicos. Um catalisador ambiental importante é o TWC que tem sido utilizado desde 1979 para controlar a poluição do ar causada pelos automóveis [7], e o catalisador contendo Pt e $\mathrm{Ru}$ numa razão de 5-20:1 como componentes chaves. Estes podem tratar simultaneamente a oxidação dos contaminantes monóxido de carbono e hidrocarbonetos $\left(\mathrm{C}_{\mathrm{x}} \mathrm{H}_{\mathrm{y}}\right)$ e, contaminantes oxidantes, $\mathrm{NO}_{\mathrm{x}}$, num reator. As reações são como seguem:

Reações de oxidação:

$$
\begin{aligned}
& \mathrm{CO}+\frac{1}{2} \mathrm{O}_{2} \rightarrow \mathrm{CO}_{2} \\
& \mathrm{C}_{X} \mathrm{H}_{Y}+\left(X+\frac{Y}{4}\right) \mathrm{O}_{2} \rightarrow \frac{Y}{2} \mathrm{H}_{2} \mathrm{O}+\mathrm{XCO}_{2}
\end{aligned}
$$

Reações de óxido-redução

$$
\begin{aligned}
& \mathrm{CO}+\mathrm{NO} \rightarrow \frac{1}{2} \mathrm{~N}_{2}+\mathrm{CO}_{2} \\
& 2\left(X+\frac{Y}{4}\right) \mathrm{NO}+\mathrm{C}_{X} \mathrm{H}_{Y} \rightarrow\left(X+\frac{Y}{4}\right) \mathrm{N}_{2}+\frac{Y}{2} \mathrm{H}_{2} \mathrm{O}+\mathrm{XCO}_{2}
\end{aligned}
$$

Os catalisadores a base de óxido metálico ou metal suportado como $\mathrm{Pt}, \mathrm{WO}_{3}$ e $\mathrm{V}_{2} \mathrm{O}_{5}$ em óxidos metálicos são ativos em degradar os componentes orgânicos voláteis (COV). Na última década, houve um rápido crescimento nos estudos de catalisadores a base de ouro suportado por causa de sua alta reatividade a temperaturas relativamente baixas para oxidação de CO. Recentemente reações de oxidação, catalisadas por Au de compostos orgânicos voláteis tais como metanol, etanol, acetona, 2-propanol, benzeno e tolueno foram pesquisadas, bem como os catalisadores a base de ouro suportado em óxido de ferro, alumina e céria [1-3]. Os resultados mostraram claramente que a 
oxidação catalítica de compostos orgânicos voláteis poderiam ser notavelmente aumentada na presença de ouro. Embora o $\mathrm{TiO}_{2}$ seja um suporte extensivamente estudado, existem poucos trabalhos que o descrevem como suporte para nanopartículas de ouro para a oxidação de compostos orgânicos voláteis.

\subsection{6. $\mathrm{CeO}_{2} / \mathrm{Al}_{2} \mathrm{O}_{3}$}

Um dos suportes mais utilizados na área de catálise é a $\gamma-\mathrm{Al}_{2} \mathrm{O}_{3}$, caracterizada por apresentar uma alta área superficial, promover boa dispersão do metal impregnado e ser relativamente barata.

Catalisadores metálicos contendo céria $\left(\mathrm{CeO}_{2}\right)$ mostram potenciais aplicações devido às propriedades ácido-base e redox da céria, promovendo uma forte interação metal suporte que incrementa o desempenho catalítico [8]. A adição de $\mathrm{CeO}_{2}$ no suporte cerâmico de $\gamma-\mathrm{Al}_{2} \mathrm{O}_{3}$ [9], contendo metais de transição como $\mathrm{Ni}, \mathrm{Pd}$, entre outros, apresenta sinergia na reação catalítica, minimizando a ocorrência de produtos indesejados, fazendo da céria um componente chave em catálise ambiental [10].

As características apresentadas pela céria podem influenciar nas seguintes propriedades:

- Dispersão dos metais suportados;

- estabilidade térmica do suporte;

- promover a redução e a oxidação dos metais suportados;

- melhorar o comportamento catalítico do metal;

- favorecer a ativação de moléculas como $\mathrm{CO}_{2}$ e $\mathrm{CH}_{4}$;

- favorecer a reação de deslocamento gás-água (deslocamento de reação); 
- capacidade de estocar e liberar oxigênio, o que favorece a redução da deposição de carbono na superfície do catalisador, devido às vacâncias de oxigênio na interfacemetal- $\mathrm{CeO}_{2}$.

$\mathrm{O} \mathrm{CeO}_{2}$ também influencia as propriedades eletrônicas e catalíticas das partículas metálicas suportadas por transferência eletrônica ou formação de ligação química.

\subsubsection{Desativação dos catalisadores}

A atividade e a seletividade são características importantes em catálise, quando um catalisador perde sua atividade e/ou sua seletividade com o tempo, se diz que um catalisador foi desativado. Os processos de desativação dos catalisadores automotivos são numerosos entre os quais, os processos químicos, mecânicos e térmicos, são considerados os modos de desativação mais relevantes. A exposição a altas temperaturas, resultado do mau funcionamento dos motores automotivos pode ocasionar uma série de alterações nos catalisadores automotivos. Os catalisadores podem sofrer modificações na sua estrutura devido à participação de seus constituintes em uma reação química. Um dos fenômenos que pode ocorrer é a sinterização, que é a formação de partículas grandes pela formação de pescoço entre as partículas pequenas levando a uma diminuição da área específica do catalisador, e consequentemente levando à diminuição da atividade catalítica. No entanto, é difícil dar uma definição precisa de desativação devido à complexidade do fenômeno [11].

Outro aspecto importante a ser considerado é a exposição a altas temperaturas que acarreta o crescimento dos cristais de $\mathrm{CeO}_{2}$, resultando na diminuição da área específica do $\mathrm{CeO}_{2}$. Assim ocorre a diminuição da interação $\mathrm{Pd}^{0}-\mathrm{CeO}_{2}$ ocasionando maior dificuldade na oscilação do Ce entre seus graus de oxidação e, consequentemente, nos processos de armazenamento e liberação de oxigênio [12].

A exposição a altas temperaturas promove, também, uma série de reações indesejáveis entre os elementos constituintes dos conversores catalíticos. Por exemplo, o 
níquel, que é algumas vezes empregado como retentor de enxofre, quando se utiliza combustíveis de alto teor de $\mathrm{S}$, reage com a alumina formando o aluminato de níquel. $\mathrm{O}$ próprio $\mathrm{CeO}_{2}$, quando exposto a temperatura elevadas em atmosfera redutora, pode formar também o aluminato de cério, o qual não é capaz de armazenar $\mathrm{O}_{2}$ [13].

Conforme se pode constatar através das informações apresentadas acima, a atual formulação dos catalisadores automotivos é fortemente influenciada pela questão da estabilidade térmica dos materiais envolvidos.

A desativação de catalisadores automotivos pode resultar, também, da interação entre os contaminantes presentes no combustível ou no motor que se depositam sobre a superfície do material catalítico bloqueando a atuação do catalisador. Destacam-se como relevantes as desativações devidas ao enxofre $\left(\mathrm{SO}_{2}\right.$ e $\left.\mathrm{SO}_{3}\right)$ presente na gasolina que podem reagir com os sítios ativos tornando o catalisador menos ativo, e deteriorando os catalisadores devido ao envenenamento por parte de aditivos (fósforo e zinco) contidos no óleo lubrificante [13].

O papel desempenhado pelo suporte numa reação catalítica proporciona maior exposição da fase ativa mantendo o material ativo disperso, podendo dissipar o calor. Portanto, promove estabilidade térmica e evita processos de sinterização. A possibilidade do suporte aumentar a acessibilidade de reagentes aos centros catalíticos incrementa a atividade do catalisador. Um dos problemas numa reação (reações de reforma do metano) é a deposição de carbono sobre o catalisador que leva à obstrução dos poros ou trincas e à destruição do catalisador.

Os hidrocarbonetos na superfície do catalisador dissociam-se sobre o metal para produzir espécies de carbono monoatômico altamente reativo $\left(\mathrm{C}_{\alpha}\right)$. Muitos destes $\mathrm{C}_{\alpha}$ são gaseificados para formar monóxido de carbono, ou se a gaseificação é lenta, são convertidos em uma espécie menos reativa $\left(\mathrm{C}_{\beta}\right)$, provavelmente por polimerização ou rearranjo das espécies $\alpha$. Esses $C_{\beta}$ podem ser gaseificados, encapsulados à superfície do catalisador ou podem se dissolver nos cristais do metal. O carbono dissolvido pode 
acumular na superfície ou difunde-se através do metal precipitando na interface metal/suporte. Este processo contínuo leva à formação de filamentos de carbono que deslocam o metal da superfície do suporte, levando inicialmente a uma maior exposição de sítios ativos. Porém, o contínuo crescimento de filamentos de carbono leva à fragmentação do filamento, com perda da fase ativa e entupimento do leito reacional [14]. A formação destes filamentos pode gerar elevadas temperaturas no leito catalítico como resultado da fragmentação e coqueificação do catalisador, sendo então necessária a substituição do catalisador. Os depósitos de carbono ainda podem ser encontrados na forma livre, que podem igualmente causar a desativação do catalisador. Carbono livre se refere à espécie de carbono condensado e depositado na superfície do sólido durante o andamento da decomposição do hidrocarboneto em altas temperaturas. Sabe-se que a presença dos sítios ácidos na superfície do catalisador (ácido de Lewis) pode promover a formação de coque pelo processo de polimerização de espécies $\mathrm{CH}_{\mathrm{X}}$, formadas durante a reação. Existem várias maneiras de minimizar a formação de coque. Uma delas consiste no controle de tamanho de partícula, pois a formação de coque é favorecida em partículas maiores do que aquelas requeridas para reforma. Outra forma de minimizar a formação de coque consiste em acelerar a gaseificação das espécies carbonáceas. Estudos mostram que suportes básicos de terras raras (base de Lewis) provocam um aumento da reforma do metano e um decréscimo significativo na formação de carbono por meio de um favorecimento da gaseificação do coque. Céria, um suporte inativo para a reforma do metano, quando combinada com níquel, provoca uma melhora no controle de coque. Estudos indicam que parte deste efeito é devido a um aumento da adsorção da água no suporte de céria e aumento da gaseificação do carbono [15]. A formação de coque não pode ser evitada, mas pode ser controlada e o suporte apresenta um importante papel na estabilidade térmica do catalisador e na remoção deste carbono indesejado. 


\subsection{Paládio como catalisador}

A poluição do ar gerada a partir do sistema automotivo é um problema de interesse público. A composição dos gases de escape de um motor varia com o tipo de motor, velocidade, carga do motor e temperatura externa. Existem também variações devido ao combustível utilizado e aditivos no combustível [16]. Os gases resultantes da exaustão, formado nos motores a gasolina, contem três poluentes principais: os óxidos de Nitrogênio (NOx), monóxido de carbono (CO) e hidrocarbonetos ( $\mathrm{HC})$. A gama de hidrocarbonetos descritos na literatura são imaginados como sendo inertes ou facilmente oxidados em temperaturas maiores. Por exemplo, Hoebink argumentou que $\mathrm{C}_{2} \mathrm{H}_{4}$ e $\mathrm{C}_{2} \mathrm{H}_{2}$ são melhores modelos de gases de exaustão do que $\mathrm{C}_{3} \mathrm{H}_{6}$, uma vez que são mais abundantes nos gases de escape e o $\mathrm{C}_{2} \mathrm{H}_{2}$ leva à formação de coque sobre o catalisador, que durante o frio atua muito melhor [17]. Catalisadores são necessários para reduzir os óxidos de Nitrogenio (NOx), monóxido de carbono (CO), e hidrocarbonetos (HC), uma vez que estes compostos contribuem para os problemas ambientais através da chuva ácida e da formação de fuligem urbana e muitos também estão ligados a problemas de saúde. Esses compostos são o resultado da combustão incompleta. Em geral, as quantidades de emissões dependem da mistura ar-combustível. O uso de catalisadores de metais nobres, como o paládio $(\mathrm{Pd})$, platina $(\mathrm{Pt})$ e ródio $(\mathrm{Rh})$ podem efetivamente purificar os gases de exaustão e reduzir estes problemas, uma vez que CO, hidrocarbonetos e $\mathrm{NO}_{\mathrm{x}}$ são convertidos por meio de processos catalíticos em produtos menos nocivos $\left(\mathrm{CO}_{2}, \mathrm{H}_{2} \mathrm{O}\right.$ e $\left.\mathrm{N}_{2}\right)$. É necessário realizar simultaneamente as reações de oxidação e redução ao longo dos catalisadores de exaustão, estas podem realizar-se através de uma variedade de reações [18]. A estrutura moderna de um TWC contém camadas a base de metais nobres, promotores, estabilizantes, entre outros. Devido a esta estrutura complexa, a pesquisa contínua é necessária para melhor entendimento das reações entre gases de exaustão e catalisadores. A remoção de óxidos de nitrogênio dos gases de escape dos motores é difícil devido à queima pobre com catalisadores de três vias. Estes catalisadores trabalham em uma atmosfera rica em oxigênio como catalisadores comburentes, mas nesta atmosfera a transformação de óxidos de nitrogênio 
é restringida [19]. Os catalisadores devem ter alta atividade e seletividade, isto significa que a conversão de $\mathrm{NOx}, \mathrm{CO}$ e $\mathrm{COV}$ deve ser superior a 98\%. Além disso, um catalisador deve ter uma alta atividade em baixas temperaturas, logo após a ignição do motor. Para TWCs, estabilidade térmica e alta capacidade de armazenamento de oxigênio também são exigidos [19]. Catalisadores comerciais devem também levar em conta o processo de desativação, que ocorre em temperaturas elevadas, que afeta a vida e atividade do catalisador através da sinterização no metal [20].

\subsubsection{Paládio como fase ativa}

Catalisadores que utilizam paládio são empregados no controle da emissão dos gases automotivos $\mathrm{NO}_{x}, \mathrm{CO}$ e $\mathrm{COV}$, principalmente, utilizados no processo de TWC. As propriedades catalíticas do paládio estão relacionadas com o tamanho de partícula, o estado de oxidação da fase, a interação metal-suporte, entre outras. A diminuição do tamanho de partícula leva a um aumento de defeitos na superfície e consequentemente a uma maior densidade eletrônica. A atividade catalítica é influenciada pela interação metal-suporte. O paládio no catalisador $\mathrm{Pd} / \mathrm{CeO}_{2}$ suportado em alumina [21], sem prévia redução, possibilita diferentes estados de oxidação como: $\mathrm{Pd}^{0}, \mathrm{Pd}^{+}$e $\mathrm{Pd}^{2+}$. Portanto, o teor, precursor de Pd utilizado, as condições de tratamento térmico e as condições de reação podem influenciar na atividade catalítica do catalisador à base de nanopartículas de paládio.

A impregnação do paládio à $\mathrm{Al}_{2} \mathrm{O}_{3}$, que é cataliticamente inativa na maioria das reações, aumenta seu grau de dispersão e inibe uma possível desativação. Este aumento da área superficial específica do $\mathrm{Pd}^{0}$ sobre a alumina é acompanhado por um aumento na absorção e atividade catalítica do $\operatorname{Pd}^{0}[21]$.

\subsection{O óxido de Cério $\left(\mathrm{CeO}_{2}\right)$}

Na sua forma mais comum, a céria é estável na sua forma não estereoquímica $\mathrm{CeO}_{2}$ $\xi$, onde $0 \leq \xi \leq 0,5$. Na céria estereoquímica, o $\mathrm{CeO}_{2}$ está no estado $\mathrm{Ce}(\mathrm{IV})$. No dióxido de 
cério não estereoquímico, o $\mathrm{Ce}_{2} \mathrm{O}_{3}$ está no estado $\mathrm{Ce}$ (III) [22]. A redução do $\mathrm{CeO}_{2}$ para $\mathrm{CeO}_{2-\xi}$ é produzida pelas vacâncias de átomos de oxigênio na rede cristalina, causando nos íons de cério adjacentes aos sítios vacantes, a redução do $\mathrm{Ce}(\mathrm{IV})$ para o $\mathrm{Ce}$ (III) [23]. As vacâncias de oxigênio que se formam, levam ao esgotamento de oxigênio deixando o íon Ce(III) empobrecido de oxigênio, acredita-se ser a causa para a alta reatividade na céria [24]. Óxido de cério possui uma estrutura cúbica do tipo fluorita, tanto no material massivo como e na forma de nanopartículas [25]. O baixo índice de planos cristalinos expostos demonstraram ter diferente reatividade [26]. O plano de superfície (111) é o mais estável, seguido pelos planos (110) e (100). A formação de uma vacância de oxigênio ocorre mais facilmente para a superfície (110) do que nas superfícies (111). A vacância tende a se formar na superfície dos planos (110) enquanto que para a superfície dos planos (111) eles tendem a se formar na camada subsuperficial [27].

O confinamento quântico não é considerado quando se analisam as nanopartículas de céria. Se confinamento quântico dos elétrons e buracos estivessem presentes, poderia ocorrer um deslocamento para o azul nas curvas de absorção de luz para partículas muito pequenas. Em estudos publicados, partículas pequenas mostraram um deslocamento para o vermelho [28]. A razão das nanopartículas de céria terem um efeito oposto ao observado em outras nanopartículas semicondutoras não está relacionada a um fenômeno quântico, mais sim ao fato delas terem uma razão elevada de Ce(III) para $\mathrm{Ce}(\mathrm{IV})$ [29,30]. O incremento nos íons $\mathrm{Ce}(\mathrm{III})$ na rede cristalina produz um deslocamento para o vermelho na absorbância do material; atribuída aos defeitos de estado associados com os íons Ce(III) e vacâncias de oxigênio. Os estados de defeito encontram-se em $3 \mathrm{eV}$ acima da banda de valência do $\mathrm{CeO}_{2} . \mathrm{O} \mathrm{CeO}_{2}$, contendo íons $\mathrm{Ce}(\mathrm{IV})$, possui uma gap de $4 \mathrm{eV}$. Como a concentração dos íons de $\mathrm{Ce}(\mathrm{III})$ aumenta, a concentração de íons $\mathrm{Ce}(\mathrm{IV})$ diminui e mais absorção irá acontecer em $3 \mathrm{eV}$ e menos absorção em $4 \mathrm{eV}$, causando um deslocamento para o vermelho no espectro de absorção.

O cério é caracterizado quimicamente por apresentar dois estados de valência: o $3^{+}$ (ceroso) e o $4^{+}$(cérico). O óxido de cério $\left(\mathrm{CeO}_{2}\right)$ é utilizado como componente catalítico 
em TWC para tratamento de gases de exaustão de veículos automotivos bem como na remoção de $\mathrm{SO}_{\mathrm{x}}$ através do craqueamento catalítico do petróleo e o uso como suporte em reações de oxidação. As técnicas de síntese utilizadas na preparação do óxido de cério, tais como: sol-gel, precipitação, decomposição ultrassônica, combustão, mecano-síntese, método de precursores poliméricos e condensação de gás inerte; demonstraram ser eficientes na síntese da céria com partículas de diâmetro nanométrico.

$\mathrm{O} \mathrm{CeO}_{2}$ possui estrutura do tipo fluorita $\left(\mathrm{CaF}_{2}\right)$, como mostra a Figura 4.1. Cada íon $\mathrm{Ce}^{4+}$ é rodeado por 8 íons $\mathrm{O}^{2-}$, formando um arranjo cúbico de corpo centrado de íon $\mathrm{O}^{2-}$ em torno de cada íon $\mathrm{Ce}^{4+}$.

$\mathrm{O} \mathrm{CeO}_{2}$ apresenta propriedades bem características como suporte de catalisadores. Entre elas, a capacidade de estocar oxigênio em atmosferas oxidantes e liberá-lo em atmosferas redutoras.

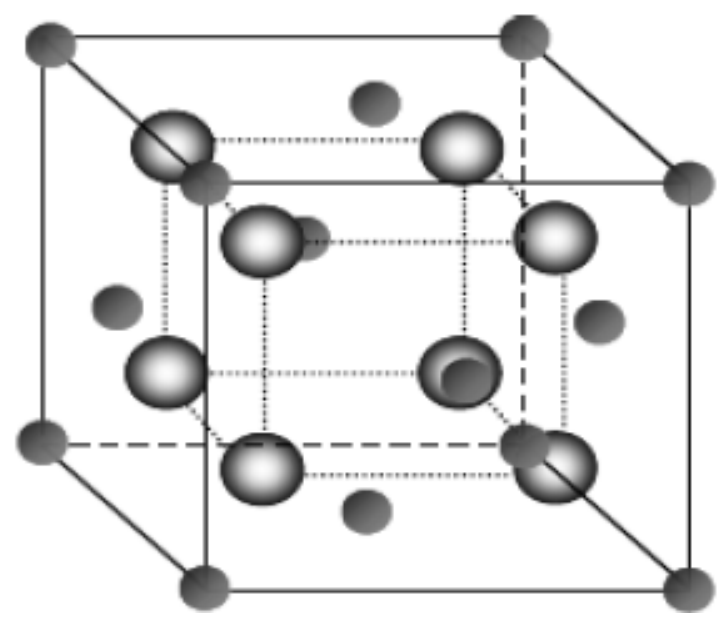

Figura 4.1: Estrutura tipo fluorita de $\mathrm{CeO}_{2}$. As esferas grandes representam os átomos de Cério, as esferas pequenas os átomos de Oxigênio. 


\subsection{Pesquisa de inovação com nanopartículas de paládio metálico e óxido de cério depositadas em anodizados de alumínio}

A proposta de utilizar catalisadores na fonte principal dos poluentes, isto é, depositando catalisadores no interior do motor automotivo, na cabeça de pistões de alumínio anodizados, é a pesquisa de inovação tecnológica que foi o objetivo do presente trabalho. As nanopartículas com propriedades catalíticas selecionadas para esta pesquisa foram as nanopartículas à base de óxido de cério e de paládio metálico. Estes catalisadores utilizam como suporte um material cerâmico (alumínio anodizado) poroso, estes poros apresentam alta área de superfície específica. Neste suporte são adicionados elementos ativos tais como o paládio e promotores como o $\mathrm{CeO}_{2}$. Neste sistema o efeito catalítico se deve ao metal nobre auxiliado pelo $\mathrm{CeO}_{2}$. O anodizado de alumínio funciona como estabilizador estrutural e térmico. As principais reações que ocorrem neste catalisador são a oxidação do $\mathrm{CO}$, diminuição do $\mathrm{COV}$ e a redução do $\mathrm{NO}_{\mathrm{X}}$. Levando em conta que as reações de oxidação e de redução são realizadas de maneira simultânea, é necessário manter um equilíbrio entre os poluentes e $\mathrm{O}_{2}$. A oscilação do teor de oxigênio é minimizada pela presença do óxido de cério no sistema. Quando a mistura ar/combustível é pobre em $\mathrm{O}_{2}$, a função do $\mathrm{CeO}_{2}$ é fornecer oxigênio, por meio da redução de $\mathrm{Ce}(\mathrm{IV})$ para Ce (II) na superfície das nanopartículas. Este óxido é posteriormente reoxidado, quando a mistura se encontra com excesso de $\mathrm{O}_{2}$ ou pela presença de $\mathrm{NO}_{\mathrm{x}}$, que é reduzido a $\mathrm{N}_{2}$ na superfície das nanopartículas.

Os motores do ciclo Otto (motores a gasolina, alcool, GLP ou GNV) geram na sua exaustão poluentes tais como $\mathrm{CO}$ e $\mathrm{CO}_{2}, \mathrm{NO}_{\mathrm{x}}$ e $\mathrm{COV}$. O monóxido de carbono é um gás mais tóxico que o $\mathrm{CO}_{2}$ e é formado durante a combustão incompleta do combustível devido a oxidação parcial do combustível. $\mathrm{O} \mathrm{NO}_{\mathrm{x}}$ é formado durante a combustão e é difícil de controlar esta emissão pois é formado a partir do próprio $\mathrm{N}_{2}$ presente no ar.

A partir de determinados níveis, estes poluentes interferem na qualidade de vida, pois afeta o metabolismo celular e, como consequência direta, a saúde dos seres vivos. 
Este fato motiva o desenvolvimento de catalisadores automotivos altamente eficientes. Hoje em dia, é difundido o uso dos catalisadores do tipo TWC [31], com objetivo de minimizar estes poluentes.

No caso do motor a gasolina a equação que representa a reação de queima é dada por:

$$
\mathrm{C}_{n} \mathrm{H}_{2 n}+\frac{(3 n+1)}{2} \mathrm{O}_{2}+\text { centelha } \rightarrow n \mathrm{CO}_{2}+(n+1) \mathrm{H}_{2} \mathrm{O}+\text { energia }
$$

onde tem-se em média n em torno de oito.

A introdução de catalisador a base de paládio nanopartículado no pistão do motor automotivo visa favorecer a quimiosorção de átomos de hidrogênio do hidrocarboneto (gasolina ou álcool).

Esta quimiosorção enfraquece a ligação entre o hidrogênio e o carbono, consequentemente a ligação entre carbonos também é enfraquecida, ver esquema.

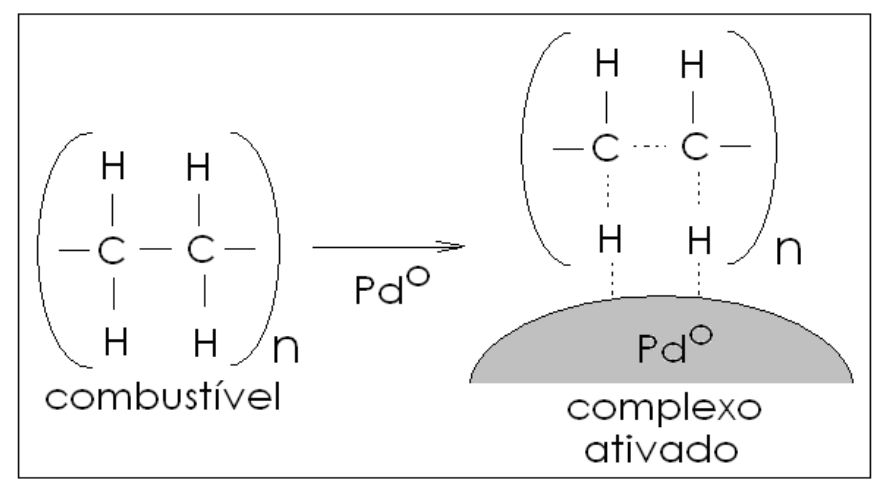

Portanto, com o enfraquecimento das ligações entre os átomos de carbono da molécula de combustível, a maior parte da molécula é oxidada. Se uma quantidade maior de combustível é queimada então os níveis de COV diminuem e, consequentemente, é esperado o aumento no rendimento do motor e diminuição no consumo de combustível. 
A introdução de catalisador a base de nanopartículas de óxido de cério age como um aceitador/doador de oxigênio. No motor a gasolina, a céria participa na reação de oxidação do $\mathrm{CO}$ para $\mathrm{CO}_{2}$ doando oxigênio, bem como na reação de redução do $\mathrm{NO}_{\mathrm{x}}$ recebendo oxigênio e liberando $\mathrm{N}_{2}$ não poluente. Estas duas reações são representadas pelas seguintes equações:

$$
\begin{array}{ll}
\mathrm{CO}+\mathrm{Ce}_{2} \mathrm{O}_{4} \rightarrow \mathrm{CO}_{2}+\mathrm{Ce}_{2} \mathrm{O}_{3} & \text { oxidação; } \\
\mathrm{NO}_{x}+x \mathrm{Ce}_{2} \mathrm{O}_{3} \rightarrow \frac{1}{2} \mathrm{~N}_{2}+x \mathrm{Ce}_{2} \mathrm{O}_{4} & \text { redução. }
\end{array}
$$

Na literatura são apresentadas as aplicações do paládio como catalisador e da céria como promotor de oxigênio, descritos nos itens anteriores com o objetivo de relatar as pesquisas realizadas com estes materiais [32-35]. No entanto, não existem pesquisas relacionadas com nanopartículas de paládio e céria depositadas sobre anodizados de alumínio porosos, muito menos pesquisas com catalisadores depositados na cabeça de pistões automotivos anodizados, nem avaliações de catalisadores introduzidos no interior de motores automotivos e de nenhum outro tipo de motor. Portanto, o principal aporte deste trabalho foi o desenvolvimento de filmes à base de nanopartículas de paládio metálico e de nanopartículas de óxido de cério, depositados na cabeça de pistões anodizados de motores automotivos com o objetivo de diminuir os poluentes resultado da má exaustão, bem como de melhorar a eficiência do motor automotivo. A camada de anodizado de alumínio poroso será denominado de suporte devido ao fato das partículas estarem impregnadas nas paredes e interior dos poros. 


\subsection{Preparação das amostras e caracterização}

\subsubsection{Síntese de nanopartículas de óxido de cério}

A preparação da solução precursora para obtenção do filme a base de óxido de cério foi realizada em duas etapas. Primeiro, o óxido de cério em pó (comercial, 99\%, fornecido pela COPAX) é adicionado em um bequer contendo ácido nítrico concentrado. A mistura é mantida sob agitação próxima da ebulição $\left(90\right.$ a $\left.110^{\circ} \mathrm{C}\right)$ até a formação de um sol vermelho (sobrenadante). O excesso de óxido de cério resta precipitado no fundo. O sobrenadante é então separado e é adicionado o surfactante Renex 95 (Nonilfenil etoxilado, Oxiteno) até a concentração de $5 \%$ em relação ao volume total da mistura. Este sol é então aquecido próximo da ebulição a fim de eliminar o excesso de ácido nítrico por evaporação. A evaporação é interrompida quando se verifica a formação de uma pasta vermelha e transparente. Esta pasta é ressuspendida em álcool n-butilico na proporção de 0,25 g para $20 \mathrm{~mL}$ do álcool. Este sol é o precursor dos filmes a base de óxido de cério, que são aplicados nos anodizados de alumínio.

Com objetivo de determinar a formação da fase cristalina da solução quando submetida a calcinação sob atmosfera de ar, o sólido obtido por evaporação foi analisado por DRX. A solução foi seca a $70^{\circ} \mathrm{C}$ e o pó obtido calcinada nas temperaturas de 200 e $450^{\circ} \mathrm{C}$ sob atmosfera de ar durante 30 minutos. A fase cristalina, após a secagem e calcinação, foi obtida mediante análise dos difratogramas de DRX. O difratograma (Figura 4.2) da amostra seca aponta para uma estrutura cristalina predominante a base de nitrato de cério (III) e nitrato de cério (IV) hidratados (4 a 5 grupos $\mathrm{H}_{2} \mathrm{O}$ por formula química). Este resultado está de acordo com as fichas JCPDS (International Centre for Diffaction Data) números 9-41 e 16-197. As amostras calcinadas sob atmosfera ambiente apresentam a fase cristalina cúbica correspondente ao óxido de cério $\left(\mathrm{CeO}_{2}\right)$. 


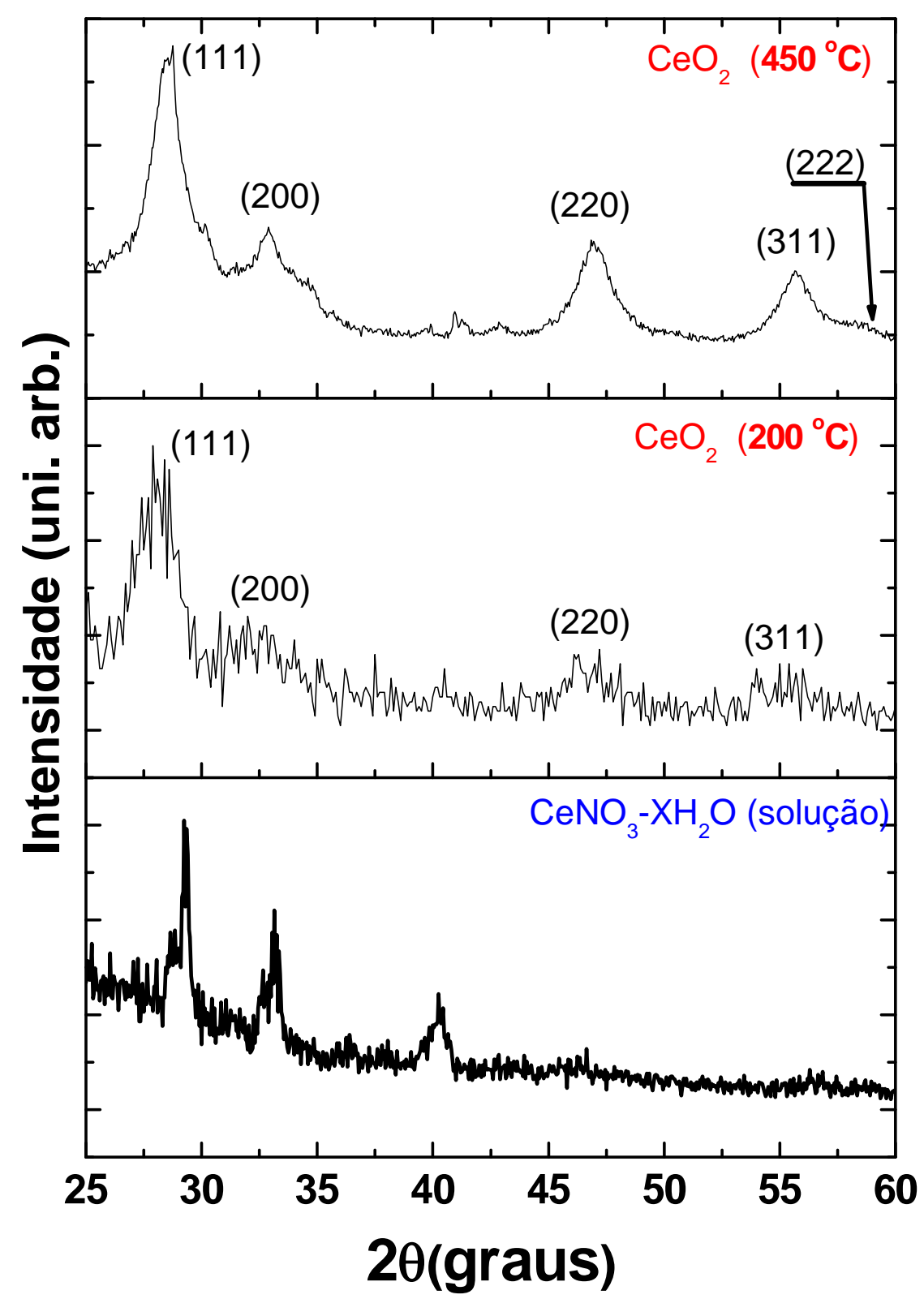

Figura 4.2: Difratogramas de DRX da solução de nitrato de cério submetida a diferentes temperaturas de calcinação sob atmosfera de ar: (a) temperatura ambiente, (b) $200^{\circ} \mathrm{C}$ e (c) $450^{\circ} \mathrm{C}$.

A Figura 4.2 evidencia a presença de óxido de cério nas amostras calcinadas, nesta figura nota-se a formação de óxido de cério à temperatura de $200^{\circ} \mathrm{C}$. Para amostra tratada a $450^{\circ} \mathrm{C}$ a quantidade do óxido de cério é aumentada. Isto demonstra que sob atmosfera de ar e temperatura o nitrato de cério se transforma em óxido de cério. A 
presença de picos largos nos espectros de DRX evidencia o tamanho nanométrico das partículas de óxido de cério.

Uma vez garantidas as condições para a formação da fase desejada de $\mathrm{CeO}_{2}$, a solução foi depositada por pintura sobre o anodizado de alumínio para a formação de um filme, o anodizado foi tratado termicamente na estufa à temperatura de $70^{\circ} \mathrm{C}$ por um período de 15 minutos e depois submetido a tratamento térmico num forno à temperatura de $400^{\circ} \mathrm{C}$ por um período de 20 minutos sob atmosfera de ar. $\mathrm{O}$ resultado do tratamento térmico permite obter filmes à base de nanopartículas de óxido de cério depositados em anodizados de alumínio.

A aplicação de filmes à base de céria nos pistões automotivos foi realizada seguindo o mesmo procedimento anterior. Desta maneira foram obtidos pistões contendo filmes de céria, também foi notada uma boa adesão da partícula sobre a cabeça do pistão.

\subsubsection{Estudo da morfologia da amostra sintetizada submetida a tratamento térmico mediante a técnica de SAXS}

Foram realizadas medidas de SAXS do sol preparado.

Os resultados de SAXS são apresentados na Figura 4.3. Nesta figura são apresentados os resultados para a amostra sem tratamento térmico e tratada a $70^{\circ} \mathrm{C} \mathrm{e}$ $200^{\circ} \mathrm{C}$ durante 15 minutos. $\mathrm{O}$ tratamento térmico do sol a $70^{\circ} \mathrm{C}$ foi realizado em bequer sobre agitador magnético com aquecimento. $\mathrm{O}$ tratamento térmico a $200^{\circ} \mathrm{C}$ foi realizado em cadinho de porcelana na estufa. Esta amostra foi ressuspensa em n-butanol. Vale ressaltar que o surfactante utilizado começa a evaporar a temperaturas superiores a $300^{\circ} \mathrm{C}$. Nota-se que a função I(q) para a amostra sem tratamento térmico e as amostras tratados termicamente apresentaram um comportamento não linear em escala $\operatorname{logI}(\mathrm{q})$ vs $\log (\mathrm{q})$. No caso da amostra tratada termicamente na temperatura de $70^{\circ} \mathrm{C}$, o gráfico mostra a formação de franjas, estas franjas são mais evidentes para a amostra tratado na 
temperatura de $200^{\circ} \mathrm{C}$ como pode ser visto na Figura 4.3. Este resultado aponta para uma distribuição estreita de tamanhos das nanopartículas.

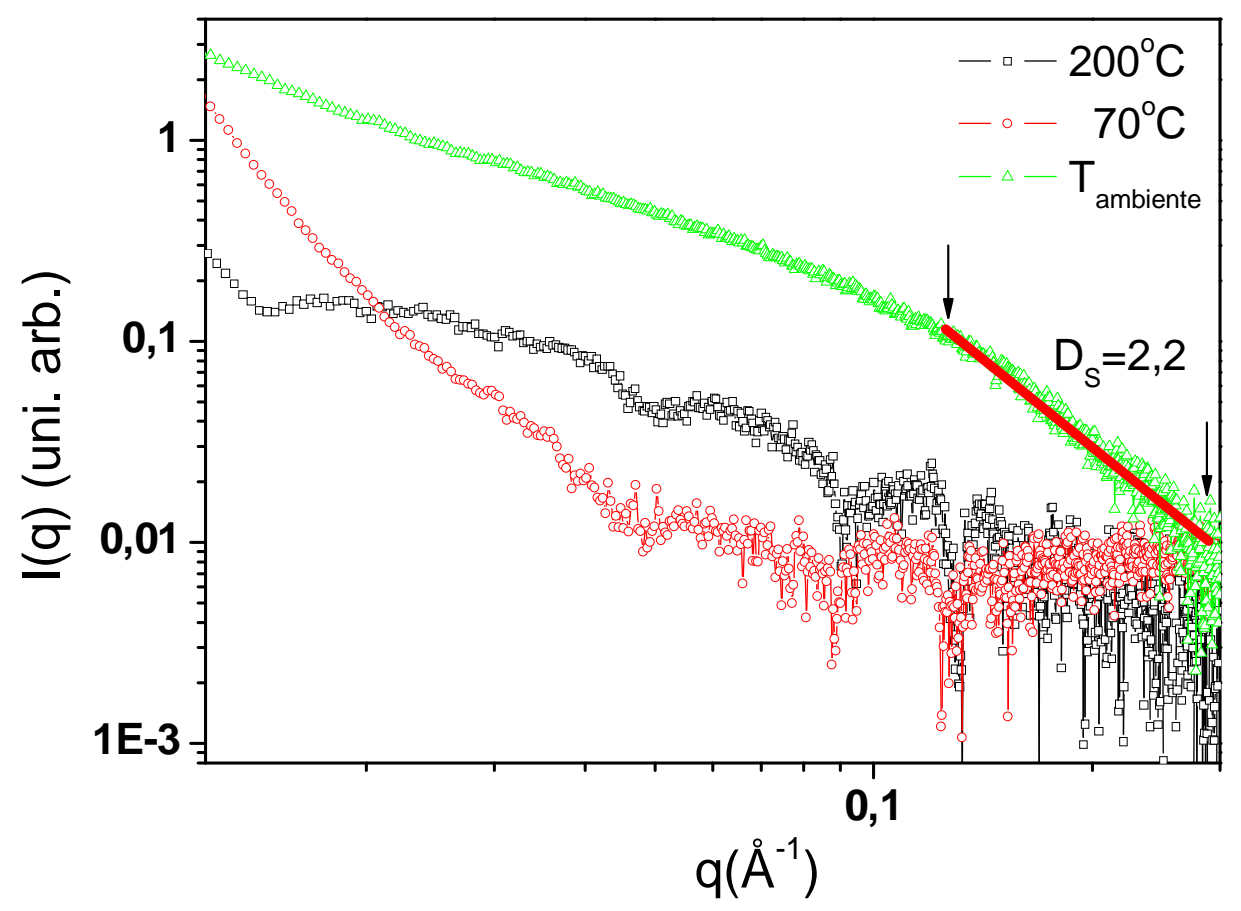

Figura 4.3: Curvas de $\mathrm{SAXS}$ correspondentes a sóis de $\mathrm{CeO}_{2}$ nas temperaturas indicadas.

A Figura 4.3 mostra que a intensidade de espalhamento diminui de forma drástica com o aumento da temperatura de tratamento térmico. Esta diminuição da intensidade da radiação espalhada sugere que a amostra passa por um rearranjo estrutural [36]. Este fenômeno indica uma grande mudança estrutural eletrônica, correspondente à transferência de estrutura química de nitrato de cério para dióxido de cério, evidenciando a formação de nanopartículas de óxido de cério mediante oxidação do $\mathrm{Ce}(\mathrm{III})$ para $\mathrm{Ce}(\mathrm{IV})$ pelo tratamento térmico. A diminuição da intensidade das curvas de SAXS não correspondente à nucleação e aglomeração de nanopartículas de $\mathrm{CeO}_{2}$. A presença de um sistema monodisperso de nanopartículas de óxido de cério pode ser evidenciada pelo aparecimento de franjas nas curvas SAXS. 
As curvas SAXS das amostras submetidas a tratamento térmico exibem um comportamento não linear, como mostrado na Figura 4.3 onde evidenciam-se a presença de oscilações. O valor do módulo da inclinação (coeficiente angular), nas regiões de altos e baixos valores de $q$, não foi determinado, isto é um claro indicativo da presença de um sistema monodisperso de partículas de óxido de cério. A ausência de regiões lineares em pelo menos uma ordem de grandeza tornam impossível o estudo na mudança da dimensão fractal de massa ou de superfície das nanopartículas de óxido de cério. No entanto, estudos revelaram que as nanopartículas de óxido de cério seguem uma lei fractal e que a dimensão fractal muda de fractais de massa para fractais de superfície com o aumento da temperatura de $25^{\circ} \mathrm{C}$ até $700^{\circ} \mathrm{C}$ [37].

Da Figura 4.3, pode-se inferir que a amostra recém preparada, na temperatura ambiente, aparentemente exibe uma estrutura de superfície fractal com dimensão de fractalidade $D_{S} \sim 2,2$, dentro de uma escala de comprimentos $1 / q \sim 1 \mathrm{~nm}$ e $1 / q_{m} \sim 0,3 n m[38$ ]. Esta característica de superfície fractal poderia resultar do arranjo aleatório de cristalitos ou, simplesmente, mudanças no número de oxidação do cério da superfície das nanopartículas e um processo de agregação das nanopartículas.

Para visualizar as características da intensidade de SAXS para baixos valores de q, apresentamos na Figura 4.4 o gráfico de Guinier. Pode-se observar que as curvas de SAXS, exibem um domínio linear para todas as amostras de $\mathrm{CeO}_{2}$. Na região de Guinier, o comportamento linear da curva indica a existência de uma distribuição de tamanho de nanopartículas larga, com raio de giro de $20,8 \pm 0,2 \mathrm{~nm}\left(70^{\circ} \mathrm{C}\right)$ e $19,0 \pm 0,4 \mathrm{~nm}\left(200^{\circ} \mathrm{C}\right)$. 


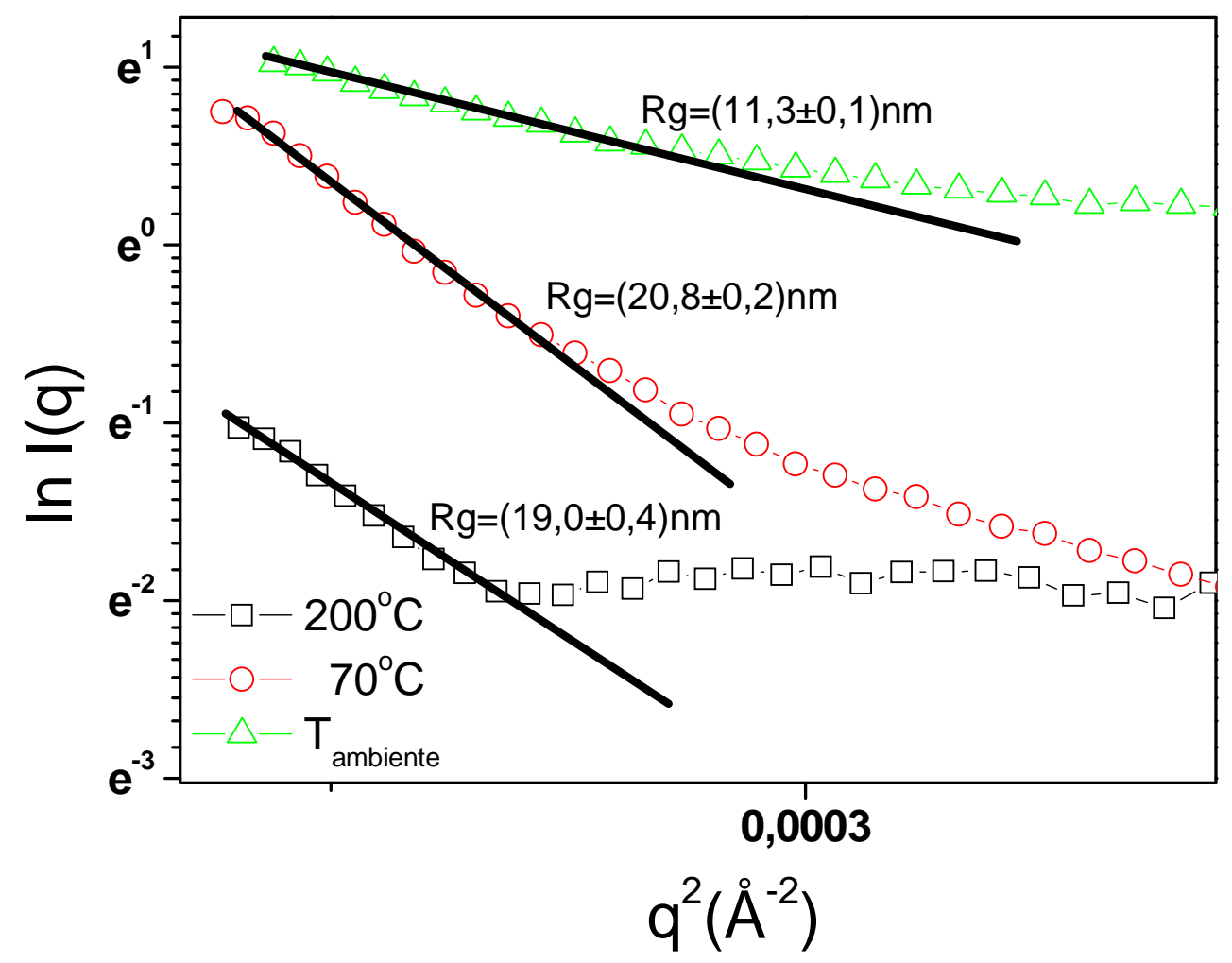

Figura 4.4: Gráfico de Guinier da intensidade SAXS apresentada na figura anterior. As temperaturas de tratamento térmico estão apresentadas na figura.

Para o caso das amostras tratadas termicamente a curva SAXS indica um claro domínio monodisperso, evidenciando a presença de nanopartículas com uma distribuição de tamanho estreita. Portanto, estas curvas foram submetidas a analise utilizando o programa GNOM, assumindo um sistema monodisperso de esferas, obtendo valores do raio de giro de 4,8 $\pm 0,1 \mathrm{~nm}\left(200^{\circ} \mathrm{C}\right)$ e $12,72 \pm 0,01 \mathrm{~nm}\left(70^{\circ} \mathrm{C}\right)$. Os resultados do ajuste e da distribuição de distância $(\mathrm{P}(\mathrm{R}))$ evoluída a partir da curva de espalhamento são mostrados na Figura 4.5. 

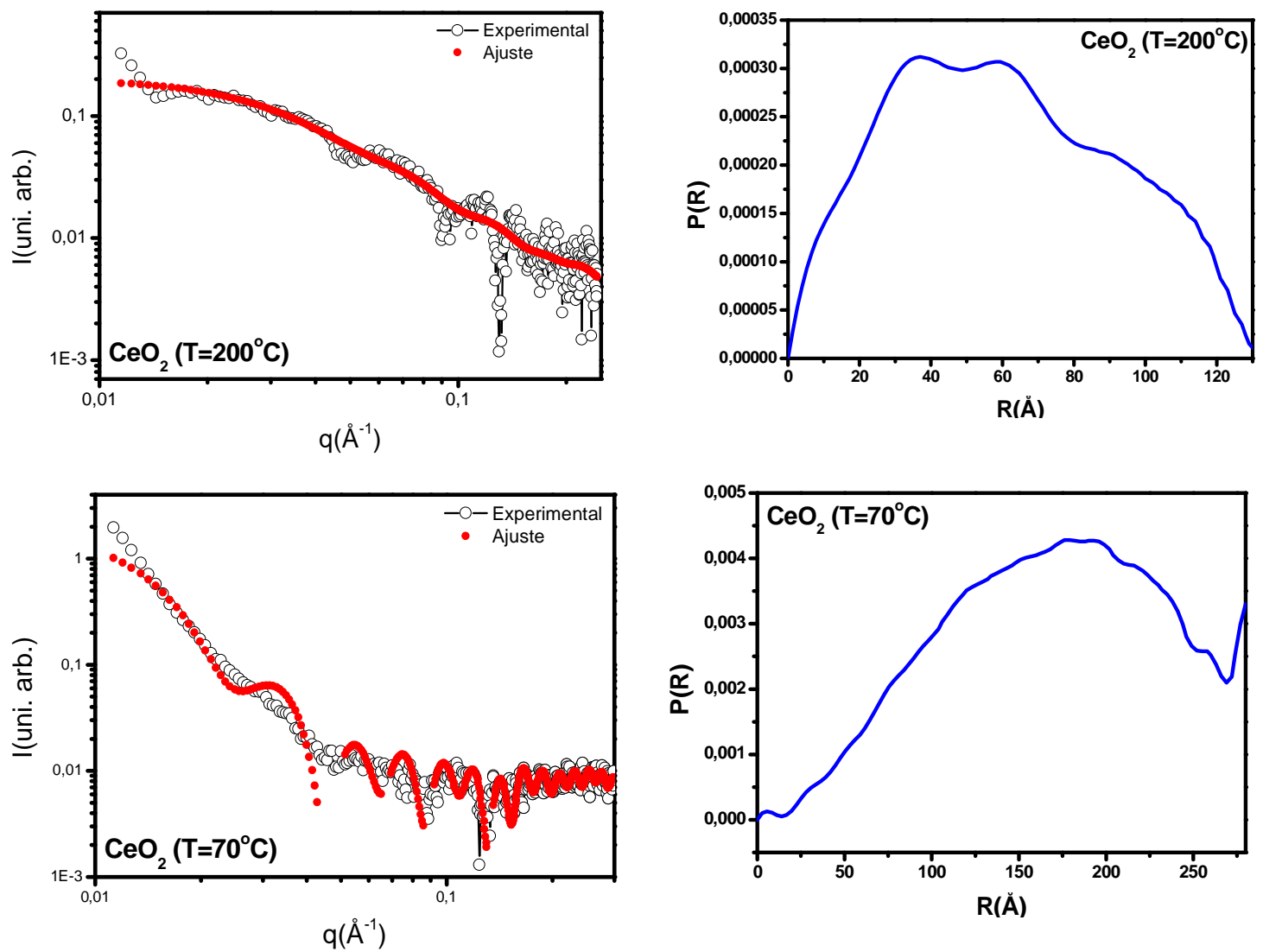

Figura 4.5: Gráficos de SAXS mostrando ajustes aos dados experimentais e as funções de distribuição de distância $\mathrm{P}(\mathrm{R})$, obtidos utilizando o programa GNOM, das amostras de oxido de cério. Os tempos de tratamento térmico estão apresentados na figura.

\subsubsection{Caracterização magnética da amostra mediante a técnica de RFM}

A céria $\left(\mathrm{CeO}_{2}\right)$ cristaliza na estrutura cúbica tipo fluorita, com número de coordenação igual a oito, isto é, cada ânion está coordenado com oito cátions. Em baixas pressões parciais de oxigênio e elevadas temperaturas, a céria facilmente libera oxigênio para formar $\mathrm{CeO}_{2-\mathrm{x}}$. Medidas de termogravimetria e condutividade elétrica confirmaram que a deficiência de oxigênio é compensada pela carga mediante a formação de $\mathrm{Ce}^{3+}$ $[39,40]$. Este íon é paramagnético e RPE poderia ser uma valiosa ferramenta para obter uma visão específica do defeito químico deste material e para monitorar o grau de não 
estequiometria. Na verdade, a maioria das pesquisas em RPE publicadas [41-48] mencionam um sinal axial com fatores $\mathrm{g}$ ou seja, $\mathrm{g}_{\perp}=1,964$ e $\mathrm{g}_{/ /}=1,943$ [44]. Vários autores atribuem o origem do sinal axial a existência de $\mathrm{Ce}^{3+}[40,44-47]$ ou para elétrons quase livres [42]. O sinal permanece facilmente detectável mesmo a temperaturas mais elevadas que $800 \mathrm{~K}$. Isso, no entanto, está em conflito com outras observações mostrando que $\mathrm{Ce}^{3+}$ geralmente é difícil de detectar com RPE a temperaturas superiores a $20 \mathrm{~K}$ devido ao forte acoplamento spin órbita e aos tempos de relaxação curtos resultantes de estados $4 \mathrm{f}^{1}$ [48]. Também, sobre a base de dados de cristais isoestruturais, poderia-se esperar que o espectro de $\mathrm{Ce}^{3+}$ poderia exibir maiores desvios do fator $\mathrm{g}$ do elétron livre de $g_{\mathrm{e}}=2,0023$ do que o sinal axial faz. Por outro lado, elétrons quase livres deveriam ainda mostrar um menor desvio do fator $\mathrm{g}$ do elétron livre e provavelmente um valor isotrópico. Esta situação insatisfatória e por vezes declarações contraditórias de estudos prévios de RPE da céria não foram resolvidos até a atualidade. A extrema sensibilidade do RPE produz espectros, mesmo em material de alta pureza, propenso a efeitos de impureza.

Na literatura observa-se ferromagnetismo à temperatura ambiente em nanopartículas de óxidos não magnéticos tais como $\mathrm{CeO}_{2}, \mathrm{Al}_{2} \mathrm{O}_{3}, \mathrm{ZnO}, \mathrm{In}_{2} \mathrm{O}_{3}$ e $\mathrm{SnO}_{2}$ que não são associados a efeitos dependentes do tamanho, mas sim, a efeitos de dopagem [49]. Por outro lado, algumas publicações recentes mencionam que óxidos semicondutores sem algum elemento magnético dopante resultam magnéticos quando apresentam cristalitos com tamanhos nanométricos [50-52].

Com objetivo de estudar as propriedades magnéticas das amostras constituídas de nanopartículas da céria foram realizadas medidas de RPE para o estudo do ferromagnetismo apresentado por este material nanoestruturado. As amostras a base de óxido de cério sintetizadas não foram dopadas com impurezas magnéticas.

Procurando a influência de uma possível contaminação da cavidade de RPE foram realizadas medidas à temperatura de $4 \mathrm{~K}$ da cavidade incluindo o porta amostra e da amostra de céria na cavidade. A subtração livre do sinal da cavidade é mostrada na 
Figura 4.6. Nesta figura observa-se o sinal produzido só por nanopartículas de céria. Uma linha de ressonância larga em $g=2,064 \pm 0,005$ é atribuída ao comportamento ferromagnético das nanopartículas de $\mathrm{CeO}_{2}$. As linhas estreitas apresentadas nos espectros em $g=4,34 \pm 0,02$ e $g=2,008 \pm 0,005$ são atribuídas a impurezas iônicas resultado da síntese e de impurezas dos materiais precursores.

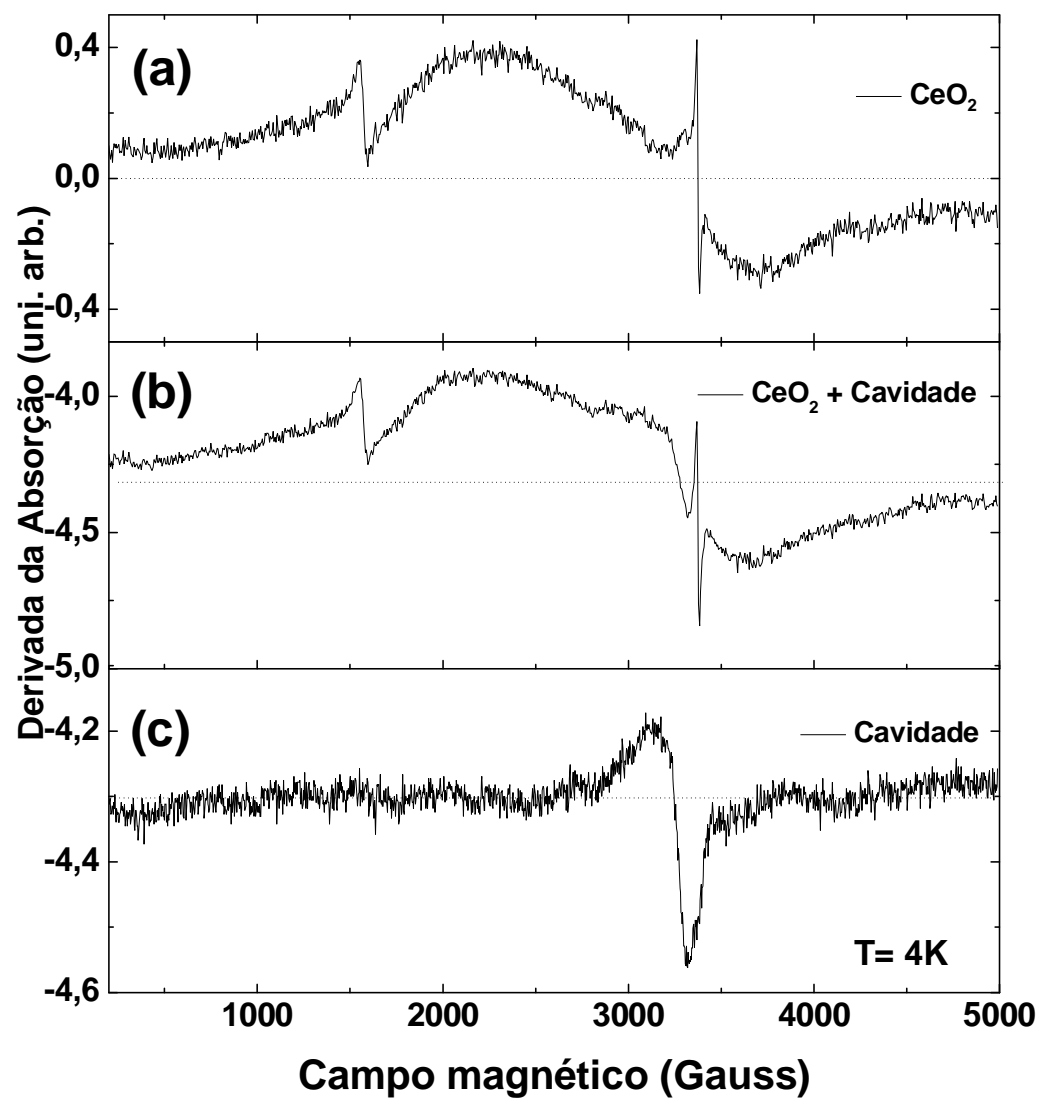

Figura 4.6: Espectros de RPE das nanopartículas de óxido de cério $\left(\mathrm{CeO}_{2}\right)$ obtidos a temperatura de $4 \mathrm{~K}$. (a) sinal da cavidade mais o porta amostra, (b) sinal do $\mathrm{CeO}_{2}$ no porta amostra mais a cavidade e (c) sinal do $\mathrm{CeO}_{2}$ obtido da subtração do porta amostra e da cavidade. 


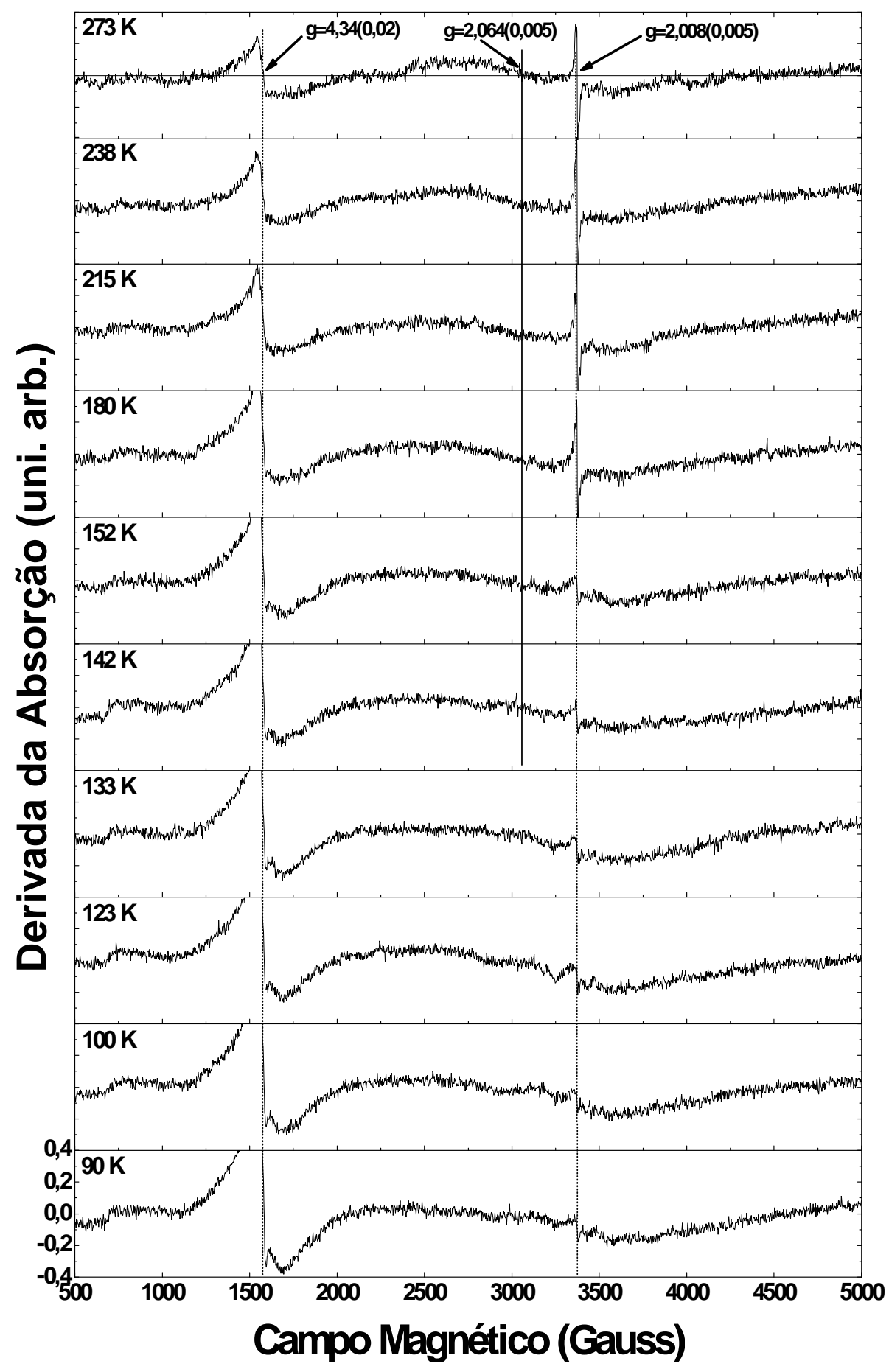

Figura 4.7: Espectros de RPE da amostra de $\mathrm{CeO}_{2}$ na faixa de temperatura de 90 até 273 $\mathrm{K}$. 


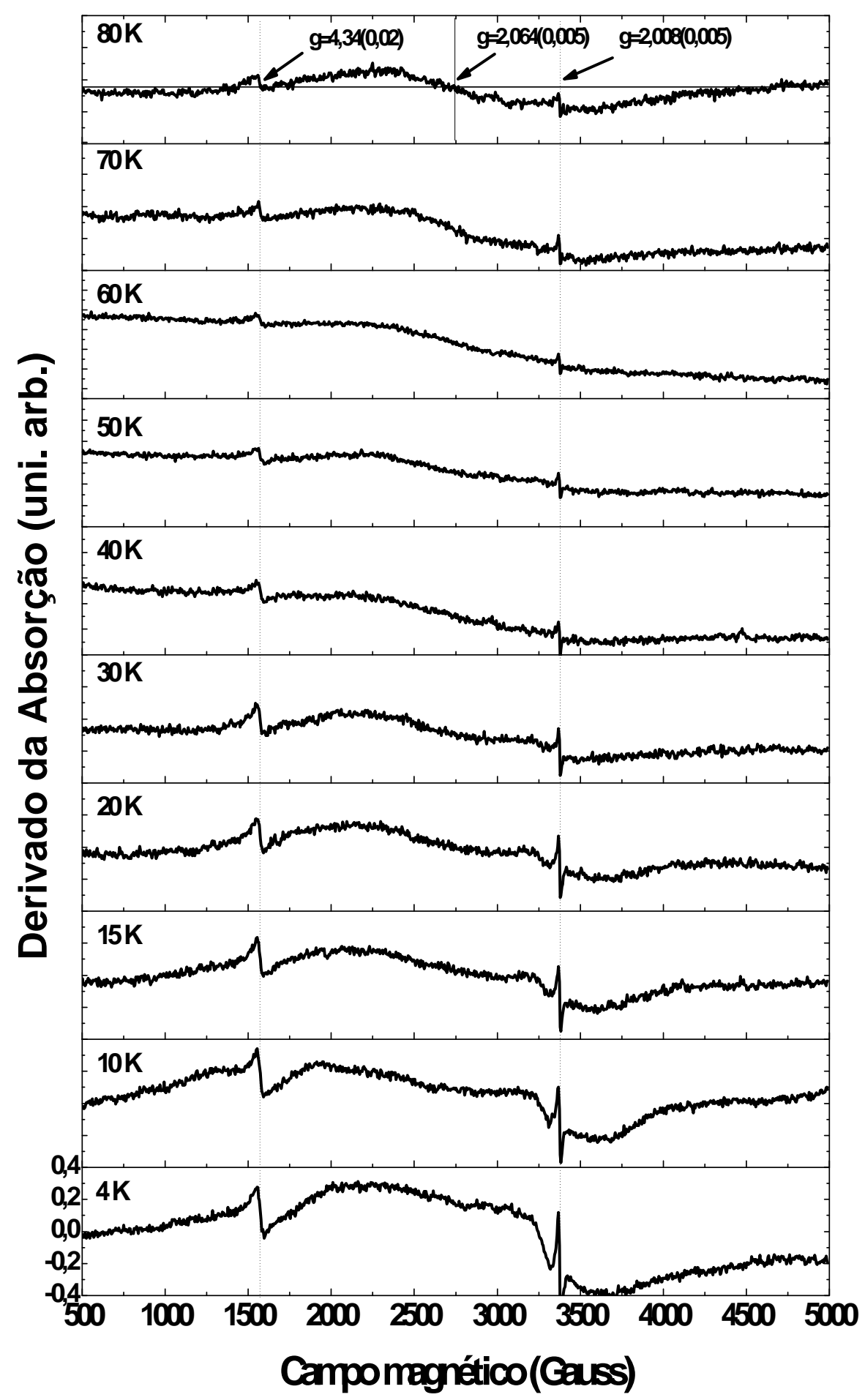

Figura 4.8: Espectros de RPE da amostra de $\mathrm{CeO}_{2}$ na faixa de temperatura de 4 até $80 \mathrm{~K}$. 
O comportamento magnético de nanopartículas de óxido de cério foi pesquisado experimentalmente mediante a técnica de RPE (Figuras 4.7 e 4.8). Neste estudo foi observado que nanopartículas de óxido de cério, sintetizadas após tratamento térmico à temperatura de $200^{\circ} \mathrm{C}$, com um diâmetro médio de $12,4 \pm 0,2 \mathrm{~nm}\left(R=\sqrt{5 / 3} R_{g}\right)$ apresentam comportamento ferromagnético em temperatura ambiente e mudanças do sinal ferromagnético são observadas com a variação de temperatura, vide Figuras 4.7 e 4.8. Os sinais de ferromagnetismo apresentados pelas nanopartículas de óxido de cério não se originam de impurezas magnéticas e não poderiam estar associadas a vacâncias de oxigênio [53]. No entanto, estudos baseados em cálculos de estrutura de bandas por primeiros princípios revelaram que vacâncias de oxigênio em dióxido de cério puro produzem polarização do spin de elétrons f para íons de cério rodeando vacâncias de oxigênio, resultando num momento magnético liquido para amostras puras de dióxido de cério [54]. Na literatura, o ferromagnetismo para nanoestruturas de óxido de cério, foi observado somente em nanoestruturas menores que $20 \mathrm{~nm}$ [53]. Uma vacância de oxigênio na superfície de nanopartículas menores que $20 \mathrm{~nm}$ pode induzir mais momentos magnéticos que aqueles induzidos mediante uma vacância de oxigênio no material massivo ou nanoestruturas maiores que $20 \mathrm{~nm}$. Portanto, o comportamento ferromagnético apresentado pelas nanopartículas de dióxido de cério, após tratamento térmico a $200^{\circ} \mathrm{C}$, é devido ao momento magnético liquido que é apresentado pelas nanopartículas à base de $\mathrm{CeO}_{2}$. De fato, para nanopartículas a contribuição das vacâncias de oxigênio na superfície é evidenciada pela maior porcentagem de átomos na superfície (em relação ao corpo) destas partículas diminutas.

\subsubsection{Síntese de nanopartículas de paládio metálico}

Cloreto de paládio $\left(\mathrm{PdCl}_{2}\right)$ foi dissolvido em álcool butílico, contendo o surfactante Renex® 95; foi usado um volume relativo de 5\% de Renex® 95 em relação ao volume do álcool butílico. Algumas gotas de $\mathrm{HCl}$ foram adicionadas até a verificação da solubilidade total do cloreto de paládio. A solução obtida foi aplicada na forma de filmes sob substratos de vidro pelo método de deposição por imersão e emersão com 
velocidade de emersão de $20 \mathrm{~cm} / \mathrm{min}$. Os filmes obtidos foram tratados termicamente na temperatura de $400^{\circ} \mathrm{C}$ sob atmosfera de ar livre e sob atmosfera de nitrogênio (neste caso atuando como atmosfera redutora) durante 30 minutos, a fase cristalina após o tratamento térmico dos filmes foi determinada mediante a técnica de DRX. Os difratogramas (Figura 4.9) revelaram que os filmes tratados termicamente sob atmosfera de ar apresentam a fase cristalina tetragonal correspondente ao óxido de paládio $(\mathrm{PdO})$, enquanto que o filme tratado termicamente sob atmosfera de $\mathrm{N}_{2}$ apresenta a fase cristalina cúbica correspondente ao paládio metálico $\left(\mathrm{Pd}^{\circ}\right)$.

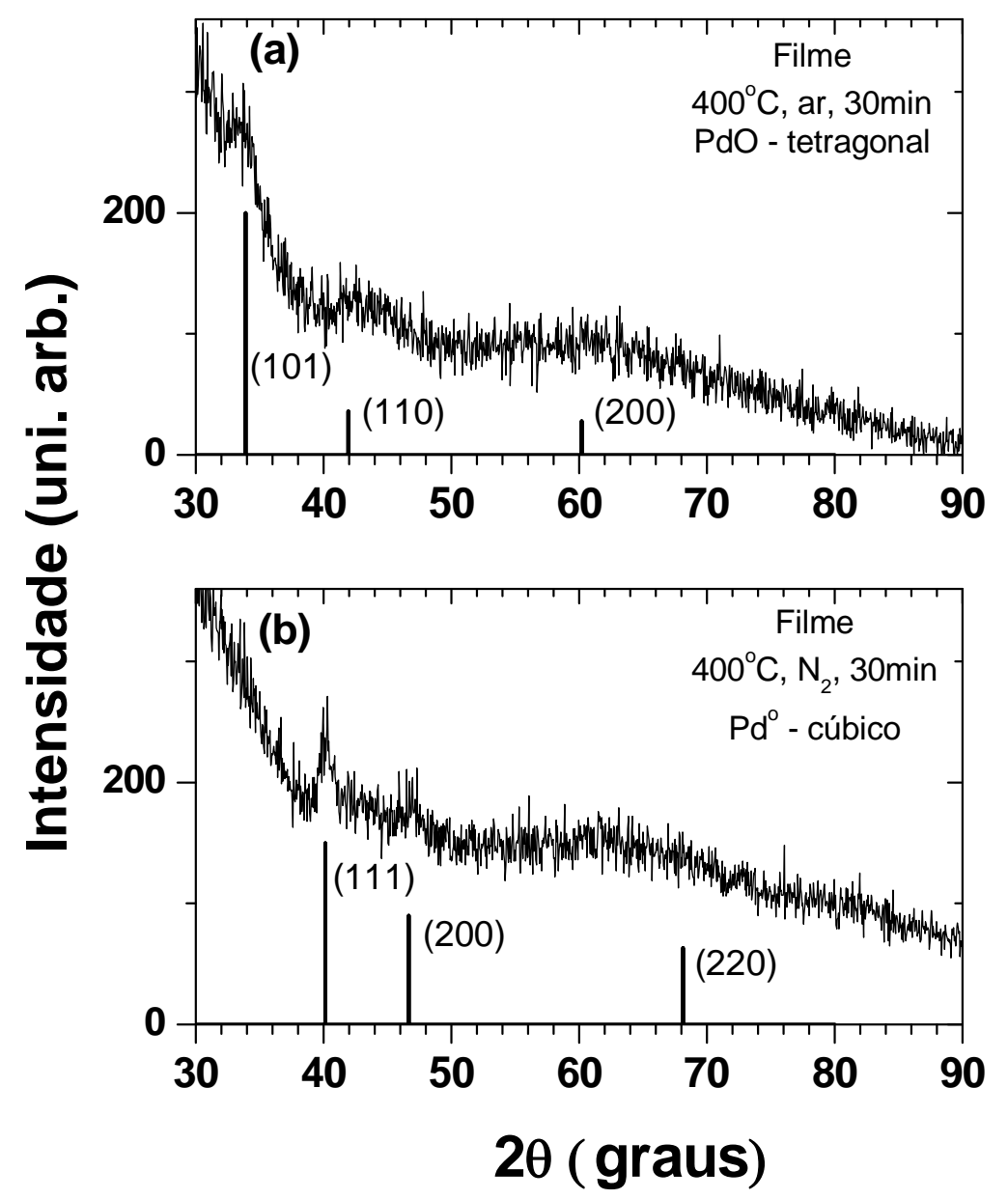

Figura 4.9: Difratogramas de raios $X$ da amostra na forma de filme após tratamento térmico à temperatura de $400^{\circ} \mathrm{C}$. (a) filme a base de $\mathrm{PdO}$ em atmosfera de ar e (b) filme a base de $\mathrm{Pd}^{\mathrm{o}}$ em atmosfera de $\mathrm{N}_{2}$. 
Uma vez garantidas as condições para a formação da fase desejada de $\mathrm{Pd}^{\circ}$, a solução de paládio foi depositada mediante impregnação por pintura do sol sobre o anodizado de alumínio para a formação de um filme, o anodizado foi tratado termicamente na estufa à temperatura de $70^{\circ} \mathrm{C}$ por um período de 15 minutos e em seguida submetido a tratamento térmico num forno à temperatura de $450^{\circ} \mathrm{C}$ por um período de 20 minutos sob atmosfera redutora de $\mathrm{N}_{2}$. $\mathrm{O}$ resultado do tratamento térmico permite obter filmes à base de nanopartículas de paládio depositados em anodizados de alumínio.

A aplicação de filmes à base de paládio nos pistões automotivos foi realizada seguindo o mesmo procedimento anterior, apenas o tratamento térmico foi modificado para $400^{\circ} \mathrm{C}$ para evitar alguma mudança de fase na liga a base de aluminio do pistão. Desta maneira foram obtidos pistões contendo filmes de paládio com propriedades catalíticas, também foi notada uma boa adesão do catalisador sobre a cabeça do pistão bem como o brilho característico do paládio metálico de metal branco prateado.

\subsection{Caracterização dos filmes à base de nanopartículas depositados sobre anodizado de alumínio}

\subsubsection{Resultados e discussões \\ 4.6.1.1. Difração de raios $X(D R X)$}

Os difratogramas de raios $\mathrm{X}$ obtidos dos catalisadores $\mathrm{Pd} / \mathrm{PdO}$ e do $\mathrm{CeO}_{2}$ formados após tratamento térmico dos pistões a $400{ }^{\circ} \mathrm{C}$ são mostrados nas Figuras 4.10 e 4.11 . A Figura 4.10 indica a formação de $\mathrm{CeO}_{2}$ (fcc).

\section{Nanopartículas a base de Dióxido de Cério}

Para verificar a cristalinidade, os filmes de nanopartículas suportados na matriz de alumina foram submetidos à análise de DRX. O difratograma de DRX do filme é mostrado na Figura 4.10. A identificação da fase cristalina foi realizada por comparação com a ficha cristalográfica PDF\#43-1002 (Cerianite). 


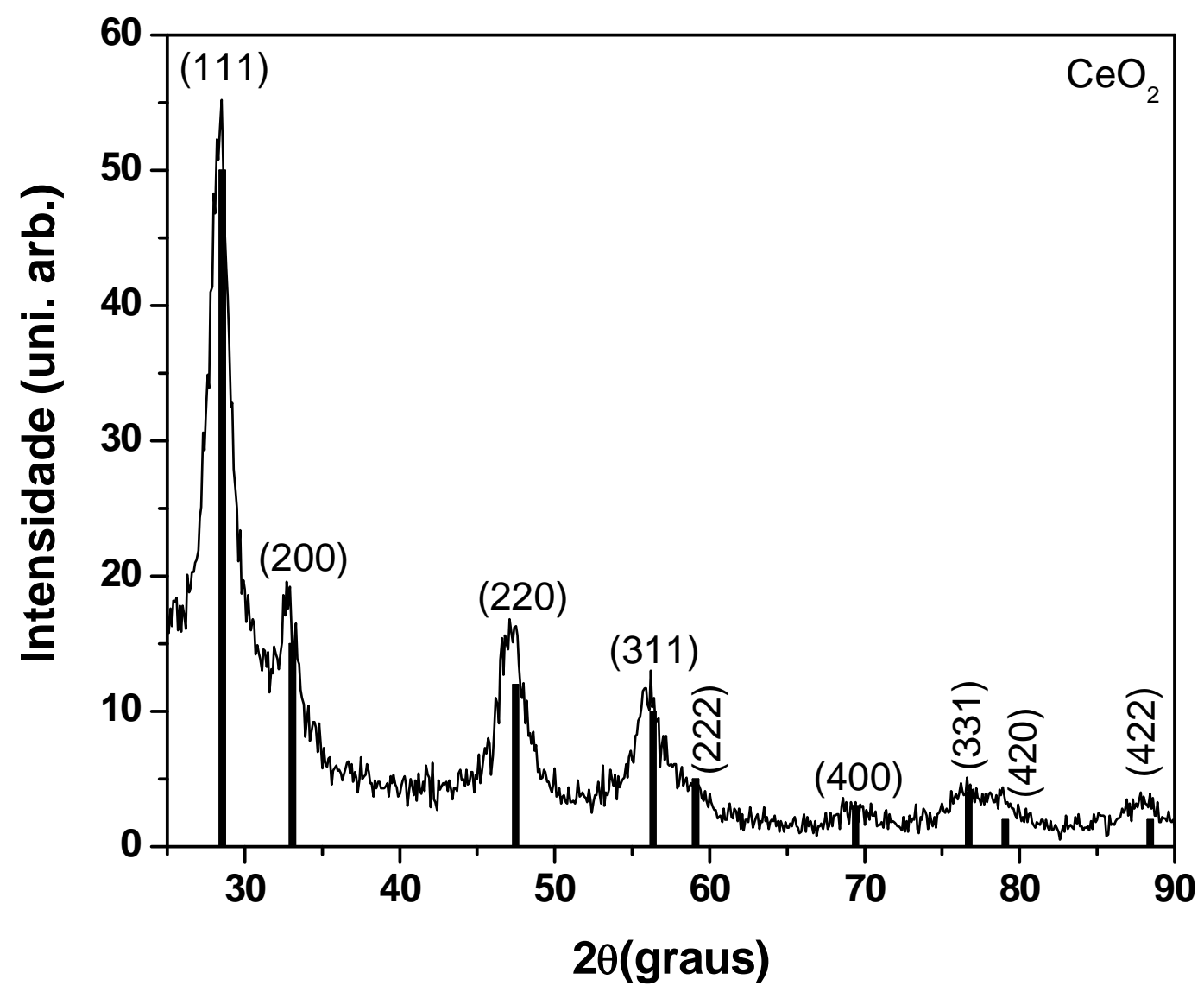

Figura 4.10: Difratograma de raios $\mathrm{X}$ do filme de nanopartículas de $\mathrm{CeO}_{2}$ suportado no anodizado de aluminio.

O filme de nanopartículas suportado na alumina mostra os picos de difração característicos do óxido de cério $\left(\mathrm{CeO}_{2}\right)$, conforme padrões da literatura. A amostra apresentou perfis com boa intensidade, indicando a cristalinidade da amostra, e característicos da estrutura tipo fluorita, do óxido de cério (IV). Não foram detectados picos relativos ao suporte de alumina e, nem foi observada difração de baixa intensidade nas posições dos ângulos de Bragg referentes a alumina, indicando que a espessura do filme de nanopartículas é maior que a profundidade de penetração dos raios X. Assim, a estrutura cristalina da alumina não é evidenciada no difratograma. Também é observada a ausência de outras fases indicando que a estrutura cristalina da fase $\mathrm{CeO}_{2}$ não sofreu alteração. Esta fase é estável e ativa na temperatura de funcionamento do motor automotivo favorecendo a ação catalítica. 


\section{Nanopartículas a base de Paládio}

Na Figura 4.11 é apresentado o difratograma de DRX do filme à base de nanopartículas de paládio obtidas mediante redução de óxido de paládio numa matriz de anodizado de alumínio. O perfil de difração de raios $\mathrm{X}$ é bastante semelhante ao de $\mathrm{PdO}$, indicando a formação da estrutura cúbica de face centrada (f.c.c). É difícil identificar a presença de picos de $\mathrm{Pd}^{\mathrm{o}}$ no difratograma da Figura 4.11. Isto é devido à baixa concentração de $\mathrm{Pd}^{\mathrm{o}}$ obtida pela redução de $\mathrm{PdO}$ formado na superfície do suporte na temperatura de tratamento térmico em atmosfera de nitrogênio num período determinado. No entanto, pequenos picos de $\mathrm{Pd}^{\mathrm{o}}$ são detectados. Embora os picos apresentem baixa intensidade, o resultado sugere a presença de $\mathrm{Pd}^{\mathrm{o}}$ no anodizado de alumínio. A partir dos difratogramas de DRX dos filmes no suporte foi possível observar a fase do óxido de paládio tetragonal, a identificação da fase cristalina foi realizada por comparação com a ficha cristalográfica PDF\#41-1107 (Paladinita).

Observaram-se perfis de difração de raios $X$ de intensidade baixa em $2 \theta=40,1$ e

46,6 $6^{\circ}$ característicos de Pd metálico cúbico ou espécies de Pd interagindo com o suporte, bem como picos de difração referentes ao suporte de alumina. Os resultados analisados sugerem que as nanopartículas de paládio metálico devem estar em baixas concentrações para serem detectadas mediante raios $X$, ou que as nanopartículas de paládio metálico estão bem dispersas na superfície do anodizado de alumínio [55]. A fase de óxido de paládio é instável e redutível na temperatura de funcionamento do motor automotivo favorecendo, portanto, a ação catalítica. 


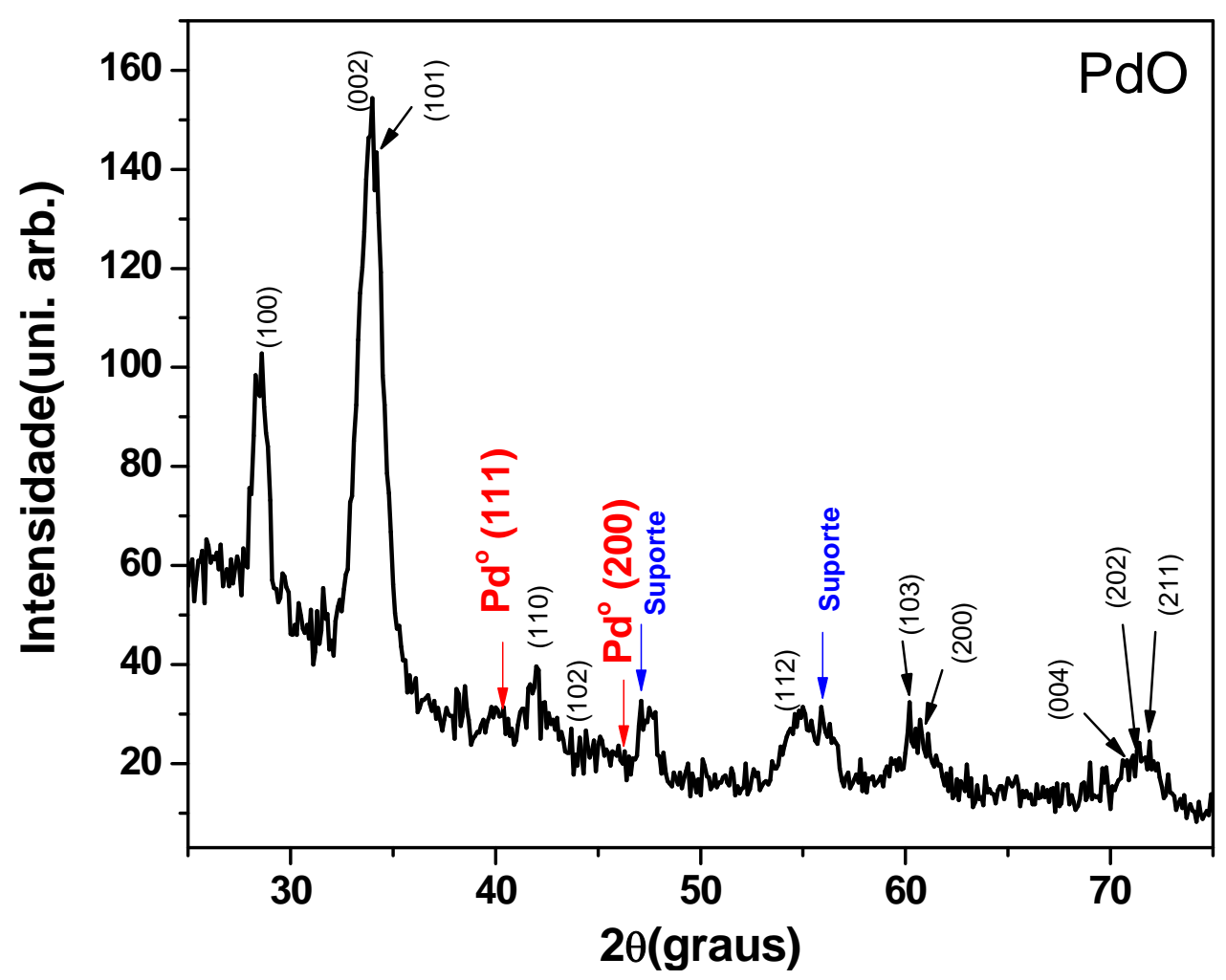

Figura 4.11: Difratogramas de raios $X$ do filme de paládio depositado sobre o anodizado de aluminio.

\subsubsection{Microscopia eletrônica de varredura (MEV) e espectroscopia de energia dispersiva (EDS)}

Com a finalidade de determinar a morfologia e a composição real dos filmes, previamente estabelecidos pela técnica de deposição sobre anodizados de óxido de alumínio, foram obtidas imagens de MEV e medidas de EDS. A morfologia das amostras foi determinada mediante um microscópio eletrônico de varredura marca 6460LV da Jeol, e as análises semi-quantitativas dos elementos com número atômico igual ou superior a 4 foram feitas por EDS acoplado ao microscópio eletrônico de varredura. Os resultados permitem verificar a homogeneidade e a composição do filme respectivamente. 
As micrografias eletrônicas de varredura para os filmes de paládio e céria apresentaram morfologia homogênea composta por aglomerados de partículas, os filmes contem fases amorfa e cristalina.

\section{Nanopartículas de Paládio}

As imagens do anodizado de alumínio e do filme de paládio obtidas por MEV estão apresentadas na Figura 4.12 e 4.13, respectivamente, as duas micrografias possuem a mesma escala, 1 um. Na imagem da Figura 4.13 é possível observar que o filme consiste em partículas nanométricas e aglomerados de partículas, caracterizando um sistema polidisperso.

Com o intuito de identificar os elementos presentes e estabelecer uma relação atômica entre eles, foram realizadas análises de EDS. A presença de paládio é confirmada por meio desta técnica, na Tabela 4.1 .

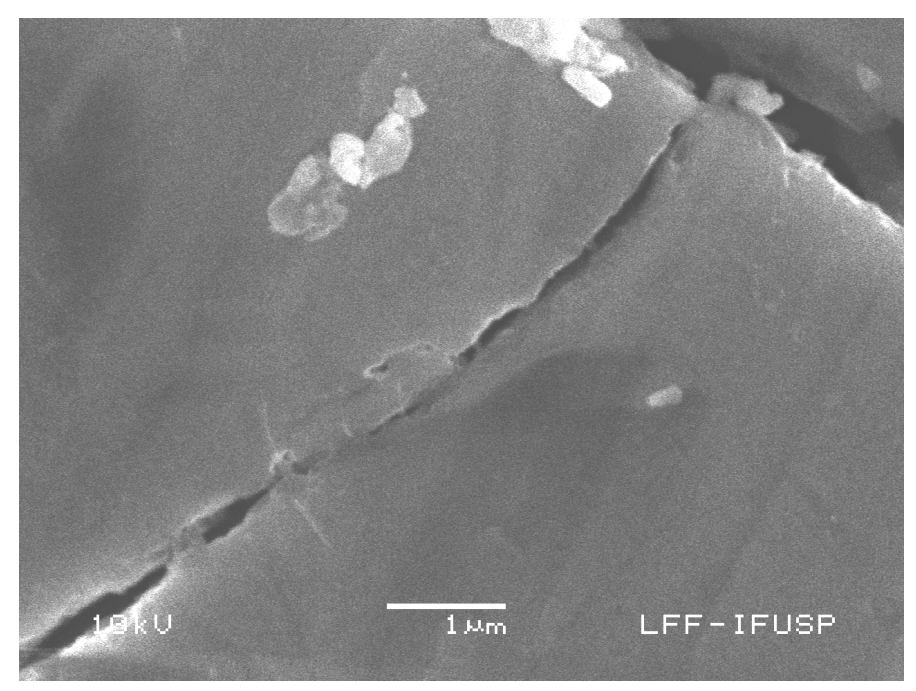

Figura 4.12: MEV do anodizado de alumínio. 


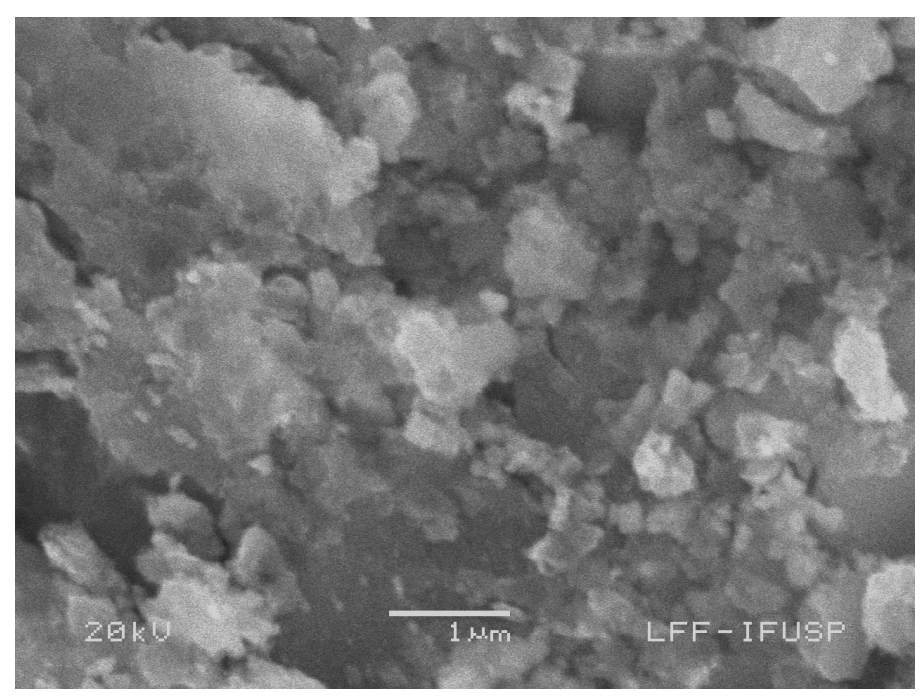

Figura 4.13: MEV do depósito de paládio no anodizado de alumínio.

A Tabela 4.1 mostra os resultados das composições elementares dos filmes obtidos pela técnica de EDS. As medidas foram efetuadas na região central dos filmes.

Tabela 4.1: Concentração de paládio na amostra determinada por EDS (\% at. Pd).

\begin{tabular}{lccc}
\hline Elemento & Contagens & Peso (\%) & Átomos(\%) \\
\hline Oxigênio & 2349 & 35,93 & 58,60 \\
Alumínio & 11366 & 24,46 & 23,65 \\
Silício & 3543 & 8,51 & 7,91 \\
Enxofre & 1486 & 3,88 & 3,16 \\
Paládio & 7161 & 27,22 & 6,67 \\
Total & & 100,00 & 100,00 \\
\hline
\end{tabular}

A análise por EDS permite a imediata identificação dos elementos químicos e o mapeamento da distribuição dos elementos por região do material, gerando mapas composicionais dos elementos desejados. Elas são consideradas quantitativas na região correspondente às micrografias, porém, para o filme como um todo, devemos considerála como semiquantitativa.

Através das análises dos elementos Pd e O por EDS não foi possível fazer uma avaliação da composição molecular dos filmes devido à interferência da composição elementar do anodizado de alumínio onde outros óxidos fazem parte de sua composição. 
De acordo com esses resultados foram encontradas as razões atômicas 0,61 e 0,53, que correspondem á composição $\mathrm{Pd}_{\mathrm{x}} \mathrm{O}$. Entretanto, a faixa da razão $[\mathrm{O}] /[\mathrm{Pd}]$ calculada, reflete a presença de partículas metálicas na superfície das partículas de PdO.

A análise por EDS confirmou a composição dos elementos químicos presentes nos filmes utilizados na síntese.

\section{Nanopartículas de Dióxido de Cério}

As micrografias por MEV do alumínio anodizado e do filme de céria sobre o anodizado são mostradas na Figura 4.14 e 4.15, respectivamente. $\mathrm{Na}$ imagem panorâmica da Figura 4.15, é possível observar o filme depositado sob o anodizado de alumina. A presença da céria no filme é confirmada por meio da análise de EDS, representado na Tabela 4.2 .

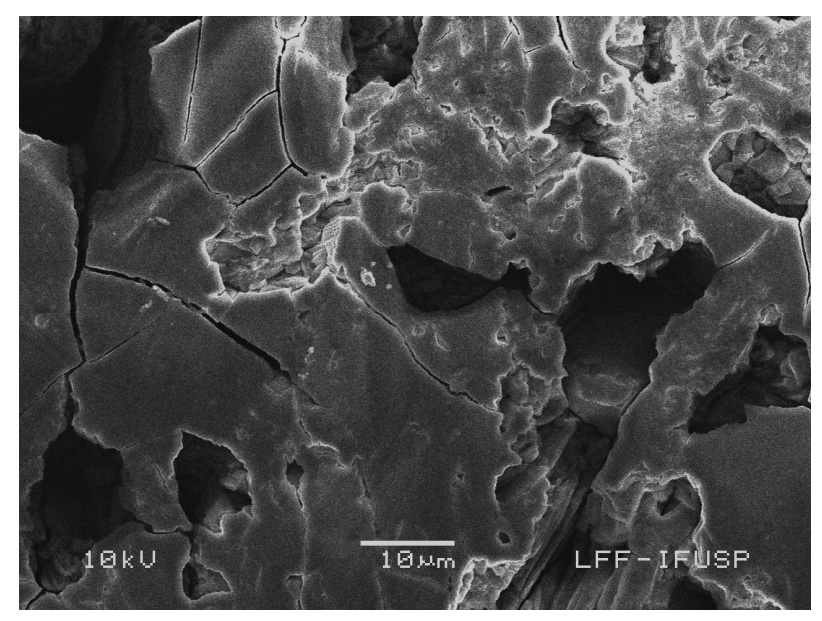

Figura 4.14: MEV do anodizado de alumínio. 


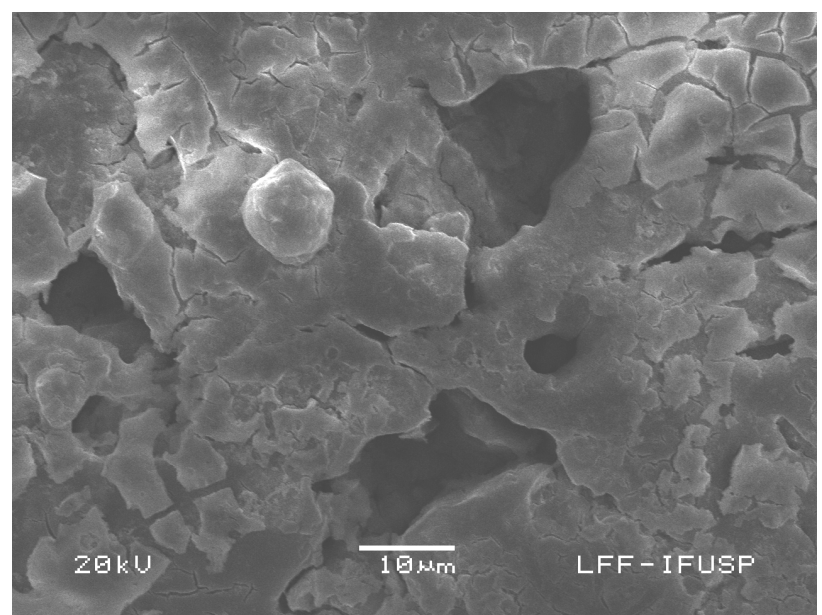

Figura 4.15: MEV do filme de céria depositado sob anodizado de alumínio.

A Tabela 4.2 mostra os resultados das composições do filme de céria obtido pela técnica de EDS. As medidas foram efetuadas na região central dos filmes.

Tabela 4.2: Concentração de cério na amostra determinada por EDS (\% at. Ce).

\begin{tabular}{lccc}
\hline Elemento & Contagens & Peso (\%) & Átomos(\%) \\
\hline Carbono & 182 & 11,23 & 19,00 \\
Oxigênio & 5874 & 42,06 & 53,41 \\
Alumínio & 14828 & 23,36 & 17,59 \\
Silício & 4789 & 8,36 & 6,05 \\
Enxofre & 1912 & 3,63 & 2,30 \\
Cério & 2068 & 11,36 & 1,65 \\
Total & & 100,00 & 100,00 \\
\hline
\end{tabular}

A análise por EDS permite a identificação imediata dos elementos químicos e o mapeamento da distribuição dos elementos que compõem o filme de céria

Através das análises dos elementos Ce e O por EDS não foi possível fazer uma avaliação da composição elementar dos filmes devido à interferência da composição elementar do anodizado de alumina.

Na micrografia observa-se na superfície do filme depositado a presença de trincas que podem ser provocadas por sinérise durante as últimas etapas de secagem do filme. Isto não é um fator limitante do processo de deposição deste catalisador sobre a 
superfície do anodizado pois a presença de trincas aumenta a área de superfície acessível ás moléculas que sofrerão transformações químicas por catálise.

\subsection{Filmes de nanopartículas de Céria e Paládio depositados na cabeça do pistão automotivo}

\subsubsection{A valiação do desempenho catalítico - Testes catalíticos}

A Volkswagen do Brasil, São Bernardo dos Campos, S.P., emprega pistões anodizados em ampla linha de motores $1000 \mathrm{~cm}^{3}$, com quatro cilindros e bicombustível. Neste ítem são mostrados alguns testes comparativos entre motor equipado com pistões anodizados (pistão de série) e motor equipado com pistões de série contendo filmes à base de óxido de cério e de paládio (pistão proposto). Estes testes foram realizados em motores de bancada e foi utilizado gasolina como combustível. Como proposto, nos interessam as evoluções, das emissões de escape e do consumo, em função da rotação (ou "giro") do motor. Informações mais detalhadas sobre os experimentos não foram divulgadas pela Volkswagen devido às estritas normas de sigilo industrial seguidas por esta fábrica.

A Figura 4.16 mostra a evolução da emissão de COV em função da rotação do motor. Pode-se notar que mesmo em regime de baixa rotação, menores que $1000 \mathrm{rpm}$, a concentração do COV produzida pelo motor equipado com pistões propostos é inferior àquela do motor de série. Para valores de rotação do motor maiores que $1000 \mathrm{rpm}$ a redução na emissão deste poluente é mais importante. A formação de COV está associada à combustão incompleta. Assim, partes não queimadas da molécula do combustível ou o rearranjo de hidrocarbonetos e de radicais são os representativos de COV. Em regime estacionário do motor, rotações entre 2000 e 3500 rpm, o pistão proposto apresenta a maior eficiência na diminuição de COV de aproximadamente $17 \%$ em comparação com pistão de série. 


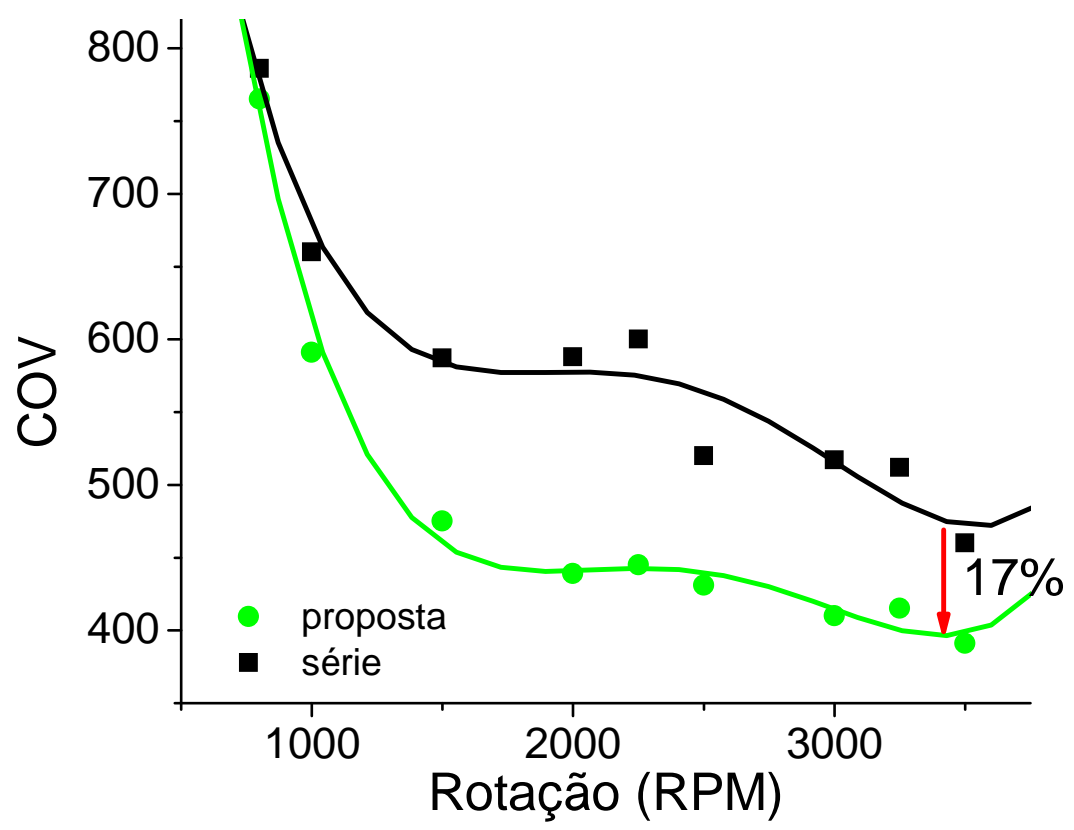

Figura 4.16: Concentração de COV (compostos orgânicos voláteis) para diversas rotações do motor.

A Figura 4.17 mostra a variação da concentração de $\mathrm{NO}_{\mathrm{x}}$ em função da rotação do motor equipado com pistões de série e equipados com pistões propostos. Neste gráfico observa-se que a concentração de $\mathrm{NO}_{\mathrm{x}}$ aumenta com a rotação do motor. Este comportamento é esperado pois para aumentar a rotação do motor é requerido maior admissão da mistura ar/combustível. Como maior volume de ar é aspirado, maior será a concentração de $\mathrm{N}_{2}$ na câmera de combustão. No entanto, o motor equipado com os pistões contendo os catalisadores propostos apresenta menor concentração de $\mathrm{NO}_{\mathrm{x}} \mathrm{em}$ todo intervalo de rotação estudado. Em regime estacionário (aproximadamente entre 2000 rpm e 3500 rpm) esta redução é de aproximadamente 8,8\%. 


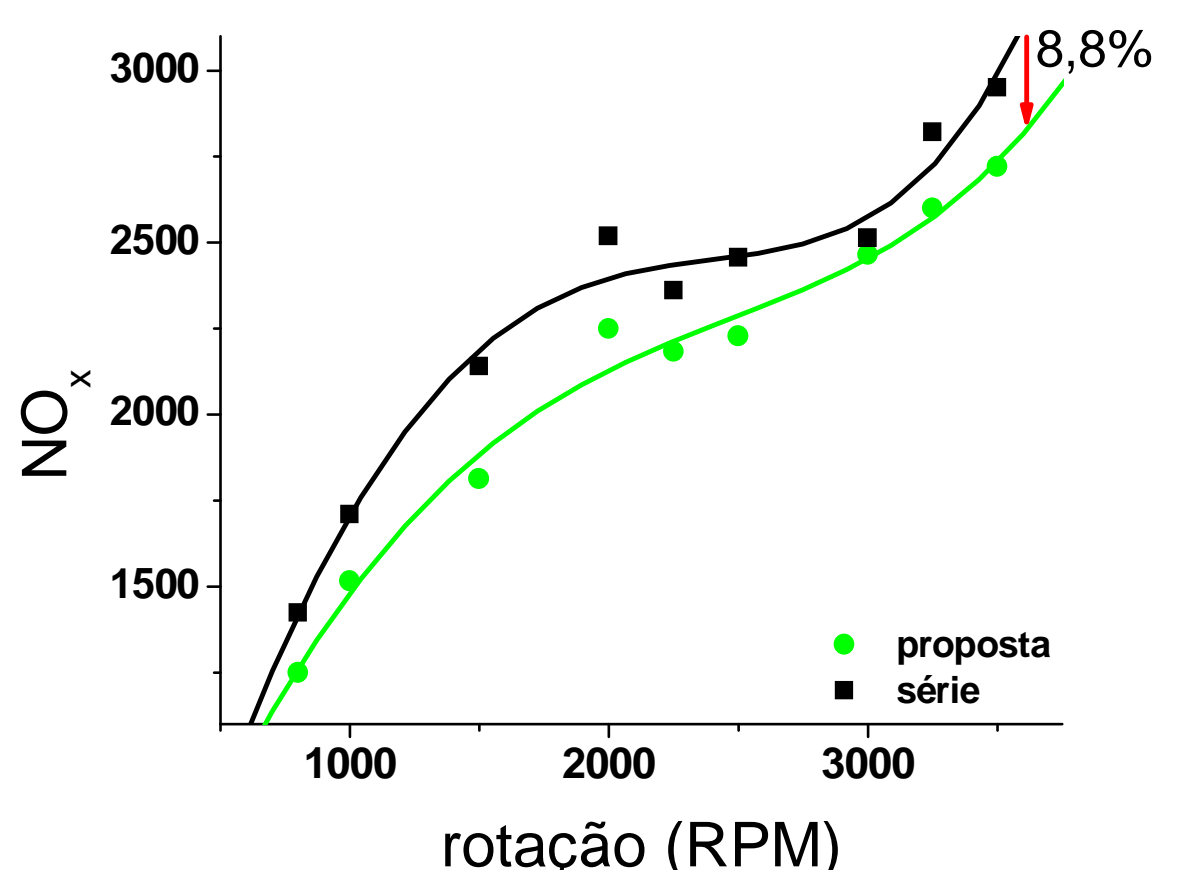

Figura 4.17: Concentração de $\mathrm{NO}_{\mathrm{x}}$ em função da rotação do motor.

A Figura 4.18 mostra a concentração de $\mathrm{CO}_{2}$ no escape do motor em função da rotação para os motores de série e equipados com pistões contendo os catalisadores propostos neste trabalho.

A emissão de $\mathrm{CO}_{2}$ em função das rotações mostra uma tendência decrescente, isto é verificado durante o intervalo de rotações do experimento, provavelmente devido ao aumento da temperatura do motor. É interessante notar que praticamente em todo regime de rotação verifica-se um aumento em torno de 2,4\% na emissão de $\mathrm{CO}_{2}$. Este aumento está associado à queima mais completa de combustível bem como à diminuição da emissão de monóxido de carbono. Estes dois fatores são dependentes entre sí: melhor queima resulta em menor produção de $\mathrm{CO}$. Ainda, o aumento da emissão de $\mathrm{CO}_{2}$ indica que mais energia foi liberada no tempo da explosão (mais trabalho é fornecido pelo motor). Além de ser uma gás menos tóxico que o $\mathrm{CO}$, o aumento da emissão $\mathrm{CO}_{2}$ pode estar associado a menor consumo de combustível. 


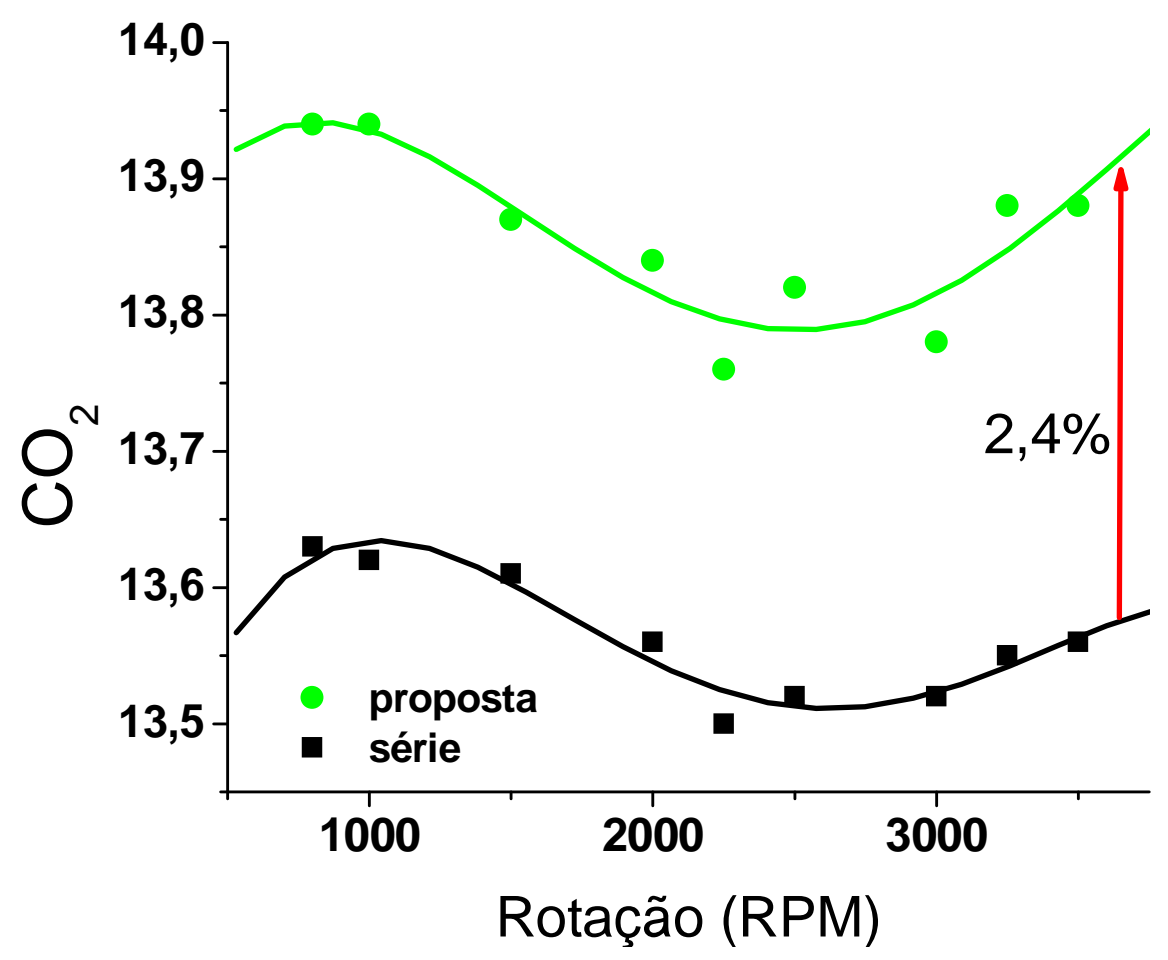

Figura 4.18: Concentração de $\mathrm{CO}_{2}$ em função da rotação.

Na Figura 4.19 é mostrado o consumo em função da rotação do motor teste equipado com pistões de série e equipados com pistões anodizados contendo filmes à base de nanopartículas de céria e paládio (proposto). Observa-se que as duas curvas seguem um comportamento similar. Para todo intervalo de rotação, o consumo do sistema proposto é menor em comparação ao sistema de serie. A diminuição relativa do consumo é de aproximadamente $4 \%$. 


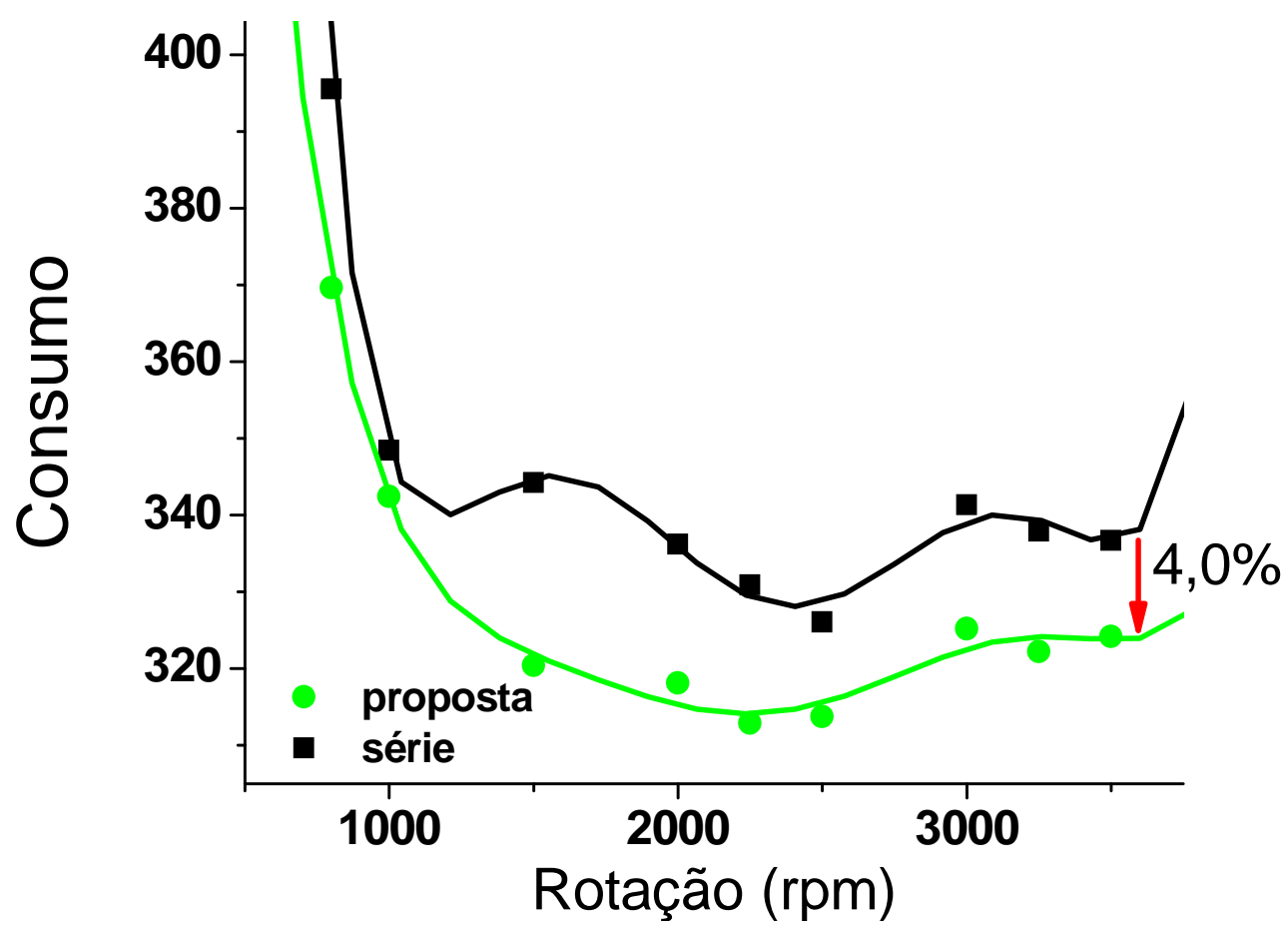

Figura 4.19: Consumo do motor em função da rotação.

Conforme proposto e verificado pelos resultados dos testes comparativos do efeito do pistão proposto no funcionamento do motor, o paládio mostrou-se um bom catalisador para queima do combustível. A presença de $\mathrm{CeO}_{2}$ no sistema torna o catalisador ativo em condições estacionárias do motor devido à alta mobilidade do oxigênio [56]. $\mathrm{O} \mathrm{Ce}_{2} \mathrm{O}_{3}$ promove a redução do $\mathrm{NO}_{x}$, oxidando-se, e promove a oxidação do $\mathrm{CO}$, reduzindo-se. Deste modo, o óxido de cério funciona como um doador ou aceptor de oxigênio que aumenta a atividade dos catalisadores estudados.

O sistema proposto mostrou-se eficiente na redução dos indices de CO, COV e NO. Isto se deve ao fato de que catalisadores baseados no Pd são bons catalisadores oxidantes e completamente ativos sob condições estequiométricas [57]. Nossos resultados indicam que a presença do $\mathrm{Ce}_{2} \mathrm{O}_{4}$ aumenta a habilidade do catalisador de $\mathrm{Pd}^{\mathrm{o}}$ sob condições deficientes de oxigênio. De fato, é bem estabelecido na literatura [56] que a mobilidade do oxigênio cumpre um papel importante nas propriedades catalíticas de materiais à base de óxido de cério. 
O resultado deste estudo mostra a eficiência de catalisadores sintetizados para a oxidação de $\mathrm{CO}$ e emissões de $\mathrm{COV}$ e $\mathrm{NO}_{\mathrm{x}}$ em condições estacionárias do funcionamento do motor. A eficiência dos catalisadores utilizados também se vê refletida na diminuição do consumo do automóvel para motores com catalisadores de $\mathrm{CeO}_{2}, \mathrm{PdO}$ e $\mathrm{Pd}^{\mathrm{o}}$ depositados na superfície da cabeça de pistões anodizados.

O desenvolvimento de uma nova geração de pistões automotivos apresenta vantagens ambientais e econômicas agregadas, em relação aos existentes no mercado. Os benefícios para o meio ambiente são refletidos na diminuição dos índices de emissões de poluentes como: NOx, $\mathrm{CO}$ e COV. O aumento no rendimento do motor automotivo, representado pela diminuição do consumo de gasolina, é um fator de impacto na política enérgicas mundial. 


\subsection{Referências Bibliográficas}

[1] Kaspar, J.; Fornasiero, P., Journal of Solid Chemistry, v.171, p. 19, 2003.

[2] Toyota Central R\&D Labs., Inc. Journal of Alloys and Compounds, v.408, p. 1061, 2006.

[3] Hadi, A.; Yaacob, I. I., Catalysis Today, v.96, p. 165, 2004.

[4] Heck, R.M.; Farrauto, R.J., Applied Catalysis A, v.221, p. 443, 2001.

[5] Neyestanaki, A.K.; Klingstedt, F.; Salmi, T.; Murzin, D.Y., Fuel, v.83, p.395, 2004.

[6] Thevenin, P.O.; Pocoroba, E.; Pettersson, L.J.; Karhu, H.; Vayrynen, I.; Jarás, S.G., Journal of Catalysis, v. 207, p. 139, 2002.

[7] Gandhi, H.S.; Graham, G.W.; McCabe, R.W., Journal of Catalysis, v.216, p. 433, 2003.

[8] Marecot, P.; Pirault, L.; Mabilon, G.; Prigent, M.; Barbier, J., Applied Catalysis B: Environmental, v.5, p. 57, 1994.

[9] Damyanova, S.; Perez, C.A.; Schmal, M.; Bueno, J.M.C., Applied Catalysis A: General, v.234, p. 271, 2002.

[10] Kaspar, J.; Fornasiero, P., Journal of Solid State Chemistry, v.171, p. 19, 2003.

[11] Bartholomew, C.H., Applied Catalysis A, v.212, p. 17, 2001.

[12] Kolli, T., Pd/Al2O3 Based automotive exhaust gás catalysts, Oulun Yliopisto, Oulu, 2006.

[13] Zotin, F.M.Z.; Noronha, F.B.; Appel, L.G, A Desativação Dos Catalisadores Automotivos, http://www.icp.csic.es/cyted/Monografias/Monografias1998/A4127.pdf.

[14] Figueiredo, J. L.; Ribeiro, F. R., Catalise heterogênea. Lisboa: Fundação Calouste Gulbenkian, p.352, 1989.

[15] Trimm, D.L., Catalysis Today, v.49, p. 3, 1999.

[16] Koltsakis, G.C.; Konstantinidis, P.A.; Stamatelos, A.M., Applied Catalysis B, v.12, p. 161, 1997.

[17] Hoebink, J.H.B.J.; Harmsen, J.M.A.; Balenovic, M.; Backx, A.C.P.M.; Schouten, J.C., Topics in Catalysis, v.16, p. 319, 2001.

[18] Taylor, K.C. Automobile catalytic converters, in: J.R. Anderson, M. Boudart (Eds.), Catalysis-Science and Technology, Springer, Berlin, Capítulo 2, p. 119, 1984.

[19] Kaspar, J.; Fornaseiro, P.; Hickey, N., Catalysis Today, v.77, p. 419, 2003.

[20] Lassi, U.; Polvinen, R.; Suhonen, S.; Kallinen, K.; Savimaki, A.; Harkonen, M.; Valden, M.; Keiski, R.L., Applied Catalysis B, v.263, p. 241, 2004.

[21] Shyu, J.Z.; Otto, K.; Watkins, W.L.H.; Graham, G.W.; Belitz, R.K.; Gandhi, H.S., Journal of Catalysis, v.114, p. 23, 1988.

[22] Skorodumova, N.V.; Ahuja, R.; Simak, S.I., Phys. Rev. B., v. 64, p. 115108, 2001.

[23] Tsunekawa, S.; Sivamohan, R.; Ito, S.; Kasuya, A.; Fukuda, T., Nanostruct. Mater., v.11(1), p. 141, 1999.

[24] Esch, F.; Fabris, S.; Zhou, L.; Montini, T.; Africh, C.; Fornasiero, P.; Comelli, G.; Rosei, R., Science, v.309, p. 752, 2005. 
[25] Tsunekawa, S.; Ito, S.; Kawazoe, Y., Appl. Phys. Lett., v.85, p. 3845, 2004.

[26] Zhou, K.; Wang, X.; Sun, X.; Peng, Q.; Li, Y., J. Catal., v.229, p. 206, 2005.

[27] Yang, Z.X.; Woo, T.K.; Baudin, M.; Hermansson, K., Journal of Chemical Physics, v.120, p. 7741, 2004.

[28] Deshpande, S.; Patil, S.; Kuchibhatla, S.; Seal, S., Applied Physics Letters, v.87, 2005.

[29] Patsalas, P.; Logothetidis, S.; Sygellou, L.; Kennou, S., Phys. Rev. B,v.68, p. 035104, 2003.

[30] Tsunekawa, S.; Fukuda, T.; Kasuya, A., Surface Science, v.457, p. L437, 2000.

[31] Twigg, M.V., Applied Catalysis B: Environmental, v.70, p. 2, 2007.

[32] Hadi, A.; Yaacob, I.I., Catalysis Today, v.96, p. 165, 2004.

[33] Graham, G.W.; O’Neill, A.E.; Chen, A.E., Applied Catalysis A: General, v.252, p. 437, 2003.

[34] Ozawa, M.; Hattori, M.; Yamaguchi, T., Journal of Alloys and Compounds, v.451, p. 621, 2008.

[35] Toyota Central R\&D Labs. Inc., Journal of Alloys and Compounds, v.408, p. 1061, 2006.

[36] Sharma, P.K.; Fischer, H.; Craievich, A.F., J. Am. Ceram. Soc., v.82 (4), p. 1020, 1999.

[37] Zhang, J.; Wu, Z.Y; Rong, L.X.; Dong, B.Z., Physica Scripta, v.T115, p. 661, 2005.

[38] Pajac, K.L.; Bierska-Picch, B.; Mrowiec-Bialón, J.; Jarzebski, A.B.; Diduszko, R., Fibres \& Textiles in Eastern Europe, v.13, No. 5(53), p. 69, 2005.

[39] Chiang, Y.M.; Lavik, E.B.; Kosacki, I.; Tuller, H.L.; Ying, J.Y., J. Electroceram., v. 11, p. 7, 1997

[40] Chiang, Y.M.; Lavik, E.B.; Kosacki, I.; Tuller, H.L.; Ying, J.Y., Appl. Phys. Lett. , v.69, p.185, 1996.

[41] Dufaux, M.; Che, M.; Naccache, C., Compt. Rend. C, v.268, p. 2255, 1969.

[42] Gideoni, M.; Steinberg, M., J. Solid State Chem., v.4, p. 370, 1972.

[43] Abi-Aad, E.; Bechara, R.; Grimblot, J.; Aboukais, A., Chem. Mater., v.5, p.793, 1993.

[44] Abi-Aad, E.; Bennani, A.; Bonnelle, J.P.; Aboukais, A., J. Chem. Soc., Faraday Trans., v.91, p. 99, 1995.

[45] Oliva, C.; Termignone, G.; Vatti, F.P.; Forni, L.; Vishniakov, A.V., J. Mater. Sci., v.31, p. 6333, 1996.

[46] Oliva, C.; Forni, L.; Ezerets, A.M.; Mukovozov, I.E.; Vishniakov, A.V., J. Chem. Soc., Faraday Trans., v.94, p. 587, 1998.

[47] Martinez-Arias, A.; Fernandez-Garcia, M.; Belver, C.; Conesa, J.C.; Soria, J., Catal. Lett., v.65, p. 197, 2000.

[48] Wertz, J.E.; Bolton, J.R., Electron Spin Resonance, Elementary Theory and Practical Applications, McGraw-Hill, New York, p.339, 1972.

[49] Sundaresan, A.; Bhargavi, R.; Rangarajan, N.; Siddesh, U.; Rao, C.N.R., Phys. Rev. B, v.74, p. 161306, 2006.

[50] Khare, N.; Kappers, M.J.; Wei, M.; Blamire, M.G.; MacManus-Driscoll, J. L., Adv. Mater., v. 18, p. 1449, 2006 
[51] Archer, P.I.; Gamelin, D.R., J. Appl. Phys., v.99, p. 08M107, 2006.

[52] Hong, N.H.; Sakai, J.; Huong, N.T.; Poirot, N.; Ruyter, A., Phys. Rev. B, v.72 ,p. 045336, 2005

[53] Liu, Y.; Lockman, Z.; Aziz, A.; MacManus-Driscoll, J., J. Phys.: Condens. Matter, v.20, p. 165201, 2008.

[54] Ge, M.Y.; Wang, H.; Liu, E.Z.; Liu, J.F.; Jiang, J.Z.; Li, Y.K.; Xu, Z.A.; Li, H.Y., Applied Physics Letters, v.93, p. 062505, 2008.

[55] Bogdanchikova, N.E.; Fuentes, S., Applied Catalysis B., v.17, p. 221, 1998.

[56] Hu, Z.; Wan, C.Z; Lui, Y.K.; Dettling, J.; Steger, J.J., Catal. Today, v.30, p. 83, 1996.

[57] Macabe, R.W.; Kisenyi, J.M., Chem. Ind., v.15, p. 605, 1995. 


\section{CAPÍTULO 5 - Nanopartículas a base de Hidroxiapatita}

Este capítulo descreve a síntese e caracterização de nanopartículas a base de hidroxiapatita (HAp), visando aplicações biomédicas na área da ortopedia e na ortodontia.

Neste trabalho apresentamos, primeiramente, os conceitos básicos necessários para uma melhor compreensão no estudo de nanopartículas de HAp. Em seguida, é proposta uma rota de síntese de HAp e a caracterização estrutural, térmica, morfológica, e magnética do material em estudo.

Apresentamos ainda, uma nova metodologia voltada à obtenção de soluções estáveis à base de nanopartículas biocompatíveis de HAp. Estas soluções foram caracterizadas pelas técnicas de SAXS e FTIR e, o xerogel, obtido pela evaporação do solvente, caracterizado por DRX.

\subsection{Introdução}

\subsubsection{Biomateriais}

Materiais utilizados na substituição ou complementação de um tecido do organismo, permanecendo por um período de tempo considerável, sem ter efeito nocivo são denominados biomateriais. Um material é biocompatível quando provoca no organismo reações desejadas, controladas e toleradas fisiologicamente [1]. Na substituição de tecidos, os biomateriais devem apresentar boa biocompatibilidade e devem ser não tóxicos, nem carcinogênicos ou radiativos, não-antigênicos e não-mutagênicos. Os biomateriais inertes, e aqueles que auxiliam na recuperação, são classificados como biotoleráveis e bioativos, respectivamente.

O desempenho de um implante é determinado pela resistência, integridade, qualidade superficial do material a ser implantado, segurança e durabilidade. Enquanto 
que, o nível de desgaste do implante, a ocorrência de fratura, a ocorrência de infecção e o desprendimento do implante contribuem para a falha do implante. Os biomateriais não se reproduzem no meio vivo celular e extracelular do osso. Para estimular a regeneração óssea são utilizados compostos osteogênicos de materiais porosos para o crescimento da matriz óssea (conhecidos como andaimes no campo da ortodontia) [2].

Biomateriais fabricados em laboratório, disponíveis no mercado, entre eles a HAp, tem aplicações ortopédicas e odontológicas tais como: reparos de defeitos ósseos, reparo de defeitos periodontais, aumento de rebordo alveolar, implantes auriculares e oftalmológicos, reconstrução maxilofacial, fusão espinhal, preenchimento de espaço ósseo, cimentos ósseos, compósitos e recobrimento de implantes.

Pesquisas atuais tentam desenvolver um biomaterial que tenha composição nanoestruturada e resposta biológica semelhante ao tecido ósseo natural [3]. Os ossos contêm macro e micro poros que são interconectados para permitir o transporte de fluidos e nutrientes para as células além de melhorar a resistência mecânica. Devido às propriedades físico-químicas, morfologia, estrutura, tipo e volume dos poros, estado da interface e taxa de degradação, uma cópia perfeita do material ósseo é quase impossível [4].

\subsubsection{Hidroxiapatita (HAp)}

A HAp, $\left(\mathrm{Ca}_{10}\left(\mathrm{PO}_{4}\right)_{6}(\mathrm{OH})_{2}\right)$, é um composto a base de cálcio e fosfatos, e é o principal constituinte mineral do osso natural, representando de 30 a $70 \%$ da massa dos tecidos ósseos e dentários. Doenças que atingem os ossos estão ligadas à sua deposição e à sua reabsorção pelo organismo. A HAp apresenta diferentes aplicações na área médica sendo utilizada como carregadora de drogas anticancerígenas para o tratamento de tumores ósseos [5, 6], como material de preenchimento em locais de reabsorção óssea devido a sua biocompatibilidade e osteointegração [7] e como recobrimento das superfícies metálicas de implantes ósseos e dentários favorecendo a osteointegração [8]. 
Este composto também é usado no tratamento de remoção de metais pesados em áreas poluídas e na análise de espectros de radicais $\mathrm{CO}_{2}$ ionizados.

A fórmula da HAp estequiométrica é $\mathrm{Ca}_{10}\left(\mathrm{PO}_{4}\right)_{6}(\mathrm{OH})_{2}$, com razão $\mathrm{Ca} / \mathrm{P}$ igual a 1,67. Porém composições estáveis podem ter esta razão estendida para aproximadamente $1,5[9]$.

Dois tipos de HAp devem ser consideradas: as sintetizadas em altas temperaturas e que apresentam boa cristalinidade e cristais grandes, e as HAp sintetizadas em baixas temperaturas que apresentam baixa cristalinidade e cristais pequenos. A HAp precipitada por via úmida possui características similares às do tecido ósseo e dentário, diferente da HAp sintetizada a altas temperaturas.

\subsubsection{Estrutura cristalina da HAp}

A HAp pertence ao sistema hexagonal [10,11], apresentando um sistema de coordenadas de seis eixos c formando ângulo de $90^{\circ}$ com três eixos a equivalentes ( $\mathbf{a}_{1}$, $\left.\mathbf{a}_{2}, \mathbf{a}_{3}\right)$, com ângulos entre si de $120^{\circ} \mathrm{C}$.

A cela unitária é formada por dez átomos de $\mathrm{Ca}$, seis tetraedros de $\mathrm{PO}_{4}$ e dois grupos de $\mathrm{OH}$, como mostrado na Figura 5.1. 


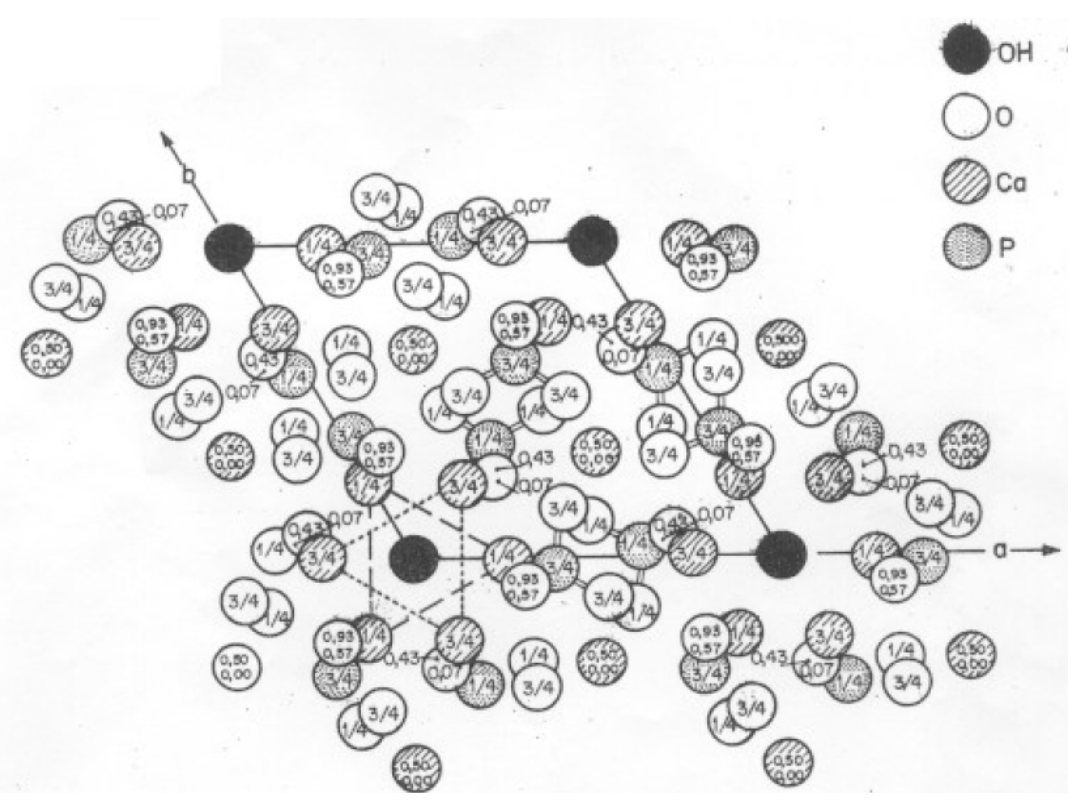

Figura 5.1: Cela unitária da HAp. Os íons de $\mathrm{OH}^{-}$localizados nos vértices da cela unitária estão rodeados por dois grupos de $\mathrm{Ca}^{2+}$ arranjados em um triângulo nas posições $\mathrm{z}=1 / 4$ e $\mathrm{z}=3 / 4$; por dois grupos de tetraedro de $\mathrm{PO}_{4}$ também arranjados em posições triangulares, e por um arranjo hexagonal de átomos de $\mathrm{Ca}^{+}$mais afastado $[12,13]$.

Os íons de $\mathrm{OH}$ localizados nos vértices da cela unitária estão rodeados por grupos de átomos de $\mathrm{Ca}(\mathrm{II})$ arranjados no padrão triangular em níveis $\mathrm{z}=1 / 4$ e $\mathrm{z}=3 / 4$; por dois grupos de tetraedros dispostos em ordem triangular em níveis $\mathrm{z}=1 / 4$ e $\mathrm{z}=3 / 4$ e por $\mathrm{um}$ arranjo hexagonal de átomos de $\mathrm{Ca}$. Os dez átomos são representados por $\mathrm{Ca}(\mathrm{I})$ e $\mathrm{Ca}(\mathrm{II})$; quatro átomos de $\mathrm{Ca}(\mathrm{I})$ ocupam posições em níveis $\mathrm{z}=0$ e $\mathrm{z}=1 / 2$; seis átomos de $\mathrm{Ca}(\mathrm{II})$ ocupam posições em níveis $\mathrm{x}=1 / 4$ e $\mathrm{x}=3 / 4$ em grupos de três.

Os grupos $\mathrm{OH}$ apresentam um arranjo linear de O-H-O-H, situado entre triângulos imaginários de cálcio, paralelo ao eixo c [12,13].

HAps minerais bem como HAps sintetizadas mediante o método de precipitação, sinterizadas a $1100^{\circ} \mathrm{C}$, apresentam a relação c/a igual a 0,7296 (Figura 5.2), enquanto que as constantes de rede valem $\mathbf{a}=\mathbf{b}=0,9422 \mathrm{~nm}$ e $\mathbf{c}=0,6880 \mathrm{~nm}[12,13]$. 


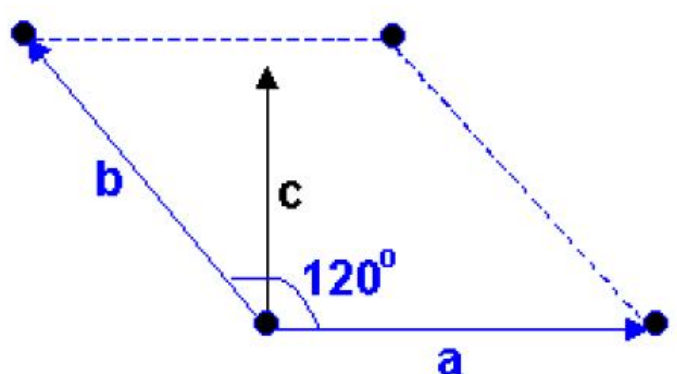

Figura 5.2: A figura mostra a forma de uma cela unitária hexagonal, onde os vetores a,b e c são os vetores primitivos.

\subsubsection{Estado de aglomeração das partículas}

O estado de aglomeração pode ser entendido como uma rede formada por partículas primárias interconectadas, com poros. As partículas são ligadas por forças superficiais maiores que a força da gravidade como forças eletrostáticas, de van der Waals, capilares [14] ou ligações fortes provenientes de processos de calcinação, fusão, reação química ou adição de um ligante. A aglomeração está relacionada com a área superficial que as partículas apresentam. Portanto, para nanopartículas existe maior tendência para a formação de aglomerados $[15,16]$. O controle da aglomeração é necessário pois a estabilidade de sóis sintetizados pode ser afetada. Deste modo, é necessário efetuar algumas etapas de processamento:

(i) A remoção de íons remanescentes da síntese: íons remansecentes absorvidos na superfície da partícula leva à aglomeração devido a atração por forças eletrostáticas entre partículas primárias e entre partículas e aglomerados. Os íons remanescentes podem ser eliminados através de diálise ou centrifugação seguida de lavagem.

(ii) A secagem por liofilização: A sublimação do solvente congelado evita a formação de aglomerado pois as forças capilares (devido à formação de um filme do solvente sobre as paredes dos poros) são extintas. 
(iii) O tratamento hidrotérmico é utilizado para obter partículas não aglomeradas, com estreita distribuição do tamanho de partícula [17,18].

A formação de aglomerados que pode ocorrer durante o processo de secagem das amostras pode ser evitado ou então criar uma distribuição estreita de aglomerados ou partículas através de técnicas como: sedimentação [19,20], moagem [21,22], ultra-som $[23,24]$ e agentes dispersantes $[25,26]$.

\subsection{Preparação da amostra e caracterização}

\subsubsection{Síntese de nanopartículas de HAp}

A síntese de partículas de HAp de tamanho nanométrico foi realizada utilizando o processo de coprecipitação, bem conhecido [27-29]. Este método consiste de uma mistura de fosfato de amônio e nitrato de cálcio. O método foi modificado através da utilização de surfactante na solução precursora da síntese. Hidróxido de amônio concentrado foi utilizado para manter estável o pH na mistura da reação.

Para a síntese de nanopartículas de HAp realizada neste trabalho, preparamos três soluções: A primeira solução foi preparada dissolvendo 11,808 g de nitrato de cálcio em $50 \mathrm{~mL}$ de água destilada deionizada. A segunda solução foi obtida dissolvendo 3,962 g de fosfato de amônio em $50 \mathrm{~mL}$ de água destilada deionizada. A terceira solução foi obtida diluindo 1,744 mL de hidróxido de amônio em $300 \mathrm{~mL}$ de água deionizada resultando num $\mathrm{pH}$ 10. Estas soluções foram preparadas à temperatura ambiente e mantidas sob agitação magnética. Na terceira solução foi diluído surfactante concentrado Renex 100 (nonilfenoletoxilado, Poli Brasil) resultando em 5\% de surfactante (em volume).

A solução de fosfato de amônio e a solução de hidróxido de amônio foram misturadas num bequer. A solução resultante foi vigorosamente agitada utilizando uma barra magnética. A reação de precipitação de HAp foi realizada pela adição lenta da 
solução de nitrato de cálcio sobre a solução de hidróxido de amônio numa razão de 4 $\mathrm{mL} / \mathrm{min}$ utilizando uma pipeta, sob forte agitação. A suspensão coloidal obtida foi mantida sob agitação durante um período de $12 \mathrm{~h}$ à temperatura ambiente $\left(\sim 25^{\circ} \mathrm{C}\right)$,

A precipitação da HAp, sob agitação magnética, é indicado pela equação [30]:

$10 \mathrm{Ca}\left(\mathrm{NO}_{3}\right)_{2}+6\left(\mathrm{NH}_{4}\right)_{2} \mathrm{HPO}_{4}+8 \mathrm{NH}_{4} \mathrm{OH}=\mathrm{Ca}_{10}\left(\mathrm{PO}_{4}\right)_{6}(\mathrm{OH})_{2}+6 \mathrm{H}_{2} \mathrm{O}+20 \mathrm{NH}_{4} \mathrm{NO}_{3}$.

O precipitado obtido foi lavado sucessivamente com água deionizada buscando-se eliminar ao máximo os íons remanescentes da reação (nitrato e amônio) na suspensão. A HAp precipitada foi lavada por cinco vezes repetindo-se as seguintes etapas: centrifugação para decantação do precipitado, descarte do sobrenadante e resuspensão em água deionizada.

Uma suspensão coloidal translúcida contendo $21,1 \mathrm{gL}^{-1}$ do material preparado é obtida. Pós finos são obtidos por meio de secagem desta suspensão a $60^{\circ} \mathrm{C}$ durante $6 \mathrm{~h}$ (este pó será chamado nos próximos parágrafos como HAp)

\subsubsection{Sóis a base de nanopartículas de HAp revestidas}

Preparou-se uma solução $8 \mathrm{mM}$ de ácido oléico em álcool isopropílico e uma solução a 5\% do surfactante Triton em água. Diferentes volumes da solução alcoólica de ácido oléico foram adicionadas a alíquotas de $2 \mathrm{~mL}$ do material sintetizado de HAp suspenso em água $(21,1 \mathrm{~g} / \mathrm{L})$. Os volumes da solução de ácido oleico adicionados a alíquotas foram: 0,25 mL (amostra S1), 0,50 mL (amostra S2), 0,75 mL(amostra S3), 1,00 mL(amostra S4) e 1,05 mL (amostra S5). Este processo foi realizado sob forte agitação a temperatura de $50{ }^{\circ} \mathrm{C}$ durante 5 min. Após este período é observada a flotação do sólido obtido, tornando o sobrenadante transparente. Este processo de separação do precipitado do solvente é observado quando a superfície das partículas tornam-se hidrofóbicas. Este fonômeno nos leva a crer que as partículas de HAp foram revestidas por moléculas de ácido oleico. As partículas revestidas (chamaremos como HApr como 
HAp revestida) foram separadas e secas a $40^{\circ} \mathrm{C}$ durante duas horas. $\mathrm{O}$ precipitado levemente seco pode ser ressuspenso em $2 \mathrm{~mL}$ da solução de Triton sob agitação magnética. Desta maneira sóis estáveis a base de HAp $(10,55 \mathrm{~g} / \mathrm{L})$ revestidas com ácido oléico podem ser obtidos.

\subsection{Resultados e discussões}

\subsubsection{Caracterização estrutural de nanopartículas HAp}

As fases cristalinas da HAp comercial (HAc) e da HAp sintetizada (HAp) foram determinadas por DRX.

As Figuras 5.3 e 5.4 mostram os resultados de DRX da HAp e HAc, respectivamente. Todos os picos nos dois padrões de difração correspondem à rede cristalina hexagonal de $\mathrm{Ca}_{10}\left(\mathrm{PO}_{4}\right)_{6}(\mathrm{OH})_{2}$. Pode-se observar em ambos os perfis que nenhuma outra forma cristalina, tal como fosfato de cálcio amido $\left(\mathrm{CaHPO}_{4}, \mathrm{DCPA}\right)$ ou $\beta$ fosfato tricalcio ( $\beta$-TCP), são detectados exceto HAp [15]. A largura e altura dos picos revela que a HAp é de tamanho nanométrico e de boa qualidade cristalina. No caso da amostra HApc, as linhas intensas e estreitas são atribuídas a partículas de tamanho micrométrico com alta qualidade cristalina. Para o caso da amostra HAp que é constituída de nanopartículas de HAp não foi possível a aplicação da formula de DebyeScherrer pois os picos de maior interesse para determinar o tamanho e forma dos cristalitos se apresentam superpostos aos perfis vizinhos. 


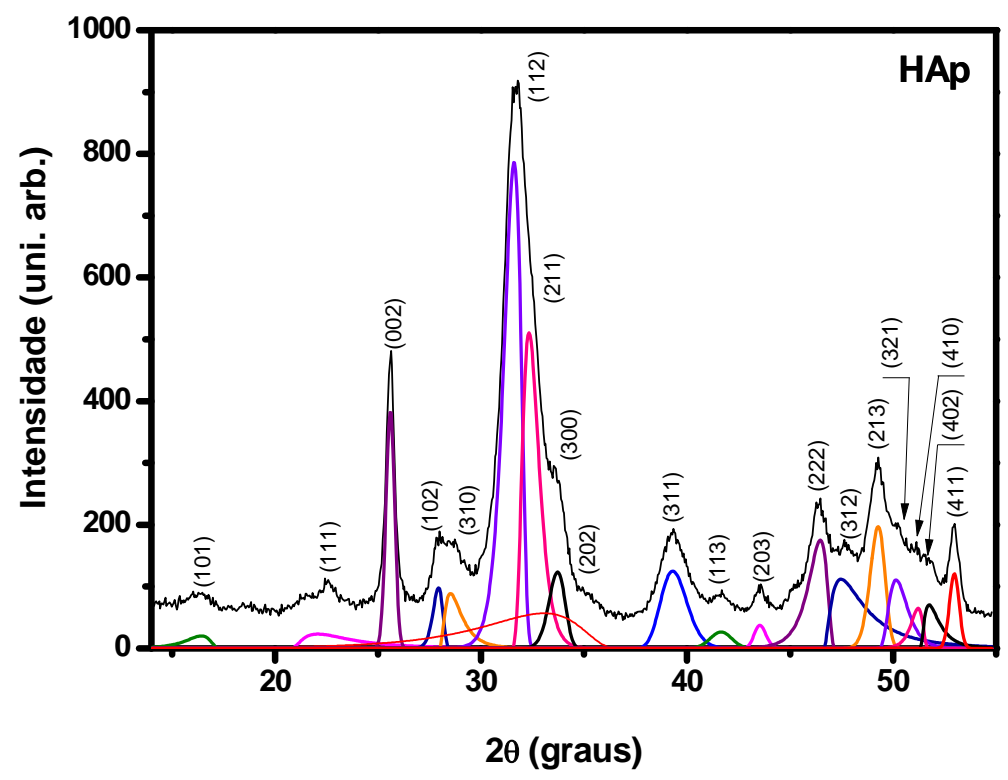

Figura 5.3: Dados de DRX da HAp sintetizada. Os índices (hkl) representam HAp padrão de acordo a JCPDS \# 721243. A intensidade (eixo-y) é em unidades arbitrárias.

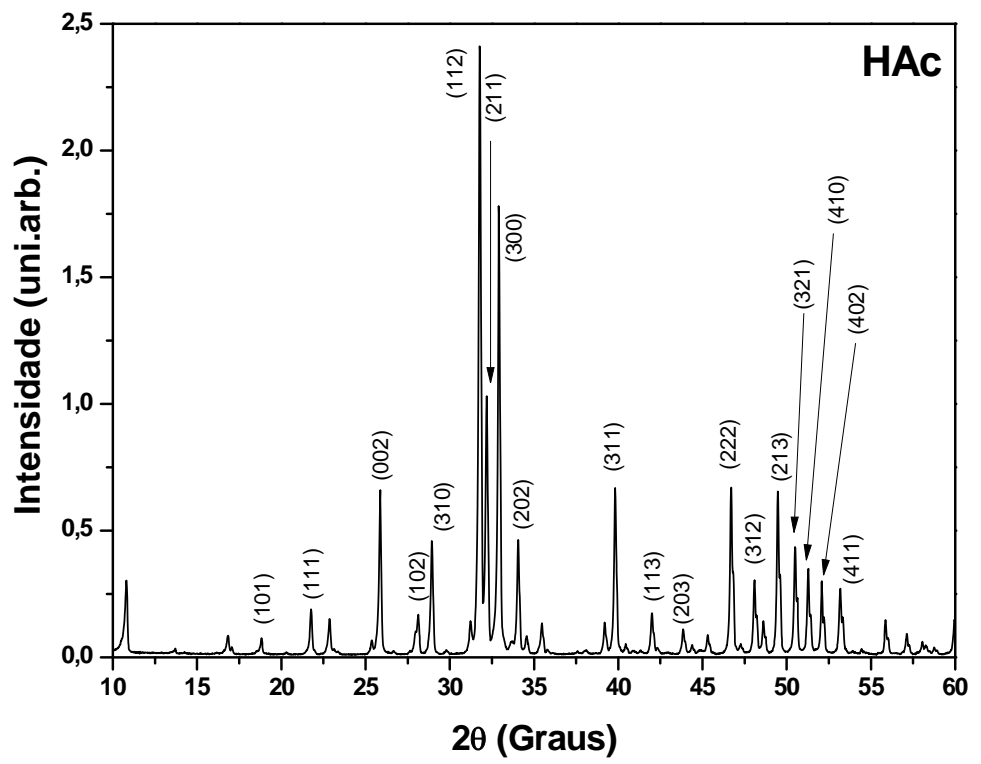

Figura 5.4: Resultados de DRX da HAp comercial. Os índices (hkl) representam HAp padrão de acordo a JCPDS \# 721243. A intensidade (eixo-y) é em unidades arbitrárias. 


\subsubsection{Calorimetria exploratória diferencial (DSC)}

Utilizou-se DSC com objetivo de pesquisar a degradação térmica da amostra do precipitado de nanopartículas de HAp.

Na Figura 5.5 é mostrada a curva de DSC da amostra do precipitado de nanopartículas de HAp sintetizada. No canto superior direito são mostrados os valores dos picos referentes às reações endotérmicos e o calor envolvido. A curva do sinal do fluxo de calor foi corrigida mediante a linha base. A curva de DSC não apresenta nenhum evento exotérmico na faixa de temperatura de $40^{\circ} \mathrm{C}$ até $600{ }^{\circ} \mathrm{C}$. A água absorvida é eliminada da amostra causando os picos endotérmicos em 64,5 (humidade) e $131,6{ }^{\circ} \mathrm{C}$ (água quimiosorvida ou desidratação da superfície pela reação entre grupos $\mathrm{OH}$ vizinhos), enquanto que o pico endotérmico em $192,2{ }^{\circ} \mathrm{C}$ é resultado da evaporação do surfactante. A transformação de HAp para fosfato de cálcio ocorre em $710^{\circ} \mathrm{C}$, não mostrado na Figura 5.5 por limitação do equipamento utilizado.

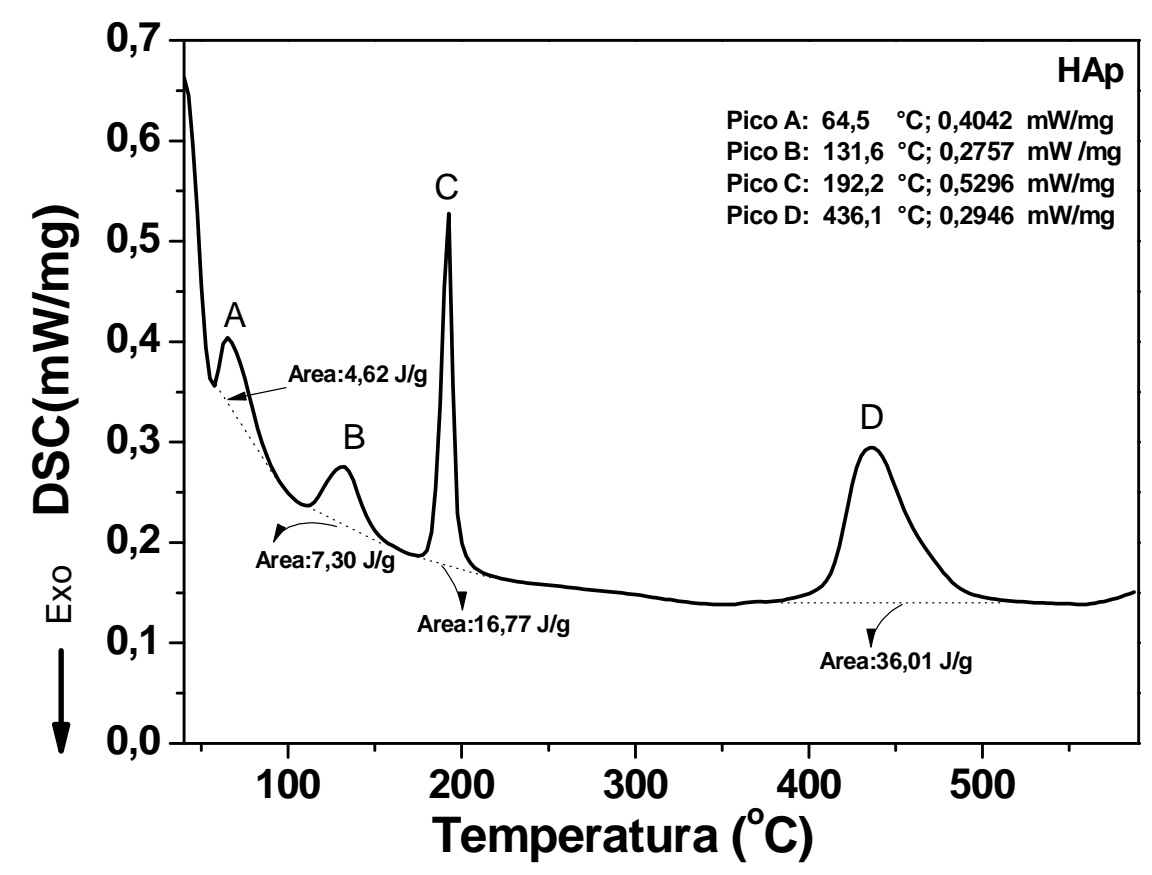

Figura 5.5: Curva de DSC para o precipitado de HAp. 


\subsubsection{FTIR da HAp sintetizada sem revestimento}

O espectro de FTIR, mostrado na Figura 5.6, corresponde ao precipitado seco de HAp, apresenta bandas características de grupos fosfato e hidroxila. A banda em 632 $\mathrm{cm}^{-1}\left(v_{\mathrm{b}} \mathrm{OH}\right)$ e $3571 \mathrm{~cm}^{-1}\left(v_{\mathrm{a}} \mathrm{OH}\right)$ é devida a uma vibração (estiramento) ("stretching”) confirmando a presença do íon hidroxila na rede da apatita. Água adsorvida também apresenta uma ampla banda na faixa de 3700-3500 $\mathrm{cm}^{-1}$ e, uma banda relativamente estreita em $1630 \mathrm{~cm}^{-1}$. Estas bandas estão sempre presentes em apatitas biológicas estabelecendo assim um relação de similaridade da HAp sintetizada em estudo com uma apatita biológica. A banda em $1385 \mathrm{~cm}^{-1}$ representa o estiramento de $\mathrm{NO}_{3}{ }^{-}$, esta banda está relacionada com os resíduos de $\mathrm{NO}_{3}{ }^{-}$utilizado como reagente de partida [31]. As bandas presentes em $1093 \mathrm{~cm}^{-1}, 1035 \mathrm{~cm}^{-1}$ e na faixa de $560-631 \mathrm{~cm}^{-1}$ enfatizam a presença de íons ortofosfato na rede cristalina da apatita [32].

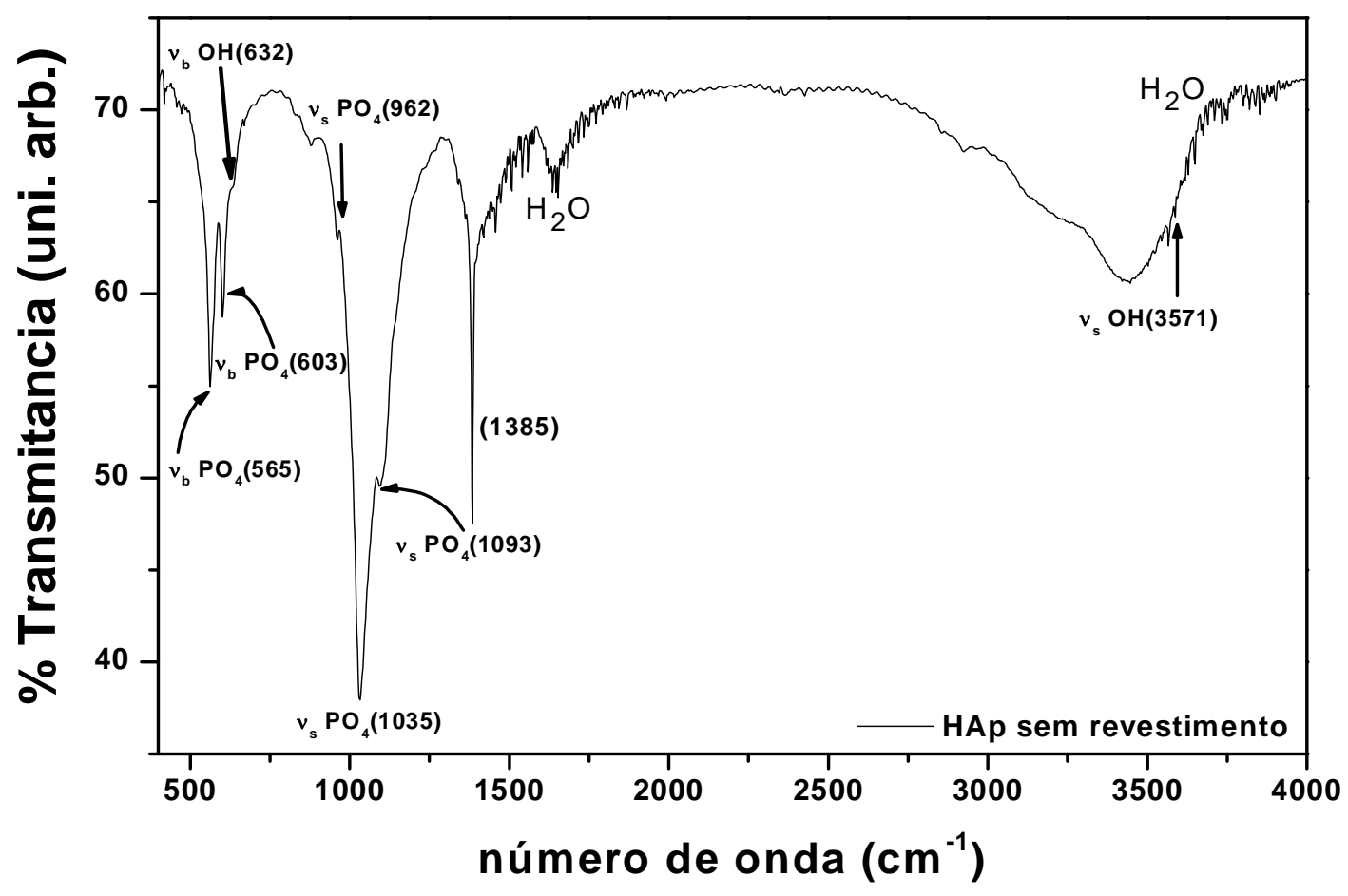

Figura 5.6: Espectro FTIR da amostra de HAp sem revestimento exibindo bandas características de grupos fosfato e hidroxila. 


\subsubsection{Sinterização}

As características químicas e estruturais da HAp possibilitam seu uso na área médica como material biocompatível em implantes e próteses. Aplicações incluem coberturas na forma de filmes em implantes dentários e ortopédicos [33].

Materiais à base de nanopartículas de HAp de tamanho nanométrico precisam ser estudados devido à sua maior bioatividade e biocompatibilidade, decorrentes de sua maior razão superfície/volume $\mathrm{O}$ controle do tamanho destas nanopartículas é alvo de estudo para o revestimento e depósito deste material em suportes metálicos (alumina, titânio, óxido de titânio, Aço) ou orgânicos (preenchimentos de ossos e dentes).

Assim, foram estudadas as evoluções de tamanho e da fase cristalina da HAp sintetizada com a temperatura de tratamento térmico. A Figura 5.7 mostra os difratogramas obtidos da amostra tratada termicamente a 110, 200, 400, 600, 800 e $1000^{\circ} \mathrm{C}$ durante 30 minutos. A sinterização foi realizada em ar.

Os difratogramas da Figura 5.7 evidenciam a cristalinidade das nanopartículas de HAp, os difratogramas obtidos nas temperaturas de 110, 200, 400 e $600^{\circ} \mathrm{C}$ apresentaram os picos mais intensos comparados ao difratograma da Figura 5.4. Para as amostras tratadas termicamente a 800 e $1000^{\circ} \mathrm{C}$, os difratogramas evidenciam uma transformação de fase da HAp correspondente a decomposição térmica. De fato, as amostras submetidas à estas temperaturas apresentaram picos correspondentes à estrutura cristalina do fosfato tricalcio $\left(\mathrm{Ca}_{3}\left(\mathrm{PO}_{4}\right)_{2}\right.$, Whitlockite, PDF\# 09-0169). Esta mudança de fase acontece na faixa de temperatura entre 600 e $800^{\circ} \mathrm{C}$ e está relacionada à perda de água estrutural (água que faz parte da estrutura da HAp) e reestruturação do fosfato. Esta mudança de estrutura cristalina nesta faixa de temperatura explica a ausência de picos exotérmicos na medida de DSC. Medidas de DSC indicam uma transição de estado sólido em torno de $757^{\circ} \mathrm{C}$ [34]. A nova fase que aparece nesta temperatura corresponde à formação inicial de $\mathrm{Ca}_{3}\left(\mathrm{PO}_{4}\right)_{2}$. A principal fase em $750^{\circ} \mathrm{C}$ é ainda a fase de HAp. 


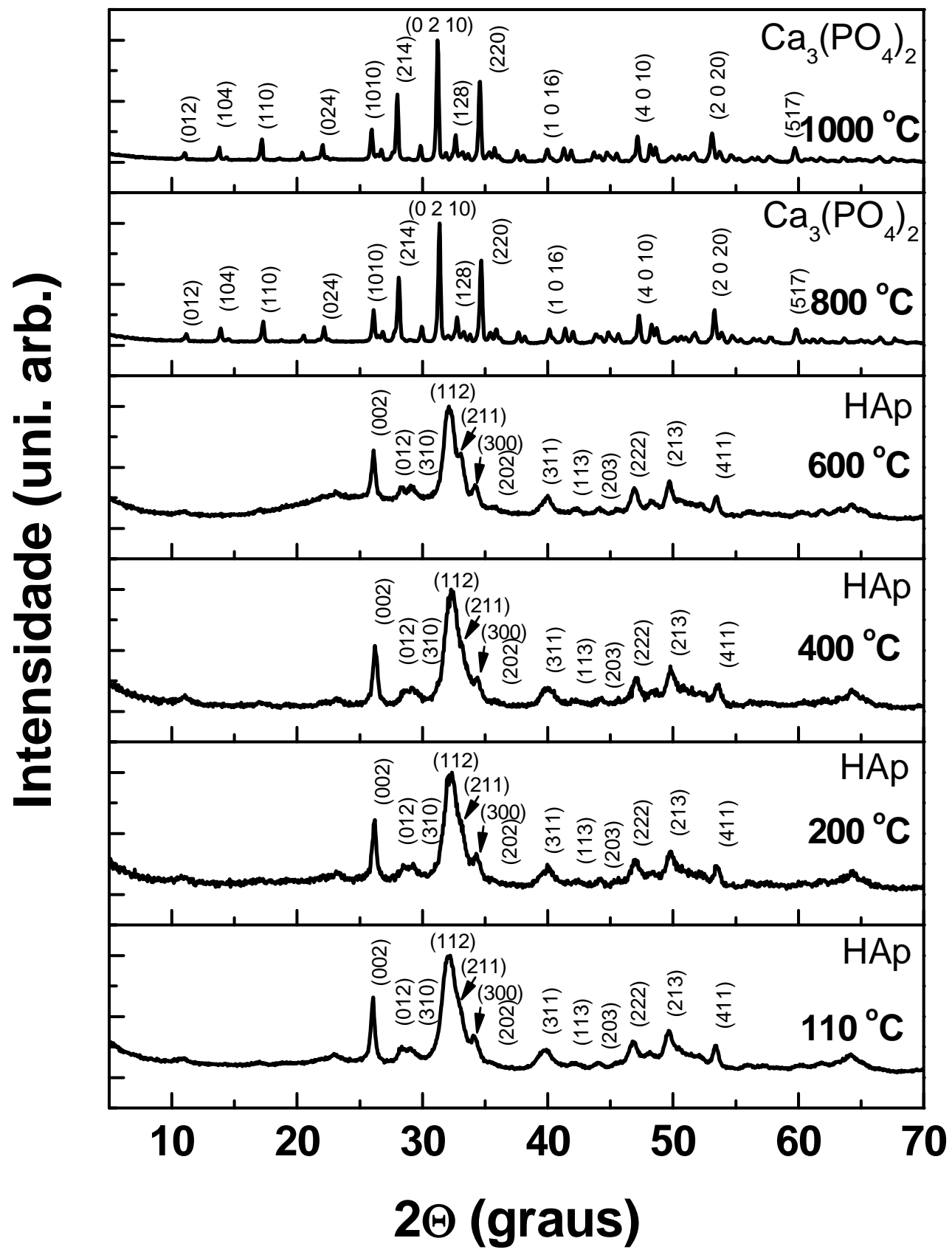

Figura 5.7: Perfil de DRX da HAp mostrando o grau de cristalinidade da amostra sintetizada e submetida a tratamento térmico em diferentes temperaturas $(110,200,400$, 600,800 e $\left.1000{ }^{\circ} \mathrm{C}\right)$. 
Quando o pó de HAp é aquecido a $1000^{\circ} \mathrm{C}$ por 30 minutos, exibe alta cristalinidade. $\mathrm{O}$ perfi de difração de raios $\mathrm{X}$ desta amostra apresenta estrutura do tipo $\mathrm{Ca}_{3}\left(\mathrm{PO}_{4}\right)_{2}$, resultante da decomposição da HAp. A transformação parcial de HAp em $\beta$-tricalcio fosfato depende da quantidade de defeitos de cálcio na estrutura cristalina da HAp.

A sinterização da amostra produz mudanças da estrutura e no crescimento das nanopartículas. Isto pode ser observado na Figura 5.8 e na Figura 5.9.

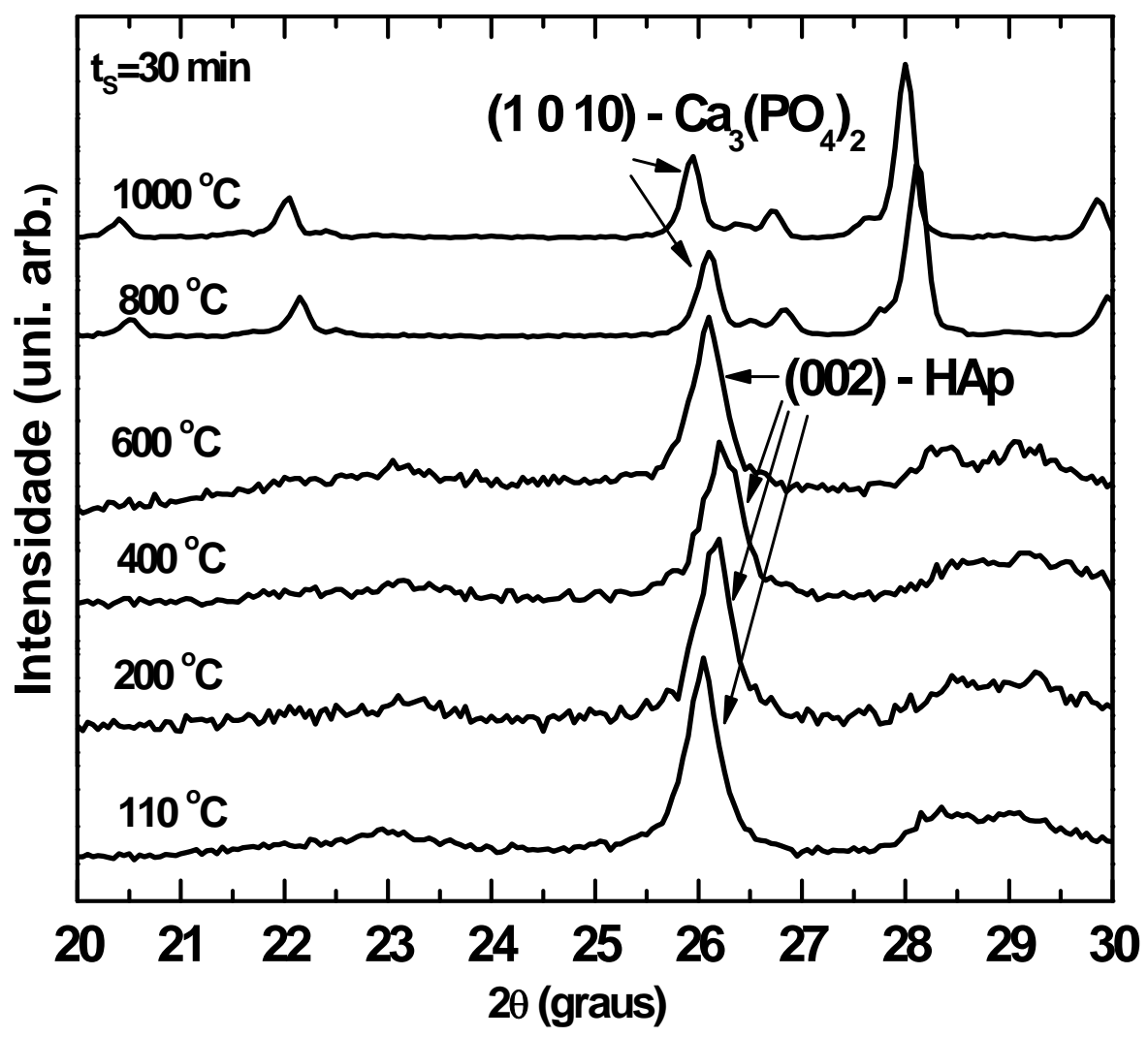

Figura 5.8: Evolução dos perfis de DRX no plano cristalográfico (002) da HAp e (1 0 10) do $\mathrm{Ca}_{3}\left(\mathrm{PO}_{4}\right)_{2}$ com a temperatura de sinterização durante 30 minutos.

A Figura 5.8 mostra a variação da largura dos perfis, em torno de $26^{\circ}$, correspondentes às direções cristalinas (002), para a HAp, e (1 0 10), para o $\left.\mathrm{Ca}_{3}\left(\mathrm{PO}_{4}\right)_{2}\right)$. O mesmo comportamento é verificado na Figura 5.9. Neste caso, foram estudadas as 
direções (311), para a HAp, e (1 0 16), para o $\mathrm{Ca}_{3}\left(\mathrm{PO}_{4}\right)_{2}$. Nestas figuras observa-se uma mudança drástica na largura dos picos para as temperaturas superiores a $600{ }^{\circ} \mathrm{C}$.

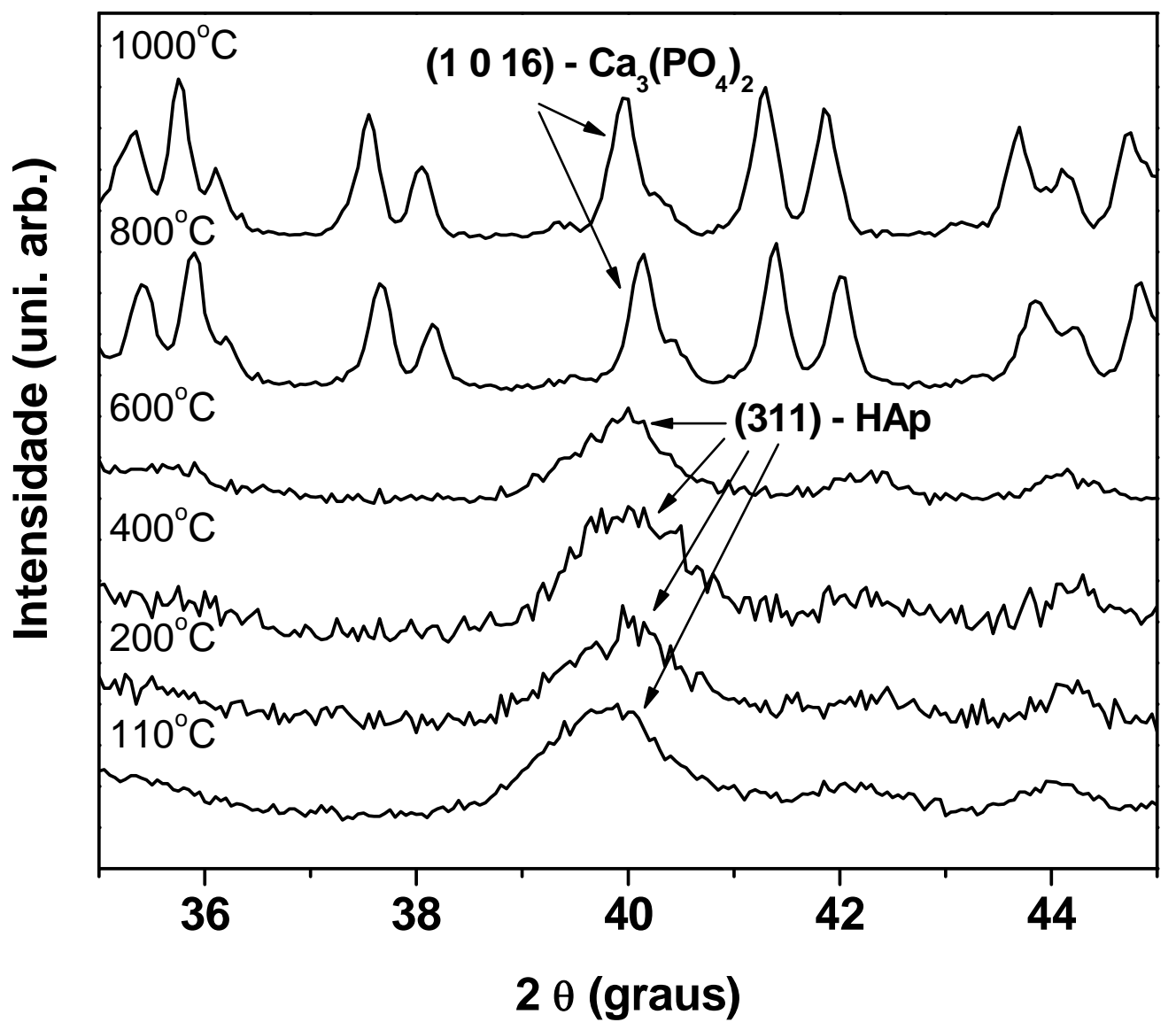

Figura 5.9: Evolução dos perfis de difração de raios $X$ no plano cristalográfico (311) e (1 0 16) com a temperatura de sinterização durante 30 minutos.

O diâmetro médio das partículas foi calculado pela formula de Scherrer aplicada aos picos isolados correspondentes às direções cristalinas (002) e (311), para HAp, e (1 0 10) e $\left(\begin{array}{lll}1 & 0 & 16\end{array}\right)$, para $\mathrm{Ca}_{3}\left(\mathrm{PO}_{4}\right)_{2}$ obtido a altas temperaturas. A Tabela 5.1 mostra os valores calculados de $\beta$ (largura a meia altura), $2 \theta$ (o ângulo de Bragg) e T (a temperatura de sinterização). 
Tabela 5.1: Parâmetros resultado da análise dos perfis de DRX dos planos (002) e (311) para HAp e (1 0 10) e (1 0 16) para $\mathrm{Ca}_{3}\left(\mathrm{PO}_{4}\right)_{2}$.

\begin{tabular}{|c|c|c|c|c|c|c|}
\hline $\mathrm{T}\left({ }^{\circ} \mathrm{C}\right)$ & $2 \theta\left(^{\circ}\right)$ & $\beta_{(1010)}\left({ }^{0}\right)$ & $D_{\left(\begin{array}{lll}1 & 0 & 10\end{array}\right)}(\mathrm{nm})$ & $2 \theta\left(^{0}\right)$ & $\beta_{(1016)}\left(^{0}\right)$ & $D_{(1016)}(\mathrm{nm})$ \\
\hline 1000 & 25,94 & 0,306 & 114 & 39,97 & 1,153 & 20 \\
\hline \multirow[t]{2}{*}{800} & 26,09 & 0,306 & 113 & 40,16 & 1,153 & 20 \\
\hline & & $\beta_{(002)}\left({ }^{0}\right)$ & $\mathbf{D}_{(002)}(\mathrm{nm})$ & $2 \theta\left(^{0}\right)$ & $\beta_{(311)}\left({ }^{0}\right)$ & $D_{(311)}(n m)$ \\
\hline 600 & 26,09 & 0,342 & 129 & 40,00 & 0,210 & 115 \\
\hline 400 & 26,22 & 0,267 & 147 & 40,00 & 0,395 & 58 \\
\hline 200 & 26,22 & 0,307 & 112 & 39,97 & 0,612 & 38 \\
\hline 110 & 26,06 & 0,311 & 112 & 39,91 & 0,970 & 24 \\
\hline
\end{tabular}

Na Figura 5.10 é mostrada a evolução do tamanho médio de cristalitos nas direções [002] e [311] para HAp e [ $\left[\begin{array}{lll}1 & 0 & 10\end{array}\right]$ e $\left[\begin{array}{lll}1 & 0 & 16\end{array}\right]$ para $\mathrm{Ca}_{3}\left(\mathrm{PO}_{4}\right)_{2}$. Neste gráfico observa-se o crescimento dos cristalitos com o aumento da temperatura de tratamento térmico para valores inferiores a $800{ }^{\circ} \mathrm{C}$ para ambas direções estudadas. Entretanto verifica-se um crescimento anisotrópico de cristalitos para as direções estudadas, ou seja, cristalitos na direção [311] apresentam crescimento maior em relação à direção [002]. Para valores maiores que $800^{\circ} \mathrm{C}$, observa-se que para o $\mathrm{Ca}_{3}\left(\mathrm{PO}_{4}\right)_{2}$ o diâmetro médio para as direções estudadas permanece praticamente constante. Para temperaturas de tratamento térmico superiores a $800^{\circ} \mathrm{C}$, não foi observado o crescimento de cristalitos calculados para as direções [lllll 010$]$ e $\left[\begin{array}{lll}1 & 0 & 16\end{array}\right]$ referentes ao trifosfato de cálcio. 


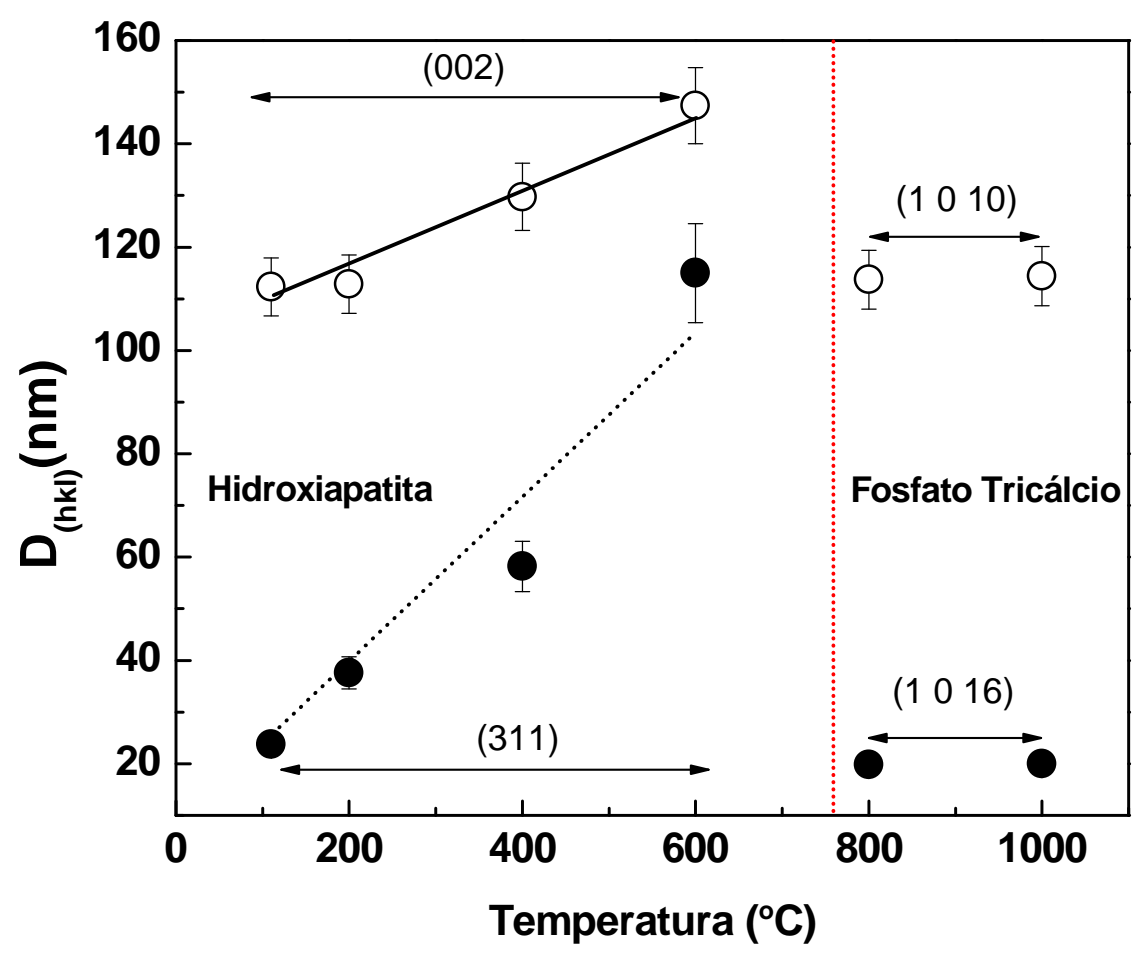

Figura 5.10: Evolução do tamanho médio de cristalito com a temperatura nos planos (002) e (311) para HAp e (ll 0 10) e (1 0 16) para $\mathrm{Ca}_{3}\left(\mathrm{PO}_{4}\right)_{2}$. para um tempo de sinterização de $30 \mathrm{mim}$.

\subsubsection{Caracterização magnética de HAp}

Uma área de interesse atual é a intensificação da bioatividade da HAp através de modificação química que poderia produzir um novo biomaterial muito similar à composição química e estrutura da fase mineral em ossos [35]. Estas substituições iônicas podem modificar a estrutura superficial e carga elétrica de HAp. Algumas das biocerâmicas usadas para implantes ósseos bioativos são obtidos substituindo parcialmente o fosfato por diferentes materiais como $\mathrm{Mg}$, silicone e grupos fosfato [36]. O ferro é um elemento essencial no metabolismo humano e como foi indicado na literatura, os ossos podem atuar como grandes reservatórios para diferentes elementos necessários para uma variedade de funções metabólicas e a incorporação de ferro na HAp poderia executar esta tarefa. 
$\mathrm{O}$ efeito do ferro nas propriedades magnéticas da HAp não foi explorado na literatura nem a utilização da HAp com Fe como um biomaterial [37]. Neste estudo, durante a caracterização magnética da HAp, descobrimos que ocorre uma substituição do cálcio por átomos de ferro, que está presente como impureza nos reagentes utilizados. Vale a pena ressaltar que cada síntese dos materiais estudados nesta tese foi realizada com vidraria selecionada, afim de excluir contaminações cruzadas. Embora baixíssima, a concentração de ferro nas amostras de HAp é detectável pela técnica de RPE, tornando plausível uma caracterização ferromagnética como é mostrado a seguir.

Mediante a técnica de RPE foram realizadas medidas na faixa de $70 \mathrm{~K}$ até a temperatura ambiente. Os espectros das amostras de nanopartículas de HAp sintetizada (HAp) e micropartículas de HAp comercial (HAc) são mostrados nas Figuras 5.11 e 5.12, respectivamente. Vale a pena ressaltar que mesmo a HAp comercial, estudada neste trabalho, apresentou sinal de FMR, mostrando que a presença de traços de ferro também é observada mesmo na HAp comercial.

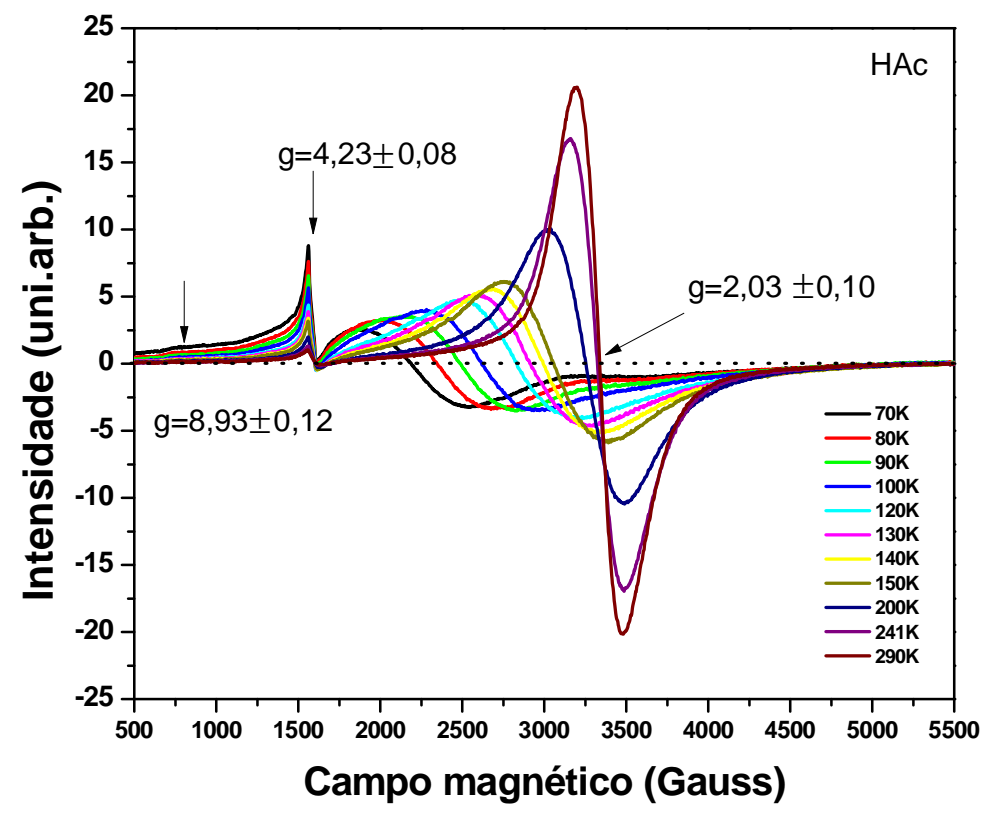

Figura 5.11: Espectros de RPE de micropartículas de HAp comercial (HAc) obtidos com mudança de temperatura na faixa de 70-290 K. 


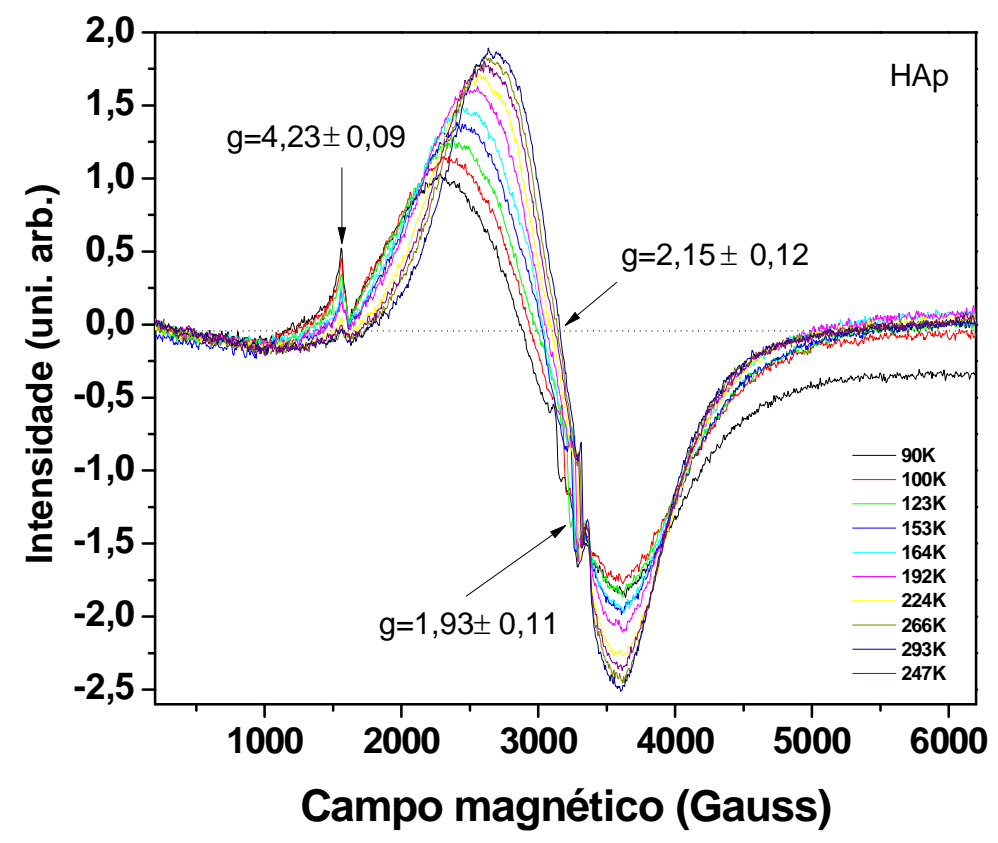

Figura 5.12: Espectros de RPE de nanopartículas de HAp sintetizada (HAp) obtidos com mudança de temperatura na faixa de 90-247 K.

Pode-se observar nas Figuras 5.11 e 5.12, que os espectros da amostra HAc

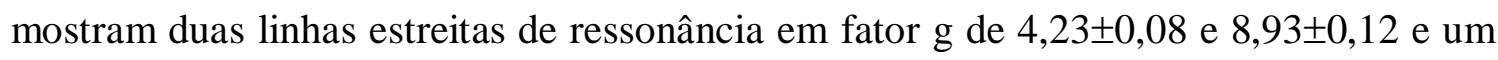
pico largo em $\mathrm{g} \cong 2,03 \pm 0,10$ que varia com a temperatura. No caso da amostra HAp

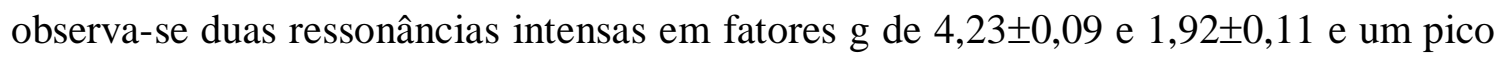
largo em $\mathrm{g} \cong 2,15 \pm 0,12$ mostrando variação com a temperatura. As linhas estreitas em $\mathrm{g}=4,23 \pm 0,08, \mathrm{~g}=4,23 \pm 0,09$ e $\mathrm{g}=8,93 \pm 0,12$ estão correlacionadas aos radicais livres que resultam do processo de síntese e é devida à absorção pelos spins $\mathrm{Fe}^{3+}$. Estas linhas são observadas praticamente em todas as temperaturas e a intensidade destas linhas diminui com o aumento da temperatura. A linha estreita em $\mathrm{g}=1,93 \pm 0,11$ é devida à absorção pelo spins dos íons fosfato, estas linhas estreitas são alinhadas em paralelo ou perpendicular ao campo magnético aplicado. A intensidade e a largura da linha da ressonância em $\mathrm{g}=4,23 \pm 0,08$ e $\mathrm{g}=4,23 \pm 0,09$ diminui com o incremento da temperatura. O valor de $g=8,93 \pm 0,12$ no espectro de HAc é pequeno e é ausente no espectro da amostra HAp. 
A largura da linha de ressonância no espectro de RPE de HAp é maior que no espectro de HAc. Isto é devido à alta concentração de íons $\mathrm{Fe}^{3+}$ na amostra HAp e ao tamanho da partícula [38]. O incremento das interações spin-eletron entre os íons vizinhos de $\mathrm{Fe}^{3+}$, produzido pela maior quantidade de íons de $\mathrm{Fe}^{3+}$, leva ao alargamento do pico em $\mathrm{g} \cong 2,15 \pm 0,12[39,40]$. Este alargamento também poderia ser associado à possibilidade que nem todos os íons de $\mathrm{Fe}^{3+}$ são incorporados na rede da HAp na forma de FeOOH $[39,40]$.

As linhas de ressonância, largas em $\mathrm{g} \cong 2,15 \pm 0,12$, são frequentemente observadas em espectros de RPE de nanopartículas à base de óxido de ferro superparamagnéticas e ferromagnéticas [41]. O alargamento da linha de ressonância nestas amostras de HAp é devido ao baixo campo coercivo que possuem todas as nanopartículas [42].

Os espectros de RPE das amostras de HAc e HAp, apresentando sinais largos foram obtidos na faixa de 70 a 300K, estes sinais são em geral assimétricos, observando-se que a amplitude pico a pico muda ao longo da gama da temperatura. Os pontos mínimo e máximo da derivada do sinal também mudam ao longo da faixa da temperatura estudada. No espectro da amostra HAc o ponto da máxima e da mínima derivada se desloca para esquerda enquanto somente o ponto da máxima derivada no espectro da amostra HAp se desloca para esquerda com a diminuição da temperatura. Isto é devido ao fato que numa dispersão ferromagnética randomicamente orientada, a largura de linha de absorção se transforma numa função monotônica da temperatura. A largura de linha aumenta com a diminuição da temperatura devido à dispersão das partículas na direção do campo da anisotropia. À medida que a temperatura aumenta, tende a formar momentos magnéticos isotrópicos causando a diminuição da largura de linha [42].

A intensidade e a largura da linha de ressonância em $g=4,23 \pm 0,08$ e $g=4,23 \pm 0,09$ diminui com o aumento da temperatura. Este decréscimo é maior em HAc que em HAp. Esta diferença de comportamento é indicativo que mais íons de $\mathrm{Fe}^{3+}$ estão fora da estrutura cristalina da HAp na amostra HAc. 
Na Figura 5.13 é apresentada a mudança do fator g com a temperatura das amostras HAc e HAp. A Figura 5.14 mostram a dependência do campo de ressonância ( $\left.\mathrm{H}_{\text {ressonância }}\right)$ em função da temperatura.

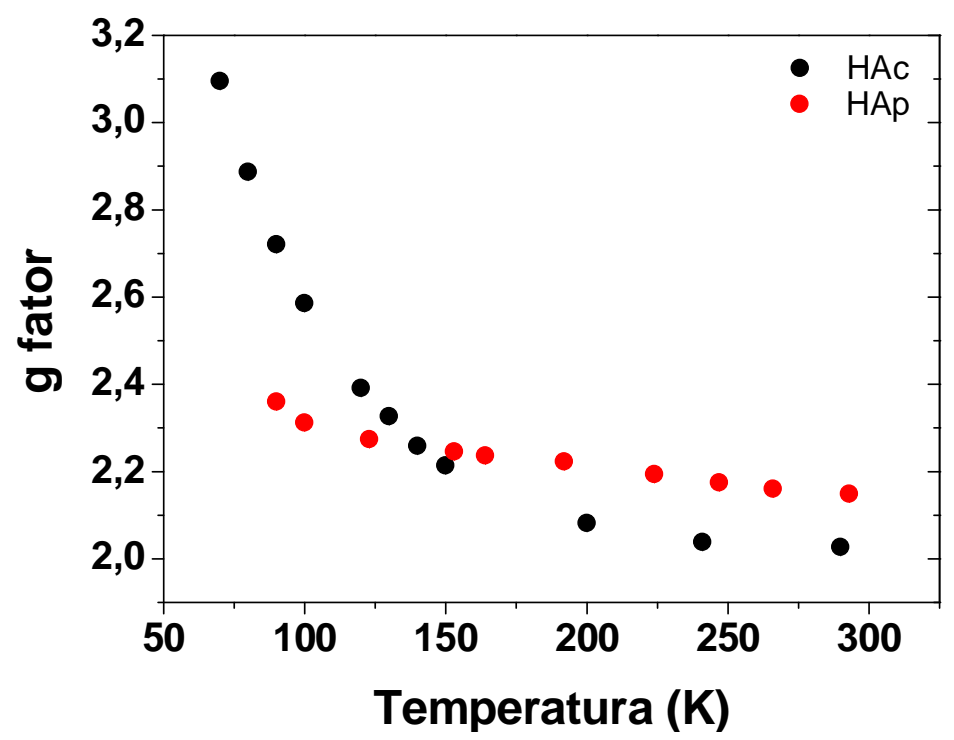

Figura 5.13: Fator giromagnético g em função da temperatura da amostra HAp e HAc.

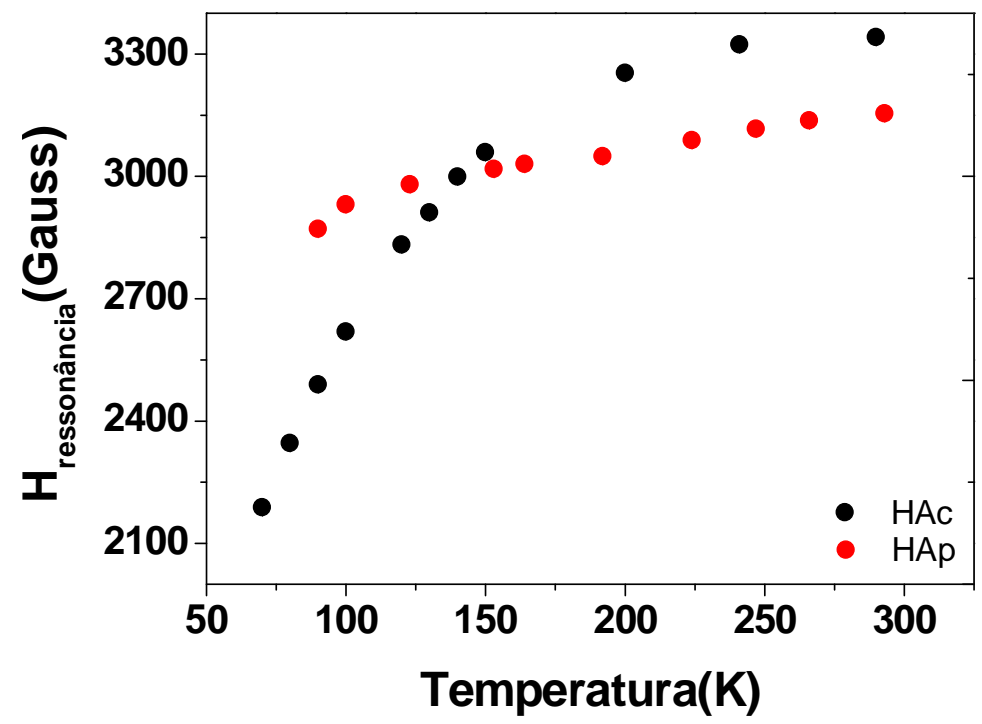

Figura 5.14: Campo de ressonância em função da temperatura para HAp e HAc. 
Na Figura 5.15 é apresentada a largura de linha pico pico $\left(\Delta \mathrm{H}_{\mathrm{PP}}\right)$ com a temperatura associada com a linha de ressonância. Esta linha diminui como o incremento da temperatura, seguindo as previsões de RFM para partículas superparamagnéticas $[43,44]$. Portanto, espera-se que o alargamento e deslocamento do sinal de ressonância estejam associados com o bloqueio da magnetização das nanopartículas.

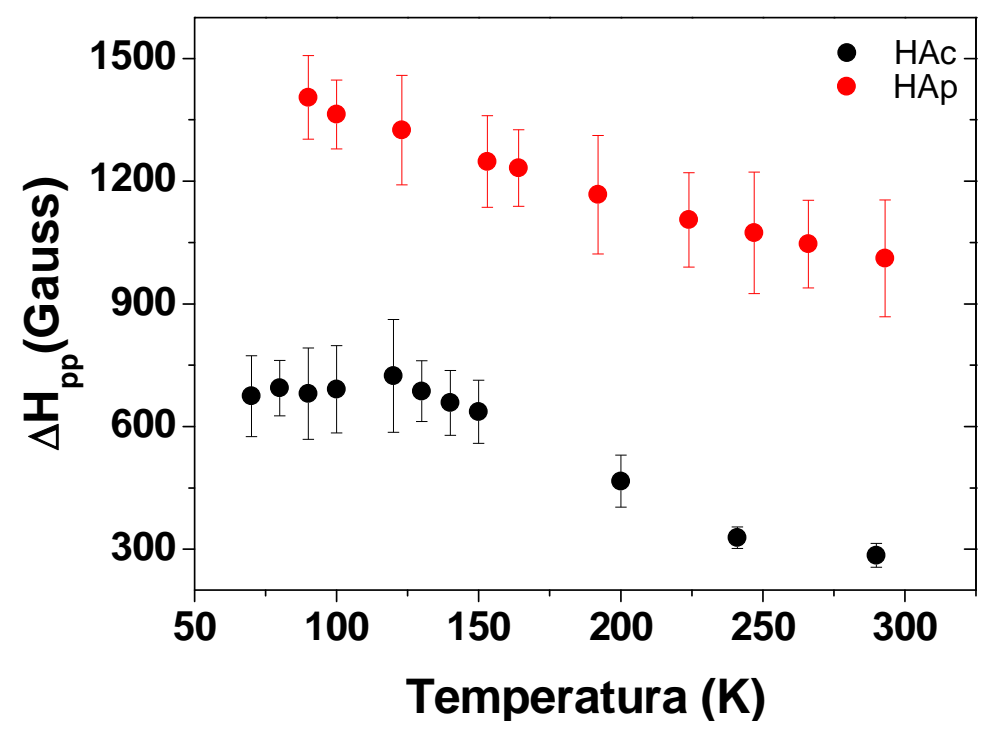

Figura 5.15: Largura de linha pico a pico $\left(\Delta \mathrm{H}_{\mathrm{PP}}\right)$ em função da temperatura para HAp e HAc.

A variação em $\Delta \mathrm{H}_{\mathrm{pp}}$ pode ser explicada usando um sistema de dois níveis e sob o equilíbrio térmico. O enfraquecimento do acoplamento magnético é responsável pelo decréscimo da largura de linha com o incremento da temperatura [44, 45].

O número de spins eletrônicos não emparelhados na amostra é proporcional a área sob a linha de absorção de RFM, sendo esta determinada pelo produto $\Delta H_{P P}^{2} . h$ onde $h$ é a altura pico a pico. Na Figura 5.16 observamos que o número de spin, da amostra HAc, aumenta com o incremento da temperatura atingindo um máximo em aproximadamente $150{ }^{\circ} \mathrm{C}$, para temperaturas maiores o número de spin diminui. No entanto, no caso da amostra HAp, a Figura 5.16 mostra a diminuição do número de spins com o incremento da temperatura. 


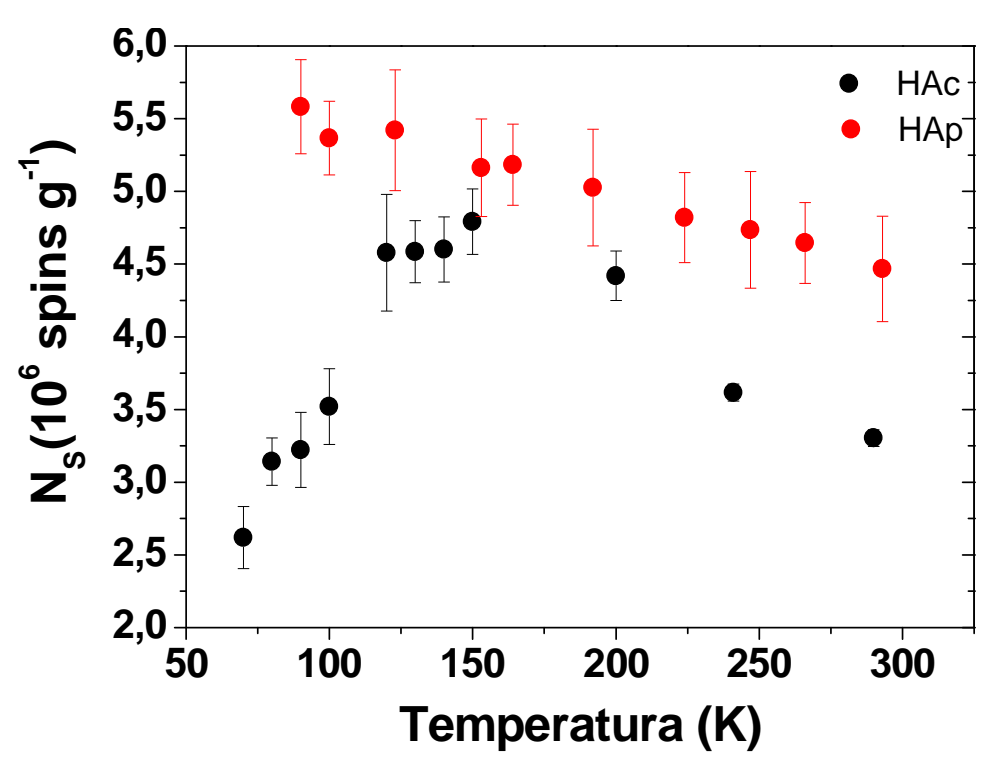

Figura 5.16: Numero de spins $\left(\mathrm{N}_{\mathrm{S}}\right)$ em função da temperatura para HAp e HAc.

Nas Figuras 5.17 é mostrada a variação de $T_{2}$ com a temperatura. A Interação de dipolo magnético entre as partículas e interação "superexchange" entre os íons magnéticos apesar da presença dos íons de oxigênio são dois fatores predominantes que determinam os parâmetros de ressonância, fator giromagnético g e $\Delta H_{P P}$. Interações de dipolo forte dão um grande $\Delta H_{P P}$ e fator g. Adicionalmente uma interação "superexchange" forte produz pequenos $\Delta H_{P P}$ e fator g [46]. O aumento da temperatura poderia aumentar o movimento dos elétrons, causando uma interação superexchange mais forte entre os cátions a apesar da presença dos íons de oxigênio e, portanto um decremento no $\Delta H_{P P}$ e fator $\mathrm{g}$. Conseqüentemente, os valores de $\mathrm{T}_{2}$ aumentam com o aumento da temperatura. Outra observação interessante é a mudança na inclinação na dependência com a temperatura como é mostrada na Figuras 5.17, evidenciando dois tipos de taxa de relaxamento. A mudança na taxa de relaxamento da HAc a T>144 K pode estar relacionado a uma mudança na susceptibilidade magnética [47]. No entanto, na Figura 5.17, para o caso da amostra HAp a ausência de mudança na inclinação do tempo de relaxação em função da temperatura evidencia uma mudança na susceptibilidade magnética para uma temperatura inferior a $90 \mathrm{~K}$. A mudança do tempo de relaxação está associada à dimensão da partícula; para partículas de HAc de tamanho 
micrométrico a mudança do tempo de relaxação $T_{2}$ ocorre para valores maiores que 140 $\mathrm{K}$ e para nanopartículas (HAp) a mudança na taxa de relaxamento é evidenciada para valores menores que $90 \mathrm{~K}$.

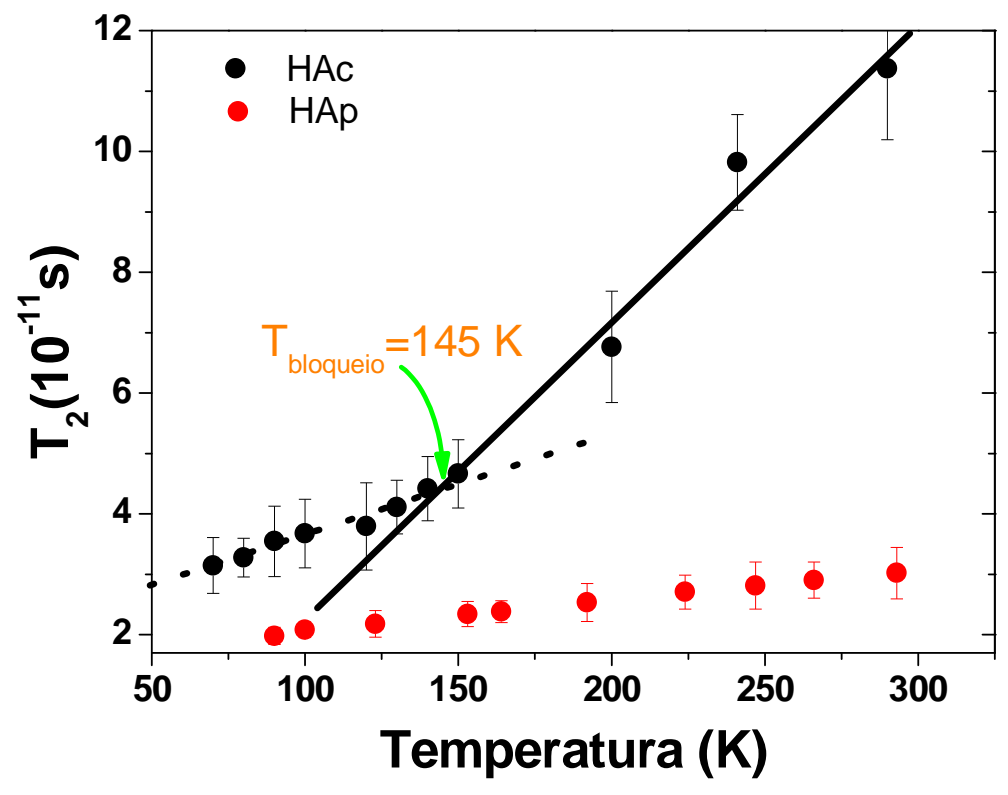

Figura 5.17: Tempo de relaxação spin-spin em função da temperatura para HAp e HAc.

\subsubsection{Soluções de nanopartículas de HAp}

\subsubsection{DRX de soluções de HAp}

A Figura 5.18 mostra os dados de DRX das nanopartículas a base de HAp revestidas com ácido oléico (HApr). As partículas de HAp foram revestidas usando diferentes quantidades de ácido oléico, sendo identificadas como HApr0,25; HApr0,5; HApr0,75; HApr1,0 e HApr1,5. 


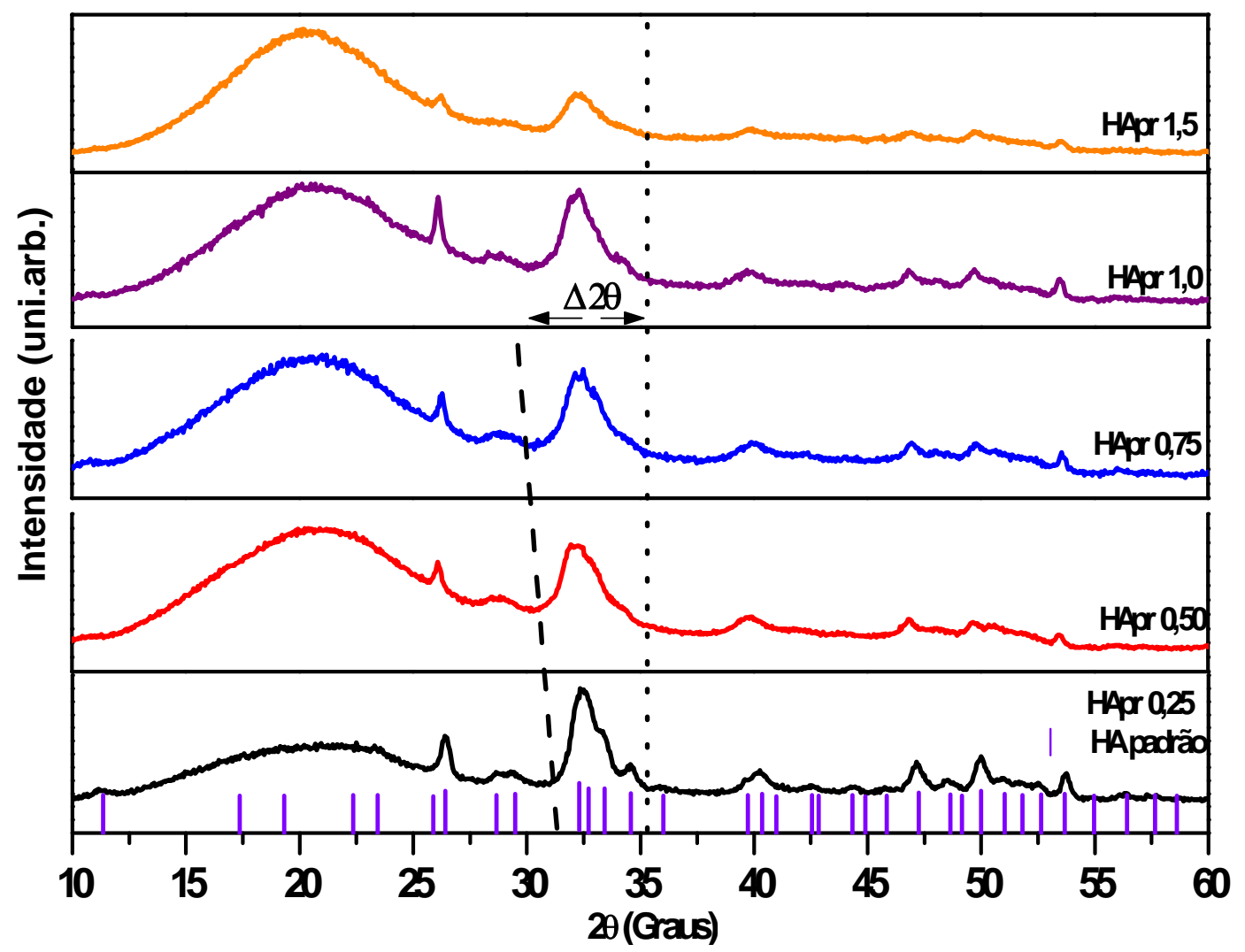

Figura 5.18: Dados de DRX das amostras a base de HAp revestidas com ácido oléico.

Nos difratogramas mostrados na Figura 5.18 observa-se que a estrutura cristalina da HApr se manteve estável com o ácido oléico na superfície das nanopartículas. A banda na faixa $2 \theta$ entre 10 e 30 graus apresentada em todos os difratogramas de DRX, corresponde ao caráter amorfo do vidro utilizado como porta amostra. Os difratogramas de DRX mostram os picos mais intensos correspondentes a fase cristalina da HAp. Aparentemente a HApr não apresenta um alto nível de cristalinidade, levando à soluções com a característica nanoamorfa. Esta característica nanoamorfa é de interesse para estudos da bicompatibilidade; que revelam que HAp nanoamorfa promove adesão de osteoblastos ao mesmo nível que HAps nanocristalinas e HAps convencionais [48]. O revestimento da HApr diminui o tamanho do aglomerado de nanopartículas, o que é evidenciado pelo alargamento da banda de comprimento $\Delta 2 \theta$ mostrado na região dos picos mais intensos no padrão de difração da HApr. Aparentemente, o revestimento da HAp com a adição de 0,5 mL da solução de ácido oléico é suficiente para diminuir estes aglomerados. A literatura relata medidas do diâmetro da partícula e do tamanho do 
aglomerado com valores de $13 \mathrm{~nm}$ e $8,78 \mu \mathrm{m}$, respectivamente; a partícula e o aglomerado apresentaram formas irregulares, estes valores correspondem ao material precipitado de HAp nanoamorfa sem revestimento [48].

\subsubsection{SAXS de soluções de HAp}

Com o intuito de realizar o estudo da morfologia das nanopartículas, foram realizadas medidas de SAXS de sóis de Hapr. As Figuras 5.19(a-f) mostram as curvas para as amostras de HApr. Todas as amostras apresentaram características similares, em particular, de agregados de massa fractal e de superfície fractal. Os expoentes da lei de potências foram calculados a partir de ajuste linear, por mínimos quadrados, dos dados experimentais sob as regiões de q mostradas na Figura 5.19 e listados na Tabela 5.2.

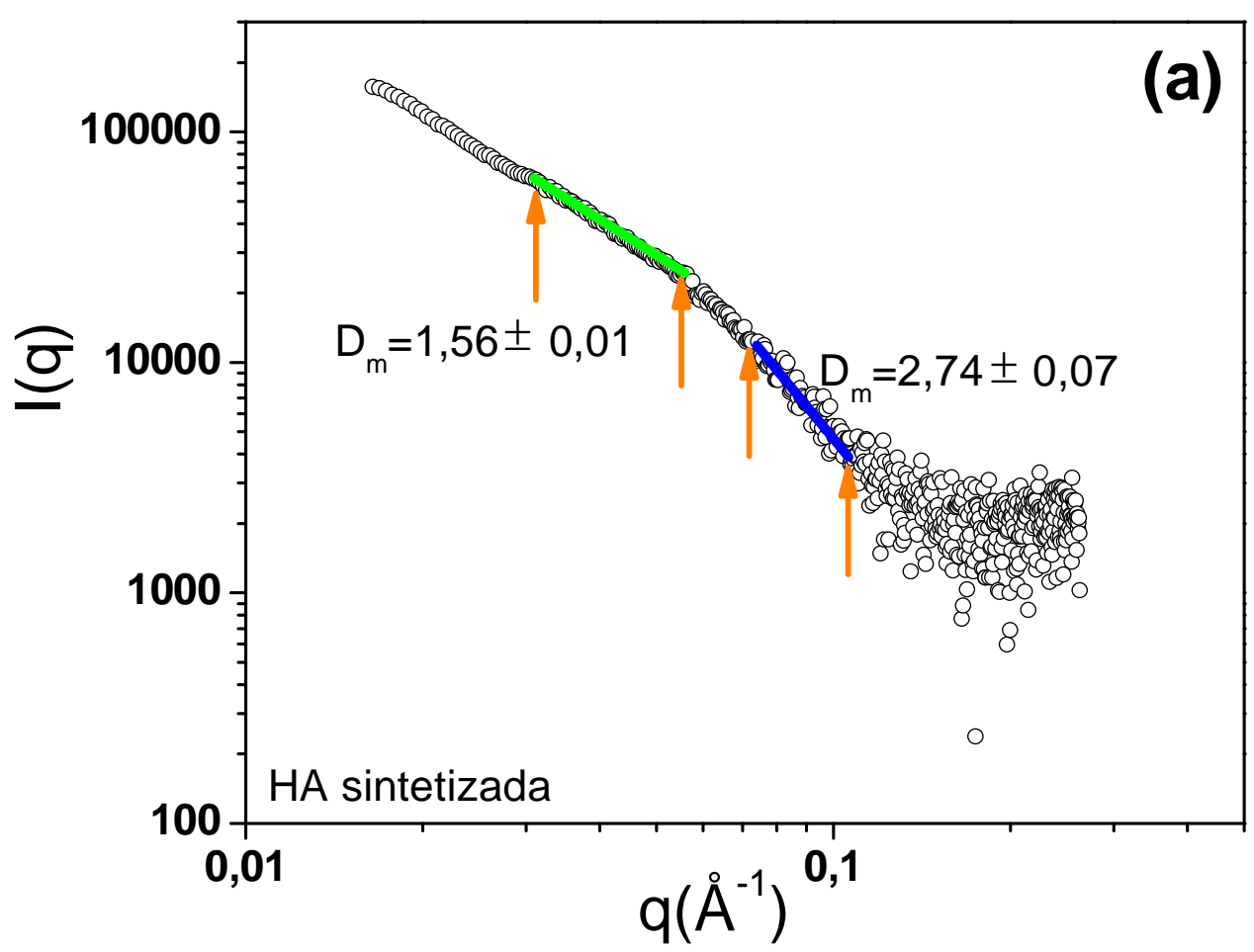



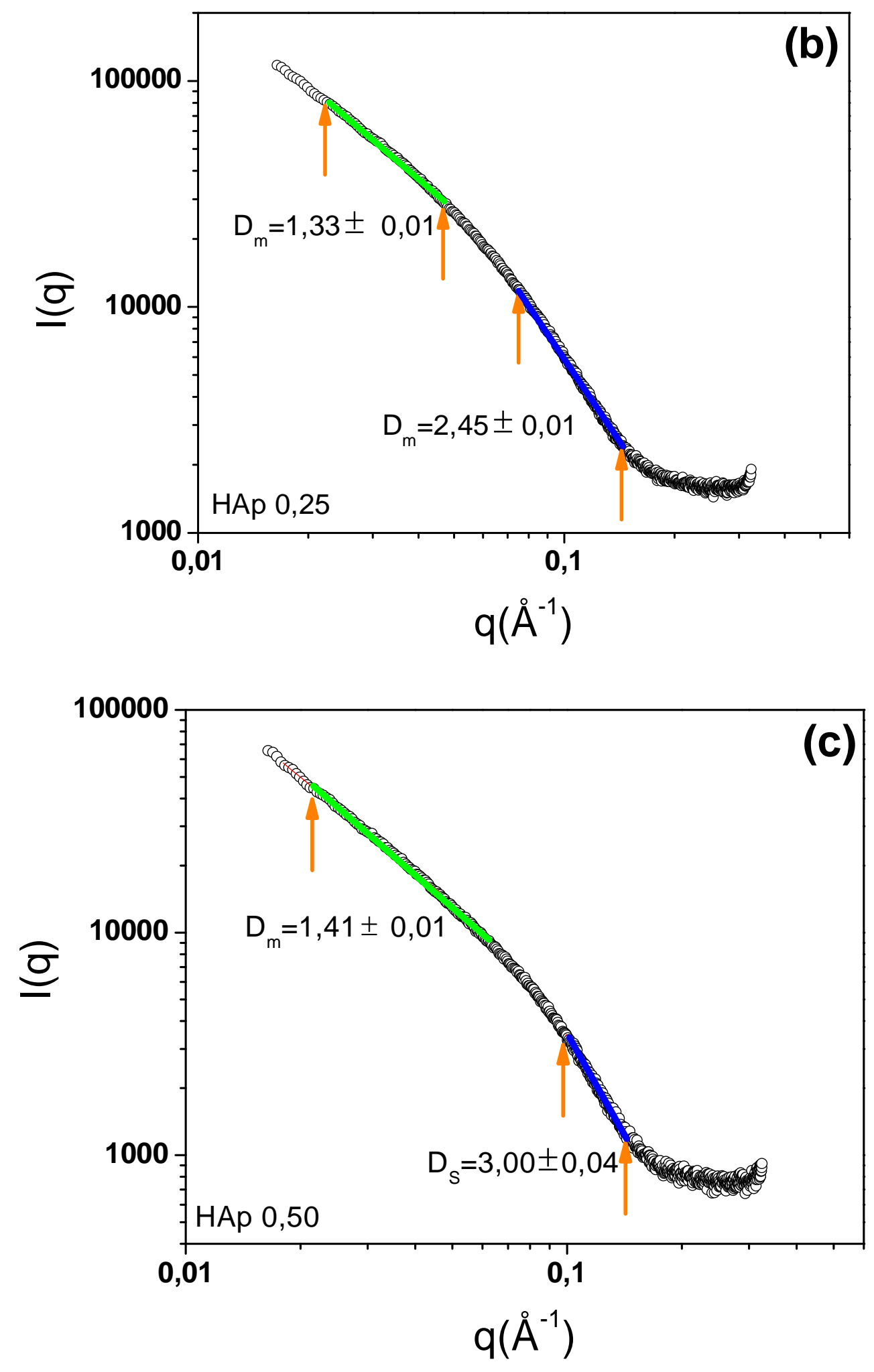

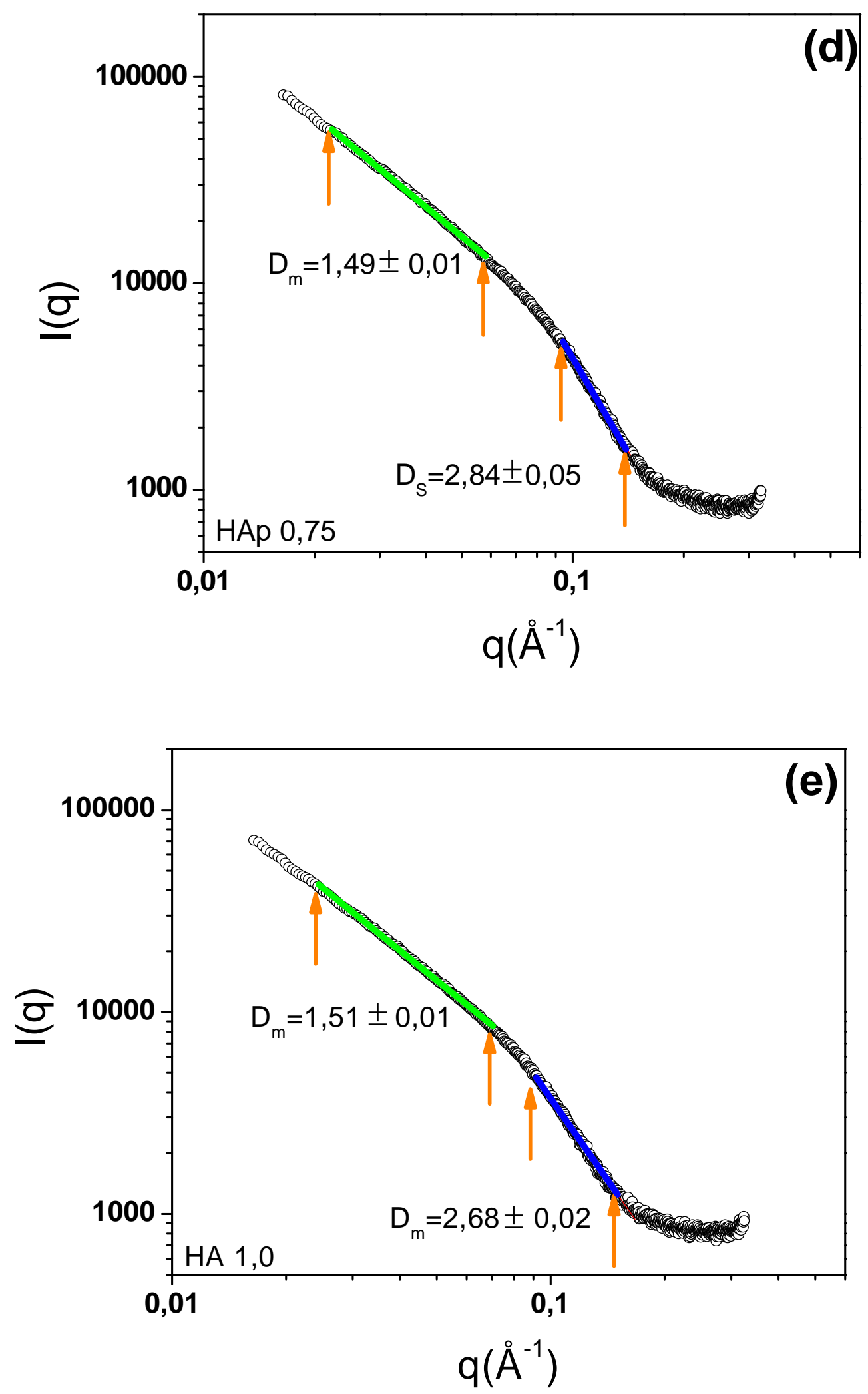


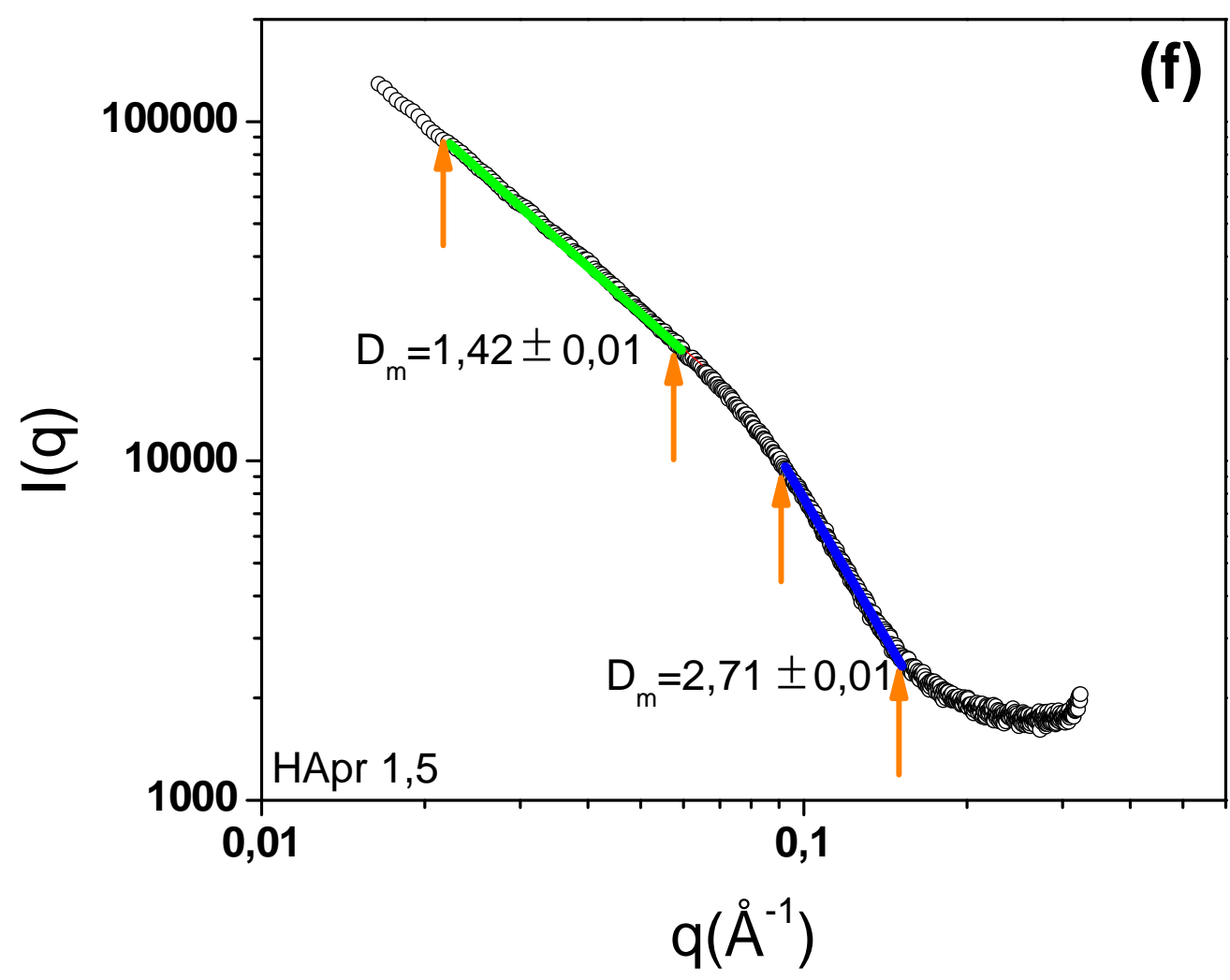

Figura 5.19: Curvas de SAXS correspondentes aos sóis a base de HAp revestidas com ácido oléico. A figura apresenta $\log \mathrm{I}(\mathrm{q})$ vs. $\log \mathrm{q}$.

Os resultados da análise fractal realizado nas curvas de SAXS das amostras de HApr estão apresentados na Tabela 5.2. A partir da localização dos pontos de transição (pontos marcados por setas nas Figuras 5.19), os limites de faixa de fractalidade no espaço real $(a, \xi)$ poderiam ser estimados como segue [49-52]:

$$
\begin{aligned}
& a=\frac{1}{q_{\max }} \\
& \xi=\frac{1}{q_{\min }}
\end{aligned}
$$


As curvas de $\log \mathrm{I}(\mathrm{q})$ vs. $\log \mathrm{q}$ mostram seções lineares ao longo de pelo menos uma ordem de grandeza no parâmetro q. No entanto, Para algumas amostras a faixa de fractalidade é mais restrita.

Tabela 5.2: Caracterização das soluções de HAp estudadas.

\begin{tabular}{|c|c|c|c|c|}
\hline \multirow[t]{2}{*}{ Amostra } & \multicolumn{2}{|c|}{ Dimensão fractal } & \multicolumn{2}{|c|}{$\begin{array}{c}\text { Faixa de } \\
\text { Fractalidade }\end{array}$} \\
\hline & $\mathbf{D}_{\mathrm{m}}$ & $\mathbf{D}_{\mathrm{S}}$ & $a(\AA)$ & $\xi(\AA)$ \\
\hline \multirow[t]{2}{*}{ HAp } & $1,56 \pm 0,01$ & - & 18 & 32 \\
\hline & $2,74 \pm 0,07$ & & 9 & 14 \\
\hline \multirow[t]{2}{*}{ HApr 0,25} & $1,33 \pm 0,01$ & - & 21 & 45 \\
\hline & $2,45 \pm 0,01$ & & 7 & 13 \\
\hline \multirow[t]{2}{*}{ HApr 0,5 } & $1,41 \pm 0,01$ & & 16 & 47 \\
\hline & & $3,00 \pm 0,04$ & 7 & 10 \\
\hline \multirow[t]{2}{*}{ HApr 0,75} & $1,49 \pm 0,01$ & & 17 & 45 \\
\hline & & $2,84 \pm 0,05$ & 7 & 11 \\
\hline \multirow[t]{2}{*}{ HApr 1,0} & $1,51 \pm 0,01$ & - & 14 & 41 \\
\hline & $2,68 \pm 0,08$ & & 7 & 11 \\
\hline \multirow[t]{2}{*}{ HApr 1,5} & $1,42 \pm 0,01$ & - & 17 & 46 \\
\hline & $2,71 \pm 0,01$ & & 7 & 11 \\
\hline
\end{tabular}

As curvas de SAXS de todas as amostras indicam fractalidade de massa do agregado de partículas primárias, cujos valores correspondentes a cada amostra estão indicados na Tabela 5.2.

Para valores de q pequenos e de q grandes as características de espalhamento nas Figuras 5.19 apresentam dois intervalos bem diferenciados. A lei de potências em $\sim 0,02<q<0,06 \AA^{-1}$ e $\sim 0,1<q<\sim 0,15 \AA^{-1}$ corresponde a espalhamento de massa fractal e no caso das amostras HApr0,5 e HApr0,75 no intervalo de q grande o espalhamento é devido a superfície fractal. Esta lei de potências correspondente a escalas de grandes comprimentos, mostra variação dependente da amostra. A lei de expoentes deduzidas da inclinação das curvas de SAXS produzem agregados de dimensão fractal de massa num alto limite de diluição. Os valores de $\mathrm{D}_{\mathrm{m}}$ menores que 2,7 podem resultar de efeitos de concentração ou de aglomeração. A característica de 
superfície fractal pode resultar de rearranjos aleatórios de cristalitos ou devido à reações de oxolação durante o processo de agregação das nanopartículas de HAp.

\subsubsection{Espectroscopia de absorção na região do infravermelho (FTIR) de soluções de HAp}

Antes de começar a discutir os resultados referentes à FTIR é interessante considerar a estrutura da molécula orgânica do ácido oléico, mostrada na Figura 5.20.

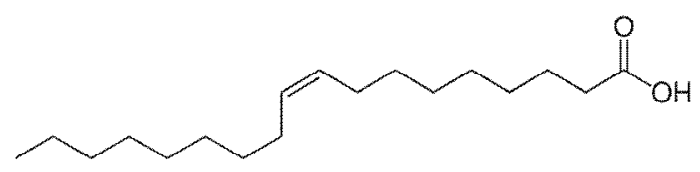

Fígura 5.20: Estrutura da molécula de ácido oléico.

Na Figura 5.21 são apresentados os espectros vibracional de infravemelho obtidos na faixa de 390 até $4000 \mathrm{~cm}^{-1}$ das suspensões coloidais de HAp revestidas com ácido oléico (amostras HApr0,25; HApr0,5; HApr0,75; HApr1,0, HAp1,5 e ácido oléico).

Considerando o espectro de FTIR da molécula do ácido oléico, este ácido apresenta bandas vibracionais devido à carbonila ( $\mathrm{C}=\mathrm{O}$ ) entre 1600 e $1890 \mathrm{~cm}^{-1}$, carboxila ($\mathrm{COOH})$ entre 1340 e $1180 \mathrm{~cm}^{-1}$, cadeia saturada - $\left(\mathrm{CH}_{2}\right)_{\mathrm{n}}$ - entre 670 e $760 \mathrm{~cm}^{-1}$, grupo O$\mathrm{H}$ ácido entre 2640 e $3390 \mathrm{~cm}^{-1}$, carbono sp2 =CH- entre 1400 e $1470 \mathrm{~cm}^{-1}$, e grupos $\mathrm{CH}_{2}$ - entre 2650 e $3130 \mathrm{~cm}^{-1}$. Para a HAp é possível notar dentre as bandas vibracionais a do fosfato entre 910 e $1270 \mathrm{~cm}^{-1}$ e de grupos -OH ligados na superfície entre 3050 e $3700 \mathrm{~cm}^{-1}$.

No caso das amostras a base de HAp revestidas por ácido oléico, observa-se o próprio sinal da HAp e, superpostos a ele, as bandas vibracionais relativas aos grupos carbonila, carbono sp2 e grupos $\mathrm{CH}_{2}$. 


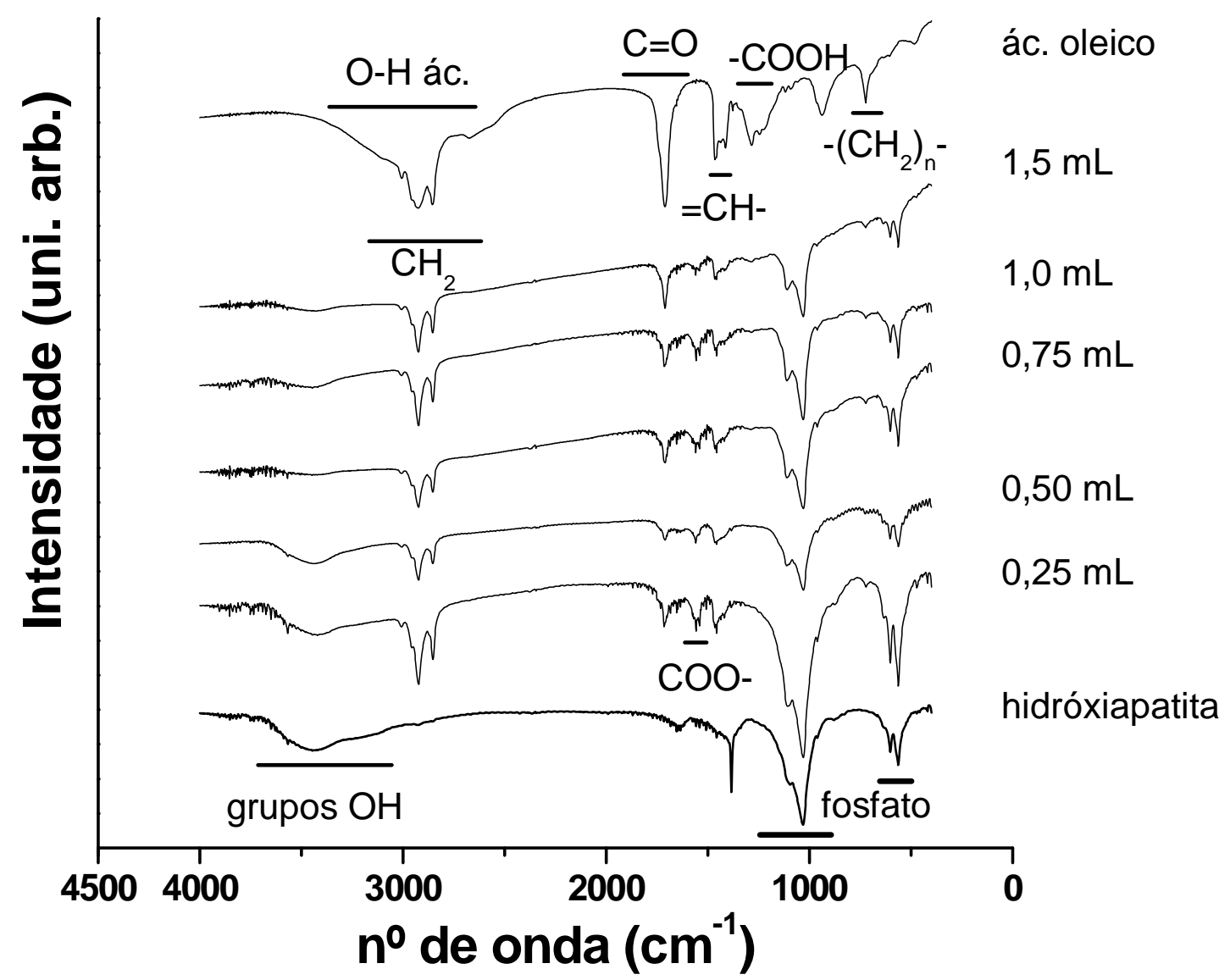

Figura 5.21: Espectro de FTIR de soluções contendo nanopartículas de HAp revestidas com ácido oléico.

É importante ressaltar que nos espectros das amostras de HApr não aparecem os sinais devido ao grupo carboxila e devido ao grupo $\mathrm{OH}$ ácido do ácido oléico. Por outro lado, verifica-se o surgimento da banda vibracional do grupo carboxilato (-COO-) entre 1500 e $1600 \mathrm{~cm}^{-1}$. O surgimento desta banda em detrimento das bandas referentes aos grupos $\mathrm{OH}$ ácido e carboxila, é uma "impressão digital" de que o ácido oléico se encontra ancorado na superfície da HApr na forma de oleato. Para as amostras HApr0,50 e HApr0,25, a banda devido ao grupo carboxila desaparece por completo, indicando que toda a partícula está estequeometricamente surfactada pelos oleatos.

A HApr apresenta um caráter hidrofóbico devido à surfactação dos oleatos pois, a cauda apolar do oleato está voltada para fora da partícula. Ao adicionar estas partículas 
nanométricas de HApr em uma solução aquosa do surfactante Triton verifica-se total redispersão da HApr na água. A redispersão ocorre pois as moléculas do surfactante se alinham com a parte hidrofóbica voltada para a HApr e, consequentemente, a parte hidrofílica voltada para fora da HApr, formando uma camada do tipo lipossomo verificado nas paredes das membranas celulares. Os sóis a base de HApr assim obtidos, são estáveis por mais de 2 anos. 


\subsection{Referências Bibliográficas}

[1] Spiekermann, H., Implantology. George Thieme Verlag, Stuttgart, cap. 01, p. 11, 1995.

[2] Ripamonti, U., J. Maxillofac Surg., v.817, p. 227, 1991.

[3] Kikuchi, M.; Itoh, S.; Ichinose, S.; Shinomiya, K.; Tanaka, J., Biomaterials, v.22, p. 1705, 2001.

[4] Ben-Nissanm, B., Current opinion in solid state and materials science, v. 7, p. 283, 2003.

[5] Yamaguchi, K.; Hirano, T.; Yoshida, G.; Iwasaki, K., Biomaterials, v.16:(13), p. 983, 1995.

[6] Lasserre, A.; Bajpai, P.K., Critical Reviews in Therapeutic Drugs Carrier Systems, v.15(1), p. 1, 1998.

[7] Rupprecht, R.D.; Horning, G.M.; Towle, H.J., Journal of Periodontology, v.72: (10), p. 1443, 2001.

[8] Manjubala, I.; Sivakumar, M.; Sureshkumar, R.V.; Sastry, T.P., Journal of Biomedical Materials Research, v.63:(2), p. 200, 2002.

[9] Fulmer, M.T; Martin, R.I; Brown, P.W., Journal of Materials Science: Materials in Medicine, v.3, p. 299, 1992.

[10] Naray-szabo, S. Z., Kristallogr., v.75, p. 387, 1930.

[11] Beevers, C. A.; Mcintyre, D. B., Miner. Mag., v.27, p. 254, 1956.

[12] Young, R. A.; Elliott, J.C., Archs Oral Biol., v.11, p. 699, 1966.

[13] Young, R. A., Clin. Orthop., v.113, p. 249, 1975.

[14] Junqueira, L.C.; Carneiro, J.; Histologia Básica, $8^{\circ}$ ed., Editora Guanabara Koogan, 1995.

[15] Roosen, A.; Hausner, K.; Adv. Cer. Mater., v.3(2), p. 132, 1988.

[16] Duckworth, W., J. Am. Cer. Soc., v.36(2), p. 68, 1953.

[17] Niesz, D.E.; Bennett, R.B.; In: Ceramic Processing Before Firing; pp. 61-73. Edited by G. Y. Onoda and LL Hench. Wiley, Inc., N. Y., 1978.

[18] Tani, E.; Yoshimura, M.; Somiya, S., J. Am. Cer. Soc., v.66(1), p. 11, 1983.

[19] Haberko, K; Pyda, W.; In: Advances in Ceramics, 12, 774-83. Science and Technology of Zirconia II. Edited by N. Claussen, M Rühle and A. H. Hener. The Am. Cer. Soc., Inc., Columbus, OH, 1984.

[20] Scott, C.E.; Reed, J.S., Am. Cer. Soc. Bull., v.58(6), p. 587, 1979.

[21] Carlstroem, E., J. Am. Cer. Soc., v.67(8), p. C169, 1984.

[22] Green, D.; Metcalf, M., Am. Cer. Soc. Bull., v.63(6), p. 803, 1984.

[23] Mizuta, S.; Parish, M.; Bowen, H.K., Cer. International, v.10(2), p. 43, 1984.

[24] Mazdiyasni, K.S; Lynch, C.T; Smith, J.S., J. Am. Cer. Soc., v.50(10), p. 532, 1967.

[25] Aksay, I.A.; Lange, F.F.; Davis, B.I., J. Am. Cer. Soc., v.66,(10), p. C190, 1983.

[26] Lange, F.F.; Davis, B.I., In: Advances in Ceramics, 12, 699-713, Science and Technology of Zirconia II. Edited by N. Claussen, M. Rühle and A. H. Hener. The Am. Cer. Soc., Inc., Columbus, OH, 1984. 
[27] Ergun, C.; Webster, T.J.; Bizios, R.; Doremus, R.H., J Biomed Mater Res, v.59, p. 305, 2002.

[28] Webster, T.J.; Massa-Schlueter, E.A.; Smith, J.L.; Slamovich, E.B., Biomaterials, v.25, p. 2111, 2004.

[29] Sato, M.; Slamovich, E.B.; Webster, T.J., Biomaterials, v.26, p.1349, 2005.

[30] Narasaraju, T.S.B.; Phebe, D.E., J Mater Sci, v.31, p. 1, 1996.

[31] Nayar, S.; Sinhá, M.K.; Basu, D.; Sinhá, A., J Mater Sci: Mater Med, v.17, p. 1063, 2006.

[32] Nayar, S.; Sinhá, A., Colloids and Surfaces B, v.35, p.29, 2004.

[33] Suchanek, W.; Yoshimura, M., J. Mater. Res., v.13, p. 94, 1998.

[34] Moharram, M.A.; Allam, M.A., Journal of Applied Polymer Science, v.105, p. 3220, 2007.

[35] Bretcanu, O.; Spriano, S.; Verne, E.; Coisson, M.; Tiberto, P.; Allia, P., Acta Biomaterialia, v.1, p. 421, 2005.

[36] Arcos, D.; Rodr'1guez-Carvajal, J.; Vallet-Regi, M., Chem. Mater., v.16, p. 2300, 2004.

[37] Abou Neel, E.A.; Ahmed, I.; Blaker, J.J.; Bismarck, A.; Boccaccini, A.R.; Lewis, M.P.; Nazhat, S.N.; Knowles, J.C., Acta Biomaterialia, v.1, p. 553, 2005.

[38] Pon-on, W.; Meejoo, S.; Tang, I-M., International Journal of Nanoscience, v. 66 No 1, p. 9, 2007.

[39] Jiang, M.; Terra, J.; Rossi, A.M.; Morales, M.A.; Baggio Saitovitch, E.M.; Ellis, D.E., Phy. Rev. B, v.66, p. 224107, 2002.

[40] Sutter, B.; Wasowicz, T.; Howard, T.; Hossner, L.R.; Ming, D.W., Soil. Sci. A. J., v.66, p. 1359, 2002.

[41] Bretcanu, O.; Spriano, S.; Verne, E.; Coisson, M.; Tiberto, P.; Allia, P., Acta Biomaterialia, v.1, p. 421, 2005.

[42] Luciene Batusta da Silveira, Estudos de propriedades magnéticas de fluidos e nanocompósitos magnéticos biocompatíveis. Tese de doutorado. IF UNB, 2006.

[43] Kinnari, P.; Upadhyay, R.V.; Mehta, R.V., J. Magn. Magn. Mater., v.252, p. 35, 2002.

[44] Stucki, J.W.; Banwart, W.L., Advanced Chemical Methods for Soil and Clay Mineral Research, Reidel, Dordrecht, 1980.

[45] Kinnari, P.; Upadhyay, R.V.; Mehta, R.V.; Srinivas, D., J. Appl. Phys., v.88, p. 2799, 2002.

[46] Li, L.; Li, G.; Smith, R.L.; Inomata, H., Chem. Mater., v.12, p. 3705, 2000.

[47] Wu, K.H.; Chang, Y.C.; Chen, H.B.; Yang, C.C.; Horng, D.N., J. Magn. Magn. Mater., v.278, p. 156, 2004.

[48] Balasundaram, G.; Sato, M.; Webster, T.J., Biomaterials, v.27, p. 2798, 2006.

[49] Martin, J.E.; Hurd, A.J., J. Appl. Cryst., v.20, p. 61, 1987.

[50] Schmidt, P.W., J. Appl. Cryst., v.24, p. 414, 1991.

[51] Teixeira, J., J. Appl. Cryst., v.21, p. 781, 1988.

[52] Pajak, L.; Bierska-Piech, B.; Mrowiec-Bialón, J.; Jarzebski, A.B.; Diduszko, R., FIBERS \& TEXTILES in Eastern Europe, v.13:5(53), p. 69, 2005. 


\section{CAPÍTULO 6 - Nanopartículas a base de Magnetita}

Neste capítulo apresentaremos, inicialmente, os conceitos necessários para compreender o comportamento magnético dos ferrofluidos, visto que o entendimento de aspectos intrínsecos às nanopartículas são importantes para explicar as características das SPIONs. Em seguida, é apresentado o processo de síntese e a caracterização estrutural mediante DRX, caracterização térmica realizada por DSC, caracterização morfológica feita através de MET e SAXS, caracterização magnética por RFM e a caracterização relaxométrica por RMN.

O objetivo do presente capítulo é apresentar o processo de síntese do ferrofluido sintetizado em nosso laboratório e o estudo das propriedades cristalinas, térmicas, morfológicas, magnéticas da suspensão coloidal à base de SPIONs. Realizamos medidas de tempos de relaxação nuclear $\mathrm{T}_{1}$ e $\mathrm{T}_{2}$ já que a caracterização dos tempos de relaxação nuclear, denominada de caracterização relaxométrica, são de importância na avaliação de um ferrofluido, cuja principal aplicação na área biomédica é o seu uso como agente de contraste para o diagnóstico de IRM, através de imagens ponderadas no tempo de relaxação longitudinal $\mathrm{T}_{1}$ e no tempo de relaxação transversal $\mathrm{T}_{2}$.

Apresentamos ainda, na caracterização magnética, o estudo por RFM que permite caracterizar algumas propriedades associadas com nanopartículas magnéticas, como $\mathrm{T}_{2}$ eletrônico, temperatura de bloqueio $\mathrm{Tb}$, número de spins e a característica ferromagnética das SPIONs que compõem a suspensão coloidal sob estudo.

\subsection{Introdução}

\subsubsection{Colóides}

Um sistema coloidal é a dispersão fina num meio contínuo de um composto particulado. A estabilidade das suspensões coloidais é determinada pelas forças atrativas 
e repulsivas de Van der Waals, forças eletrostáticas e forças que resultam de polímeros adsorvidos [1].

A estabilização eletrostática que é resultado da ação combinada entre a força atrativa de Van der Waals e/ou a repulsão elétrica de dupla camada é uma das vias para a estabilização de colóides; a outra via é a estabilização estérica que resulta do equilíbrio entre a força atrativa de Van der Waals e as forças repulsivas estéricas.

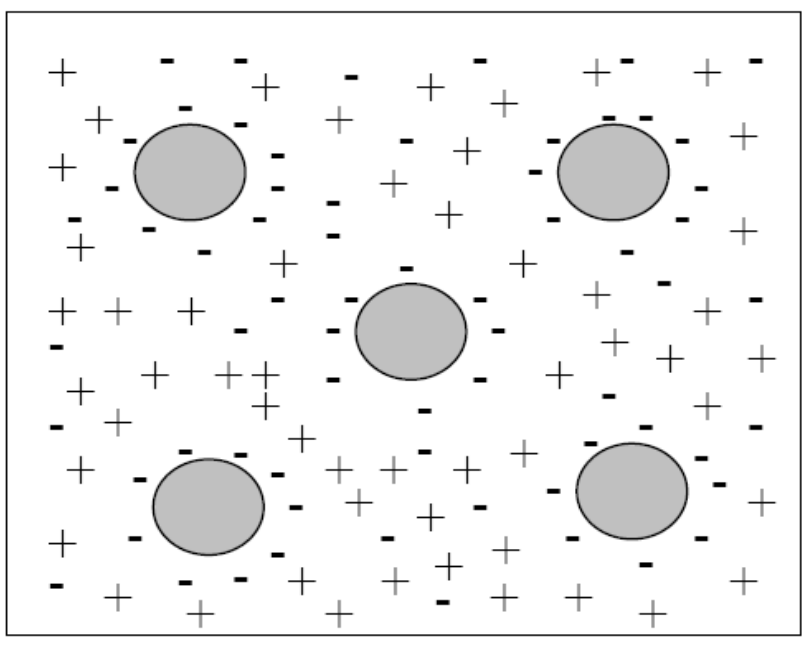

Figura 6.1: Esquema da dupla camada elétrica perto de um colóide.

\subsubsection{Fluidos magnéticos}

Ferrofluidos, ou fluidos magnéticos, são dispersões coloidais de partículas metálicas magnéticas (fase dispersa sólida) da ordem de nanômetros dispersas num líquido carregador que pode ser um meio orgânico ou aquoso (fase dispersora líquida) [2].

Para aplicações biomédicas, o uso de nanopartículas magnéticas numa suspensão coloidal apresenta comportamento superparamagnético e alta susceptibilidade, características importantes para aplicações na biologia, no diagnóstico médico e terapia. É necessário que as partículas magnéticas sejam estáveis em água com pH neutro e salinidade fisiológica. A estabilidade coloidal deste fluido dependerá primeiro, das 
dimensões das partículas, que deverão ser suficientemente pequenas para evitar a precipitação devido às forças gravitacionais; e segundo, da química de troca na superfície, que resulta no aumento das repulsões estéricas e de Coulomb.

A introdução de agentes de contraste à base de SPIONs abre um importante campo de pesquisas para os cientistas, industriais e radiologistas clínicos.

A estabilidade da suspensão coloidal resulta do equilíbrio entre as interações partícula-partícula e interações entre partículas e as moléculas do solvente, sendo essencial que as partículas sejam quimicamente estáveis e muito pequenas de modo que o movimento Browniano possa se opor à tendência de precipitação ou aglomeração das partículas.
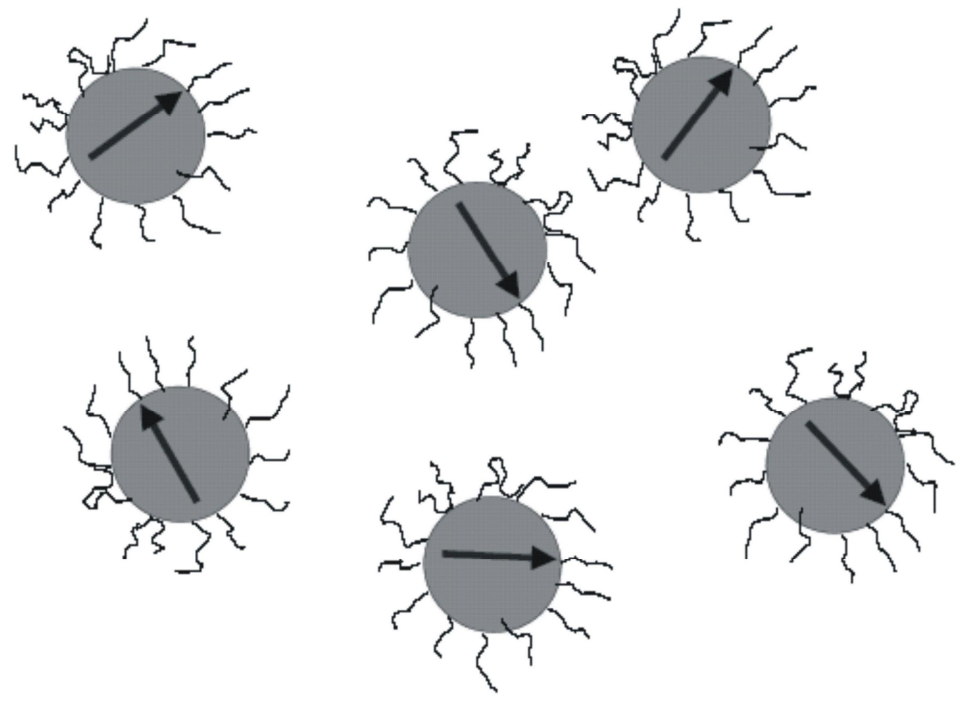

Figura 6.2: Representação esquemática de um ferrofluido; as partículas foram revestidas com surfactante.

Em aplicações biomédicas as partículas magnéticas devem atravessar a barreira endotelial acumulando-se nas células alvo para não induzir danos nas células normais, portanto um ferrofluido deve ser biocompatível (biodegradável e hemocompatível). Consegue-se esta biocompatibilidade revestindo as partículas magnéticas com materiais biologicamente ativos. 
$\mathrm{Na}$ nanomedicina, nanopartículas magnéticas são utilizadas em imagens por ressonância magnética nuclear, carregadores de drogas, hipertermia magnética e aplicações terapêuticas.

Um colóide é descrito como um sistema onde ao menos um dos componentes está em nível nanométrico ou micrométrico. O ferrofluido é composto basicamente pelo componente disperso que é constituído de nanopartículas magnéticas recobertas por uma camada molecular estabilizante e pelo dispersante que pode ser um solvente orgânico ou inorgânico. As nanopartículas são monodomínios magnéticos, tipicamente esféricos e com diâmetros $(d)$ entre 3 e 15 nm, apresentando ordenamento ferromagnético (Fe, Co) ou ferrimagnético ( $\left.\mathrm{Fe}_{3} \mathrm{O} 4, \mathrm{NiFe} 2 \mathrm{O} 4\right)$. A camada molecular estabilizante adsorvida (quimiossorvida ou fisiossorvida) na superfície da nanopartícula, com espessura $(\delta)$ tipicamente entre 1 e 4 nm, pode ser tanto de natureza inorgânica [3] ou orgânica [4]. Outra das componentes do ferrofluido é o fluido dispersante, que por sua vez, pode ser orgânico (óleo) ou inorgânico (água). Em tese, a enorme variedade de opções para os três ingredientes básicos de um ferrofluido: a nanopartícula magnética, a camada molecular estabilizante e o solvente, pode ser utilizada para dois propósitos. Primeiro, para atender a aplicações tão distintas quanto, como por exemplo, a separação de diamantes e a separação celular. Segundo, para investigar fenômenos físicos tão diferentes entre si como viscosidade negativa e tunelamento do momento magnético.

A característica mais importante de um ferrofluido é a sua estabilidade, ou seja, a propriedade das nanopartículas magnéticas de permanecerem em suspensão na forma de entidades isoladas (monodomínios), evitando a aglomeração das nanopartículas e subseqüente precipitação.

Para entender a importância da estabilidade coloidal é fundamental ter a informação prévia sobre as forças atrativas e repulsivas inerentes nos ferrofluidos e dos mecanismos da estabilidade coloidal. 


\subsubsection{Estabilidade coloidal}

No que concerne a influência de fatores intrínsecos, a estabilidade do ferrofluido decorre de um equilíbrio muito delicado das interações atrativas e repulsivas entre as nanopartículas. A interação dipolar magnética e a de Van der Waals são atrativas. Por outro lado, as interações repulsivas mais importantes são a estérica e a eletrostática. $\mathrm{O}$ equilíbrio entre interações de naturezas opostas e presentes em um ferrofluido é modulado pelo movimento Browniano associado às nanopartículas magnéticas dispersas no líquido carreador. Um ferrofluido típico contém de $10^{16}$ a $10^{17}$ partículas $/ \mathrm{cm}^{3}$. Assim, as distâncias interpartículas situam-se entre 20 e $50 \mathrm{~nm}$.

As forças de interação dipolar magnética (interações magnetostáticas) são atrativas e podem ser devido à magnetização de uma amostra quando colocada em um campo magnético externamente aplicado ou qualquer magnetização remanescente inerente das partículas individuais. Somente o primeiro caso tem sido considerado e a atração magnetostática entre duas partículas é descrita pela energia associada à interação dipolar entre duas nanopartículas de momentos magnéticos $\vec{m}_{1}$ e $\vec{m}_{2}$, separadas por uma distância $r$ do centro-centro das partículas, dada por [5-7]:

$$
U_{d}=\frac{\mu_{0}}{4 \pi r^{3}}\left[\left(\vec{m}_{1} \cdot \vec{m}_{2}\right)-3\left(\vec{m}_{1} \cdot \hat{r}\right)\left(\vec{m}_{2} . \hat{r}\right)\right]
$$

onde $\hat{r} . r$ é o vetor que conecta os centros das partículas, com módulo $\ell$ (vide Figura 2.1). 


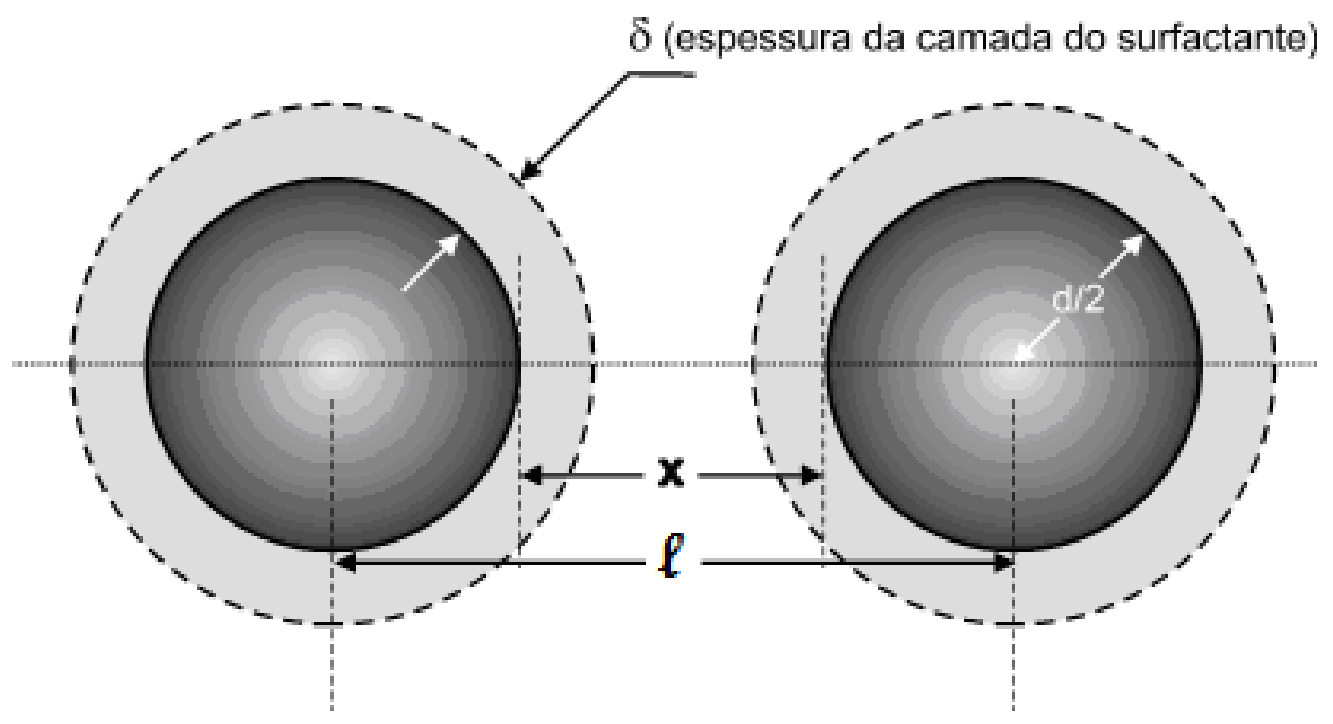

Figura 6.3 Parâmetros usados nas equações.

O momento magnético associado à nanopartícula é, por sua vez, dado pela magnetização $(M)$, conforme $m=\mu_{0} M V$ (sendo $V$ o volume da nanopartícula).

As forças de Van der Waals surgem a partir de uma variedade de interações dipolo-dipolo: dipolo permanente - dipolo permanente, dipolo permanente - dipolo induzido e dipolo induzido - dipolo induzido. A força devido a esta última forma de interação, também chamada de força de dispersão de London, é a principal força de atração de longo alcance envolvida em sistemas coloidais. A mudança de polarização de nuvens de elétrons é espontânea e ocorre em uma escala de tempo de fentosegundos [8]. A força mutuamente atrativa entre dois átomos é fraca; no entanto, quando o número de átomos das partículas na suspensão coloidal e a soma de suas forças são considerados, a atração resultante é significativa. A energia associada à interação de Van der Waals entre duas nanopartículas idênticas de diâmetro d e onde a distância centro a centro é r, é dada pela relação [9]:

$$
U_{v}=-\frac{A}{6}\left[\frac{2 R^{2}}{(2 R+\ell)^{2}-4 R^{2}}+\frac{2 R^{2}}{(2 R+\ell)^{2}}+\ln \left(\frac{(2 R+\ell)^{2}-4 R^{2}}{(2 R+\ell)^{2}}\right)\right],
$$


onde $R$ é o raio das partículas (assumindo serem monodispersas), $\ell$ é a distância entre os centros de duas partículas (vide a Figura 6.3) e $A$ é a constante de Hamaker $\left(\sim 10^{-20} \mathrm{~J}\right)$ para magnetita [8].

A força atrativa de Van der Waals é inversamente proporcional à sexta potência da distância entre as partículas [10]. A força de atração de Van der Waals precisa ser minimizada para prevenir a aglomeração de partículas, o que pode levar à sedimentação.

Por outro lado, temos a repulsão estérica que está diretamente relacionada com a camada do estabilizante (surfactante) adsorvida na superfície das nanopartículas. Quanto maior for a camada, tanto maior será a estabilidade da dispersão coloidal

A energia por unidade de área $\left(u_{S}\right)$ associada à repulsão estérica entre duas esferas é [11]:

$$
u_{s}=8 \pi R^{2} \xi\left[2-\frac{s}{t} \ln \left(\frac{2+2 t}{s}\right)-\frac{s-2}{t}\right](k T)
$$

onde a densidade superficial de moléculas adsorvidas na superfície da nanopartícula é descrita pelo parâmetro $\xi$ ("grafting"), com $t=\delta / \mathrm{R}$ e $\mathrm{s}=\mathrm{x} / \mathrm{R}+2$ obtidos a partir da Figura 6.3 Valores típicos do "grafting" estão entre $10^{15}$ a $10^{18}$ ligantes $/ \mathrm{m}^{2}$.

Finalmente a estabilização eletrostática envolve a criação de cargas na superfície das partículas coloidais. Quando a superfície da partícula é carregada, os íons opostos também estão presentes, e criam uma dupla camada elétrica. A energia potencial entre duas partículas igualmente carregadas aumenta de acordo com a aproximação entre elas, levando à repulsão [11].

A energia associada à repulsão eletrostática entre duas esferas idênticas, com densidade superficial de carga $\rho$, em um solvente iônico de constante dielétrica $\varepsilon$ e força iônica $\kappa=\sum_{i} n_{i} Z_{i}^{2}$, é dada por [12]: 


$$
U_{e}=\frac{\pi \rho^{2} d^{4}}{4 \varepsilon l} e^{-\frac{l}{\lambda}}
$$

onde $\lambda=\left(2 \times 10^{3} N e^{2} \kappa / \varepsilon k_{B} T\right)^{-1 / 2}, N$ é o número de Avogadro, $e$ a carga elementar, $k_{B}$ a constante de Boltzmann, $T$ a temperatura absoluta, $d$ o diâmetro da nanopartícula e $n_{i}$ a concentração de íons de carga $Z_{i}$ dispersos no solvente.

As equações acima podem ser utilizadas para estimar parâmetros associados às nanopartículas que levem à estabilidade contra agregação. Por exemplo, se consideramos a condição de estabilidade devido à interação dipolar entre duas nanopartículas esféricas de magnetita $\left(M=4,5 \times 10^{5} \mathrm{~A} / \mathrm{m}\right)$ dispersas em um líquido carreador a 300 K. Para que a condição de estabilidade coloidal seja atingida a energia térmica $\left(k_{B} T\right)$ deverá superar a interação dipolar. Pode-se, portanto, estimar o diâmetro máximo para a nanopartícula magnética. No caso de duas nanopartículas, com cobertura molecular de espessura $2 \mathrm{~nm}$, estarem se tocando $(\ell=d+2 \delta)$ e apresentarem momentos magnéticos colineares $\left(\vec{m}_{i} \cdot \vec{\ell}=m \ell\right)$, encontramos que a condição de estabilidade exige que, o diâmetro máximo para partículas de magnetita deve ser da ordem de $10 \mathrm{~nm}$. Estima-se que a razão entre as energias de interação dipolar e a de Van der Waals, no caso especificado anteriormente (magnetita de $10 \mathrm{~nm}$ com cobertura de 2 nm) é aproximadamente 4. Entretanto, ferrofluidos à base de magnetita, com partículas de 12 nm de diâmetro, são estáveis à temperatura ambiente [13]

A discussão acima mostra a importância das interações repulsivas na determinação da condição de estabilidade do ferrofluido. Isto significa que a interação repulsiva, estérica ou eletrostática desempenha um papel relevante na estabilidade coloidal do ferrofluido. De fato, há um paralelo importante entre o tipo de interação repulsiva predominante e a classificação dos ferrofluidos. Os ferrofluidos surfactados foram os primeiros a serem produzidos, sendo a sua estabilidade primordialmente dependente da repulsão estérica. Neste caso, a superfície da nanopartícula é recoberta por uma camada molecular (estabilizante) apresentando uma terminação polar 
(Exemplo: carboxila, hidroxila, amina) usada para complexar um sítio ativo na superfície da nanopartícula. Nos ferrofluidos surfactados à base de ferritas magnéticas, o ácido dodecanóico pode ser usado como agente estabilizante, ficando o grupo carboxila fortemente ligado à superfície da nanopartícula e a cadeia carbônica (alifática) voltada para o solvente (Exemplo: octano). Nos ferrofluidos iônicos, preparados a partir da década de 80 , a estabilidade está essencialmente associada à repulsão eletrostática. Neste caso, o solvente é tipicamente a água e a nanopartícula é carregada com densidade superficial de carga positiva ou negativa. Nos ferrofluidos iônicos à base de ferritas magnéticas, a densidade superficial de carga elétrica é estabelecida a partir de um equilíbrio do tipo ácido-base envolvendo espécies presentes no meio aquoso e na camada superficial da nanopartícula [14]. Em meio básico (ácido) a superfície da nanopartícula de ferrita fica carregada negativamente (positivamente). O processo de carga e descarga envolve transferência de prótons entre a camada superficial da nanopartícula, uma espécie de polióxido-hidróxido envolvendo íons metálicos e espécies presentes no meio aquoso [15]. Finalmente, é possível a existência de ferrofluidos surfactados em meio aquoso. Neste caso, a extremidade da molécula do surfactante (estabilizante) voltada para o solvente deve apresentar um grupo polar (Exemplos: carboxila, amino, hidroxila). Este grupo polar pode participar de um equilíbrio tipo ácido-base, podendo ficar positiva ou negativamente ionizado numa faixa ampla de valores de $\mathrm{pH}$. Quando isto ocorre a estabilidade do ferrofluido será determinada simultaneamente por repulsão eletrostática.

Há situações onde o grupo polar voltado para o meio aquoso permanece ionizado mesmo em pH próximo ao do ponto neutro. Assim, a estabilidade do ferrofluido pode ser conseguida em pH neutro e salinidade de 0,9\%, ou seja, compatível com as condições fisiológicas. Neste caso, o ferrofluido pode vir a ser considerado biocompatível e, portanto, adequado a uma grande variedade de aplicações biomédicas [16]. Outra estratégia para se conseguir um sistema material consistindo de nanopartículas magnéticas recobertas com uma camada molecular, estável em condições fisiológicas, é baseada no encapsulamento de nanopartículas em lipossomos 
sintéticos. Neste último caso, o sistema material é conhecido como lipossomos magnéticos [17]. As propriedades e aplicações dos ferrofluidos biocompatíveis [18] e lipossomas magnéticos [19] representam, atualmente, o foco de interesse científico da área. Neste ponto, é preciso esclarecer que um ferrofluido biocompatível ou um magnetolipossoma não deve necessariamente operar, quando injetado no organismo, como um vetor de droga. Assim, para atingir um certo alvo específico no organismo, seja uma célula cancerosa, bactéria ou vírus, é preciso recobrir o material com agentes específicos. Os anticorpos monoclonais são os melhores candidatos para o recobrimento do material magnético. Obviamente, várias questões estão envolvidas neste procedimento, desde a eficiência do processo de cobertura da nanopartícula magnética com o anticorpo (grafting), passando pela estabilidade da ligação anticorpo-superfície da nanopartícula pré-recoberta até o nível de comprometimento da estereoquímica do sítio ativo. Daí decorre a importância da utilização de diversas técnicas de caracterização de nanoestruturas magnéticas recobertas com biomoléculas.

\subsubsection{Características físico-químicas dos agentes de contraste de óxido de ferro superparamagnético}

A composição química de óxido de ferro superparamagnético tem a fórmula geral

$$
\mathrm{Fe}_{2}^{3+} \mathrm{O}_{3} \mathrm{M}^{2+} \mathrm{O}
$$

onde $\mathrm{M}^{2+}$ é um íon de um metal divalente tal como o ferro, manganês, níquel, cobalto ou magnésio. A magnetita é um óxido de ferro superparamagnético quando o íon do metal $\left(\mathrm{M}^{2+}\right)$ é o ferro ferroso $\left(\mathrm{Fe}^{2+}\right)$.

$$
\mathrm{Fe}_{2}^{3+} \mathrm{O}_{3} \mathrm{Fe}^{2+} \mathrm{O} \rightarrow \mathrm{Fe}_{3} \mathrm{O}_{4}
$$

O superparamagnetismo ocorre quando o material é composto por cristais suficientemente pequenos com spins orientados em monodomínios que podem ser 
considerados como partículas termodinamicamente independentes. Os momentos magnéticos de tais monodomínios magnéticos refletem na interação dos elétrons desemparelhados. O momento magnético resultante torna-se muito maior do que o de uma substância paramagnética, e a susceptibilidade magnética especifica destas partículas pode exceder significativamente o valor da correspondente espécie paramagnética solúvel, devido a este ordenamento magnético [20,21]. As substâncias superparamagnéticas carecem de magnetização remanescente quando o campo magnético é removido, pois as orientações dos monodomínios voltam a ser aleatórios. Isto significa que os agentes de contraste de óxido de ferro superparamgnético não se agregarão devido á atração magnética. O superparamagnetismo tem uma natureza cristalina obrigatória; agentes superparamagnéticos serão então necessariamente ordenados e particulados [22].

O tamanho da partícula, a carga e a natureza da cobertura determinam a estabilidade, a biodistribuição e o metabolismo dos agentes de contraste de óxido de ferro superparamagnético. Embora muitas partículas superparamagnéticas sejam cobertas com dextran e derivados de dextran, eles também podem ser cobertos por outros compostos, tais como amido, albumina e arabino-galactose. Estes compostos são biocompatíveis, permitindo assim a administração intravenosa segura e a pronta biodegradabilidade [23].

\subsubsection{A magnetita}

$\mathrm{O}$ elemento ferro pode ser encontrado sob a forma de três óxidos: $\mathrm{FeO}, \mathrm{Fe}_{2} \mathrm{O}_{3}$ e o $\mathrm{Fe}_{3} \mathrm{O}_{4}$, e todos eles tendem a ser não estequiométricos. O composto $\mathrm{FeO}$ quando analisado estruturalmente apresenta certa deficiência em metal, e fórmula $\mathrm{Fe}_{0,95} \mathrm{O}$. A tendência à não estequiometria exibida por óxidos de ferro se relaciona com a fácil mudança estrutural. Os óxidos de ferro apresentam formas cúbicas que diferem muito pouco entre si, sendo observada apenas alguma diferença na disposição dos íons $\mathrm{Fe}^{2+} \mathrm{e}$ $\mathrm{Fe}^{3+}$ nos interstícios octaédricos ou tetraédricos, Figura 6.4. 


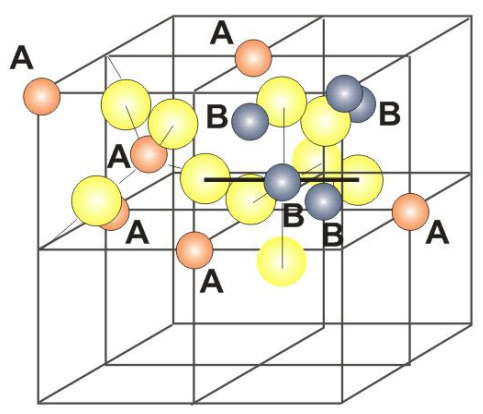

Oxigênio

Fe tetraédrico sítio-A

Fe otaédrico sítio-B

Figura 6.4: Estrutura da magnetita $\left(\mathrm{Fe}_{3} \mathrm{O}_{4}\right)$ spinelio invertida. As esferas grandes representam os átomos de oxigênio, as esferas claras pequenas os sítios $\mathrm{A}$ e as esferas escuras pequenas denotam os sítios B [24].

A estrutura cristalina da magnetita é muito semelhante à de muitos minerais. Essa estrutura é composta basicamente por duas camadas octaédricas com as extremidades apresentando hidroxilas e uma camada central tetraédrica, Figura 6.5. As três camadas apresentam aproximadamente $14,1 A^{o}$.

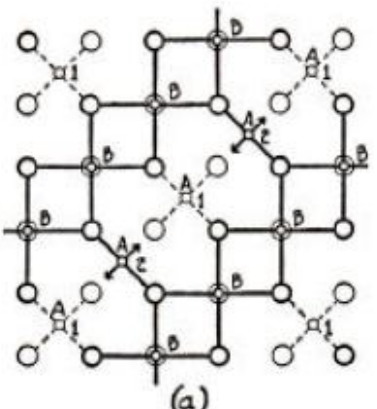

(a)

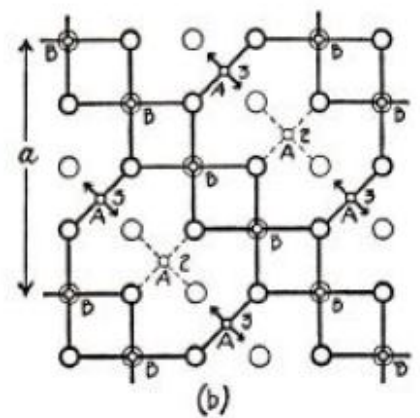

(b)

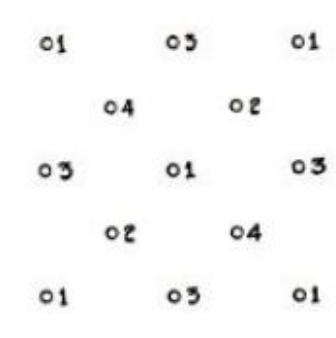

(d)

(c)<smiles>O=P(O)(O)O</smiles>

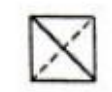

Tetraedrico

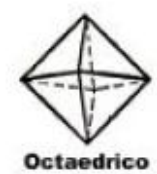

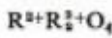

Figura 6.5: Estrutura cristalina do $\mathrm{Fe}_{3} \mathrm{O}_{4}$ [25]. 
A magnetita $\left(\mathrm{Fe}_{3} \mathrm{O}_{4}\right)$ apresenta estrutura octaédrica, sendo usualmente maciça e granular, um mineral de elevada dureza, traço preto e caráter fortemente magnético, comportando-se como um imã natural. A composição química corresponde à da fórmula, apresentando alguma contaminação por magnésio e manganês bivalente. O mineral é considerado quimicamente estável, sendo infusível, vagarosamente solúvel em ácido clorídrico e apresenta o elemento ferro nos seus dois estados de oxidação, $\mathrm{Fe}^{2+}$ e $\mathrm{Fe}^{3+}$.

A magnetita $\left(\mathrm{Fe}_{3} \mathrm{O}_{4}\right)$ é um dos minérios mais empregados para a obtenção do ferro. Esse minério é um óxido de ferro misto com $\mathrm{FeO}$ e $\mathrm{Fe}_{2} \mathrm{O}_{3}$ apresentando estrutura semelhante à montmorilonita, de espinélio invertida, com os íons $\mathrm{O}^{2-}$ de empacotamento cúbico, os íons maiores $\mathrm{Fe}^{2+}\left(0,7610^{-8} \mathrm{~m}\right)$ nos interstícios octaédricos, a metade do íons $\mathrm{Fe}^{3+}\left(0,6410^{-8} \mathrm{~m}\right)$ em sítios octaédricos e a metade restante em posições tetraédricas. Análises detalhadas revelam que os íons $\mathrm{Fe}^{3+}$ são divididos quase igualmente entre as posições tetraédricas e octaédricas e que assim sendo, não existe momento magnético resultante da presença destes íons. Entretanto, quase todos os íons $\mathrm{Fe}^{2+}$ residem nos interstícios das posições octaédricas, e serão estes íons os responsáveis pela magnetização de saturação ou ainda pelo comportamento magnético do material cerâmico. A magnetização do $\mathrm{Fe}_{3} \mathrm{O}_{4}$ ocorrerá com a presença de campo magnético externo, desaparecendo quando o campo for retirado, esse efeito é devido à não conservação da orientação magnética dos átomos individuais [26,27].

\subsubsection{Domínios magnéticos}

Em materiais magnéticos, como o ferro e o aço, os campos magnéticos dos elétrons (grupos de até 1012 elétrons) se alinham (acoplamento de troca) formando regiões que apresentam magnetismo espontâneo. Essas regiões são chamadas de domínios. Os domínios são entidades isoladas, isto é, cada domínio é independente dos domínios vizinhos. Em uma peça não-magnetizada de um material magnético os domínios estão distribuídos de forma aleatória e o campo magnético total em qualquer direção é zero. Quando esse material sofre a ação de uma força magnetizante externa, os domínios que estão aproximadamente alinhados com o campo aplicado crescem à custa 
dos outros domínios, como mostrado na figura abaixo. Se o campo externo aplicado for suficientemente intenso, todos os domínios se orientarão nessa direção e, daí em diante, qualquer aumento do campo externo não causará nenhum aumento na magnetização da peça. Nesse caso diz-se que o material atingiu a saturação.

Quando o campo magnético externo é removido, o grau de alinhamento diminui e o campo no interior do material cai para um valor, não necessariamente igual ao anterior, ou seja, a remoção da força magnetizante faz com que alguns domínios voltem a ficar desalinhados. Essa perda do alinhamento, porém, não é total e os domínios alinhados remanescentes são os responsáveis pela existência dos imãs permanentes.

As partículas em escala nanométrica podem ser monodomínios ou multidomínios [28]. A parede de domínio é a interface que separa dois domínios adjacentes com sentidos e direções opostos (Figura 6.6).

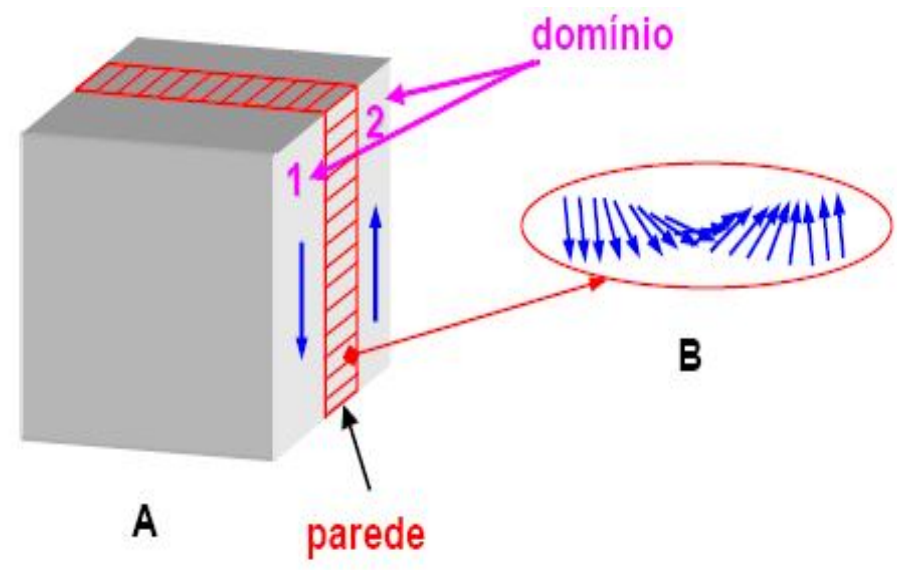

Figura 6.6: Esquema de uma parede de $180^{\circ}$ (A) e da ordenação dos momentos em uma parede de domínios adjacentes (B) [29].

O deslocamento das paredes de domínios magnéticos e/ou a rotação da magnetização local dentro dos domínios leva à magnetização do material. A movimentação e nucleação das paredes de domínio minimizam a energia magnetostática. A energia para produzir paredes de domínios torna-se maior do que a redução da energia magnetostática com a diminuição do tamanho a níveis críticos 
levando à formação de um monodomínio com momento magnético gigante [30]. Em um sistema de monodomínio, o movimento da parede de domínio não conduz à reversão da magnetização, a desmagnetização requer rotação coerente dos spins, resultando em grande coercividade [30].

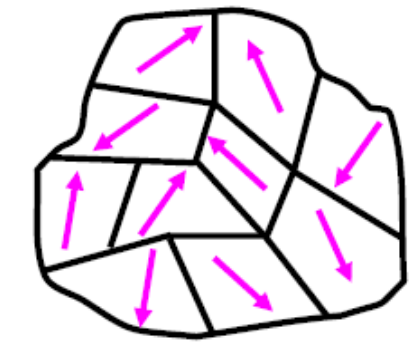

(A) Multidomínio $D>D_{c}$

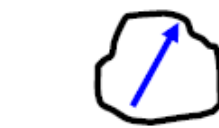

$D_{\mathrm{sp}} \approx 10 \mathrm{~nm}$

(B) Monomínio $\mathbf{D}<\mathrm{D}_{\mathrm{c}}$

Figura 6.7: Esquema de dois materiais ferromagnéticos exibindo estrutura de multidomínios (A) e de monodomínios (B).

\subsubsection{Anisotropia magnética}

Quando se aplica uma intensidade de campo magnético nas diversas direções de determinado cristal que compõe um material magnético observa-se que a densidade de fluxo resultante varia de direção para direção, mostrando que a permeabilidade magnética é uma função da orientação do campo aplicado, caracterizando, portanto, a existência de uma anisotropia cristalina.

Em monodomínios a reversão da direção da magnetização é dependente da anisotropia magnética. A anisotropia cristalina (ou magnetocristalina) que é intrínseca do material [28], a anisotropia de forma [28], e a anisotropia de tensão ou (magnetoelástica) [29] são as três contribuições principais desta propriedade.

A anisotropia magnetocristalina é resultado do efeito das direções cristalográficas do material sobre a energia de magnetização. 
A anisotropia de forma afeta a energia necessária para vencer a retulância geométrica da amostra ou das partículas que a compõem. O formato esférico, por exemplo, não possui anisotropia de forma [28].

A anisotropia magnetoelástica é decorrente das deformações da estrutura cristalina provocadas pelas tensões mecânicas [28].

O termo intrínseco da anisotropia é a energia de anisotropia cristalina. Esta energia é dada por:

$$
E_{K}=K_{1} \operatorname{sen}^{2} \theta+\Phi\left(\operatorname{sen}^{4} \theta\right)
$$

Com $\mathrm{K}_{1}$ a constante de anisotropia uniaxial, $\theta$ é o ângulo entre a magnetização e a direção de fácil magnetização, e $\Phi\left(\operatorname{sen}^{4} \theta\right)$ representa termos de quarta ordem no seno.

\subsubsection{Relaxação Superparamagnética}

De um ponto de vista mais fundamental, as possíveis aplicações dos fluídos magnéticos requerem o conhecimento de como as propriedades magnéticas das nanopartículas diferem quando comparadas com ao material maciço. Nesse contexto, a interpretação dos fenômenos quando o tamanho do cristal é reduzido à escala nanométrica é de fundamental importância na compreensão das propriedades desses sistemas particulados [29].

Existem atualmente evidências experimentais [31] de mudanças nas propriedades de sistemas de tamanho nanométrico em relação ao material maciço. Nessa escala, o confinamento geométrico em um volume fixo provoca dois tipos de efeitos frequentemente misturados: o efeito de tamanho finito em decorrência do número pequeno de átomos em interação e o efeito de superfície, relativo à existência de uma interface e à quebra de simetria no limite da partícula. À medida que o tamanho do nanocristal diminui, a relação entre os átomos da superfície e do núcleo da partícula se torna maior, de tal maneira que as propriedades magnéticas passam a ser dominadas 
pelos átomos da camada superficial. Nesse caso, devido à coordenação reduzida e a descontinuidade das interações de troca, é possível observar fenômenos de frustração e desordem de spins. À baixa temperatura, a estrutura magnética das nanopartículas é bem descrita por um núcleo monodomínio ordenado e uma superfície com spins desordenados, os quais podem flutuar livremente a altas temperaturas.

As partículas à base de SPIONs, que compõem o ferrofluido aqui investigado, possuem dimensões nanométricas, inferiores as dimensões típicas das paredes de Bloch, portanto podem ser consideradas monodomínios magnéticos. A cada partícula associa-se um momento magnético $\mu=m_{S} V$ função de sua magnetização de saturação $m_{S}$ e do volume $V$ da partícula. No interior de um monodomínio magnético (partícula) isolado, o momento magnético está orientado, segundo a direção definida pelo eixo de fácil magnetização do cristal. Para partículas esféricas com uma anisotropia uniaxial a energia é: $E=K_{u} V \operatorname{sen}^{2} \theta$, onde $K_{u}$ é a constante de anisotropia e $\theta$ é o ângulo entre o eixo fácil e a magnetização. A barreira de energia $\left(E_{B}=E_{\max }-E_{\operatorname{mim}}=K_{u} V\right)$ separa os dois mínimos em $\theta=0$ e $\theta=\pi$ correspondente a uma magnetização paralela e antiparalela ao eixo fácil, mostrado na Figura 6.8 .
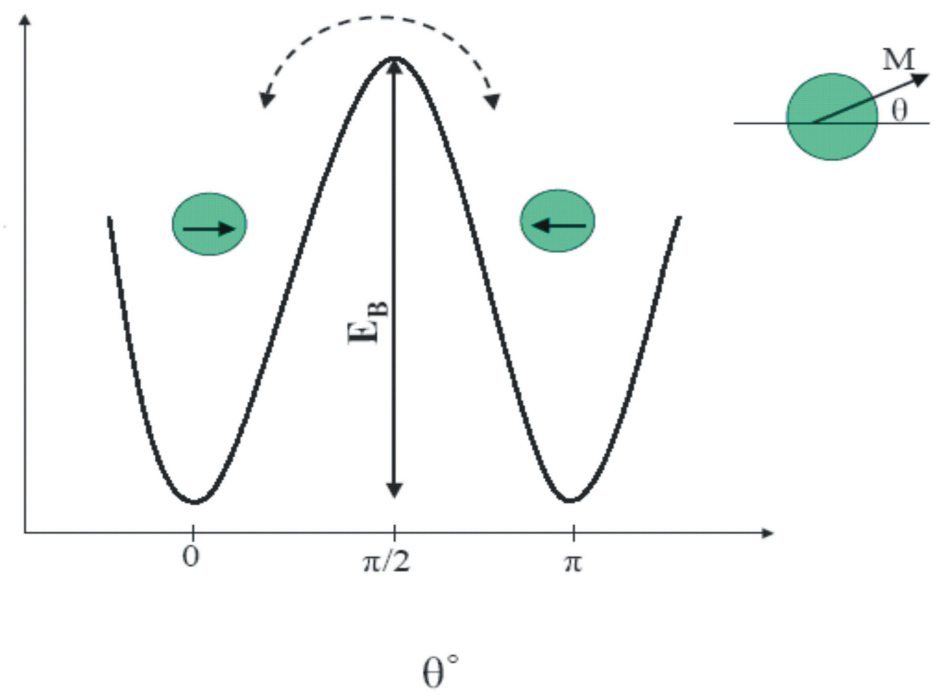

Figura 6.8: Representação esquemática da barreira de energia para magnetização reversa. 
Esta direção determinada pela existência de uma barreira de energia de anisotropia $\mathrm{E}_{\mathrm{a}}$, que bloqueia o momento nessa direção e é dada por $E a=K V$. Como conseqüência do tamanho das partículas, $E a$ é pequena e pode ser tornar comparável à energia térmica. Neste caso, a probabilidade de passagem de uma direção de fácil magnetização a outra não é mais nula e o sistema de spins pode relaxar com certo período $\tau$ entre as direções de fácil magnetização. Neste contexto, o mecanismo de relaxação do momento é um processo termicamente ativado caracterizado por um tempo de relaxação que depende exponencialmente da razão entre a energia de anisotropia e a energia térmica [32]. A caracterização dos fenômenos magnéticos depende do tempo de medida. Se a partícula é observada durante um tempo muito curto comparado $\operatorname{com} \tau$, o momento magnético não flutua e o estado magnético é congelado (material maciço). Para tempos de observação mais longos que o tempo característico de relaxação, as propriedades magnéticas resultam de uma média efetuada durante o tempo de relaxação de spins: a partícula se comporta como uma entidade paramagnética, mas associada a um momento magnético gigante igual ao da partícula: é o superparamagnetismo.

\subsubsection{Comportamento dos tempos de relaxação nuclear dos prótons de soluções coloidais à base de SPIONs}

A ressonância magnética nuclear tem assumido grande importância em relação a outras técnicas de obtenção de imagem. Baseada no comportamento diferente dos prótons em diferentes tecidos, a técnica fornece uma imagem das estruturas anatômicas as quais podem ser melhor destacadas pelo uso de agentes de contraste. As nanopartículas magnéticas, especialmente as menores que $10 \mathrm{~nm}$ [33], denominadas SPIONs, representam uma classe alternativa de agentes de contraste para IRM nuclear com vantagens do ponto de vista físico, pois destacam ainda mais o comportamento dos prótons de diferentes tecidos [34].

Um caso especial de obtenção de IRM nuclear é obtido pela associação de anticorpos monoclonais às nanopartículas magnéticas. Esta associação permite a 
detecção precoce de micrometástases por IRM nuclear, possibilitando o tratamento subsequente pelo processo de magnetohipertermia, facilitando a erradicação do câncer [35].

Imagem molecular com SPIONs representa uma nova ferramenta que permite a detecção, por exemplo, de tumores em faixa de tamanho ou em estágio inicial que não são detectáveis com protocolos convencionais de imagem. SPIONs tem encontrado diferentes aplicações nas diversas áreas. Seu uso na biomedicina tem crescido rapidamente os últimos anos no diagnóstico e terapia assim como na terapia e diagnóstico simultaneamente e mais recentemente na imagem molecular. No diagnóstico uma das principais aplicações é como agentes de contraste para IRM. A aplicação dos SPIONs como agente de contraste é devido à capacidade de modificar os tempos de relaxação $\mathrm{T}_{1}$ e $\mathrm{T}_{2}$ dos tecidos biológicos e tendo particularmente um efeito importante no tempo de relaxação $\mathrm{T}_{2} *$. O uso de SPIONs como agentes de contraste em IRM nuclear alteram o campo magnético local e parâmetros de relaxação no tecido a ser examinado. Estas partículas geram contraste na IRM encurtando os tempos de relaxação longitudinal $\left(\mathrm{T}_{1}\right)$ e transversal $\left(\mathrm{T}_{2}\right.$ e $\left.\mathrm{T}_{2} *\right)$ de spins nuclear do próton de moléculas de água, que fazem parte de 70 a $90 \%$ da maioria dos tecidos.

A técnica de IRM baseia-se na relaxação dos prótons da água que depende do campo magnético, sequência de pulsos, distribuição heterogênea e do meio ambiente da água no organismo. A interpretação da IRM resultante ajuda identificar e demarcar a maioria dos tecidos. O contraste pode ser melhorado utilizando agentes de contraste positivo ou negativo. Agentes de contraste negativo induzem um grande encurtamento do tempo de relaxação transversal $\left(\mathrm{T}_{2}\right)$ conduzindo a um escurecimento das imagens obtidas por IRM, o contato estreito de moléculas de água com agente de contraste positivo é refletida por um brilho que encurta o tempo de relaxação longitudinal $\left(\mathrm{T}_{1}\right)$.

Para agentes de contraste convencionais por RMN, SPIONs são sintetizadas através da precipitação do óxido de ferro numa solução aquosa contendo sais de ferro mediante 
adição de uma solução alcalina. Tais SPIONs são usualmente insolúveis, portanto é requerido o seu revestimento para serem solúveis num meio aquoso [36].

A determinação dos tempos de relaxação $T_{1}$ e $T_{2}$ de soluções aquosas de SPIONs estão entre os parâmetros físicos mais pertinentes para caracterizar a eficiência de SPIONs como um agente de contraste para imagem por RMN [36].

\subsection{Síntese de nanopartículas de magnetita}

A suspensão coloidal à base de SPIONs, compostos por magnetita, foram preparadas seguindo o método de coprecipitação, que consiste de uma mistura de cloreto férrico e ferroso [37-39]. O método foi modificado através da utilização de surfactante nas dissoluções precursoras da síntese.

O processo de coprecipitação consiste basicamente na mistura de sais inorgânicos em ambiente aquoso seguido de precipitação com hidróxido. $\mathrm{O}$ precipitado resultante é digerido, filtrado e seco. Usando o princípio deste processo as SPIONs foram sintetizadas. As vantagens deste método são: homogeneidade química, temperaturas de reação e sinterização baixas, distribuição de tamanho de partícula estreita, fácil aplicação e baixo custo. Para garantir a reprodutibilidade do produto, o pH, tipo de ânion, ordem de adição dos reagentes, concentração dos metais, razão molar dos metais, temperatura, agitação, etc. foram cuidadosamente controlados.

Para a síntese da suspensão coloidal à base de SPIONs realizada neste trabalho, preparamos duas soluções. A primeira solução foi preparada dissolvendo 2,0 $\mathrm{g}$ de cloreto ferroso em $5 \mathrm{~mL}$ de uma solução de $\mathrm{HCl}$ (ácido clorídrico). A segunda solução foi obtida dissolvendo 3,2 g de cloreto férrico em $20 \mathrm{~mL}$ da solução de $\mathrm{HCl} 2 \mathrm{M}$. Estas soluções foram preparadas a temperatura ambiente e mantidas sob agitação magnética. $\mathrm{Na}$ solução de $\mathrm{HCl}$ foi diluído surfactante concentrado Renex 95 (nonilfenoletoxilado, Poli Brasil) resultando em 5\% de surfactante (em volume). 
As soluções de cloreto ferroso e cloreto férrico foram combinados em um beaker, a solução resultado da mistura foi vigorosamente agitada utilizando uma barra magnética. A reação de precipitação do óxi-hidróxido do ferro foi realizada pela adição lenta de uma solução concentrada de hidróxido de amônia. Utilizou-se $30 \mathrm{~mL}$ de uma solução de hidróxido de amônia que foi adicionado lentamente no beaker utilizando uma pipeta. Magnetita na forma de um precipitado preto formou-se imediatamente. A agitação magnética foi continuada por um período de 30 minutos após a adição do hidróxido de amônia. O precipitado obtido foi lavado sucessivamente com água deionizada para eliminar ao máximo o eletrólito cloreto de amônio da suspensão e com ajuda de um imã a separação magnética foi realizada. O processo de lavagem foi realizado utilizando uma ultracentrífuga para separar o precipitado da suspensão, foram realizados cinco ciclos de lavagem.

Para o revestimento das nanopartículas de magnetita, $1 \mathrm{~g}$ do precipitado preto foi disperso em $20 \mathrm{~mL}$ de água deionizada e, 1,25 g de ácido láurico foi dissolvido em 20 $\mathrm{mL}$ de água deionizada aquecida a $70^{\circ} \mathrm{C}$ e mantida sob agitacão. A solução de ácido láurico foi adicionado à solução de partículas de magnetita. O revestimento das nanopartículas (flocunação) de magnetita é formada imediatamente. Um magneto muito intenso foi utilizado para se fixar à flocunação e a solução foi decantada. O precipitado foi lavado com acetona cindo vezes para remover o excesso de ácido gorduroso e seco em estufa numa temperatura de $70^{\circ} \mathrm{C}$ por 60 min. A suspensão do precipitado de nanopartículas de magnetita revestidas com ácido láurico foi realizado utilizando o surfactante Renex-100 para esta finalidade $5 \mathrm{~mL}$ de Renex foram dissolvidos em $50 \mathrm{~mL}$ de água deionizada sob aquecimento e agitação magnética, o precipitado foi adicionado a esta solução e foi submetido a ultrasom e centrifugado para separar as partículas maiores e ter um suspensão de partículas com uma faixa estreita de tamanhos.

Assim, seguindo o procedimento acima descrito, foi obtido uma suspensão coloidal à base de SPIONs de magnetita, apresentando a propriedade de redispersão em água. 


\subsection{Resultados e discussões}

\subsubsection{Difração de raios X (DRX)}

A DRX foi utilizada para determinar as fases cristalinas presentes na amostra e para estimar o tamanho médio dos monocristais das SPIONs. Os resultados de DRX mostraram a formação da fase desejada da magnetita (Figura 6.9), comprovando a eficiência do método de sintese.

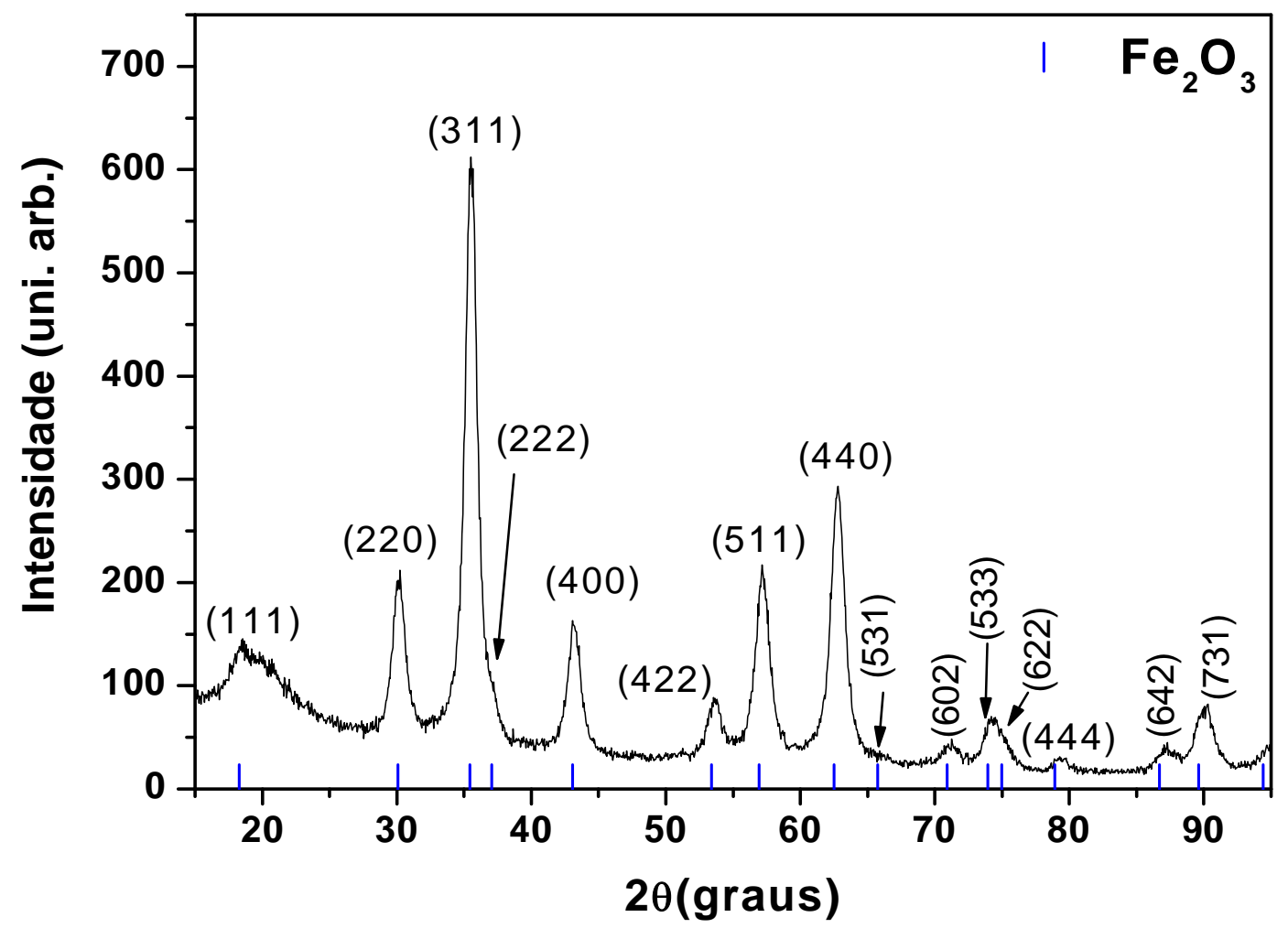

Figura 6.9: Difratograma de raios $X$ da amostra sintetizada à base de SPIONs. O difratograma evidencia a presença de uma fase de óxido de ferro-Magnetita.

No difratograma obtido do pó depois da suspensão coloidal ser sonificada e centrifugada (Figura 6.9) não observa-se a preservação do estabilizante (Renex 100) e nem do revestimento (ácido laúrico), mostrando somente os picos mais intensos correspondentes a fase de magnetita. A amostra apresenta os picos de difração em (111), (220), (311), (222), (400), (422), (511), (440), (620), (533), (622), (444), (642), e (731) 
que correspondem à estrutura spinélio invertido da magnetita (PDF\#19-0629) com parâmetro de rede $\mathrm{a}_{0}=8,394 \AA$ A. O resultado também mostra que a fase determinada se manteve estável, depois de coberta pelo polímero. Resumindo, a Figura 6.9 indica que estas amostras não submetidas a tratamento térmico são cristalinas e apresentam os picos referentes à magnetita.

Mediante a DRX foi estimado o tamanho médio das nanopartículas para o qual empregou-se a equação do Scherrer [40] sendo esta aplicada à linha mais intensa do padrão de DRX da amostra do ferrofluido, resultando em um diâmetro médio $D_{(h k l)}=(9,6 \pm 1,7) n m$.

\subsubsection{Microscopia eletrônica de transmissão (MET)}

A micrografia de MET obtida das SPIONs é mostrada na Figura 6.10. A polidispersividade do tamanho das nanopartículas foi analisada das imagens de MET usando um software de análise de imagem (java version of ImageJ v 1.33u [41]). O diâmetro médio foi obtido ajustando os dados experimentais com uma função de distribuição log normal, como sugerido por O’Grady and Bradbury [42], dada pela expressão:

$$
f\left(D_{p}\right)=\frac{1}{\sqrt{2 \pi} \omega_{P} D_{P}} \exp \left(-\frac{\left(\ln D_{P}-\ln D_{P}^{0}\right)^{2}}{2 \omega_{P}^{2}}\right),
$$

com diâmetro médio $\left\langle D_{P}\right\rangle=D_{P}^{0} \exp \left(\omega_{P}^{2} / 2\right)$ e $\omega_{P}$ como o desvio padrão em torno de $\ln D_{P}^{0}$. O desvio padrão e o diâmetro médio $\sigma_{P}$ é $\sigma_{P}=D_{P}^{0}\left[\exp \left(2 \omega_{P}^{2}\right)-\exp \left(\omega_{P}^{2}\right)\right]^{1 / 2}$

A análise da polidispersividade do tamanho das nanopartículas e sua distribuição, ajustados a uma distribuição log-normal indica um diâmetro médio $\left\langle D_{P}\right\rangle=8,8 \mathrm{~nm}$ e o desvio padrão $\sigma_{P}=1,5 \mathrm{~nm}$. Esta análise foi baseada no correspondente histograma de distribuição de tamanho (Figura 6.10) onde foram usadas mais de 300 partículas. 

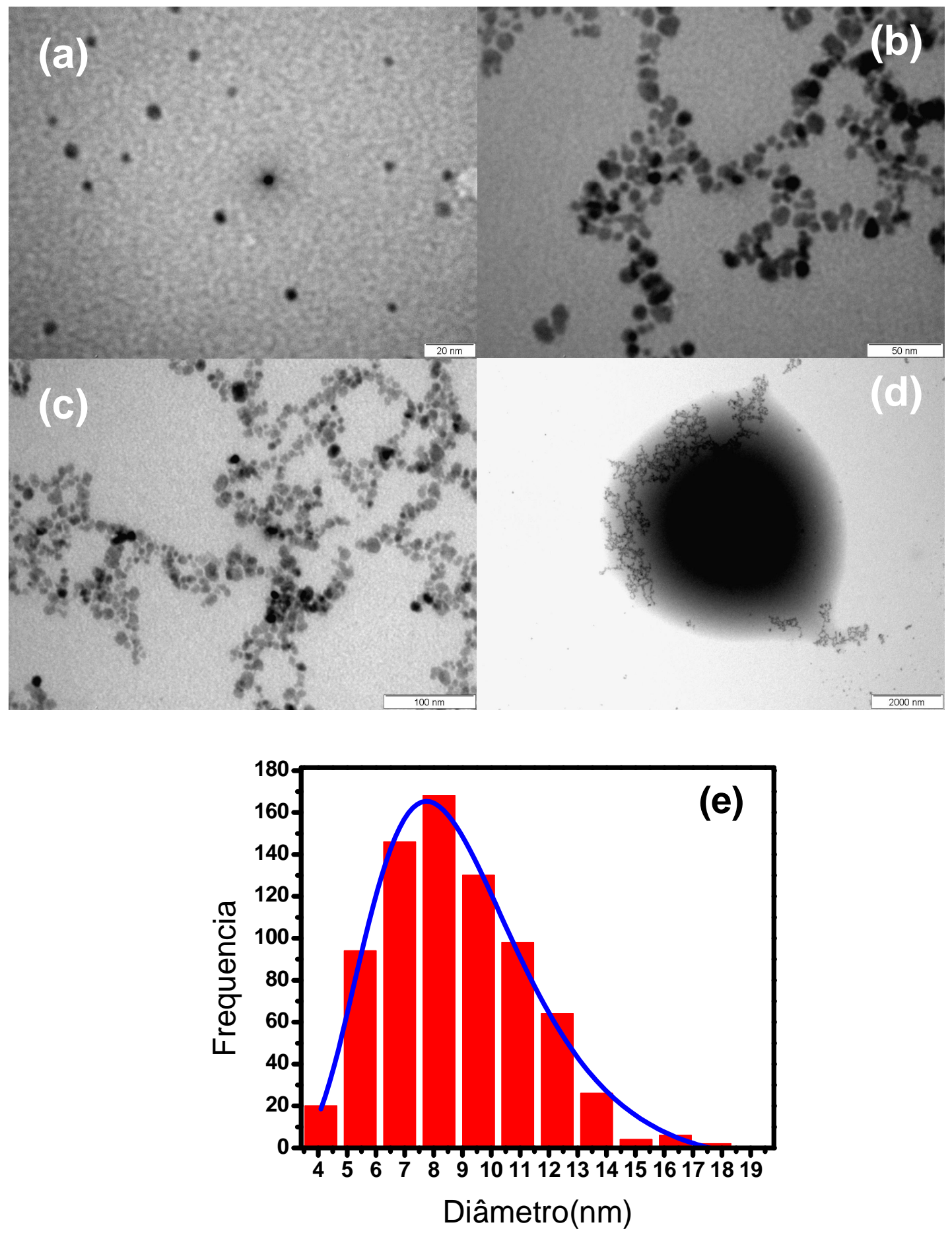

Figura 6.10: Imagem obtida por MET do ferrofluido em pó após sonificação e centrifugação e, o correspondente histograma de distribuição de tamanho de partículas. $\mathrm{O}$ diâmetro médio das partículas e o desvio padrão são $\left\langle D_{P}\right\rangle=8,65 \mathrm{~nm}$ e $\sigma_{P}=0,12 \mathrm{~nm}$, respectivamente. 


\subsubsection{Calorimetria exploratória diferencial ("DSC")}

Na Figura 6.11 é mostrada a reação térmica do ferrofluido. A curva do sinal do fluxo de calor foi corrigida mediante a linha base. A curva de DSC mostra um evento exotérmico na temperatura de $252,4{ }^{0} \mathrm{C}$ que está associada com a oxidação de $\mathrm{Fe}_{3} \mathrm{O}_{4}$ (Magnetita) para $\gamma-\mathrm{Fe}_{2} \mathrm{O}_{3}$ (Magemita) $[43,44]$. Nesta reação $\mathrm{O}_{2}$ é requerida para completar a reação (Magnetita para Mgemita). Esta interpretação é apoiada pelo esgotamento de $\mathrm{O}_{2}$ durante a transição [44].

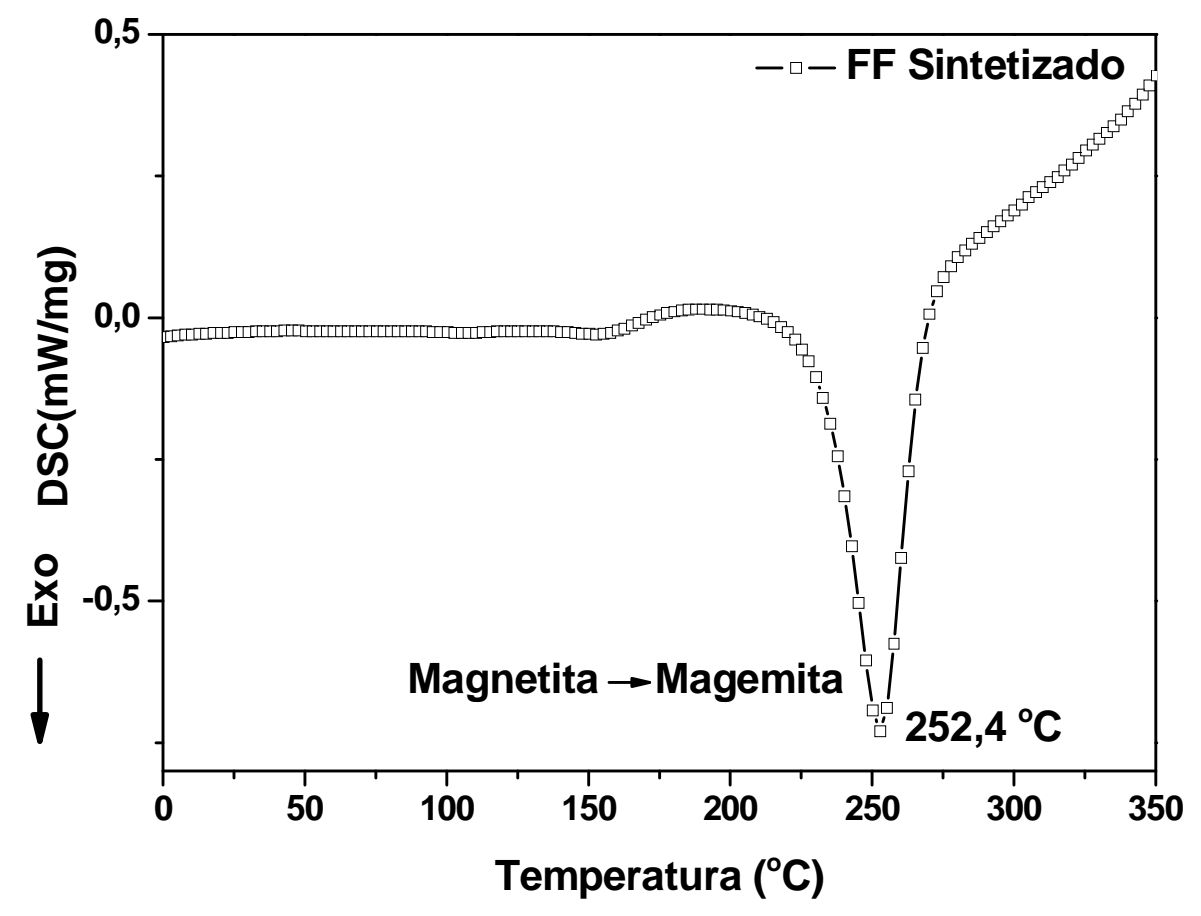

Figura 6.11: Curva de DSC para a oxidação da magnetita em $20 \% \mathrm{O}_{2}$ e $80 \% \mathrm{~N}_{2}$

\subsubsection{Ressonância Ferromagnética (RFM)}

Foram realizadas medidas de RFM na faixa de $4 \mathrm{~K}$ até $261 \mathrm{~K}$ e a temperatura ambiente onde os espectros são mostrados nas Figuras 6.12 e 6.13, respectivamente. As Figuras 6.12 e 6.13 mostram os espectros de RFM da suspensão coloidal sintetizada à 
base de SPIONs. A quantidade de ferrofluido utilizada para as medidas foi de $5 \mu \mathrm{L}$. Os espectros são descritos por uma única linha de ressonância.

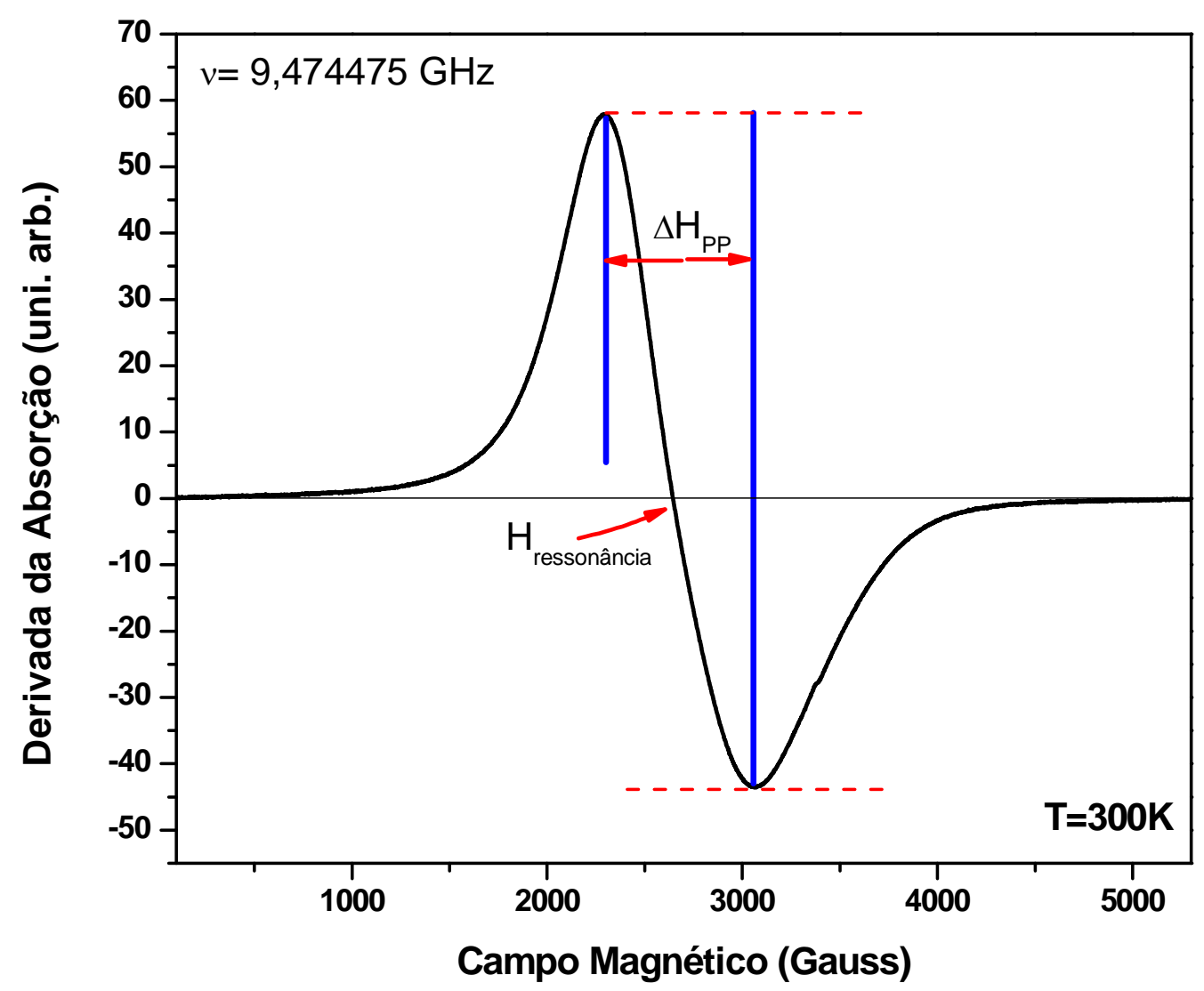

Figura 6.12: Espectro de RFM da suspensão coloidal à base de SPIONs obtido a temperatura ambiente, $\mathrm{T}=300 \mathrm{~K}$. 


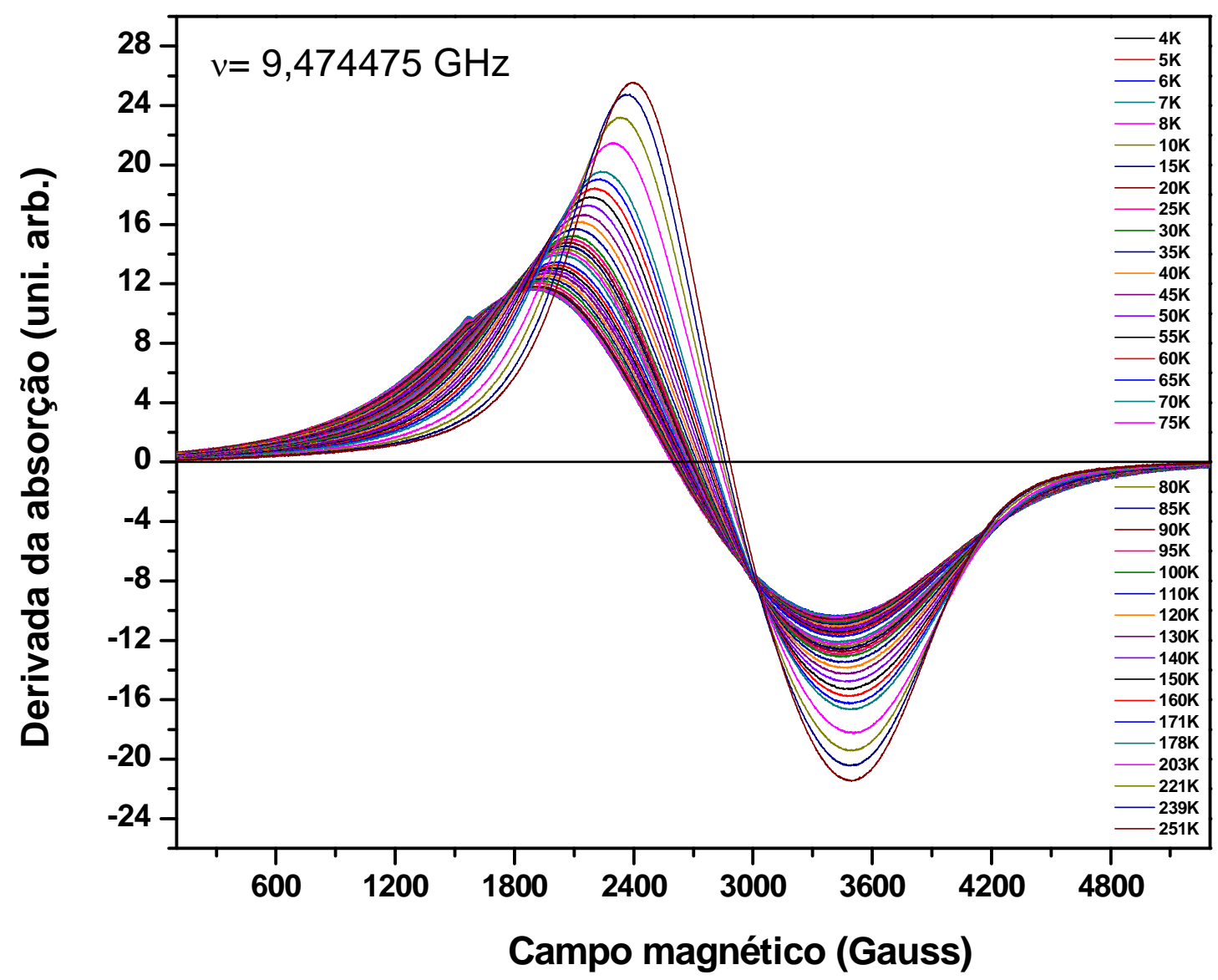

Figura 6.13: Espectros de RFM do ferrofluido, para temperaturas variando entre 4 e $261 \mathrm{~K}$.

A Figura 6.13 mostra a variação térmica dos espectros do ferrofluido sintetizado. Observa-se que o campo de ressonância aumenta com a temperatura. Os espectros também mostram o comportamento da largura de linha de ressonância em função da temperatura. Nestes espectros verifica-se que a largura de linha aumenta com a diminuição da temperatura.

Foi obtido o valor de $\mathrm{g}=\left(h v /\left(\beta \mathrm{H}_{0}\right)\right)=(2,18 \pm 0,02)$ (temperatura do ambiente), com $v=9,428 \mathrm{GHz}$, onde $h$ é a constante de Planck, $v$ é a freqüência do espectrômetro e $\beta$ é o magneton de Bohr. A linha em $g=2,18 \pm 0,02$ (Figura 6.12), correlacionada ao ferro, com largura de 4000 Gauss, apresenta um comportamento tipicamente superparamagnético. Está linha é relacionada a nanopartículas esféricas isoladas de 
magnetita, a ausência de linhas estreitas, correlacionadas aos radicais livres possivelmente resultantes do processo de sínteses, confirma a ausência de radicais livres na amostra. $\mathrm{O}$ valor de $\mathrm{g}$ calculado na região de alta temperatura está em bom acordo com $\mathrm{g}=2,25$ de nanopartículas de magnetita.

Espectros típicos de ferrofluido são sinais largos como pode ser observado na Figura 6.13 na faixa de 4 até $261 \mathrm{~K}$. Os espectros são em geral assimétricos, observando que a amplitude pico a pico e o ponto mínimo da derivada varia ao longo da gama da temperatura enquanto o ponto da máxima derivada aumenta e se desloca para direita com o aumento da temperatura. Isto é devido ao fato que numa dispersão ferromagnética randomicamente orientada a largura de linha de absorção é uma função monotonica da temperatura. À baixa temperatura a largura de linha é grande devido à dispersão das partículas na direção do campo da anisotropia. A medida que a temperatura diminui, são formados momentos magnéticos isotrópicos causando a diminuição da largura de linha.

Portanto, a variação em $\Delta \mathrm{H}_{\mathrm{pp}}$ pode ser explicada usando um sistema de dois níveis e sob o equilibro térmico, a largura de linha de RFM é dado por:

$$
\Delta H_{P P}=L \tanh \left[\frac{\Delta E}{2 k T}\right], \quad L=\frac{5 g \beta S n}{R^{3}}
$$

onde $n$ é o número de centros magnéticos, g fator de "spliting”, $\beta$ é o magneton de Bohr, $\mathrm{R}$ é a distancia média entre nanopartículas, $\mathrm{S}$ é o spin efetivo dos centros magnéticos e $\Delta \mathrm{E}$ é a barreira de energia. Portanto L se mantém inalterado e a principal contribuição para $\Delta \mathrm{H}_{\mathrm{pp}}$ seria o termo $\Delta \mathrm{E}$. O enfraquecimento do acoplamento magnético é responsável pelo decremento da largura de linha $[45,46]$.

A Figura 6.14 mostra a mudança do fator g com a temperatura, observando-se uma diminuição quase linear com o incremento da temperatura. A Figura 6.15 mostra a dependência da largura de linha pico pico $\left(\Delta \mathrm{H}_{\mathrm{PP}}\right)$ com a temperatura associada com a linha de ressonância. Esta linha diminui como o incremento da temperatura, seguindo as 
previsões de RFM para partículas superparamagnéticas [47]. Portanto, espera-se que o alargamento e deslocamento do sinal de ressonância estejam associados com o bloqueio da magnetização das nanopartículas de $\mathrm{Fe}_{3} \mathrm{O}_{4}$.

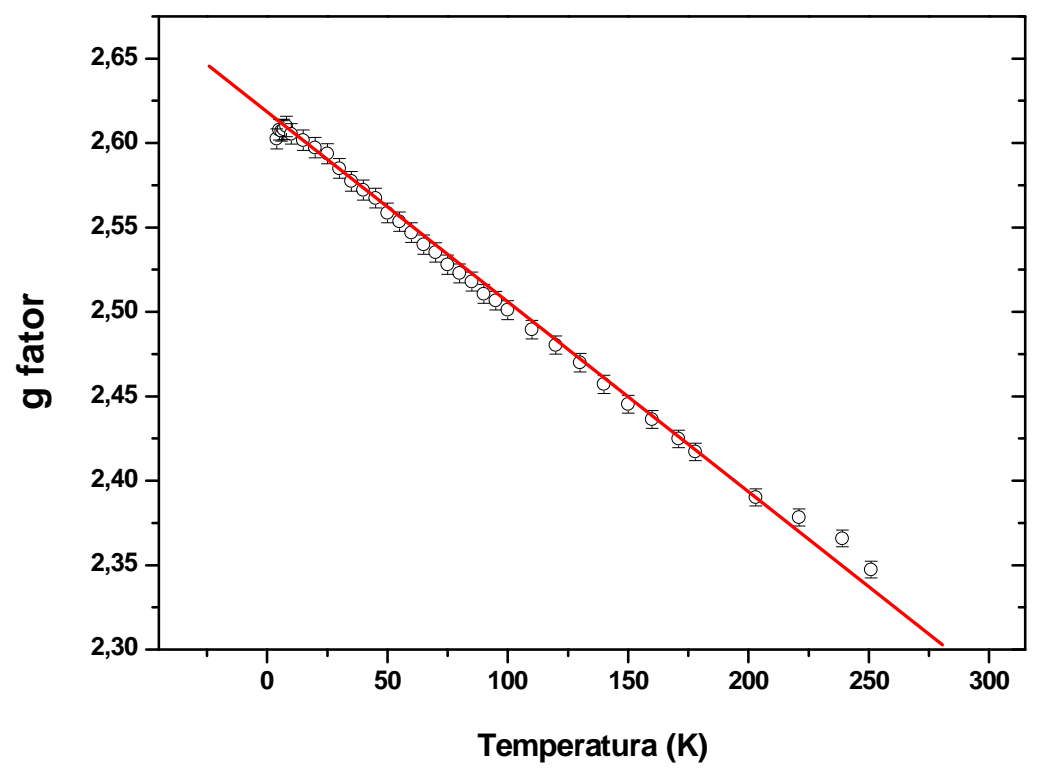

Figura 6.14: Variações térmicas do fator $g$.

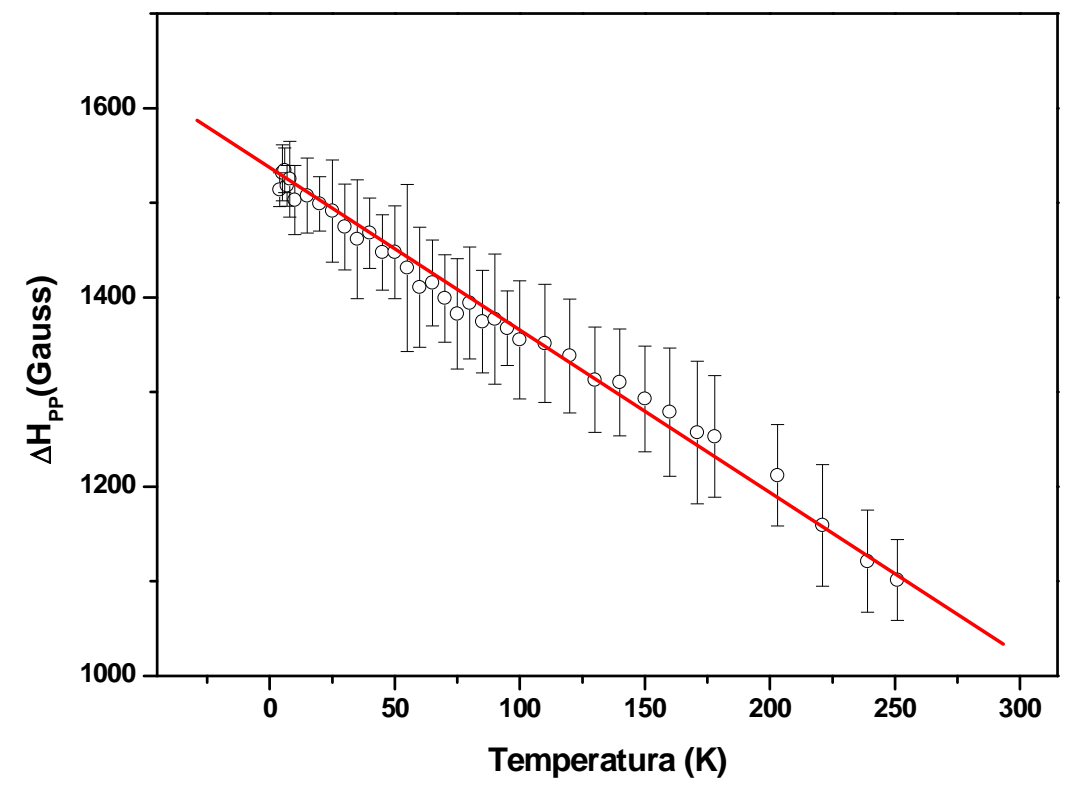

Figura 6.15: Variações térmicas de $\Delta \mathrm{H}_{\mathrm{PP}}$ do sinal do espectro de absorção. 
A Figura 6.16 mostra a variação térmica dos campos de ressonância ( $\left.\mathrm{H}_{\text {ressonância }}\right)$ obtidos do análise dos espectros da amostra de magnetita sintetizada. Na faixa de

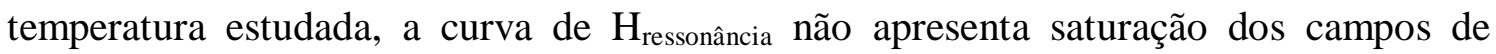
ressonância.

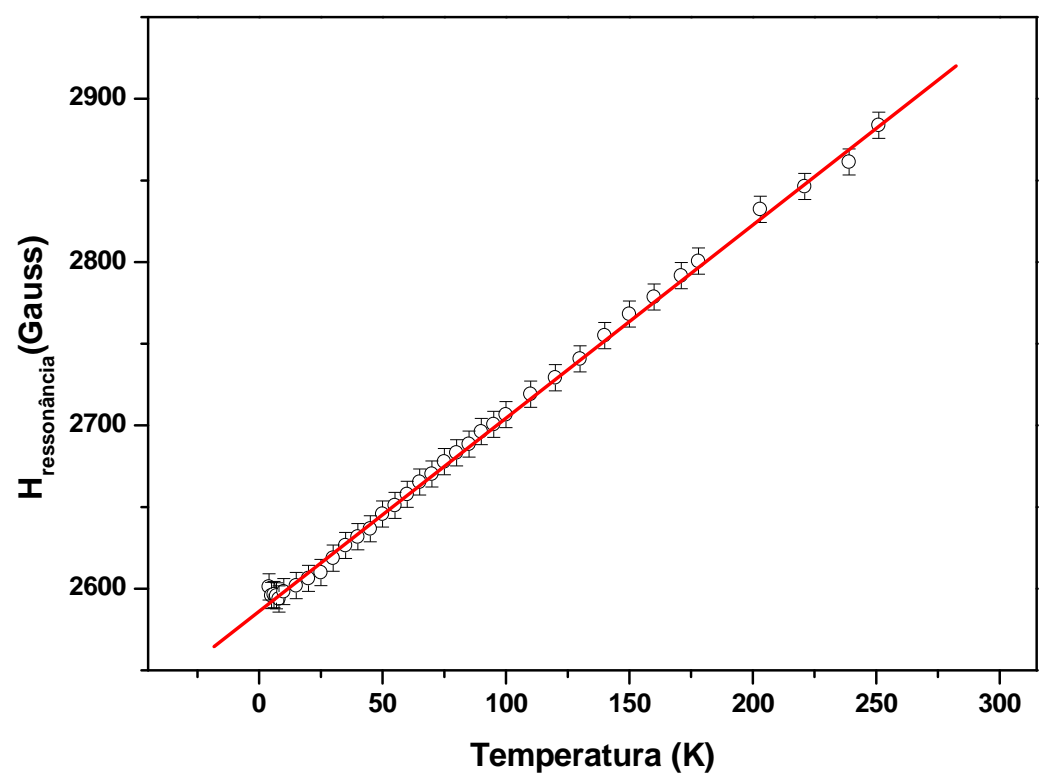

Figura 6.16: Variações térmicas dos campos de ressonância da amostra à base de nanopartículas de óxido de ferro.

$\mathrm{O}$ valor de $\Delta H_{p p}$ decresce na faixa de temperatura estudada em que $\mathrm{H}_{\text {resonância }}$ cresce, mostrando um comportamento inverso espelhado, isto é um comportamento característico de nanopartículas sintéticas [48,49].

De modo geral, para um sistema superparamagnético de partículas tendo uma distribuição estatística de formas e tamanhos, a simples relação de potência entre o deslocamento do campo de ressonância $\delta H_{\text {resonance }}$ e a largura de linha pode ser expressa de acordo com o modelo de Nagata e Ishihara [50], o deslocamento do campo de ressonância $\delta \mathrm{H}_{\text {resonance }} \mathrm{e}$ a largura de linha $\Delta \mathrm{Hpp}$ são devidos a campos de desmagnetização de amostras não esféricas e eles são relacionados através de $\delta H_{r e s}$ $\sim(\Delta H p p)^{2}$ para partículas parcialmente orientadas e $\delta H_{r e s} \sim(\Delta H p p)^{3}$ para partículas 
aleatoriamente orientadas. Para testar esta relação de potência foram graficados dados em uma escala logarítmica dupla. $\mathrm{O}$ gráfico de $\ln \delta \mathrm{H}_{\mathrm{r}}$ vs $\ln \Delta \mathrm{Hpp}$ é mostrado na Figura 6.17 , onde $\delta \mathrm{H}_{\mathrm{r}}=\mathrm{H}_{\mathrm{o}}-\mathrm{H}_{\mathrm{r}}$ correspondente a $\mathrm{g}=(2,18 \pm 0,10)$ e $v=9,428 \mathrm{GHz}$ foi usado. A inclinação $n=2,8 \pm 0,1$ para $T<77 \mathrm{~K}$ é consistente com um sistema parcialmente orientado, a inclinação da reta de aproximadamente $n=7,0 \pm 0,1$ para $T>70 \mathrm{~K}$ expressa um comportamento superparamagnético onde as nanopartículas de magnetita se encontram isoladas e orientadas aleatoriamente.

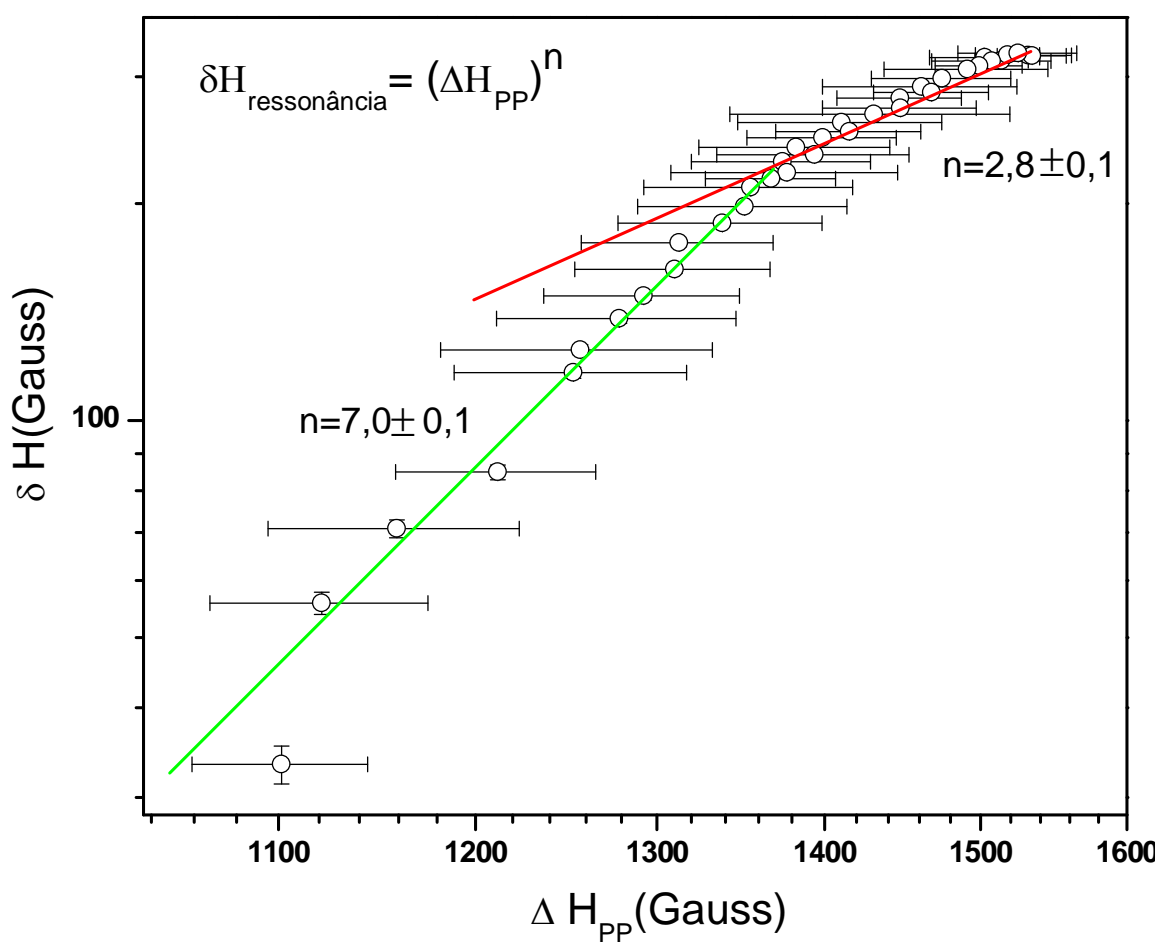

Figura 6.17: Relação entre $\delta H_{\text {ressonância }}$ e $\Delta H_{P P}$, mostrando uma dependência de ordem $\mathrm{n} \cong 2,8 \pm 0,1$ e $\mathrm{n} \cong 7,0 \pm 0,1$.

Na Figura 6.18 é mostrada a variação do $\mathrm{T}_{2}$ com a temperatura. A interação dipolo magnético entre as partículas e interação "superexchange" entre os íons magnéticos apesar da presença dos íons de oxigênio são dois fatores predominantes que determinam os parâmetros de ressonância, factor giromagnético g e $\Delta H_{P P}$. Interações de dipolo forte dão um grande $\Delta H_{P P}$ e factor g. Adicionalmente uma interação 
"superexchange" forte produz pequenos $\Delta H_{P P}$ e factor g [51]. $\mathrm{O}$ aumento da temperatura poderia aumentar o movimento dos elétrons, causando uma interação "superexchange" mais forte entre os cátions apesar da presença dos íons de oxigênio e portanto um decremento no $\Delta H_{P P}$ e factor g. Consequentemente, os valores de $\mathrm{T}_{2}$ aumentam com o aumento da temperatura. Outra observação interessante é a mudança na inclinação na dependência com a temperatura como é mostrada na Figura 6.18, evidenciando dois tipos de taxa de relaxação. A mudança na taxa de relaxação do óxido de ferro superparamagnético a $\mathrm{T}>77 \mathrm{~K}$ pode estar relacionado a uma mudança na susceptibilidade magnética [52].

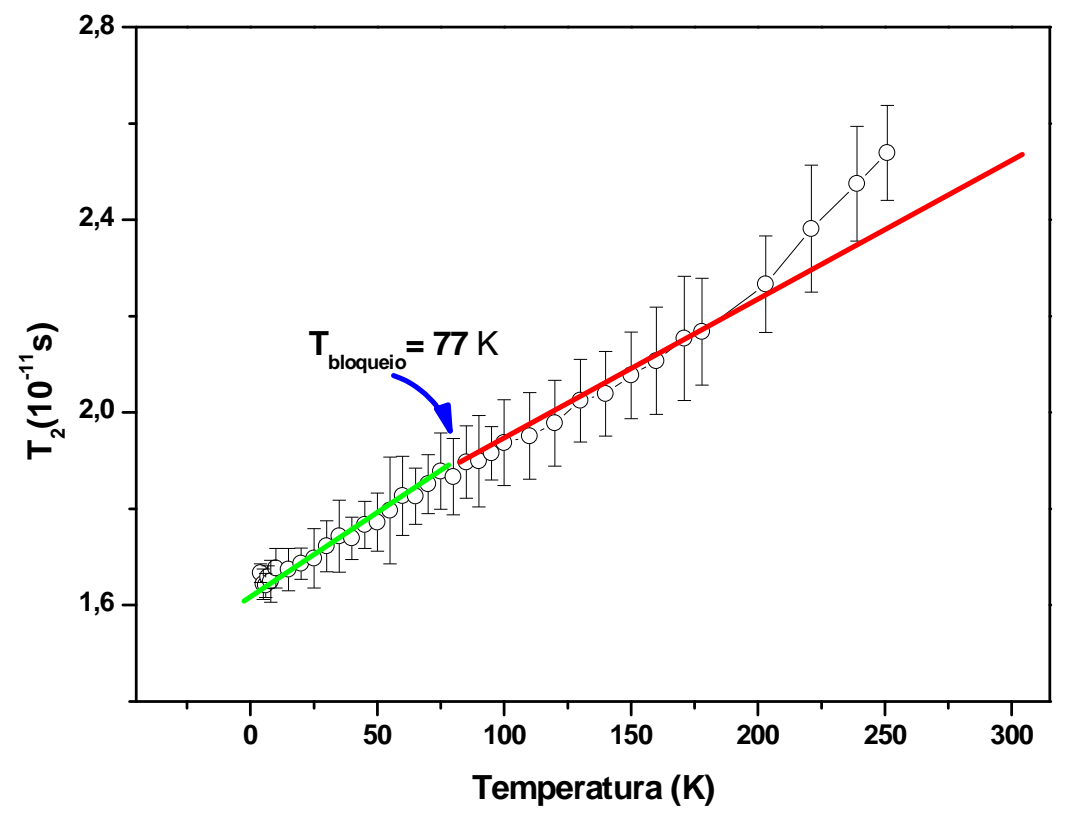

Figura 6.18: Tempo de relaxação spin-spin, $T_{2}$, em função da temperatura.

Na Figura 6.19 observamos que o número de spin praticamente permanece constante com o aumento da temperatura. 


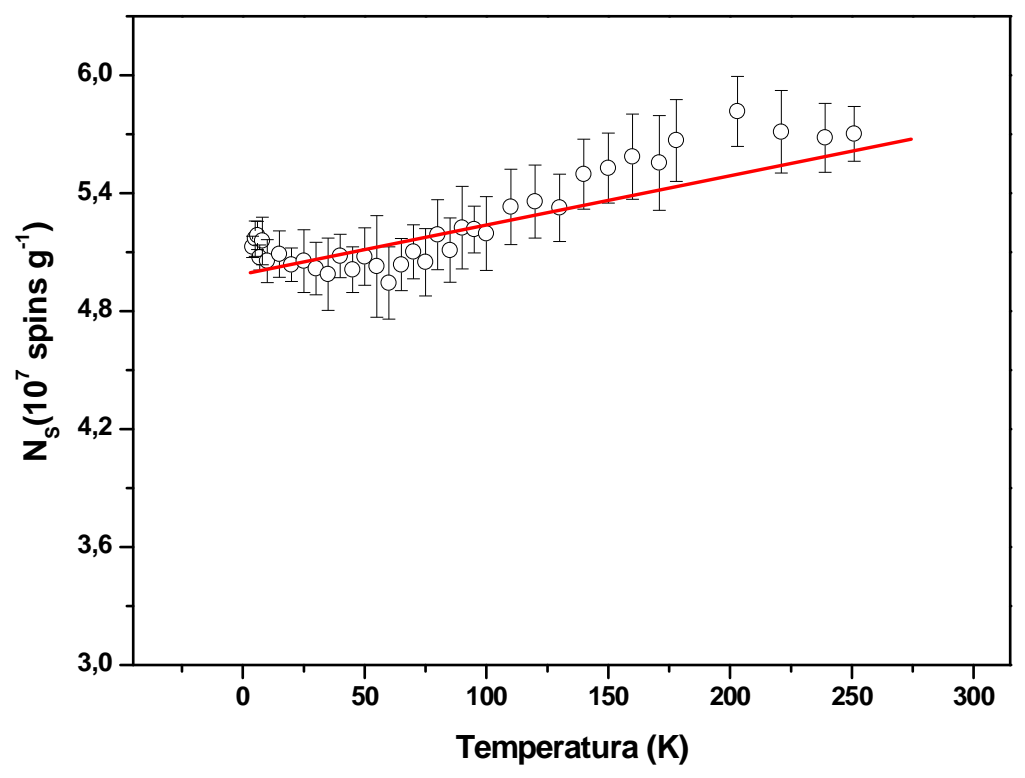

Figura 6.19: Numero de spins $\left(\mathrm{N}_{\mathrm{S}}\right)$ em função da temperatura.

A técnica de RFM foi empregada para a caracterização magnética da suspensão coloidal à base de SPIONs. Foram feitos estudos sistemáticos das linhas ferromagnéticas visando o estudo do superparamagnetismo do material sintetizado. Para este estudo foram realizadas medidas de variações térmicas, a baixa temperatura, da amostra sintetizada à base de SPIONs.

\subsubsection{Espalhamento de raios $X$ a baixo ângulo (SAXS)}

Na Figura 6.20 observamos o gráfico característico da curva SAXS. Os dados de espalhamento são apresentados como $\log \mathrm{I}(\mathrm{q})$ vs. $\log \mathrm{q}$ e figuras de Porod (I(q) $\mathrm{q}^{3}$ vs. q).

A amostra de ferrofluido em estudo encontra-se na forma de agregados de partículas primárias. Pode-se deduzir dos resultados de MET que a forma destas nanopartículas é similar à forma esférica. As curvas de SAXS indicam a fractalidade de massa do agregado de partículas primárias com uma dimensão fractal de massa. A Figura 6.20 de $\log \mathrm{I}(\mathrm{q})$ vs. $\log \mathrm{q}$ indica o espalhamento de objetos em duas diferentes 
escalas de comprimento, mostrando dois limites de fractalidade nesta amostra, restrita aos seguintes intervalos: $D_{m}=1,75 \pm 0,02$ e $D_{m}=2,36 \pm 0,02$.

As características do espalhamento da Figura 6.20 são como segue: (a) a lei de potencias em $0,02<q<0,04 \stackrel{o}{A^{-1}}$, correspondentes a escalas de comprimentos curtos, apresentaram um expoente $\alpha=D_{m}=1,75 \pm 0,02$ mostrando variação dependente da amostra, (b) a lei de potência de Porod apresenta-se em q intermediário, $0,05<q<0,11 A^{-1}$, a lei de potências em q intermediário tem um expoente $\alpha=D_{m}=2,36 \pm 0,02$. A característica de espalhamento por massa fractal deve-se ao fato das partículas serem formadas por difusão limitada de aglomerados de nanopartículas. Espera-se uma dimensão de massa fractal resultado de efeitos de concentração ou de aglomerados. A lei de potências deduzida da inclinação das curvas de SAXS produzem o agregado real de dimensão fractal de massa no limite de alta diluição da amostra.

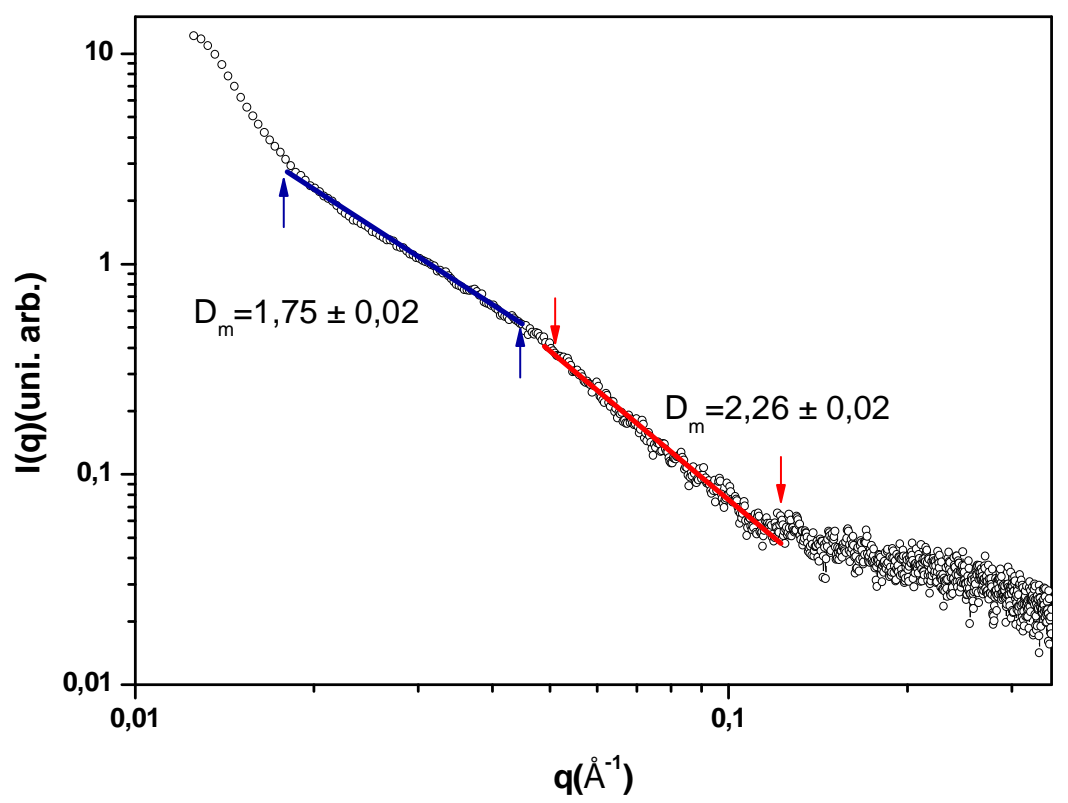

Figura 6.20: Curvas de SAXS correspondentes a xerogéis de $\mathrm{Fe}_{2} \mathrm{O}_{3}$. 
Para visualizar as características da intensidade de SAXS para baixos valores de q, apresentamos, na Figura 6.21, o gráfico de Guinier. Pode-se observar que a curva SAXS, exibe um domínio linear na região de Guinier. O diâmetro médio da partícula determinado pelo raio de giro $R_{g}=8,50 \pm 0,14 \mathrm{~nm}$, assumindo partículas de forma esférica, foi de $D=22,0 \pm 0,4 \mathrm{~nm}$.

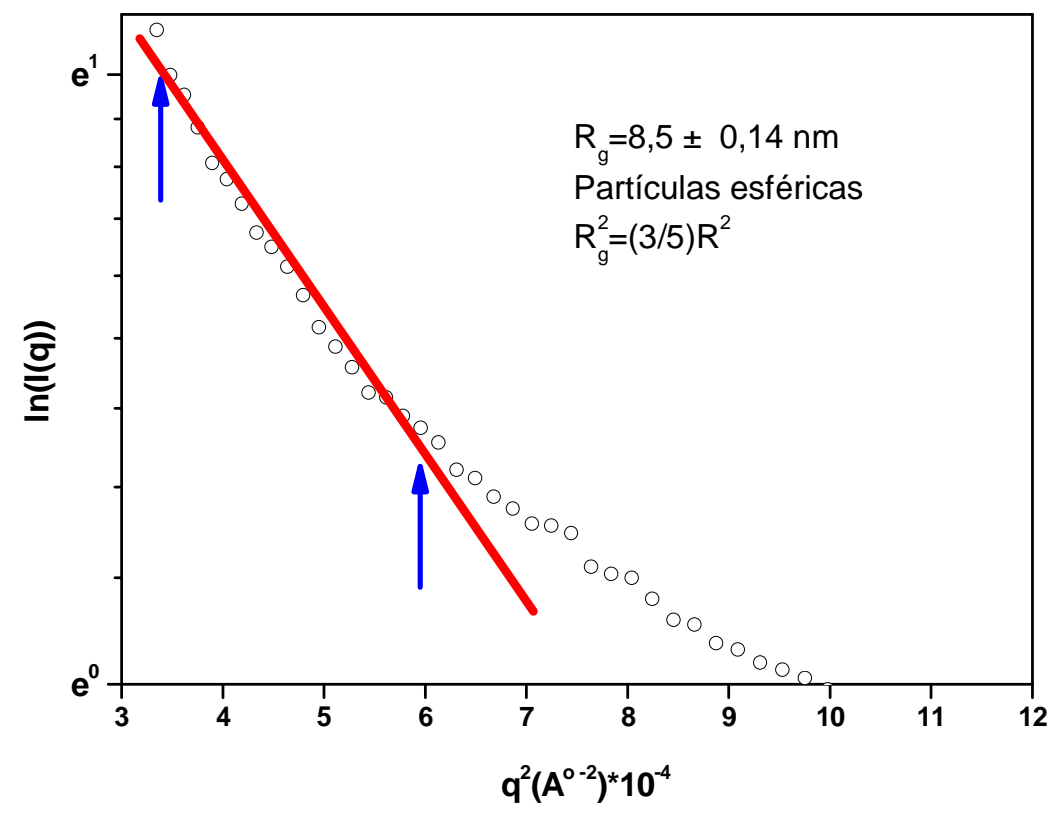

Figura 6.21: Gráfico de Guinier da intensidade SAXS apresentada na figura anterior.

\subsubsection{Caraterização relaxometrica mediante IRM}

As SPIONs são objetos muito interessantes que tem diversas aplicações entre as quais agente de contraste para IRM é uma das mais importantes. Nesta parte do trabalho os tempos de relaxação longitudinal $\left(\mathrm{T}_{1}\right)$ e transversal $\left(\mathrm{T}_{2}\right.$ e $\left.\mathrm{T}_{2}{ }^{*}\right)$, de uma suspensão coloidal à base de SPIONs, foram medidos em intensidades de campo magnético similares aos usados em exames clínicos de IRM. Especificamente, apresentamos a caracterização dos tempos de relaxação nuclear $\mathrm{T}_{1}$ e $\mathrm{T}_{2}$ num campo magnético de $3 \mathrm{~T}$ a temperatura ambiente de uma suspensão aquosa de SPIONs. Nestas suspensões aquosas, que foram resultado de diluições em água, foram estudados os tempos de relaxação de 
prótons de moléculas de água envolvendo as nanopartículas. Mais especificamente, o efeito da concentração de SPIONs nos tempos de relaxação nuclear foram estudados.

Os tempos de relaxação do próton $\mathrm{T}_{1}, \mathrm{~T}_{2}$ e $\mathrm{T}_{2} *$ de suspensões coloidais à base de SPIONs para diferentes concentrações são mostradas na Figura 6.23, 6.24 e 6.25 . Estes tempos de relaxação foram obtidos mediante IRM utilizando um phantom (Figura 6.22) formado por cavidades as quais contem uma suspensão coloidal de SPIONs com uma concentração determinada como é indicada na Tabela 6.1.

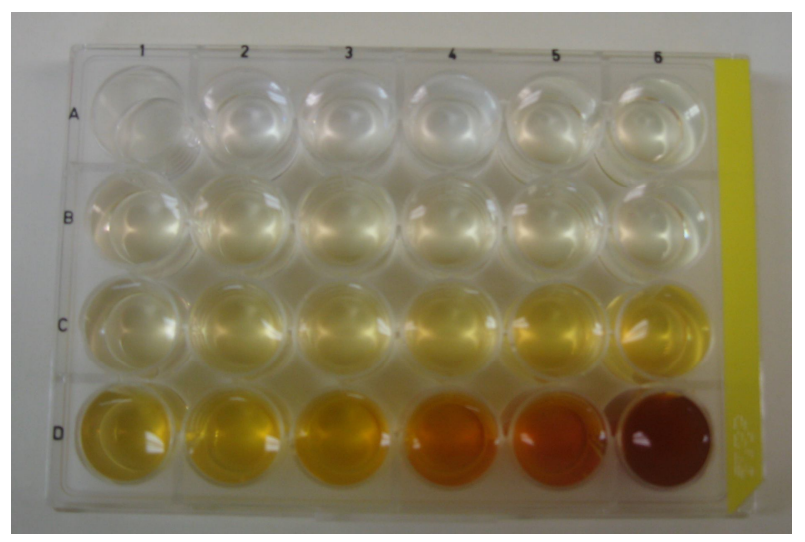

Figura 6.22: "Phanthom" utilizado na caracterização relaxométrica para a obtenção de imagens no tomógrafo de RMN.

Tabela 6.1: Concentrações, em $\mu \mathrm{M}$, de SPIONs utilizadas no phantom na avaliação do agente de contraste para medidas dos tempos de relaxação nuclear.

\begin{tabular}{ccccccc}
\cline { 2 - 7 } $\boldsymbol{A}$ & $\mathbf{1}$ & $\mathbf{2}$ & $\mathbf{3}$ & $\mathbf{4}$ & $\mathbf{5}$ & $\mathbf{6}$ \\
\cline { 2 - 7 } & Sem & $\mathrm{H}_{2} \mathrm{O}$ & 1,04 & 2,08 & 3,13 & 4,17 \\
& amostra & & & & & \\
$\boldsymbol{C}$ & 5,21 & 6,25 & 7,29 & 8,33 & 9,38 & 10,42 \\
$\boldsymbol{D}$ & 20,83 & 31,25 & 41,67 & 52,08 & 62,50 & 72,92 \\
& 83,33 & 125,00 & 208,33 & 520,83 & 729,17 & 3125,00 \\
\hline
\end{tabular}

Nas Figuras 6.23, 6.24 e 6.25 é mostrada a redução de $T_{1}, T_{2}$ e $T_{2} *$ associados com o incremento das concentrações de SPIONs no phantom. Em baixas concentrações de SPIONs o efeito do tempo de relaxação $\mathrm{T}_{2}$ é predominante. Em altas concentrações de SPIONs o tempo de relaxação $\mathrm{T}_{1}$ também é reduzido. 


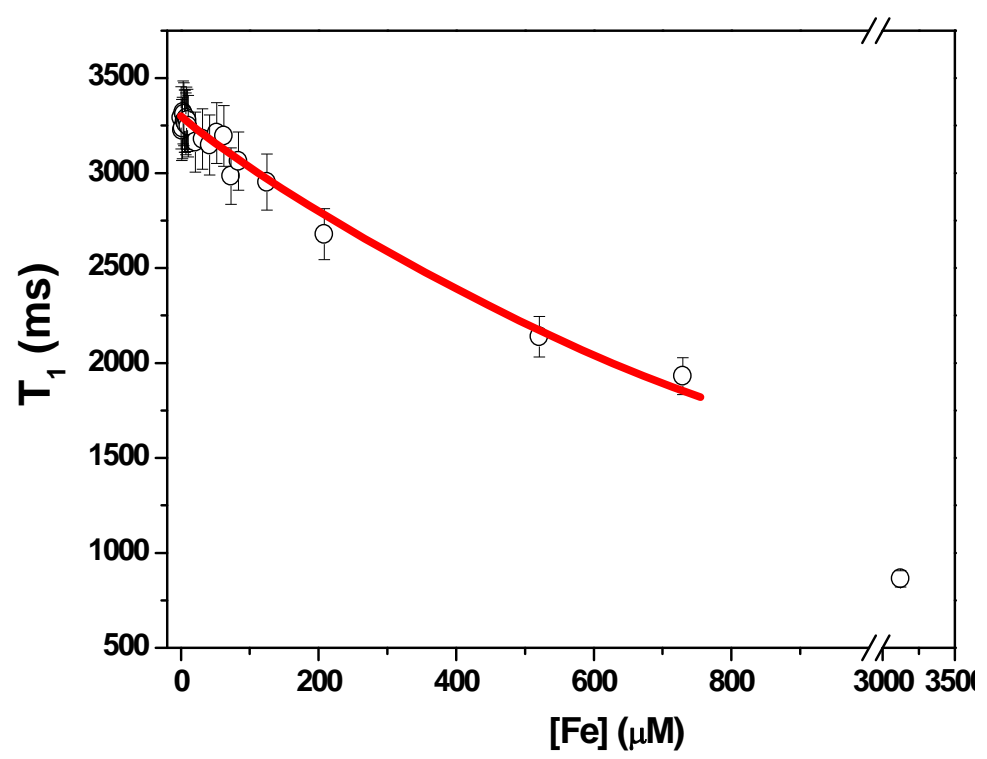

Figura 6.23: Tempos de relaxação $T_{1}$ em função da concentração de SPIONs uniformemente distribuído em solução surfactada com concentrações de ferro na faixa de $1 \mu \mathrm{M}$ a $3125 \mu \mathrm{M}$. As imagens foram feitas a temperatura ambiente utilizando um tomógrafo de RMN de corpo inteiro de $3 \mathrm{~T}$.

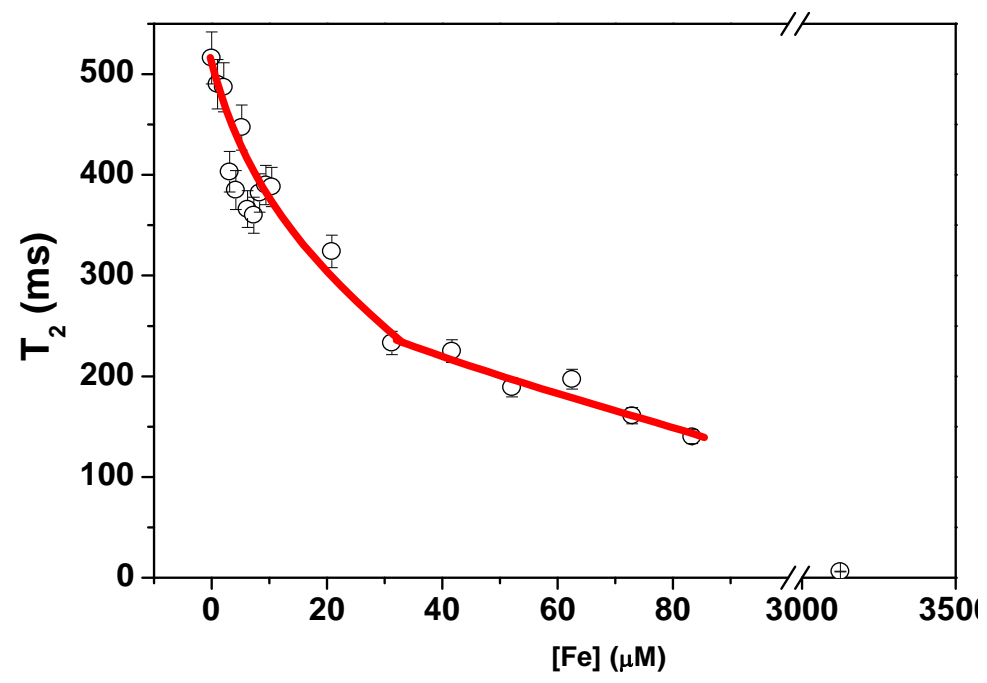

Figura 6.24: Tempo de relaxação $T_{2}$ em função da concentração de SPIONs uniformemente distribuído em solução surfactada com concentrações de ferro na faixa de $1 \mu \mathrm{M}$ a $3125 \mu \mathrm{M}$. As imagens foram feitas a temperatura ambiente utilizando um tomógrafo de RMN de corpo inteiro de $3 \mathrm{~T}$. 


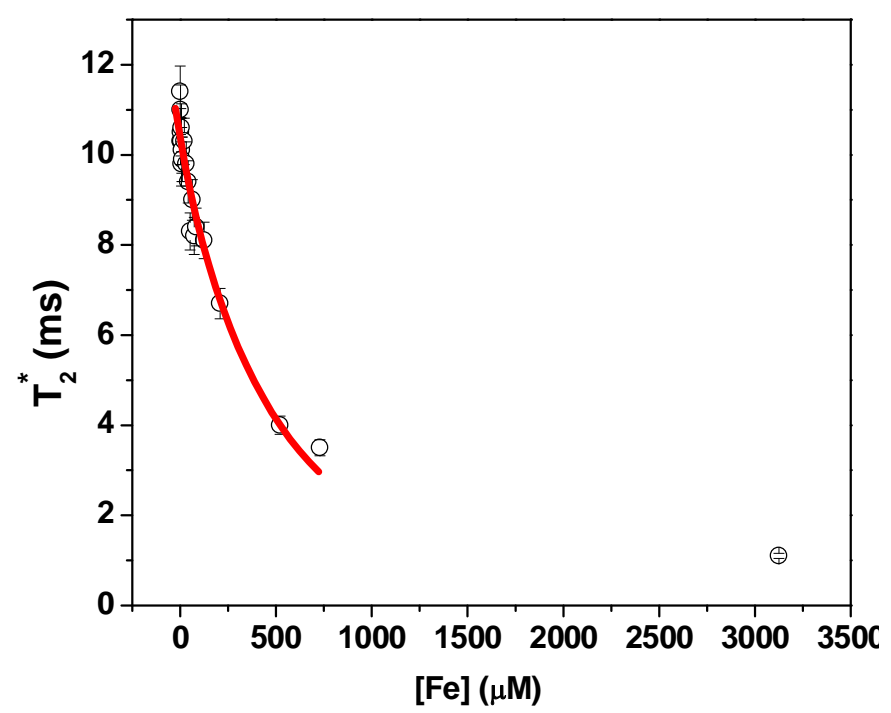

Figura 6.25: Tempos de relaxação $\mathrm{T}_{2} *$ em função da concentração de Ferro em concentrações na faixa de $1 \mu \mathrm{M}$ a $3125 \mu \mathrm{M}$ como é indicado no phantom. As IRMs foram adquiridas a temperatura ambiente usando um tomógrafo de RM de $3 \mathrm{~T}$.

O efeito induzido pelas SPIONs no tempo de relaxação $\mathrm{T}_{2} *$ (como é mostrada na Figura 6.25) na forte diminuição da intensidade do sinal é devido a que os SPIONs produzem domínios de magnetização espontânea que alinham seus momentos de dipolo magnético e se tornam magnetizados fortemente por um campo magnético externo. A presença dos SPIONs aumenta localmente o campo magnético externamente aplicado, produzindo heterogeneidade no campo magnético que por sua vez, promove defasagem resultando em perda do sinal, alterando assim o tempo de relaxação T2*.

As imagens obtidas mediante as seqüências SE_MC (exemplo as imagens da Figura 6.27 A e B) e GE (exemplo as imagens do inset Figura 6.29 A e B) nas diferentes concentrações de SPIONs mostra o decréscimo da intensidade do sinal pelo incremento da concentração dos SPIONs. Em uma mesma imagem dado um tempo TE determinado, a perda do sinal é alta para amostras mais concentradas, a imagem mostra que a altas concentrações dos SPIONs corresponde a uma perda alta do sinal devido ao encurtamento de T2 and T2*. No caso de T2 este efeito pode ser observado na Figuras 6.27 A e B nas imagens obtidas por SE_MC para um TE=26.2ms e TE=301.3ms 
respectivamente, mantendo o TR constante a 3000ms. Para o tempo de relaxação T2* este efeito é mostrado na Figuras 6.29 A e B nas IRM obtidas pela seqüência GE para um TE $=3,61 \mathrm{~ms}$ e $\mathrm{TE}=11,49 \mathrm{~ms}$ respectivamente, mantendo o TR constante a $100 \mathrm{~ms}$.

Nas imagens obtidas pela seqüência de multiple SE (TE constante e variando o TR) foi observada uma diminuição da intensidade do sinal com o incremento da concentração de SPIONs como é mostrada na imagem da Figura 6.31 obtida como um $\mathrm{TR}=250 \mathrm{~ms}$ e $\mathrm{TE}=11 \mathrm{~ms}$.

As relaxatividades $r_{1}, r_{2}$ e $r_{2} *$, em $\mathrm{mM}^{-1} \mathrm{~s}^{-1}$ foram determinadas mediante o ajuste linear pelo método dos mínimos quadrados das inclinações dos gráficos $1 / \mathrm{T}_{1}, 1 / \mathrm{T}_{2} \mathrm{e}$ $1 / \mathrm{T}_{2} *$ versus concentração molar do agente de contraste, (Figuras 6.26, 6.28 e 6.30) utilizando diferentes concentrações de ferro (desde $1 \mu \mathrm{M}$ até $3125 \mu \mathrm{M}$ ). Os valores obtidos foram: $\mathrm{r}_{1}=(0,29 \pm 0,03) \mathrm{mM}^{-1} \mathrm{~s}^{1}, \mathrm{r}_{2}=(73 \pm 2) \mathrm{mM}^{-1} \mathrm{~s}^{1}$ e $\mathrm{r}_{2} *=(277 \pm 15) \mathrm{mM}^{-1} \mathrm{~s}^{1}$.

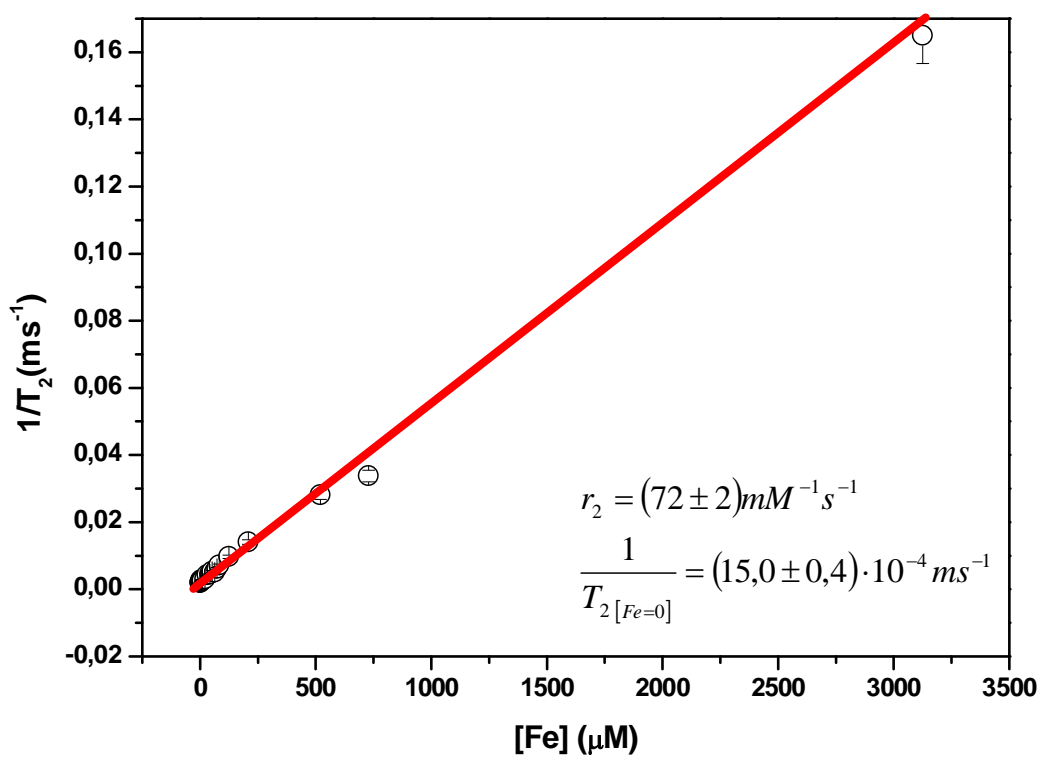

Figura 6.26: Correlação entre a taxa de relaxação $R_{2}=1 / T_{2}$ e a concentração dos SPIONs 

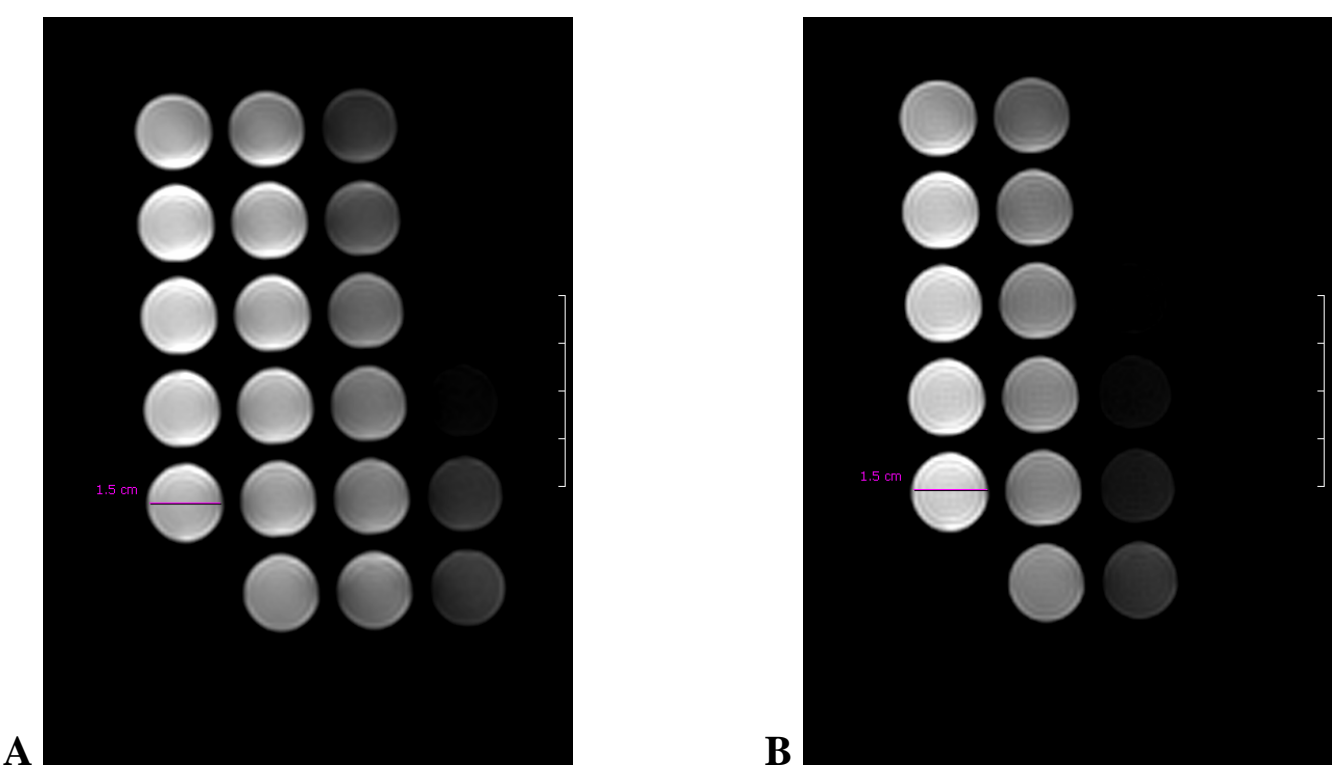

Figura 6.27: Imagens ponderadas em $T_{2}$ obtidas utilizando a seqüência de SE_MC do phantom com um TR constante de 300ms com um (A) TE=26,2 ms e (B) TE=3013 ms.

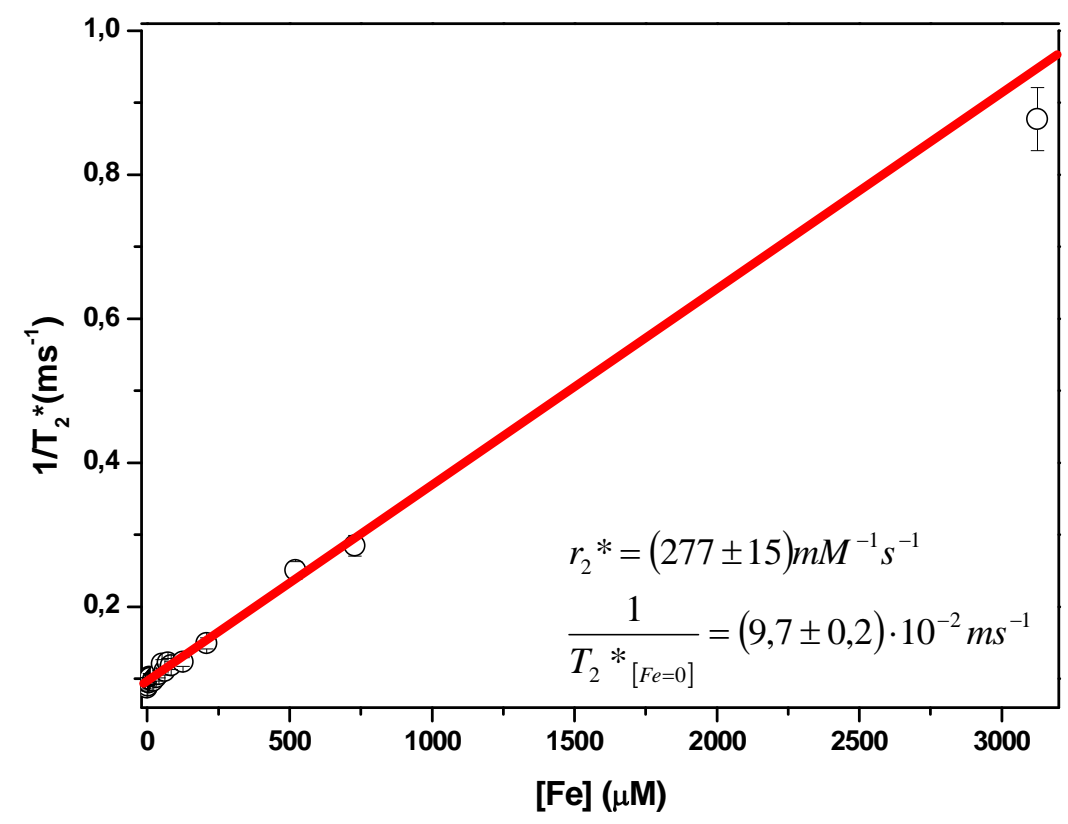

Figura 6.28: Correlação entre a taxa de relaxação $R_{2}{ }^{*}=1 / T_{2} *$ e a concentração dos SPIONs. 
A
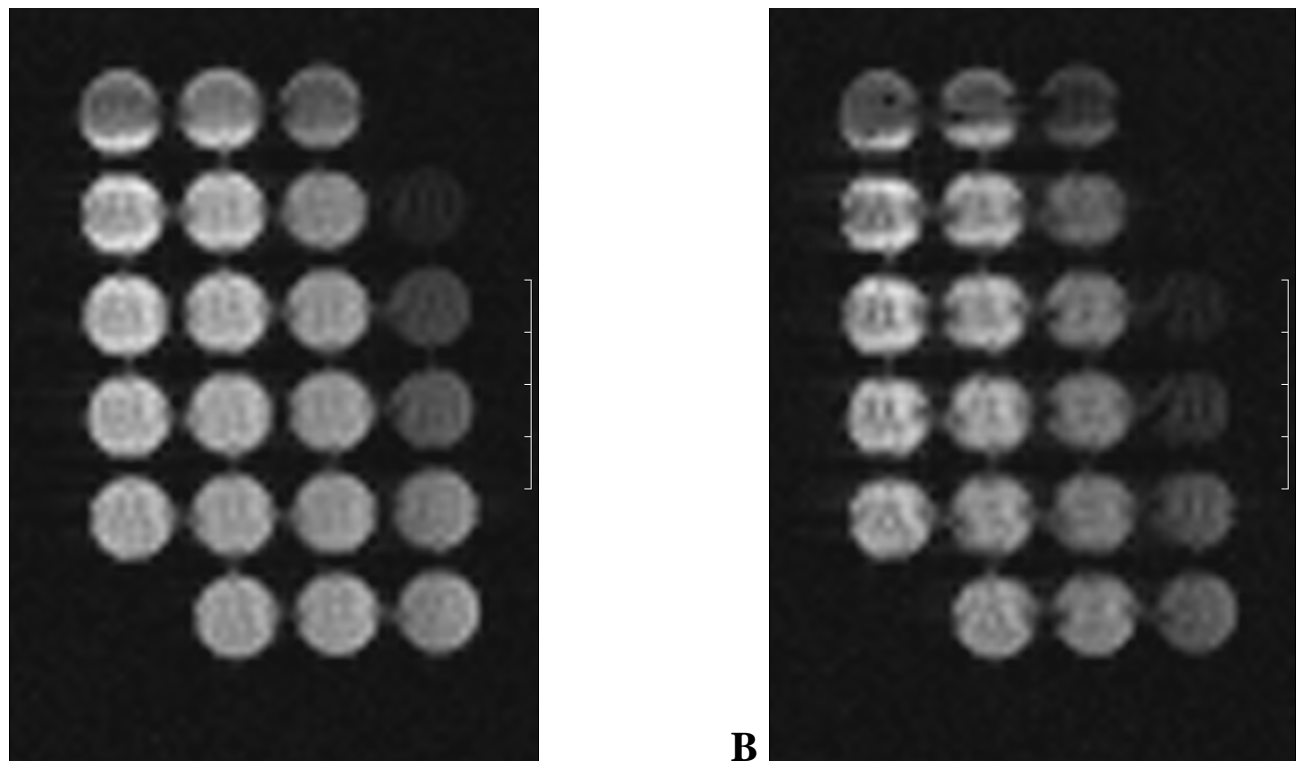

Figura 6.29: Imagens ponderadas em $T_{2} *$ obtidas mediante a seqüência GE do phantom com um TR constante de $100 \mathrm{~ms}$ com um (A) TE=3,61 ms e (B) TE=11,49 ms.

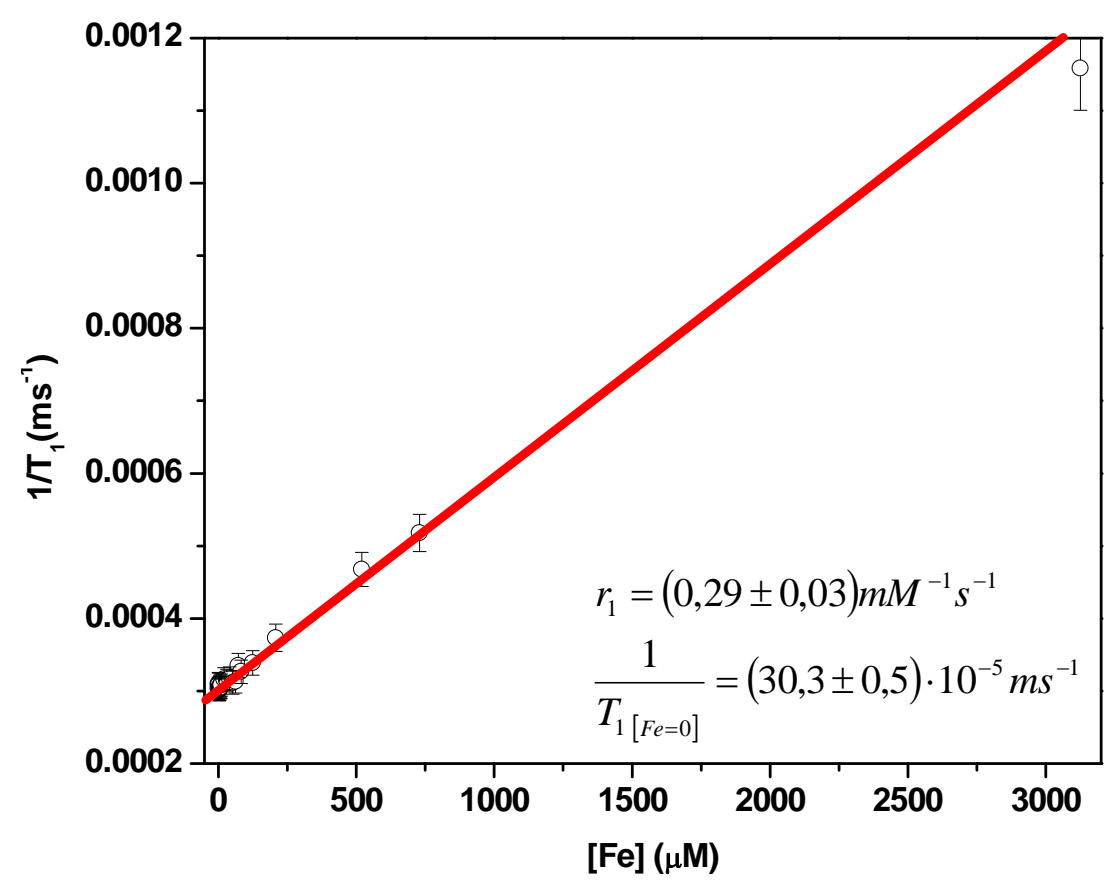

Figura 6.30: Correlação entre a taxa de relaxação $R_{1}=1 / T_{1}$ e a concentração dos SPIONs. 


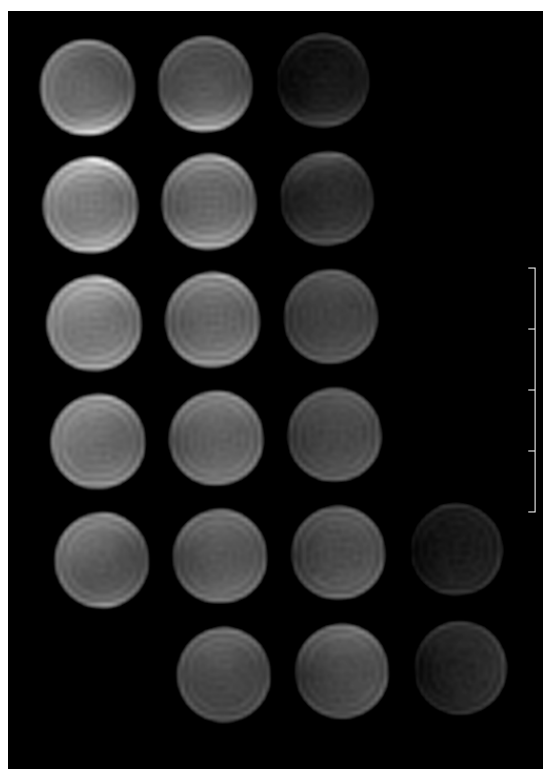

Figura 6.31: Imagem ponderada em $T_{1}$ obtida mediante a sequiência de multiple $S E$ do phantom com um TR de $250 \mathrm{~ms}$ e um TE de $11 \mathrm{~ms}$.

Pode ser visto nas Figuras 6.26, 6.28 e 6.30 que a dependência linear das taxas de relaxação $R 2=1 / T 2 ; R_{2}^{*}=1 / T_{2}^{*} \quad e \quad R 1=1 / T 1$ para a amostra à base de SPIONs é bem preservada. A inclinação das curvas determinou os valores das relaxitividades. Pode-se notar que a relaxatividade $r_{l}$ é pequena. Este resultado é consistente com as nossas expectativas mostrando que a distancia entre as moléculas de água e os núcleos de ferrita de partículas magnéticas revestidas é pequena. Uma relaxatividade levemente maior poderia refletir o fato de partículas agregadas as quais geram uma flutuação de campo magnético local um pouco maior do que as nanopartículas dispersas. Podemos ver que a relaxatividade $r_{2}$ é grande. Isto significa que $\mathrm{T}_{2}$ é muito mais influenciado pelo revestimento das nanopartículas que $\mathrm{T}_{1}$. $\mathrm{O}$ motivo para isto é que $\mathrm{T}_{2}$ é mais sensível a inomogeneidades magnéticas que $\mathrm{T}_{1}$. Para alcançar o efeito máximo do agente de contraste no $\mathrm{T}_{2}$, as ferritas devem ser revestidas com camadas delgadas quanto possível, uma vez que a interação entre partículas magnéticas e moléculas da água dependem da sua distância. A razão das relaxatividades $r_{2} / r_{1}$ para as SPIONs sintetizadas neste trabalho é aproximadamente 256; assim, podemos ver que as mudanças da relaxatividade de $\mathrm{T}_{2}$ de acordo com a concentração das partículas é muito maior. 
Consequentemente, podemos ver que agentes de contraste em IRM usando SPIONs são muito mais eficazes para imagens ponderadas em $\mathrm{T}_{2}$ que para imagens ponderadas em $\mathrm{T}_{1}$.

Finalmente o sinal obtido por IRM é influenciado pela presença de SPIONs devido aos efeitos de susceptibilidade dos SPIONs e taxas de relaxação dos prótons. Pequenas doses otimizadas de concentrações de SPIONs conduzem a uma otimização do sinal para uma detecção adequada dos sinais dos prótons nos diferentes tecidos. Usando os nossos resultados, seremos capazes de formular a relação entre as mudanças de tempos de relaxação de prótons de hidrogênio e a concentração de SPIONs injetadas em um corpo experimental. Estes resultados nos ajudarão a desenvolver agentes de contraste em IRM baseados em SPIONs cujos tempos de relaxação serão controláveis mediante o ajuste da concentração de SPIONs. 


\subsection{Referências Bibliográficas}

[1] Myers, D., Surfaces, Interfaces, and Colloids. VCH, New York, 1991.

[2] Rosensweig, R.E., Ferrohydrodynamaics. Dover publications, INC, 1997.

[3] Morais, P.C.; Garg, V.K.; Oliveira, A.C.; Silva, L.P.; Azevedo, R.B.; Silva, A.M.L.; Lima, E.C.D. Journal of Magnetism and Magnetic Materials, v.225, p.37, 2001a.

[4] Gunther, D.; Buske N. Patent 25386,1993a.

[5] Chantrell, R.W.; Bradbury, A.; Popplewell, J.; Charles, S.W. Journal of Applied Physics, v.53, p.2742, 1982.

[6] Janssen, J.J.M.; Baltussen, J.J.M.; Gelder, A.P.V.; Perenboom, J.A.A., J. Journal of Physics D: Applied Physics, v.23, p.1447, 1990.

[7] Svoboda, J., IEEE Transactions on Magnetics, v.18, p.796, 1982.

[8] Napper, D.H., Polymeric Stabilization of Colloidal Dispersions, Academic Press, New York, 1983.

[9] Berkovsky, B.M.; Mecvedev, V.F.; Krakov, M.S. Magnetic Fluids: Engineering Applications. Oxford University Press, New York, 1993.

[10] Zalich, M.A. Physical properties of magnetic macromoleculemetal and macromolecule-metal oxide nanoparticle complexes. Tese (doutorado). Faculty of the Virginia Polytechnic Institute and State University. Blacksburg, Virginia, p. 127, 2005.

[11] Massart, R., IEEE Transactions on Magnetics, v.17, p.1247, 1981.

[12] Bockris, J.O.M.; Khan, Shahed, U.M. Surface Electrochemistry, a Molecular Level Approach. Plenun Press, New York, 1993.

[13] Morais, P.C. Ferrofluidos Biocompatíveis e Magnetolipossomas, III Escola Brasileira de Magnetismo Jorge André Swieca - Porto Alegre - RS, 2001b.

[14] Qu, F.; Morais, P.C., The Journal of Chemical Physics, v.111, p.8588, 1999.

[15] Qu, F.; Morais, P.C., The Journal of Chemical Physics B, v.104, p.5232, 2000.

[16] Gunther, D.; Busken, N., Patent 4372826, 1993 b.

[17] De Cuyper, M; Joniau, M., Langmuir, v.7, p.647, 1991.

[18] Lacava, Z.G.M.; Azevedo, R.B.; Laçava, L.M.; Martins, E.V.; Garcia, V.A.P.; Rebola, C.A.; Lemos, A.P.C.; Sousa, M.H.; Tourinho, F.A.; Morais, P.C.; Da Silva, M.F., Journal of Magnetism and Magnetic Materials, v.194, p.90, 1999a.

[19] De Cuyper, M., Applications of Magnetoproteoliposomes. In: Bioreactors Operating In High-Gradient Magnetic Fields. In: Barenholz, Y.; Lasic, D.D. (Eds.), Handbook of Nonmedical Applications of Liposomes - From Design to Microreactors, v.III, CRC Press, Boca Raton, FL, p.325, 1996.

[20] Bean, C.P., Journal of Applied Physics, v.26, n.11, p.1381, 1995.

[21] Bean, C.P.; Livingston, J.D., Journal of Applied Physics, v.30, p.120, 1959.

[22] Bach-Gansmo, T., Acta Radiológica. [supplementum], v.387, p.1, 1993.

[23] Weissleder, R.; Bogdanov, A.; Neuwelt, E.A.; Papisov, M., Advanced Drug Delivery Reviews, v.16, n.2, p.321, 1995.

[24] Verwey, E.J.W.; Heilmann, E.L., J.Chem. Phys., v.15, n.4, p.174, 1947. 
[25] Klein, C.; Hurlbut, C.S., Manual of mineralogy revised, Longmans, $21^{\text {st }}$ Ed. 374, 1993.

[26] Van Vlack, L.H., Princípios de ciência e tecnologia dos materiais $4^{\text {a }}$. Edição Campus, São Paulo, 322, 1988.

[27] Ortiz, N, Estudo da utilização de magnetite como material adsorvedor dos metais $\mathrm{Cu}^{2+}, \mathrm{Pb}^{2+}, \mathrm{Ni}^{2+}$ e $\mathrm{Cd}^{2+}$, em solução, Tese de doutoramento, Instituto de Pesquisas Energéticas e nucleares, USP, 2000.

[28] Conceitos básicos sobre o ferromagnetismo. Disponível em: http://sites.uol.com.br/lancaro/intro.html Acesso em 03 out. 2008.

[29] Cullity, B.D., Introduction to magnetic materials. Addison Wesley Publishing Company, 1972.

[30] Knobel, M. Os superpoderes dos nanomagnetos. Ciência Hoje, v. 27 (159), p. 32, 2000.

[31] Granulares, A.P.; Guimarães R., Propriedades Magnéticas de Sistemas, Revista Brasileira de Ensino de Física, v. 22 (3), 2000.

[32] Klabunde, K.J., Nanoscale materials in chemistry. John Wiley and Sons, 2001.

[33] Tarjat, P. et al., J. Phys. D: Appl. Phys., v.36, p. R182, 2003.

[34] Berry, C. C.; Curtis, A. S. G., J. Phys. D: Appl. Phys., v.36, p. R198, 2003.

[35] Fidler, I. J., Cancer metastasis. Brit. Med. Bull., v. 47, p. 157, 1991.

[36] Hong, S.; Rhee, I., International Journal of magnetic resonance imaging, v. 01(1), p. 015, 2007.

[37] Lopez, J. A.; Lopez-Quintela, M. A.; Mira, J.; Rivas, J. IEEE Trans. Magn., v. 33, p. 4359, 1997.

[38] Berger, P.; Adelman, N.B.; Beckman, K. J.; Campell, D. J.; Ellis, A. B.; Lisensky, G. C., J. Chem. Educ., v.76, p. 943, 1999.

[39] Lei F.; Dravid, V. P.; Johnson, D. L., Applied Surface Science, v.181, p. 173, 2001.

[40] Kim, D.K.; Zhang, Y.; Kehr, J.; Klason, T.; Bjelke, B.; Muhammed, M., J. Magn. Magn. Mater., v.225, p. 256, 2001.

[41] Rasvand, W., Image processing and analysis in Java URL http://rsb.info.nig.gov/ij 06-10-2004.

[42] O’grady, K.; Bradbury, A., J. Magn. and Magn. Mater., v.39, p. 91, 1983.

[43] Sanders, J.P.; Gallagher, P.K., Thermochim. Acta, v. 406, p. 241, 2003.

[44] Lauer Jr., H.V.; Ming, D.W.; Golden, D.C., Lunar and Planetary Science Conference XXXIV, 2003.

[45] Stucki, J.W.; Banwart, W.L., Advanced Chemical Methods for Soil and Clay Mineral Research, Reidel, Dordrecht, 1980.

[46] Kinnari, P.; Upadhyay, R.V.; Mehta, R.V.; Srinivas, D., J. Appl. Phys., v. 88, p. 2799, 2002.

[47] Kinnari, P.; Upadhyay, R.V.; Mehta, R.V., J. Magn. Magn. Mater., v.252, p. 35, 2002.

[48] Lacava, B.M.; Azevedo, R.B.; Silva, L.P.; Lacava, Z.G.M.; Skeff Neto, K.; Buske, N.; Bakuzis, A.F.; Morais, P.C., Appl. Phys. Lett., v.77, p.1876, 2000.

[49] Rasvand, W., Image processing and analysis in Java URL http://rsb.info.nig.gov/ij 06-10-2004. 
[50] Nagata, K.; Ishihara, A., J. Magn. Magn. Mater., v.1571, p. 104, 1992.

[51] Li, L.; Li, G.; Smith, R.L.; Inomata, H., Chem. Mater., v.12, p. 3705, 2000.

[52] Wu, K.H.; Chang, Y.C.; Chen, H.B.; Yang, C.C.; Horng, D.N., J. Magn. Magn. Mater., v.278, p. 156, 2004. 


\section{Capítulo 7 - Conclusões e Perspectivas}

Os resultados apresentados nesta tese são relevantes tanto do ponto de vista teórico e de metodologia empregada, quanto para a compreensão das mudanças estruturais e microestruturais que ocorrem durante o processamento dos materiais estudados nos capítulos anteriores.

\section{Nanopartículas a base de Céria}

A caracterização estrutural dos filmes à base de nanopartículas de $\mathrm{CeO}_{2}$ depositadas no anodizado de alumínio e tratado termicamente a $400^{\circ} \mathrm{C}$ por DRX evidenciou uma fase cristalina cúbica correspondente ao $\mathrm{CeO}_{2}$. Os resultados obtidos por SAXS das redispersões indicam que a distribuição de tamanhos das nanopartículas depende da temperatura de tratamento térmico das amostras. A diminuição da intensidade SAXS sugere reordenamento estrutural indicando uma grande mudança estrutural eletrônica, evidenciando a formação de nanopartículas de $\mathrm{CeO}_{2}$ mediante oxidação do $\mathrm{Ce}(\mathrm{III})$ para $\mathrm{Ce}(\mathrm{IV})$ causado pelo tratamento térmico. A característica de superfície fractal da amostra pode resultar do arranjo aleatório de cristalitos ou, mais provavelmente, no processo de oxidação durante tratamento a $200^{\circ} \mathrm{C}$ envolvido na síntese. Vacâncias de oxigênio na superfície de nanopartículas menores que $20 \mathrm{~nm}$ podem induzir momentos magnéticos devido a estrutura eletrônica gerada pelas vacâncias. Assim, o comportamento ferromagnético apresentado pelas nanopartículas de dióxido de cério após tratamento térmico de $200^{\circ} \mathrm{C}$, está associado ao momento magnético liquido que apresentam as nanopartículas de $\mathrm{CeO}_{2}$. Esta fase, é estável mesmo na temperatura de funcionamento do motor automotivo. A análise por EDS permite a imediata identificação dos elementos químicos e o mapeamento da distribuição dos elementos que compõem o filme de céria. Nas micrografias obtidas mediante MEV observa-se na superfície o depósito do filme de céria algumas irregularidades, trincas ou fissuras, que podem ser provocadas durante a secagem do filme depositado sobre o anodizado de alumínio. Estas trincas ou fissuras não interferem na atividade catalítica, ao contrário, elas contribuem para aumentar a superfície disponível para as reações de catálise. 


\section{Nanopartículas a base de Paládio}

O estudo realizado mediante a técnica de DRX revela que os filmes tratados termicamente sob atmosfera de ar apresentam a fase cristalina tetragonal correspondente ao óxido de paládio ( $\mathrm{PdO}$ ), enquanto que o filme tratado termicamente sob atmosfera de $\mathrm{N}_{2}$ apresenta a fase cristalina cúbica de corpo centrado correspondente ao paládio metálico $\left(\mathrm{Pd}^{\circ}\right) . \mathrm{O}$ filme depositado sobre alumínio anodizado é semelhante ao de $\mathrm{PdO}$, a presença de pequenos picos de $\mathrm{Pd}^{\mathrm{o}}$ são detectados. Apesar de serem picos de baixa intensidade, o resultado comprova a presença de $\mathrm{Pd}^{\mathrm{o}}$ no anodizado de alumínio. Os resultados sugerem que o paládio reduzido (metálico) se apresenta na superfície dos filmes à base de PdO e, por estar em baixas concentrações, pouco detectadas por DRX. Observações experimentais mostram que o óxido de paládio não é estável e se reduz facilmente durante os primeiros ciclos de funcionamento do motor automotivo. A análise por EDS confirmou a composição dos elementos químicos presentes nos filmes utilizados na síntese. Nas micrografias obtidas mediante MEV observa-se na superfície o depósito do filme de paládio e irregularidades do substrato de alumínio anodizado.

\section{Testes catalíticos no motor automotivo}

O catalisador proposto para uso na cabeça de pistões automotivos mostrou-se eficiente na oxidação de $\mathrm{CO}$, redução de $\mathrm{NO}_{\mathrm{x}}$ e diminuição das emissões de COV. Os catalisadores baseados no Pd são capazes de promover maior oxidação do combustível pela maior quebra das moléculas de combustível. Além disso, a capacidade de reserva de oxigênio do $\mathrm{Ce}_{2} \mathrm{O}_{4}$ apresenta sinergia na atividade do catalisador a base de paládio. Os resultados indicam que a presença do $\mathrm{CeO}_{2}$ aumenta a habilidade do catalisador de $\mathrm{Pd}^{\mathrm{o}}$ sob condições deficientes de oxigênio na mistura ar combustível.

O rendimento da atividade catalítica do $\mathrm{CeO}_{2}$ e $\mathrm{Pd}$ na redução de $\mathrm{CO}, \mathrm{COV}$ e emissões de NOx de um motor a gasolina, indica que sua atividade é alta. A atividade catalítica de $\mathrm{CeO}_{2}$ é significativa para valores de rotação em condições estacionárias. A diminuição relativa do consumo é de aproximadamente $4 \%$ evidenciando a atividade dos catalisadores. 
Finalmente, o resultado deste estudo mostra a eficiência de catalisadores sintetizados para a oxidação de $\mathrm{CO}$ e emissões de $\mathrm{COV}$ e $\mathrm{NO}_{\mathrm{x}}$ em condições de funcionamento do motor. A eficiência dos catalisadores utilizados é reflexo da diminuição do consumo e, consequência do aumento da potência e torque do motor a combustão com catalisadores de $\mathrm{CeO}_{2}$ e $\mathrm{Pd}^{\mathrm{o}}$ depositados na superfície da cabeça de pistões anodizados.

\section{Nanopartículas a base de Hidroxiapatita}

O presente estudo mostra que a HAp sintetizada corresponde à rede cristalina hexagonal de $\mathrm{Ca}_{10}\left(\mathrm{PO}_{4}\right)_{6}(\mathrm{OH})_{2}$. A análise da largura dos perfis de DRX revela que as HAp apresentam tamanho nanométrico e grau de cristalinidade suficiente para aplicações biomédicas. A HAp revestida apresenta cristalinidade característica de estruturas nanoamorfas. Mudança de fase de HAp acontece na faixa de temperatura entre 600 e $800^{\circ} \mathrm{C}$ isto é devido à perda da água cristalina e reestruturação do fosfato na estrutura devido à formação inicial de $\mathrm{Ca}_{3}\left(\mathrm{PO}_{4}\right)_{2}$. A sinterização da amostra produz crescimento do tamanho médio de cristalitos. Para as direções de crescimento das HAp estudadas, [200] e [311], pode-se notar um crescimento anisotrópico.

As linhas estreitas dos espectros de RPE em $\mathrm{g}=4,23 \pm 0,08, \mathrm{~g}=4,23 \pm 0,09$ e $\mathrm{g}=8,93 \pm 0,12$ são correlacionada aos radicais livres que resultam do processo de síntese e é devida à absorção pelos spins $\mathrm{Fe}^{3+}$. Estas linhas são observadas praticamente em todos os espectros da gama de temperaturas estudadas. A intensidade destas linhas diminui com o aumento da temperatura. A linha estreita em $g=1,93 \pm 0,11$ é devida à absorção pelo spin dos íons fosfato. $\mathrm{O}$ estudo realizado na HAp por RFM em diferentes temperaturas (4-300 K) mostrou que os parâmetros de RFM dependem fortemente da temperatura, isto é, $\Delta H_{P P}$, factor $\mathrm{g}, N_{S}$ decrescem com o aumento da temperatura enquanto $T_{2}$ diminui. Estes comportamentos nos parâmetros podem ser atribuídos ao incremento da interação "superexchange".

Por meio das curvas de SAXS, verificou-se que as amostras apresentaram características autosimilares, em particular, de agregados de massa fractal e de superfície fractal. As curvas de SAXS de todas as amostras indicam fractalidade de massa do agregado de partículas primárias. A característica de superfície fractal pode resultar de rearranjos aleatórios de cristalitos ou pelo 
processo de oxolação, que leva à agregação das nanopartículas de HAp. O modelo de geometria fractal foi o mais adequado na descrição da morfologia do sistema em estudo.

A análise dos espectros de FTIR, das amostras revestidas com ácido oleico, mostra que as moléculas deste ácido apresentam-se ligadas pelo grupo carboxilato na superfície das nanopartículas. As amostras HApr0,50 e HApr0,25 apresentam a relação esperada entre o número de moléculas ligadas à superfície e área de superfície das nanopartículas preparadas. As moléculas de oleato, ligadas na superfície, conferem característica hidrofóbica às nanopartículas. Deste modo, podem ser facilmente redispersas em soluções aquosas de surfactantes, formando sóis estáveis.

\section{Nanopartículas a base de Magnetita}

A partir dos dados de DRX da amostra sintetizada, foi determinada a estrutura cristalina do tipo magnetita que apresenta tamanho médio de cristalito de $(9,6 \pm 1,7) \mathrm{nm}$. Este dado foi confirmado por micrscopia eletrônica de transmissão, onde o diâmetro médio calculado pelo programa do equipamento foi de $(8,65 \pm 0,12) \mathrm{nm}$. Pela técnica de DSC foi possível determinar a oxidação do $\mathrm{Fe}_{3} \mathrm{O}_{4}$ (magnetita) em $\gamma-\mathrm{Fe}_{2} \mathrm{O}_{3}$ (magemita) na temperatura de $253,1^{\circ} \mathrm{C}$. As propriedades superparamagnéticas foram estudadas mediante a técnica de RPE, mostrando a formação de aglomerados típicos de uma substância superparamagnética, com valor de g=2,1 característico dos spins do $\mathrm{Fe}^{+3}$. O estudo, por meio da técnica de RPE do ferrofluido em diferentes temperaturas (4-300 K), mostrou que os parâmetros de RFM dependem fortemente da temperatura ou seja, $\Delta H_{P P}$, fator $\mathrm{g}, N_{S}$ decrescem com o aumento da temperatura enquanto $T_{2}$ diminui. Estes comportamentos dos parâmetros podem ser atribuídos ao aumento da interação superexchange. A caracterização relaxométrica mostrou que o aumento da concentração dos SPIONs em suspensões aquosas diminui os tempos de relaxação da solução. Isto se deve à influencia que os SPIONs exercem nos átomos de hidrogênio da água tornando os tempos de relaxação mais curtos do que em água pura. A correlação entre a concentração de SPIONs e 1/T ${ }_{1}$, $1 / \mathrm{T}_{2}$ e $1 / \mathrm{T}_{2} *$ tem um comportamento linear cuja inclinação fornece valores de relaxatividade $\mathrm{r}_{1}=(0,243 \pm 0,005) \mathrm{mM}^{-1} \mathrm{~s}^{-1}, \mathrm{r}_{2}=(1,41 \pm 0,03) \mathrm{mM}^{-1} \mathrm{~s}^{-1}$ e $\mathrm{r}_{2}{ }^{*}=(5,78 \pm 0,31) \mathrm{mM}^{-1} \mathrm{~s}^{-1}$. Estes valores foram obtidos para um campo magnético de 3T (tesla) a temperatura ambiente. Os resultados mostraram que tanto $1 / \mathrm{T}_{1}$ quanto $1 / \mathrm{T}_{2}$ são linearmente dependentes da concentração das 
nanopartículas. Os resultados das medidas de relaxação por RMN evidenciam o incremento dos tempos de relaxação $T_{1}, T_{2}$ e $T_{2} *$ como conseqüência da diminuição da concentração de nanopartículas de óxido de ferro.

\section{Perspectivas para Trabalhos Futuros}

Os resultados desta tese podem ser complementados por trabalhos futuros que poderiam auxiliar no entendimento de algumas questões ainda não bem respondidas. A característica de nanopartícula é muito importante nas aplicações utilizando catalisadores de céria e paládio sendo importantes para evitar a sinterização deste material em condições de funcionamento do motor automotivo a gasolina, tendo em vista a temperatura e o tempo de funcionamento do motor automotivo. Como proposta, pode-se estudar detalhadamente o crescimento das nanopartículas de céria e paládio, bem como a influência destes materiais no aumento da eficiência do motor automotivo a gasolina, bem como a álcool. Este estudo é fundamental para a extensão dessa aplicação a outros tipos de motores a combustão interna, tal como o motor automotivo a diesel. Testes mais detalhados de emissão, torque, potência, avanço e consumo em motores biocombustível podem buscar um melhor alinhamento do tipo de calisador aplicado e formas distintas de aplicação.

Um assunto que vem merecendo destaque especial recentemente é a obtenção de nanopartículas de hidroxiapatita para aplicações em implantes dentários, onde aceleram a osteointegração diminuindo o tempo de tratamento, que hoje em dia, leva um período de aproximadamente seis meses. Com a aplicação da HAp nanopartículada na forma de filmes sobre a superfície dos pinos de implante, poderia diminuir este período para no máximo três meses, dependendo das características fisiológicas de cada paciente.

O estudo in vivo do agente de contraste sintetizado, é de interesse em IRM. A caracterização relaxométrica in vivo leva a avaliações na determinação da qualidade de tipo positivo ou negativo do agente de contraste para utilização em exames clínicos, melhorando o contraste dos diferentes tecidos biológicos. Além de exames de câncer de fígado e de baço, já é possível a realização de exames em outros órgãos por IRM. 